MAUREN AURICH

\title{
SIMULAÇÃO COMPUTACIONAL DO COMPORTAMENTO DO CONCRETO NAS PRIMEIRAS IDADES
}

Tese apresentada à Escola

Politécnica da Universidade de São

Paulo para a obtenção do título de

Doutor em Engenharia. 


\section{SIMULAÇÃO COMPUTACIONAL DO COMPORTAMENTO DO CONCRETO NAS PRIMEIRAS IDADES}

Tese apresentada à Escola

Politécnica da Universidade de São

Paulo para a obtenção do título de

Doutor em Engenharia.

Área de concentração:

Engenharia de Estruturas

Orientador:

Prof. Livre-Docente

Túlio Nogueira Bittencourt 


\section{FICHA CATALOGRÁFICA}

\section{Aurich, Mauren}

Simulação computacional do comportamento do concreto nas primeiras idades / M. Aurich. -- São Paulo, 2008.

$190 \mathrm{p}$.

Tese (Doutorado ) - Escola Politécnica da Universidade de São Paulo. Departamento de Engenharia de Estruturas e Geotecnica.

1.Concreto 2.Análise numérica 3.Análise térmica 4.Análise mecânica I.Universidade de São Paulo. Escola Politécnica. Departamento de Engenharia de Estruturas e Geotécnica II.t. 
Dedico este trabalho a meus pais paulistas,

Érica e Gustavo, pelo incentivo, paciência e amor imensuráveis. 


\section{AGRADECIMENTOS}

Desejo externar meu sincero reconhecimento e agradecimento por todo apoio que me foi dispensado no decorrer deste período de estudo.

Agradeço ao Professor Túlio Nogueira Bittencourt pela sua orientação. Suas valiosas sugestões e ensinamentos transmitidos foram fundamentais para o desenvolvimento desta tese

Agradeço ao Professor Américo Campos Filho pela permanente colaboração, amizade e constante estímulo, imprescindíveis para a realização deste trabalho.

De modo muito especial, agradeço ao Professor Surendra P. Shah, por seu incentivo, valiosos ensinamentos e, principalmente, pelo seu exemplo como professor e pesquisador.

Aos Professores do Programa de Pós-Graduação em Engenharia da USP pelos ensinamentos ministrados e, em especial, à Janete Santana, pela amizade.

Aos amigos do ACBM e da Northwestern University, Raissa e Marc, Kwon, Nathan, Richard e Kim, Stefan, Peter, pela paciência, apoio, conselhos e amizade, indispensáveis no ano que passei em Chicago.

Aos Professores Maria Regina Leggerini, Almir Schäffer e Henrique Gutfreind pelo permanente estímulo e apoio. Em especial, ao Professor Eduardo Todt, pela amizade e incansável incentivo, importantíssimo para o término deste trabalho.

Às amigas Patrícia Neves e Heloisa Fernandes pelo companheirismo, amizade e risadas compartilhadas neste período. Dê, Marcus Vinicius e Karen, obrigada pela força e amizade. E, à Ângela, pela ajuda inicial e imenso incentivo.

De forma muito especial agradeço às pessoas mais importantes da minha vida, pelo infinito apoio e amor... pai e mãe, Taís e vó Ilza! Isabela, Samir, Lú, tio Leo e Inez, tia Helena, Su e Ric, Dri e Déia, muitíssimo obrigada pela força e carinho.

À PUCRS, ao CNPq e à CAPES por terem possibilitado a realização deste doutorado.

E, a Deus, por iluminar meu caminho. 
"Nada é verdadeiro enquanto não for experimentado" Keats 


\section{RESUMO}

O estudo do comportamento do concreto nas primeiras idades está se tornando cada vez mais importante, pois os efeitos térmicos e de retração do concreto, neste período inicial, geram fissuras, aumentando a permeabilidade das estruturas e podendo induzir problemas de durabilidade e funcionalidade das mesmas. Um detalhado estudo da evolução das tensões durante as primeiras idades pode ser decisivo para manter baixos os níveis de fissuração.

Neste trabalho foi implementado um modelo computacional, baseado no método dos elementos finitos, para a simulação do comportamento de peças de concreto nas primeiras idades, tendo, em especial, o propósito de avaliar o potencial risco de fissuração. A análise por elementos finitos abrange a modelagem computacional dos fenômenos químicos, térmicos, de difusão de umidade e mecânicos que ocorrem nos primeiros dias após o lançamento do concreto. $\mathrm{Na}$ análise química é determinado o calor gerado pelas reações exotérmicas de hidratação do cimento. $\mathrm{Na}$ análise térmica o programa considera ainda o fluxo de calor devido à diferença de temperatura entre o corpo e o ambiente. Em função das propriedades térmicas e geométricas do corpo em estudo são determinadas as temperaturas nodais. Na seqüência, realiza-se a análise de difusão de umidade. Aproveitando a semelhança entre as equações que regem os fenômenos de transferência de calor e difusão de umidade, empregam-se os mesmos procedimentos da análise térmica para a determinação do valor nodal da umidade relativa dos poros. $\mathrm{Na}$ análise mecânica, por sua vez, são calculados os estados de tensões decorrentes das variações de temperatura e umidade determinadas nas etapas anteriores e dos fenômenos de retração e fluência do concreto. Quando o estado de tensão de determinado ponto de integração atinge a superfície de ruptura, o ponto passa a ser considerado fissurado. O programa considera a fissuração através de um modelo de fissuras distribuídas com fisssura fixa.

Os resultados desta modelagem computacional foram comparados com valores experimentais encontrados na literatura, demonstrando excelente aproximação em todas as etapas de solução implementadas.

Palavras-chave: Concreto. Primeiras Idades. Análise Térmica. Análise de Difusão de Umidade. Análise Mecânica. 


\section{ABSTRACT}

The study of the early age properties of concrete is becoming more important, because the thermal effects and the shrinkage, even in the first hours, could generate cracks, increasing the permeability of the structure and being able to induce problems of durability and functionality in the same ones. The detailed study of the stresses development during the construction process can be decisive to keep low the cracking levels.

In this work a computational model, based on the finite element method was implemented, to simulate the early age concrete behavior, having as a special feature, the evaluation of the cracking risk. The finite element analysis encloses the computational modeling of the following phenomena: chemical, thermal, diffusion and mechanical which occur at the first days after the concrete cast. In the chemical analysis, the heat generated by the exothermic reactions of cement hydration is evaluated. In the thermal analysis the program still considers the heat flow due to differences in temperatures between the body and the environment. Considering the thermal and geometric properties of the body, the nodal temperatures are determined. The following analysis is the humidity diffusion. Using the similarity between the equations that describe the phenomena of heat transfer and humidity diffusion, the same thermal analysis procedures are used to evaluate the pore relative humidity's nodal values. In the last analysis, mechanical, the stress states due to temperature and humidity variations, evaluated in the previous steps, and also due to shrinkage and creep are calculated. When the stress state in a determined sample point reaches the rupture surface, the point is considered cracked. The program evaluates cracking through a smeared fixed crack model.

The developed software results were compared with experimental values found in the literature, demonstrating an excellent approach for all the implemented analysis.

Keywords: Concrete. Early age. Thermal analysis. Diffusion analysis. Mechanical Analysis. 


\section{LISTA DE ILUSTRAÇÕES}

\section{Capítulo 2 - Comportamento do Concreto nas Primeiras Idades}

Figura 2.1 - Fatores que influenciam no comportamento estrutural do concreto nas primeiras idades (Prato, 1999)

Figura 2.2 - Processo de microdifusão da água livre através das camadas de hidratos já formados

Figura 2.3 - Modelagem do concreto, segundo Ulm e Coussy (1995)

Figura 2.4 - Resistência à tração em função do grau de hidratação (Rostásy et al. 2001)

Figura 2.4 - Deformação por retração autógena (estimada) pelos modelos de Tazawa e Miyazawa (1997) e por Dilger, Niitani e Wang (1997) segundo os resultados da análise desenvolvida por Cusson e Repette (2000)

\section{Capítulo 3 - Análise do problema químico}

Figura 3.1 - Exemplo de elevação adiabática de temperatura, conforme Witasse (2003)

Capítulo 4 - Análise de elementos finitos aplicada à transferência de calor

Figura 4.1 - Transferência de calor por condução e convecção

Figura 4.2 - Associação da transferência de calor por condução à difusão de energia provocada pela atividade molecular

Figura 4.3 - Transferência convectiva de calor entre uma superfície limitante e um fluido em movimento 


\section{Capítulo 6 - Análise da etapa de solução do problema mecânico}

Figura 6.1 - Modelo elasto-viscoplástico 96

Figura 6.2 - Analogia da técnica de camadas em duas dimensões 105

Figura 6.3 - Evolução da deformação por fluência para uma tensão constante aplicada em t' 106

Figura 6.4 - Curva de deformação por retração 107

Figura 6.5 - Modelo reológico do concreto 112

Figura 6.6 - a. Meridianos da superfície de ruptura

b. Seções tranversais da superfície de ruptura 129

Figura 6.7 - Relação bilinear da tensão-abertura de fissuras 129

Capítulo 7 - Algoritmo proposto para análise do concreto nas primeiras idades

Figura 7.1 - Elementos isoparamétricos quadrangulares 133

Figura 7.2 - Fluxograma básico do algoritmo de solução do EACB 136

Figura 7.3 - Propriedades da malha de elementos finitos 137

$\begin{array}{lll}\text { Figura } 7.4-\text { Opções gerais do programa } & 138\end{array}$

$\begin{array}{lll}\text { Figura } 7.5-\text { Análise química } & 140\end{array}$

$\begin{array}{lll}\text { Figura } 7.6-\text { Análise térmica } & 140\end{array}$

Figura 7.7 - Análise de difusão de umidade 142

$\begin{array}{lll}\text { Figura } 7.8 \text { - Análise mecânica } & 143\end{array}$

Figura 7.9 - Tela de gravação do arquivo de dados 144 


\section{Capítulo 8 - Aplicações numéricas}

Figura $8.1-$ Dimensões dos anéis ensaiados (cotas em cm) 146

Figura 8.2 - Dimensões do corpo de prova usado para determinação da retração livre

Figura 8.3 - Dimensões do corpo de prova usado para determinação dos parâmetros de fratura

Figura 8.4 - Dimensões do corpo de prova usado para determinação da resistência à compressão

Figura 8.5 - Forma para o anel de concreto, posição dos strain-gages no anel de aço e o anel de concreto finalizado para ser ensaiado

Figura 8.6 - Malhas de elementos finitos utilizadas:

(a) 42 elementos

(b) 168 elementos

Figura 8.7 - Condições de contorno para a análise térmica

Figura 8.8 - Condições de contorno para a análise de difusão de umidade

Figura 8.9 - Condições de contorno para a análise mecânica

Figura 8.10 - Evolução da temperatura nos pontos P1 e P2, utilizando a malha 1 (42 elementos)

Figura 8.11 - Evolução da temperatura nos pontos P1 e P2, utilizando a malha 2 (168 elementos)

Figura 8.12 - Evolução das temperaturas $\left[{ }^{\circ} \mathrm{C}\right]$

Figura 8.13 - Evolução da difusão de umidade nos pontos P1 e P2, utilizando a malha 1 (42 elementos)

Figura 8.14 - Evolução da difusão de umidade nos pontos P1 e P2, utilizando a malha 2 (168 elementos)

Figura 8.15 - Evolução difusão de umidade [\%]

Figura 8.16 - Abertura de fissuras para anel 1 (Shah, 1994), resultados para a malha 1

Figura 8.17 - Abertura de fissuras para anel 1 (Shah, 1994), resultados para a malha 2 
Figura 8.18 - Abertura de fissuras para anel 1 (Shah, 1993), resultados para a malha 1

Figura 8.19 - Abertura de fissuras para anel 1 (Shah, 1993), resultados para a malha 2

Figura 8.20 - Evolução das tensões circunferenciais $\left[\mathrm{kN} / \mathrm{cm}^{2}\right]$,resultados para a malha 1

Figura 8.21 - Evolução das tensões circunferenciais $\left[\mathrm{kN} / \mathrm{cm}^{2}\right]$,resultados para a malha 2

Figura 8.22 - Anel fissurado após a realização do ensaio

Figura 8.23 - Dimensões do prisma ensaiado (cotas em $\mathrm{cm}$ )

Figura 8.24 - Ensaio do prisma

Figura 8.25 - Malha de elementos finitos utilizada

Figura 8.26 - Condições de contorno para a análise térmica

162

Figura 8.27 - Condições de contorno para a análise de difusão de umidade

Figura 8.28 - Condições de contorno para a análise mecânica 163

Figura 8.29 - Evolução das temperaturas $\left[{ }^{\circ} \mathrm{C}\right]$

Figura 8.30 - Evolução difusão de umidade [\%] 166

Figura 8.31 - Tensões atuantes para o prisma 1167

Figura 8.32 - Tensões atuantes para o prisma $2 \quad 167$

Figura 8.33 - Evolução das tensões $\left[\mathrm{kN} / \mathrm{cm}^{2}\right] \quad 168$

Figura 8.34 - Execução dos tetrápodes nos Molhes de Rio Grande - RS 169

Figura 8.35 - Colocação dos tetrápodes nos Molhes de Rio Grande - RS 169

Figura 8.36 - Características geométricas dos tetrápodes 170

Figura 8.37 - Malha de elementos finitos utilizada 170

Figura 8.38 - Condições de contorno para a análise térmica 171

Figura 8.39 - Condições de contorno para a análise de difusão de umidade

Figura 8.40 - Condições de contorno para a análise mecânica 


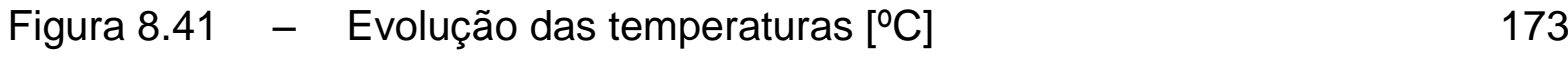

Figura 8.42 - Evolução difusão de umidade [\%] 174

Figura 8.43 - Evolução das tensões principais $\left[\mathrm{kN} / \mathrm{cm}^{2}\right]$

Figura 8.44 - Tetrápodes fissurados 176 


\section{LISTA DE TABELAS}

\section{Capítulo 2 - Comportamento do Concreto nas Primeiras Idades}

Tabela 2.1 - Variáveis de Estado Externas, macroscopicamente 42

Tabela 2.2 - Variáveis de Estado Internas, macroscopicamente 42

Tabela 2.3 - Variáveis de Estado Externas e forças associadas 45

Capítulo 3 - Análise do problema químico

Tabela $3.1 \quad$ - Valores de calor específico (Breugel, 1980)

Capítulo 5 - Análise de elementos finitos aplicada à difusão de umidade

Tabela 5.1 - Propriedades químicas do concreto 95

Capítulo 6 - Análise da etapa de solução do problema mecânico

Tabela 6.1 - Expressões para a matriz constitutiva D 98

Tabela 6.2 - Expressões para o vetor de fluxo plástico 99

Tabela 6.3 - Expressões para a matriz de relações deformaçõesdeslocamentos $B \quad 101$

$\begin{array}{lll}\text { Tabela } 6.4 & \text { Representação das soluções das equações } 7.23 \text { e } 7.27 & 111\end{array}$

Tabela 6.5 - Valores do coeficiente $\alpha_{F}$ e $\beta_{F} \quad 131$ 
Capítulo 7 - Algoritmo proposto para análise do concreto nas primeiras idades

Tabela 7.1 _ Propriedades dos materiais requeridas para cada análise

\section{Capítulo 8 - Aplicações numéricas}

Tabela 8.1 - Propriedades térmicas dos materiais 150

Tabela 8.2 - Propriedades de difusão de umidade dos materiais 150

Tabela 8.3 - Propriedades mecânicas dos materiais 150

Tabela 8.4 - Propriedades térmicas do concreto 163

Tabela 8.5 - Propriedades de difusão de umidade do concreto 164

Tabela 8.6 - Propriedades mecânicas do concreto 164

Tabela 8.7 - Propriedades térmicas do concreto 171

Tabela 8.8 - Propriedades de difusão de umidade do concreto 171

Tabela 8.9 - Propriedades mecânicas do concreto 172 


\section{LISTA DE SÍMBOLOS}

\section{Letras romanas maiúsculas}

A _ - área da seção transposta

$A_{c} \quad-\quad$ área da seção transversal

B _ - matriz de relações deformações-deslocamentos

$\mathrm{B}^{(\mathrm{m})} \quad-$ matriz de interpolação dos gradientes de temperatura no elemento

C $\quad$ - conteúdo em cimento do concreto

tensor de rigidez elástica (tangente)

$\mathrm{CH}$ - calor de hidratação do cimento obtido no ensaio de calorimetria

D $\quad-\quad$ matriz constitutiva do material

tensor do calor latente para deformações elásticas

$D(H) \quad-\quad$ coeficiente de difusão do material

$D_{0} \quad-\quad$ mínimo valor de $\mathrm{D}(\mathrm{H})$ para $\mathrm{H}=0$

$D_{1} \quad-\quad$ máximo valor de $\mathrm{D}(\mathrm{H})$ para $\mathrm{H}=1$

Ea $\quad-$ energia de ativação 


$$
\begin{aligned}
& \text { E } \quad-\text { módulo de elasticidade longitudinal } \\
& \mathrm{E}_{\mathrm{c}} \quad-\quad \text { módulo de elasticidade tangente } \\
& \mathrm{F}_{\mathrm{i}} \quad-\text { parâmetros que descrevem a influência da temperatura } \\
& \mathrm{G}_{\mathrm{F}} \quad-\quad \text { energia de fratura } \\
& \mathrm{H} \quad-\text { módulo de endurecimento } \\
& \text { umidade relativa do poro } \\
& \mathrm{H}^{(\mathrm{m})} \quad-\quad \text { matriz de temperaturas no elemento } \\
& H^{(S)} \quad-\quad \text { matriz de interpolação das temperaturas na superfície } \\
& \mathrm{H}_{c} \quad-\quad \text { umidade relativa do poro } \operatorname{com} \mathrm{D}(\mathrm{H})=0,5 . \mathrm{D}_{1} \\
& \mathrm{H}_{\mathrm{e}} \quad-\quad \text { umidade relativa nos poros junto à superfície do sólido } \\
& \mathrm{H}^{\mathrm{S}} \quad \text { - umidade relativa do ambiente } \\
& J(t, \tau) \quad \text { - função de fluência } \\
& \mathrm{J} \quad-\text { matriz Jacobiana do elemento } \\
& \mathrm{K}_{0} \quad-\quad \text { fator básico de velocidade de reação } \\
& \mathrm{K}^{\mathrm{C}} \quad-\text { matriz de convecção } \\
& \mathrm{K}^{\mathrm{k}} \quad-\quad \text { matriz de condutividade } \\
& K_{n} \quad-\quad \text { matriz de rigidez tangente global } \\
& \text { Lm - calor latente de hidratação } \\
& \mathrm{N}_{\mathrm{i}} \quad \text { - funções de interpolação ou de forma } \\
& \mathrm{P}_{\mathrm{n}} \quad-\quad \text { vetor de incrementos de cargas nodais equivalentes } \\
& P_{1}, P_{2} \text { - parâmetros específicos dependentes do grau de hidratação }
\end{aligned}
$$




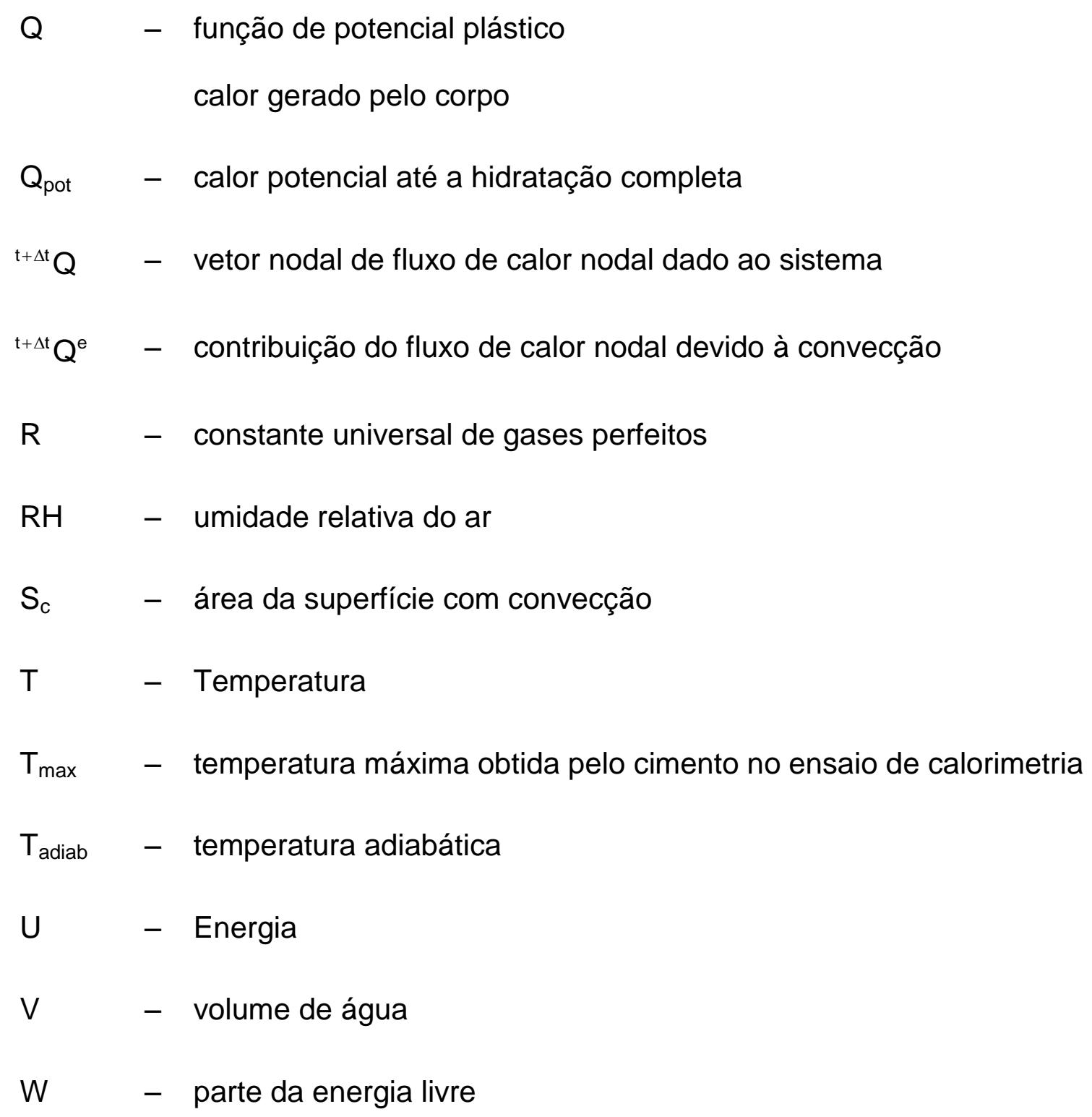

\section{Letras romanas minúsculas}

a $\quad-\quad$ vetor de fluxo plástico tensor dos coeficientes de dilatação térmica (tangente)

b - - tensor dos coeficientes de dilatação química (tangente)

c - - capacidade térmica do material

$\mathrm{C}_{\mathrm{e}} \quad-$ calor específico 


$$
\begin{aligned}
& \text { Cagg - calor específico do agregados } \\
& \mathrm{C}_{\mathrm{c}} \quad-\text { calor específico do concreto } \\
& \mathrm{C}_{\mathrm{cem}} \quad-\quad \text { calor específico do cimento } \\
& \mathrm{C}_{\mathrm{w}} \quad-\quad \text { calor específico do água } \\
& e_{i j} \quad-\quad \text { espessura no ponto de integração } \\
& \mathrm{f}_{\mathrm{c}} \quad-\quad \text { resistência à compressão } \\
& \mathrm{f}_{\mathrm{ck}} \quad-\quad \text { valor característico da resistência à compressão } \\
& \mathrm{f}_{\mathrm{cm}} \quad-\quad \text { resistência média à compressão do concreto aos } 28 \text { dias } \\
& f_{c m}(t) \quad-\quad \text { resistência média à compressão do concreto à idade t } \\
& \mathrm{f}_{\mathrm{ct}} \quad-\quad \text { resistência à tração } \\
& \mathrm{f}_{\mathrm{ctm}} \quad-\quad \text { valor médio da resistência à tração } \\
& g(\sigma, \zeta) \quad-\quad \text { potencial plástico } \\
& \text { h } \quad-\text { coeficiente de convecção } \\
& \text { espessura fictícia } \\
& h(\sigma, \zeta) \quad-\quad \text { potencial de endurecimento } \\
& \mathrm{k} \quad-\quad \text { condutividade térmica } \\
& \text { (m) elemento considerado } \\
& n \quad-\quad \text { vetor unitário normal à superfície do corpo } \\
& \mathrm{n}_{\mathrm{g}} \quad-\quad \text { número de pontos de integração em cada direção do elemento } \\
& \mathrm{q}_{\mathrm{B}} \quad-\quad \text { taxa de calor gerado por unidade de volume } \\
& \mathrm{q}_{\mathrm{s}} \quad \text { - fluxo de calor prescrito }
\end{aligned}
$$




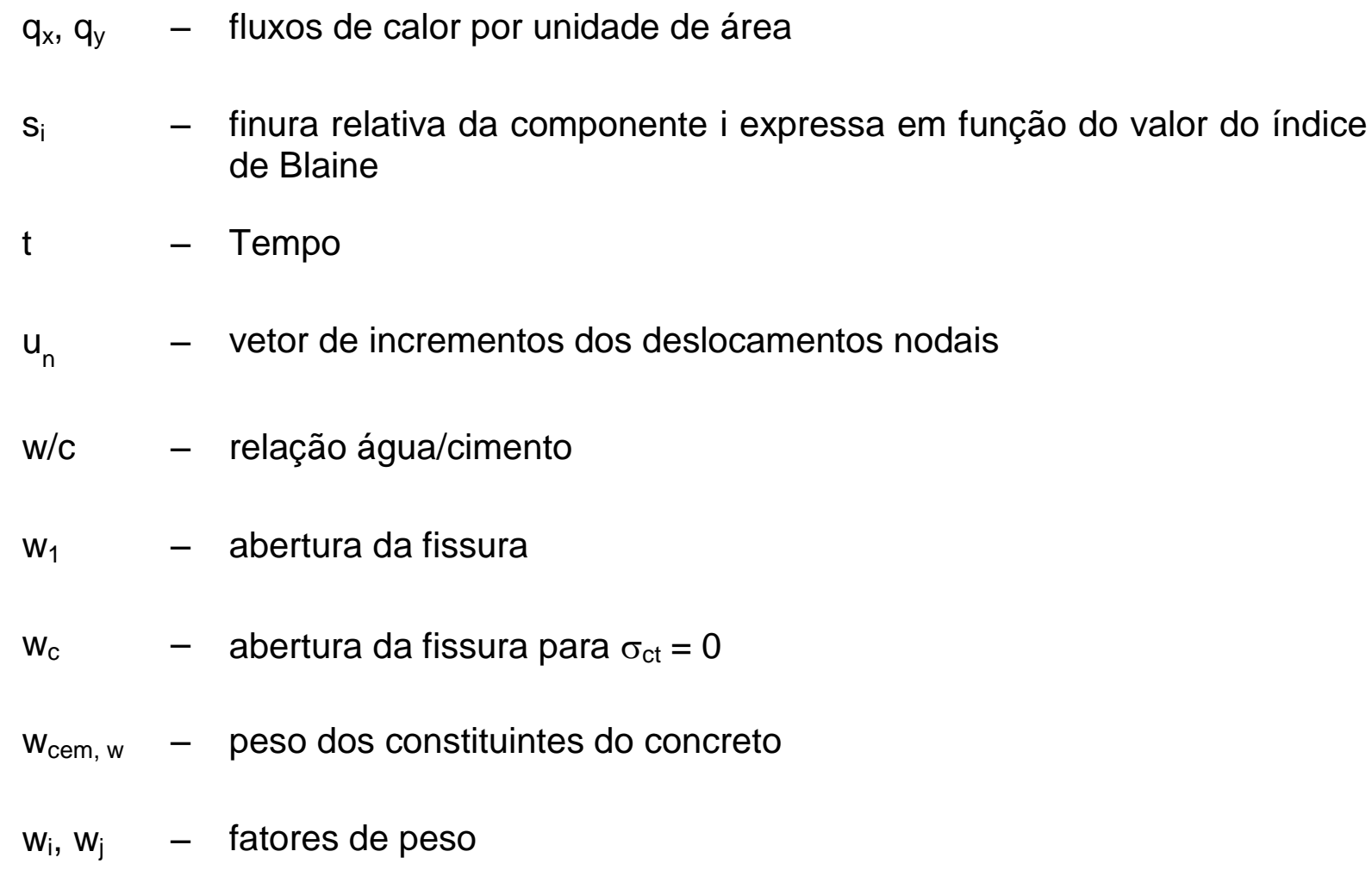

\section{Letras gregas maiúsculas}
$\Delta \quad-$ Variação
$\Omega_{\mathrm{i}} \quad-$ parâmetros que relacionam os efeitos da água sobre os mecanismos de hidratação
$\Psi \quad-\quad$ energia livre (Helmholtz)

\section{Letras gregas minúsculas}

$$
\begin{array}{ll}
\alpha \quad-\quad \text { grau de hidratação } & \text { variável interna arbitrária } \\
& \\
\alpha_{F} \quad-\quad \text { coeficiente que depende do tamanho máximo do agregado }
\end{array}
$$




$$
\begin{aligned}
& \alpha_{m} \quad-\quad \text { fator de transferência de massa } \\
& \beta-\quad-\text { variável interna arbitrária } \\
& \beta_{c} \quad-\text { descreve o desenvolvimento da fluência com o tempo } \\
& \beta_{F} \quad-\quad \text { coeficiente que depende do tamanho máximo do agregado } \\
& \beta_{c c}(t) \quad-\text { coeficiente que depende da idade do concreto } \\
& \beta_{E}(t) \quad-\text { coeficiente que descreve a evolução de } E_{c i} \text { com o tempo } \\
& \beta_{s}(t) \quad \text { - função que descreve a evolução no tempo da retração autógena } \\
& \chi \quad-\text { massa de esqueleto de hidratos } \\
& \chi_{\infty} \quad-\quad \text { valor final de } \chi \text { em condições ideais } \\
& \delta_{\mathrm{tr}} \quad-\quad \text { espessura limite de transição } \\
& \delta_{\mathrm{j}} \quad-\quad \text { aumento da profundidade de penetração } \\
& \frac{\partial \mathrm{H}}{\partial \mathrm{n}} \quad-\quad \text { gradiente de umidade na superfície } \\
& \frac{\partial \theta}{\partial \mathrm{n}} \quad-\quad \text { gradiente térmico na superfície } \\
& \varepsilon \quad-\quad \text { tensor de deformações totais } \\
& \varepsilon_{c}(t, T) \quad-\text { extensão de fluência durante o período } t \text {, com início em } T \\
& \varepsilon_{c 0} \quad-\quad \text { valor final da retração autógena } \\
& \varepsilon_{\mathrm{ct}} \quad-\quad \text { deformação de tração } \\
& \varepsilon_{c s} \quad-\quad \text { retração autógena para a idade } t \\
& \varepsilon_{\text {cso }} \quad-\quad \text { coeficiente de retração autógena }
\end{aligned}
$$




$$
\begin{array}{ll}
\varepsilon^{\mathrm{e}} & - \text { deformação elástica } \\
\varepsilon^{\mathrm{p}} & - \text { deformação plástica } \\
\phi\left(\mathrm{t}, \mathrm{t}^{\prime}\right) & - \text { coeficiente de fluência }
\end{array}
$$

$\phi_{0} \quad-\quad$ coeficiente de fluência nominal

diâmetro mínimo dos poros capilares

申por $\quad$ - diâmetro máximo dos poros capilares da pasta

$\phi_{\text {wat }} \quad$ - diâmetro máximo dos poros capilares completamente preenchidos por água

$\gamma \quad-$ coeficiente de fluidez

coeficiente que tem em conta o tipo de cimento

$\eta \quad-\quad$ coordenada normalizada

$\eta_{\mathrm{i}} \quad$ - espessura fictícia da camada de produtos hidratados em torno das partículas anidras

$\eta_{\mu} \quad-\quad$ coeficientes de viscosidade

$\varphi \quad-$ dissipação

$\varphi^{\mathrm{c}} \quad-$ dissipação química

$\varphi^{\mathrm{p}} \quad$ - dissipação plástica

$\lambda \quad-\quad$ multiplicador plástico

$\mu \quad-\quad$ perímetro de contato com a atmosfera

v $\quad-\quad$ coeficiente de Poisson

$v(\overline{\mathrm{T}}) \quad$ - densidade dos produtos de hidratação para a temperatura $\overline{\mathrm{T}}$ 


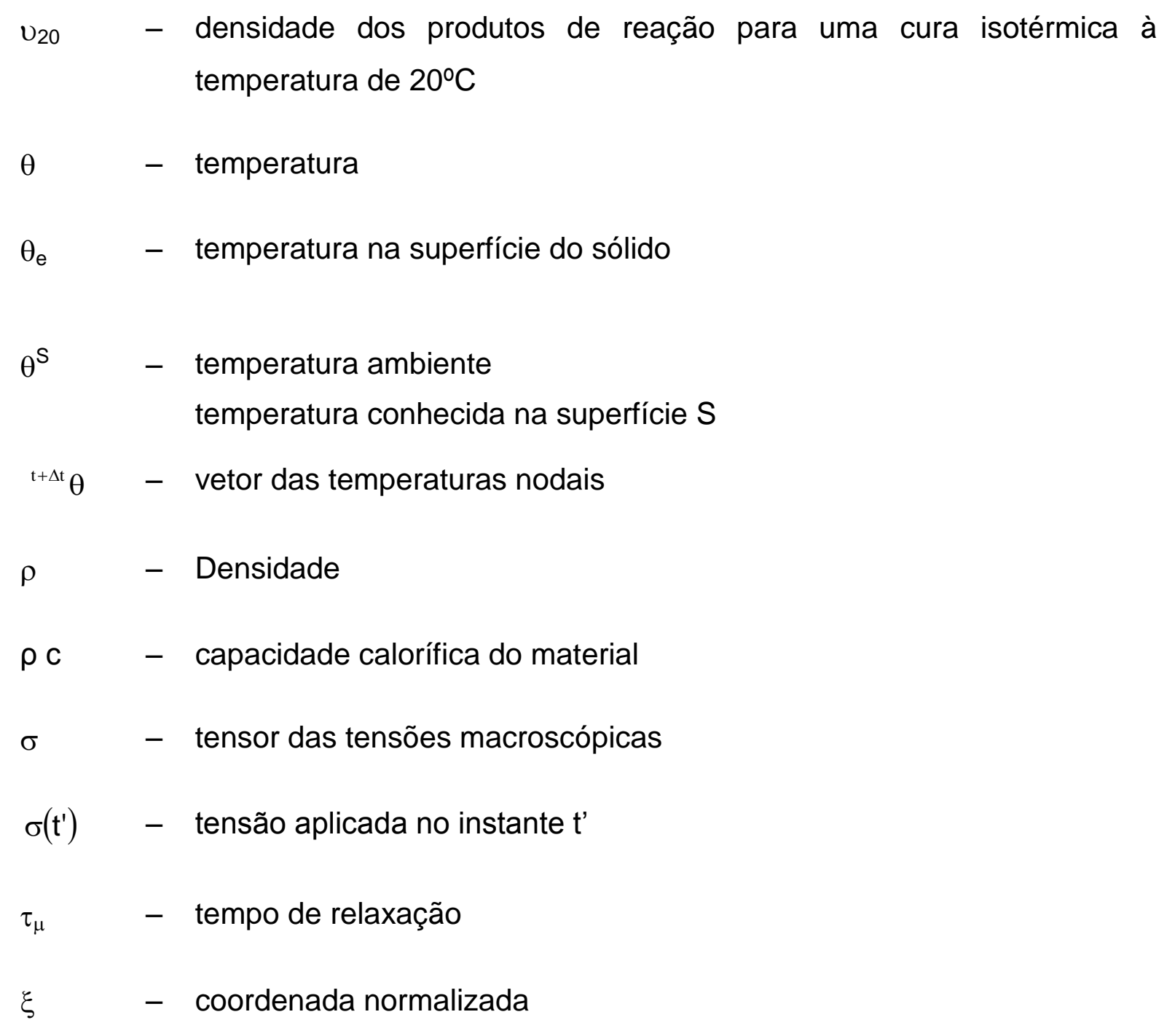




\section{SUMÁRIO}

\section{CAPÍTULO 1 - INTRODUÇÃO}

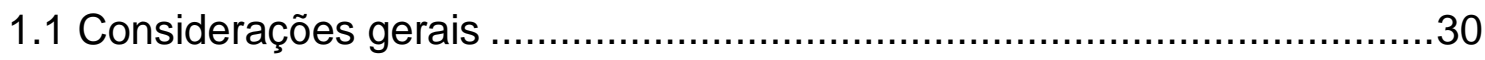

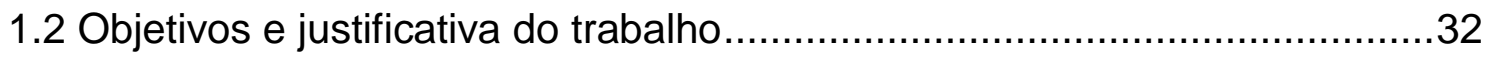

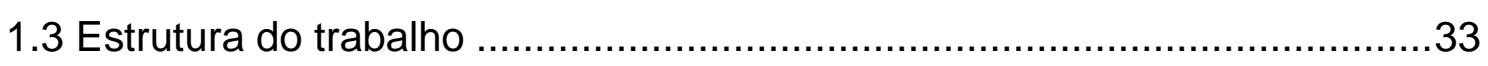

\section{CAPÍTULO 2 - COMPORTAMENTO DO CONCRETO NAS PRIMEIRAS IDADES}

2.1 Introdução

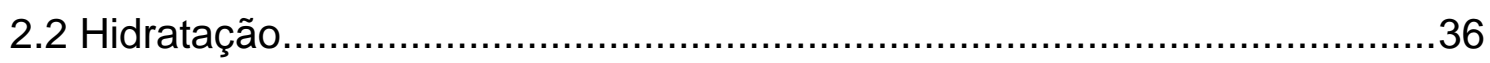

2.2.1 Modelo proposto por Ulm e Coussy ...........................................39

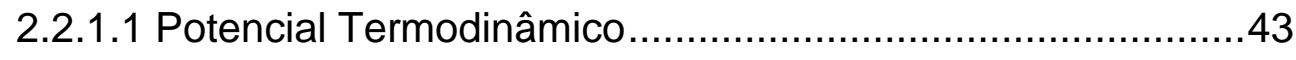

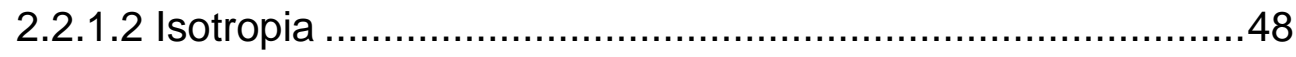

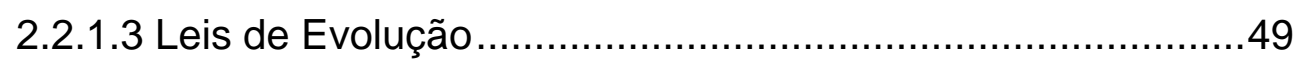

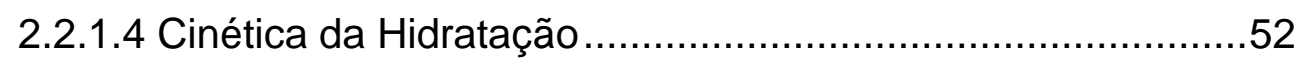

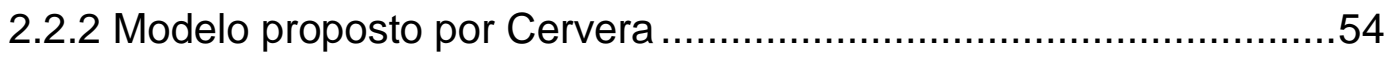

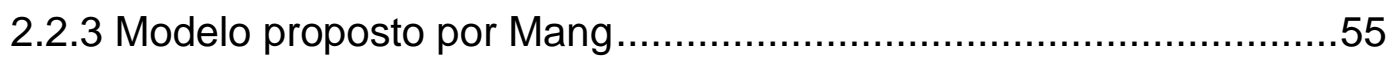

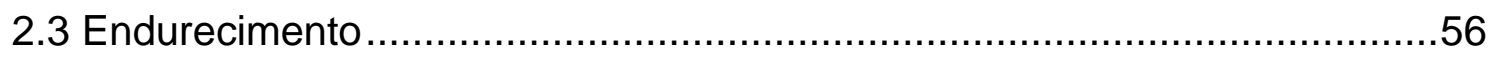

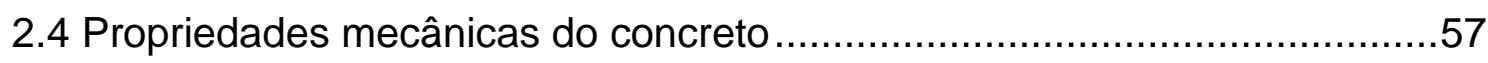

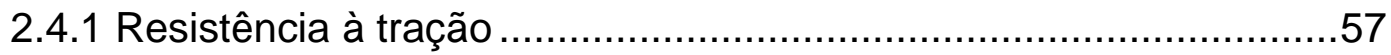

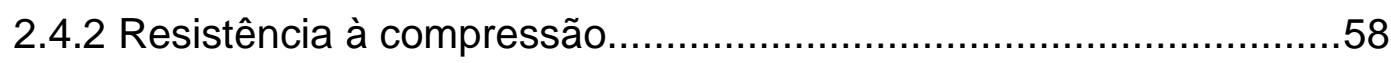

2.4.3 Módulo de elasticidade ..........................................................59 
2.5 Fluência .60

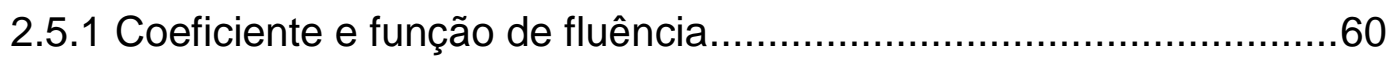

2.5.2 Fluência com história de tensão variável.........................................61

2.6 Retração 62

\section{CAPÍTULO 3 - ANÁLISE DO PROBLEMA QUÍMICO}

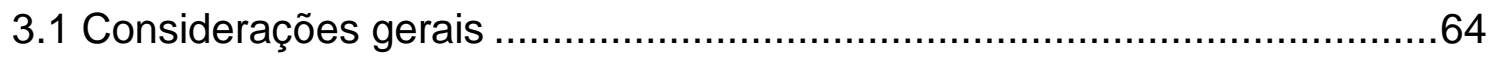

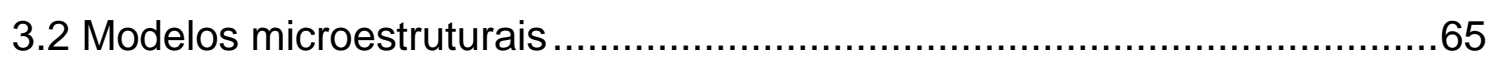

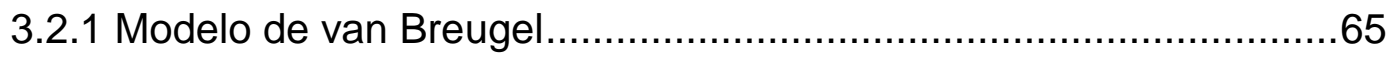

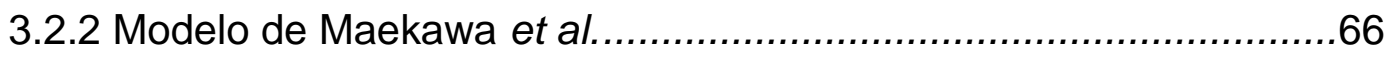

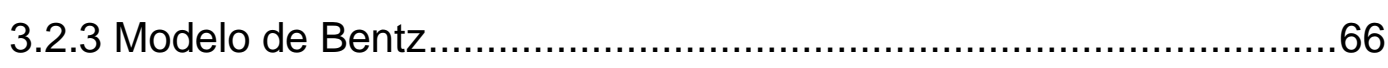

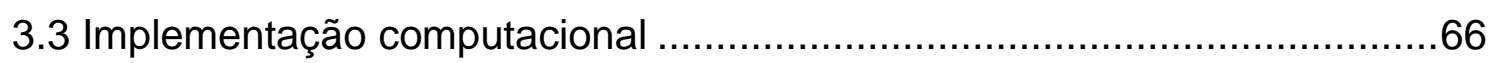

3.3.1 Curva de elevação adiabática de temperatura - JSCE ..................67

3.3.2 Estimativa da elevação adiabática de temperatura .........................68

\section{CAPÍTULO 4 - ANÁLISE DE ELEMENTOS FINITOS APLICADA À TRANSFERÊNCIA DE CALOR}

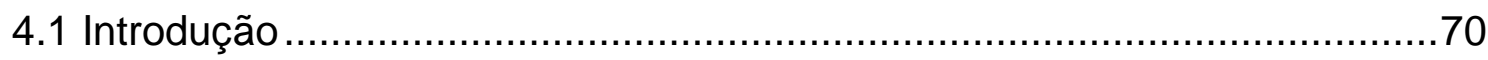

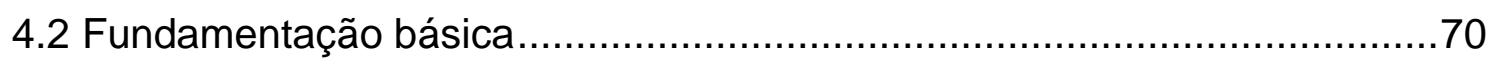

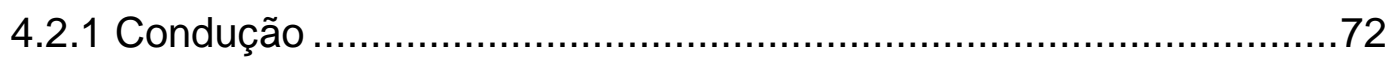

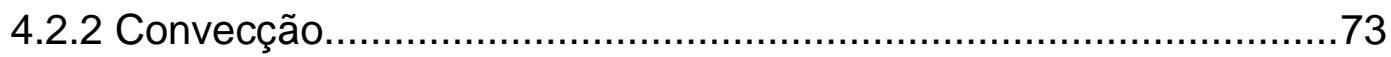

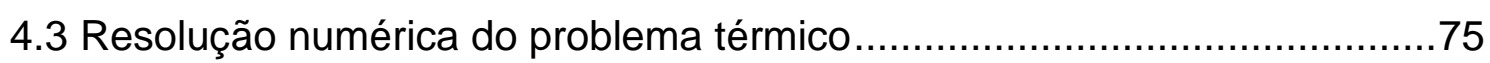

4.4 Equações clássicas de transferência de calor ........................................76

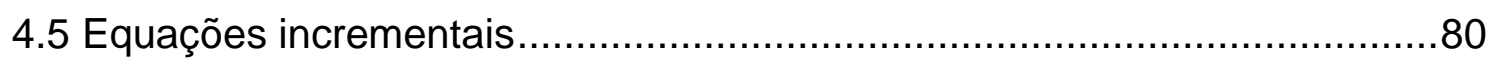

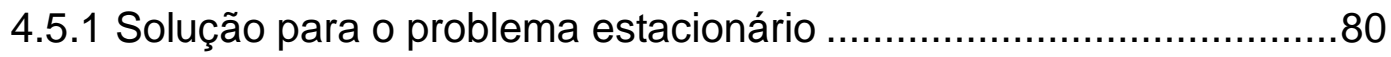

4.5.2 Solução para o problema transiente .............................................. 82

4.6 Discretização das equações de transferência de calor ...............................83

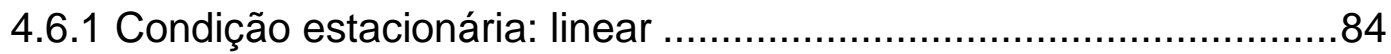

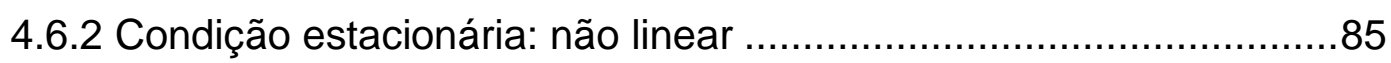

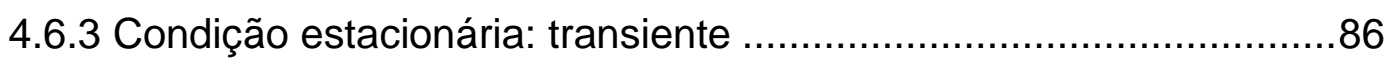




\section{CAPÍTULO 5 - ANÁLISE DE ELEMENTOS FINITOS APLICADA À DIFUSÃO DE UMIDADE}

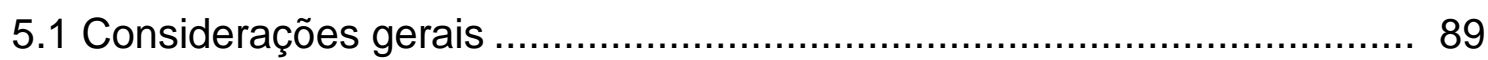

5.2 Primeira Lei da Difusão de Fick ......................................................... 90

5.3 Lei de Fick aplicada a concreto......................................................... 90

5.4 Resolução numérica de um problema de difusão de umidade ................. 92

5.4.1 Analogia entre transferência de calor e difusão de umidade ......... 93

\section{CAPÍTULO 6 - ANÁLISE DA ETAPA DE SOLUÇÃO DO PROBLEMA MECÂNICO}

6.1 Modelo para um material elasto-viscoplástico ….................................. 96

6.1.1 Formulação do comportamento elasto-viscoplástico .................... 97

6.1.1.1 Incremento de deformação viscoplástica ..........................100

6.1.1.2 Incremento de tensão ....................................................100

6.1.1.3 Equações de equilíbrio.................................................101

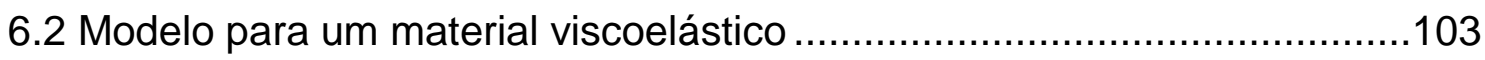

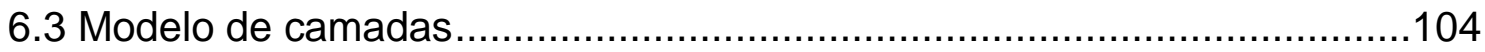

6.4 Propriedades dos materiais dependentes do tempo .............................106

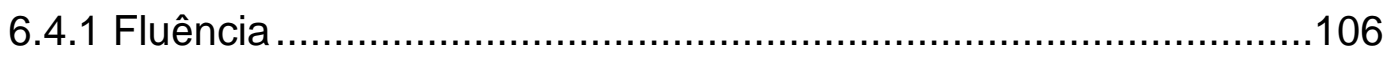

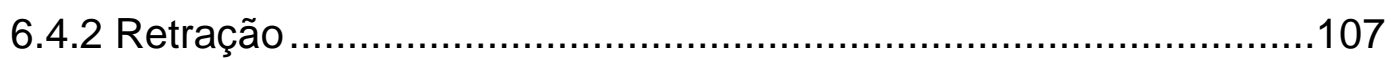

6.5 Relações constitutivas uniaxiais para o concreto..................................108

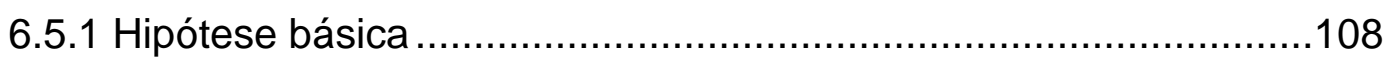

7.5.1.1 Lei do tipo integral para fluência ......................................108

7.5.1.2 Lei do tipo integral para relaxação ....................................109

7.5.1.3 Discussão das leis do tipo integral para fluência e relaxação ...............................................................110

6.5.2 Inclusão da fluência no modelo ...............................................112

6.5.2.1 Formulação matemática do modelo de Maxwell ................113

6.5.2.2 Determinação da função de relaxação a partir da função

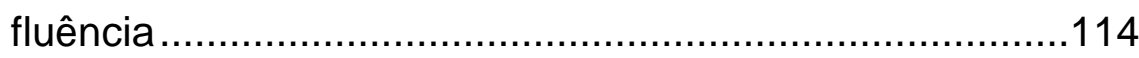

6.5.2.3 Determinação dos parâmetros $E_{\mu}(t)$ e $\eta_{\mu}(t) \ldots \ldots \ldots \ldots \ldots \ldots \ldots \ldots . . .117$ 
6.5.2.4 Determinação dos parâmetros da função de fluência 119

6.5.2.4.1 Equação básica

6.5.2.4.2 Coeficiente de fluência

6.5.2.4.3 Efeito do tipo de cimento e variação de temperatura 122

6.5.3 Inclusão da retração no modelo 123

6.5.3.1 Determinação dos parâmetros de retração 124

6.6 Critério de fissuração 126

6.6.1 Critério de ruptura 126

6.6.2 Comportamento pós-fissuração. 129

\section{CAPÍTULO 7 - ALGORITMO PROPOSTO PARA ANÁLISE DO CONCRETO NAS PRIMEIRAS IDADES}

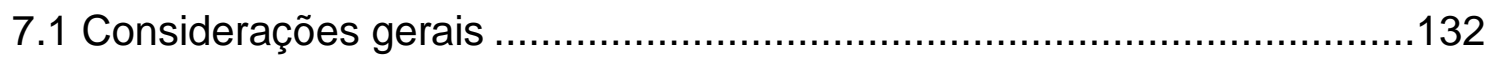

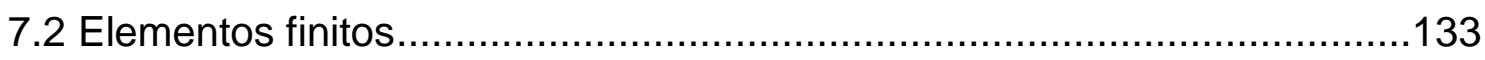

7.3 EACB - Programa Early Age Concrete's Behavior ................................136

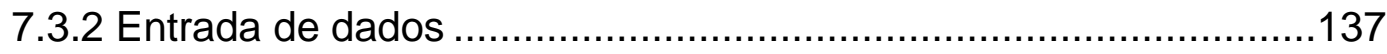

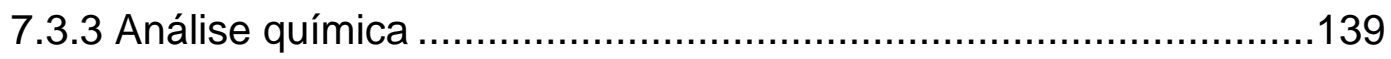

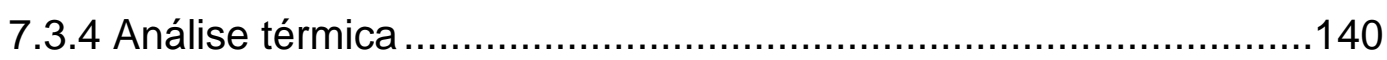

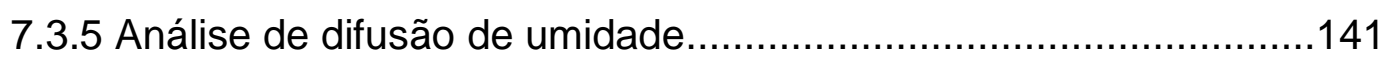

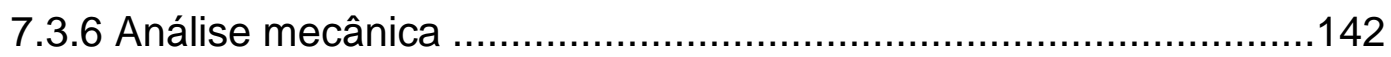

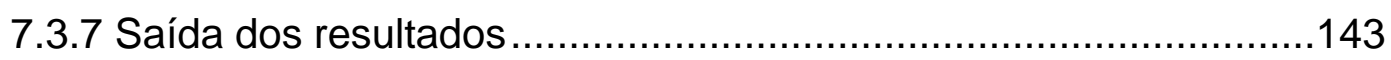

\section{CAPÍTULO 8 - APLICAÇÕES NUMÉRICAS}

8.1 Introdução

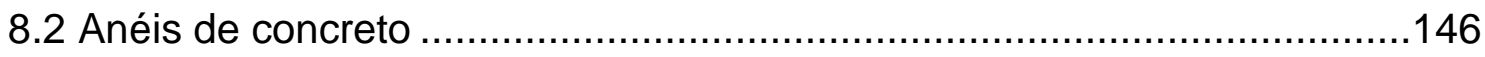

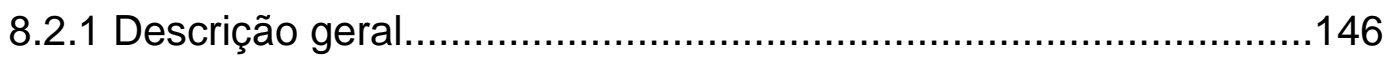

8.2.2 Geometria e parâmetros utilizados na modelagem

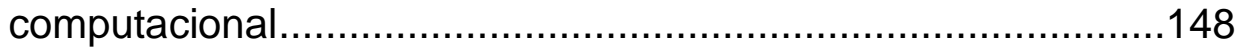

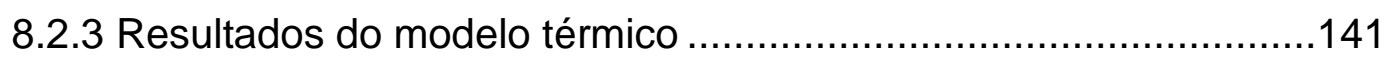

8.2.4 Resultados do modelo de difusão de umidade ............................153

8.2.5 Resultados do modelo mecânico..................................................154 
8.3 Prismas de concreto 160

8.3.1 Descrição geral.

8.3.2 Geometria e parâmetros utilizados na modelagem computacional

8.3.3 Resultados do modelo térmico 164

8.3.4 Resultados do modelo de difusão de umidade ............................165

8.3.5 Resultados do modelo mecânico................................................166

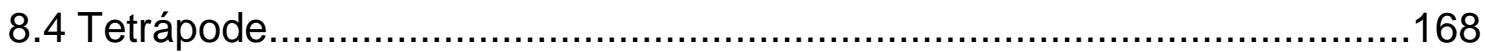

8.4.1 Descrição geral.....................................................................168

8.4.2 Geometria e parâmetros utilizados na modelagem

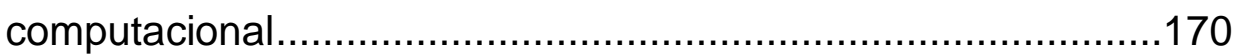

8.4.3 Resultados do modelo térmico ...............................................173

8.4.4 Resultados do modelo de difusão de umidade...........................174

8.4.5 Resultados do modelo mecânico..................................................174

\section{CAPÍTULO 9 - CONCLUSÕES}

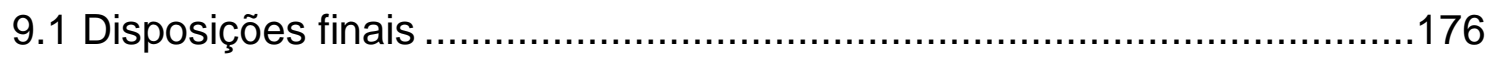

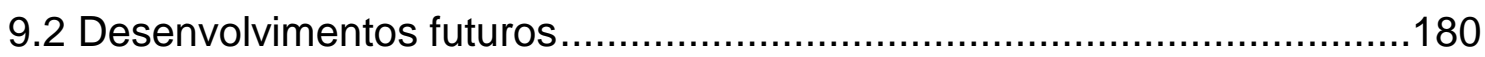





\section{CAPÍTULO 1}

\section{INTRODUÇÃO}

\subsection{Considerações gerais}

Nos últimos sessenta anos o concreto tem sido o material estrutural mais utilizado no mundo. É empregado em todos os tipos de construção por suas inúmeras vantagens. Estas incluem, por exemplo, o fato do mesmo ser facilmente moldável, adaptando-se a qualquer tipo de forma, ser resistente ao fogo, às influências atmosféricas e ao desgaste mecânico, e, principalmente, por ser uma alternativa econômica, uma vez que é constituído de matéria prima barata.

Todavia, o comportamento do concreto é bastante complexo, o que vem a criar dificuldades na análise das estruturas executadas com este material. Estas dificuldades são decorrentes, entre outros fatores, da significativa diferença entre as resistências à tração e à compressão do concreto, da não-linearidade da relação tensão-deformação já para níveis de tensão relativamente baixos, dos fenômenos de fluência e retração que dependem, por exemplo, da umidade e temperatura ambientes e das dimensões do elemento estrutural, da fissuração do concreto, que pode ocorrer já nas primeiras idades, e da transmissão de esforços através das fissuras. 
A análise tradicional de estruturas de concreto é baseada em ensaios de estruturas ou de peças estruturais em laboratório. Os resultados obtidos nessa forma de análise são limitados e, às vezes, de difícil interpretação. É necessário, portanto, o desenvolvimento de modelos matemáticos para complementar a análise experimental e possibilitar a generalização dos resultados para diferentes estruturas e formas de carregamento.

Nestas lacunas encaixa-se a simulação numérica. Esta pode ser definida como a capacidade de prever, computacionalmente, o comportamento que seria observado numa estrutura ou elemento estrutural. O Método dos Elementos Finitos é seguramente o processo numérico que mais tem sido usado para a análise deste tipo de estrutura. A sua larga utilização se deve ao avançado grau de desenvolvimento alcançado pelo método na análise de estruturas de concreto armado, aliada à analogia física direta que se estabelece, com o seu emprego, entre o sistema físico real, a estrutura em análise, e o modelo, malha de elementos finitos. Através dele pode-se simular numericamente o funcionamento das estruturas de concreto armado.

O estudo da evolução das propriedades do concreto nas primeiras idades está se tornando cada vez mais importante, pois a liberação do calor de hidratação e a retração do concreto, logo nas primeiras horas, podem gerar fissuras, aumentando a permeabilidade da estrutura e induzindo problemas de durabilidade e funcionalidade das mesmas. Na realidade, há um limitado entendimento do comportamento do concreto nas idades iniciais e questionamentos sobre a validade dos modelos utilizados. Um detalhado estudo da evolução das tensões durante este período pode ser decisivo para manter baixos os níveis de fissuração.

O emprego da técnica de análise por elementos finitos pode propiciar avaliações mais precisas do comportamento do concreto nas primeiras idades. A possibilidade de integração dos efeitos térmicos e da retração, ambos dependentes das condições de contorno e das propriedades dos materiais utilizados, faz do emprego do Método dos Elementos Finitos uma ferramenta potencialmente econômica e tecnicamente adequada para a análise desta questão, podendo vir a substituir com vantagens os métodos de dimensionamento usuais que não consideram os efeitos térmicos e da retração. 
Embora o desenvolvimento de inúmeros softwares na área de elementos finitos tenha difundido esta técnica, exige-se uma adequação destes programas para a incorporação dos principais fatores transientes relacionados à retração e à deformação do concreto nas primeiras idades, para a modelagem do sistema de maneira adequada. Neste aspecto, os resultados obtidos computacionalmente serão comparados com resultados de ensaios controlados em modelos realizados no laboratório, com o objetivo de validar a modelagem. Como conseqüência, busca-se o melhor entendimento do comportamento do concreto armado nas idades iniciais e o desenvolvimento de uma ferramenta que visa o combate à fissuração do concreto nessas idades.

A proposta do presente trabalho é desenvolver estratégias de modelagem computacional dos fenômenos químicos, térmicos, de difusão de umidade e mecânicos que englobam o histórico do concreto nas primeiras idades, para uma melhor interpretação dos resultados experimentais e avaliação de diferentes tipos de solicitações, com objetivo de avaliar a fissuração inicial do concreto.

Com este intuito, se faz necessário, inicialmente, o estudo de leis constitutivas apropriadas para a modelagem da hidratação, retração e fissuração no concreto. A partir daí serão abordadas as técnicas de modelagem e efetuadas simulações, a serem validadas por meio de comparação com resultados de experimentação física já realizada por outros pesquisadores. Após o decorrer dessas avaliações, pretendese interpretar de maneira mais consistente os resultados experimentais disponíveis na literatura e oriundos de outros programas.

\subsection{Objetivos e justificativa do trabalho}

Durante os últimos anos vêm sendo desenvolvidas diversas ferramentas numéricas com o objetivo de avaliar as medidas adotadas para diminuir o risco de fissuração (Lura, 2000; Morabito, 1998; Shah, 1994). O estudo numérico de um problema tão complexo quanto o da fissuração nas primeiras idades, deve se basear em um modelo matemático, que seja capaz de descrever o acoplamento térmico, 
hídrico, químico e mecânico. Apresentam-se, nos primeiros capítulos deste trabalho, modelos que descrevem os principais aspectos da hidratação, retração, fluência e fissuração do concreto, a fim de ser implementado através do Método dos Elementos Finitos.

O objetivo principal do presente trabalho é desenvolver uma metodologia que seja capaz de avaliar o potencial risco de fissuração de uma estrutura de concreto nas primeiras idades, para poder assim propor, estudar e avaliar medidas para obter um projeto estrutural adequado e um conjunto de estratégias para facilitar o controle de qualidade das obras.

Para tanto, pretende-se que, ao fim da pesquisa, estejam estabelecidos subsídios que permitam, por meio de análise numérica, desenvolver metodologias de análise e modelagem para um melhor entendimento do comportamento de estruturas de concreto nas primeiras idades. Metodologias estas que permitam avaliações técnicas necessárias para o estabelecimento de um conjunto de técnicas e processos de construção e projeto, a fim de diminuir o risco de fissuração.

Além disso, almeja-se avaliar o emprego da modelagem por elementos finitos, na análise do efeito da hidratação, retração e fissuração em estruturas de concreto nas primeiras idades e verificar a necessidade de aprimoramento das ferramentas numéricas em questão, de acordo com o observado em ensaios experimentais.

\subsection{Estrutura do trabalho}

O presente estudo descreve as etapas envolvidas na resolução do problema da modelagem do concreto nas primeiras idades, através do acoplamento dos fenômenos químicos, térmicos e mecânicos, utilizando o Método dos Elementos Finitos.

O capítulo 2 aborda o comportamento do concreto nas primeiras idades. São discutidos aspectos como hidratação, endurecimento, retração e fluência, e a importância dos mesmos dentro do referido tópico. 
O capítulo 3 descreve a solução do problema químico. Faz-se uma análise de outros programas computacionais que utilizam a composição química do concreto e a validade de utilizá-los no Brasil. Apresenta-se ainda a curva elevação adiabática de temperatura como metodologia alternativa para determinação do calor gerado pelas reações de hidratação do cimento.

No capítulo 4 descreve-se a implementação computacional do problema térmico, resultado da reação exotérmica de hidratação do concreto. Destaca-se a modelagem do fluxo de calor no interior do corpo de concreto, bem como as soluções adotadas para condutividade e convecção.

O capítulo 5 apresenta a terceira etapa do algoritmo proposto pela presente tese, a difusão de umidade no interior do corpo de concreto.

O modelo mecânico é descrito no capítulo 6. São apresentadas as formulações para a consideração de um material viscoelástico no programa, as relações constitutivas para o concreto e critério de fissuração.

O capítulo 7 é dedicado à descrição da implementação computacional do comportamento do concreto nas primeiras idades, através do Método dos Elementos Finitos. Modelagem esta inovadora, que propõe o acoplamento de quatro diferentes etapas em seqüência. Descrevem-se as quatro etapas de análise propostas pela presente tese: química, térmica, difusão de umidade e mecânica.

Os resultados obtidos através do programa computacional, desenvolvido nesta tese, são confrontados com valores experimentais no capítulo 8 , demonstrando a capacidade dos modelos implementados de simular 0 comportamento real do concreto nas primeiras idades.

O capítulo 9 encerra o presente estudo com o delineamento das conclusões e sugestões para novas pesquisas. 
CAPÍTULO 2

COMPORTAMENTO DO CONCRETO NAS PRIMEIRAS IDADES

\subsection{Introdução}

Entre os vários fenômenos que se produzem nas primeiras idades do concreto, pode-se destacar, como sendo os mais importantes: a hidratação do cimento, a retração devida à secagem, às retrações autógena e plástica, os efeitos térmicos, químicos e de hidratação, a fluência, o envelhecimento e a fissuração. Cabe salientar que estes fenômenos interagem entre si, portanto, não podem ser analisados isoladamente, a menos que se considerem hipóteses simplificadoras bem fundamentadas. A figura 2.1, baseada em Prato (1999), esquematiza, de maneira resumida, os fatores fundamentais que influem no comportamento do concreto nas primeiras idades. 


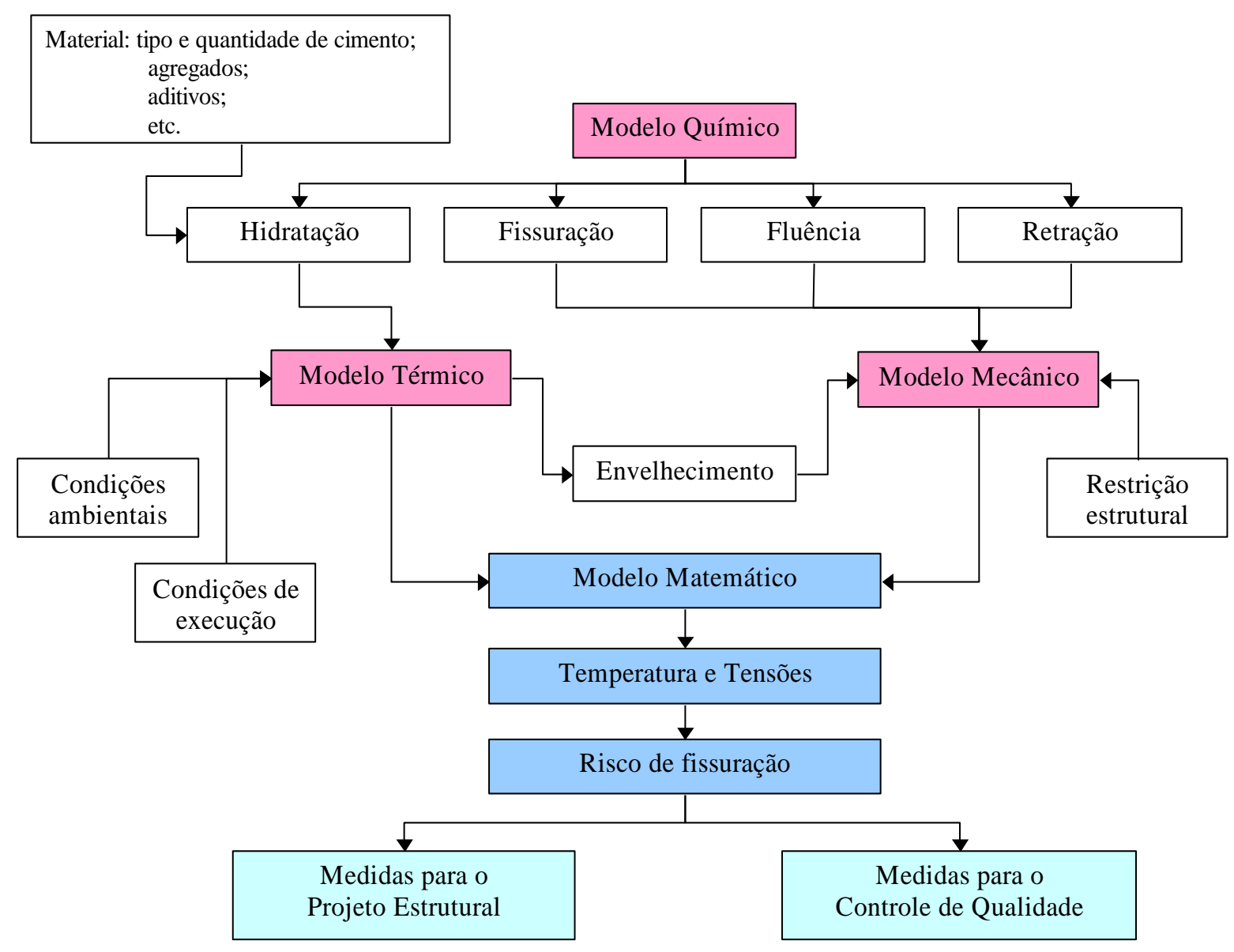

Figura 2.1 - Fatores que influenciam no comportamento estrutural do concreto nas primeiras idades (Prato, 1999)

O presente capítulo tem como objetivo apresentar o que tem sido estudado dentro do assunto Primeiras Idades do Concreto, analisando aspectos como hidratação, endurecimento, retração e fluência, e a importância dos mesmos dentro do referido tópico.

\subsection{Hidratação}

A hidratação do cimento é uma reação altamente exotérmica (reação química que ocorre em um sistema em que há liberação de calor para o meio externo), 
durante a qual o calor gerado pode provocar um aumento de temperatura de até 50 $60^{\circ} \mathrm{C}$ em condições adiabáticas (processo de transformação de um sistema em que não ocorrem trocas térmicas com o exterior).

O processo de hidratação se apresenta, desde o nível macroscópico, como uma reação química em que a água livre, na fase reativa, se combina com o cimento, para formar, como produto, água combinada nos hidratos. A figura 2.2 mostra o processo de formação dos hidratos (Ulm e Coussy, 1996).

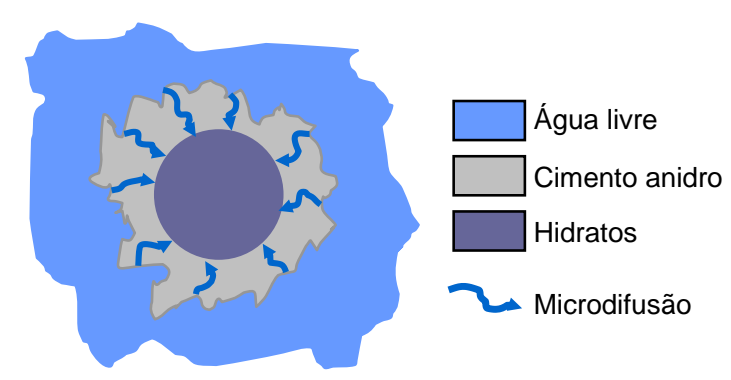

Figura 2.2 - Processo de microdifusão da água livre através das camadas de hidratos já formados

A baixa condutividade do concreto e os fenômenos de radiação e convecção com o meio ambiente podem gerar gradientes térmicos importantes. A restrição externa, aliada ao processo evolutivo de construção e a baixa resistência à tração nas primeiras idades, podem produzir fissuras. Por outro lado, as características de deformabilidade do concreto, variam com o tempo. Estes efeitos reológicos não podem ser desprezados e são de uma natureza extremamente complexa. A consideração destes efeitos adquire particular importância quando se estuda 0 comportamento de estruturas protendidas, esbeltas ou com grande volume de concreto.

As razões mencionadas no parágrafo anterior põem em evidência que as solicitações mais prejudiciais a que se pode ver submetido o concreto são as de origem térmica. De acordo com Prato (1999), para poder quantificar corretamente este tipo de ação, é necessário conhecer em detalhes três aspectos básicos: as 
propriedades térmicas da mistura utilizada, as condições ambientais e as condições de execução da obra.

A propriedade mais importante que se deve ter em conta é a capacidade de liberação de calor durante o processo de hidratação do cimento. A velocidade de hidratação, a velocidade de liberação de calor e a quantidade total de calor gerado durante o processo de cura dependem basicamente do tipo e quantidade de cimento utilizado e da temperatura inicial ambiente na obra. A capacidade de dissipar o calor gerado depende das propriedades térmicas (calor específico e condutividade) do concreto e fundamentalmente das condições ambientais e de execução da obra. A temperatura ambiente, a velocidade do vento, o grau de isolação e a inclusão da umidade relativa do ar podem condicionar o fluxo de calor dirigido ao exterior da estrutura devido aos fenômenos de condução, radiação e convecção. Por outro lado, a velocidade de construção ou o tipo de molde utilizado são fatores que estão relacionados com o processo de execução e podem influir de maneira importante na determinação da ação (carga) térmica a ser considerada.

Para controlar o efeito prejudicial das ações térmicas sobre o comportamento estrutural é necessário tentar diminuir as temperaturas máximas e os gradientes térmicos que podem gerar-se dentro da massa de concreto. Para isso, durante as últimas décadas têm-se desenvolvido diferentes técnicas. Pode citar-se, por exemplo, a diminuição da temperatura inicial através do resfriamento dos aglomerados. Uma temperatura inferior encontrada em obra permite desacelerar o processo de hidratação e, portanto, permite dissipar mais facilmente o calor à medida que ele vai sendo gerado, diminuindo assim, consideravelmente, o risco de fissuração.

Em relação às condições de execução que podem diminuir tanto as temperaturas máximas quanto os gradientes de temperatura no interior da massa de concreto, pode citar-se a utilização de canais de refrigeração e o uso de isolantes térmicos nas formas.

Muitos dos fatores anteriormente mencionados afetam diretamente 0 processo de hidratação do cimento e, por conseqüência, a ação térmica a que será submetida à estrutura. Contudo, a hidratação do cimento é a responsável pelo 
processo de endurecimento, aumento de resistência e rigidez do concreto, ou seja, é responsável também pela capacidade do concreto para resistir às citadas ações de origem térmica.

Nos últimos tempos notou-se que a evolução das propriedades mecânicas do concreto está condicionada não somente ao grau de avanço da reação de hidratação, mas também pela cinética da mesma. Foi verificado experimentalmente que o valor da resistência à compressão e, por conseqüência, o valor da resistência à tração e o módulo de elasticidade no final do processo de cura dependem da temperatura máxima na qual foi curado o material.

Do exposto nos parágrafos anteriores se deduz que a reação de hidratação do cimento define de maneira fundamental tanto as ações quanto a capacidade de resistência do concreto nas primeiras idades. É por isso que o presente estudo analisa, em detalhes, o fenômeno de hidratação e o conseqüente endurecimento do concreto.

\subsubsection{Modelo proposto por Ulm e Coussy}

Olivier Coussy e Franz-Josef Ulm publicaram diversos trabalhos em conjunto, sobre a modelagem computacional do comportamento do concreto nas primeiras idades. O modelo proposto por eles, publicado no Journal of Engineering Mechanics (ASCE) nos anos de 1995 e 1996, serviu de base para as publicações de Cervera et al. (2002) e de Mang et al. (2003).

No modelo proposto por Ulm e Coussy, como pode ser observado na figura 2.3, o concreto é modelado como um meio poroso quimicamente reativo. Na fase fluida há presença de água livre, esqueleto de hidratos e cimento anidro. À medida que água reage com o cimento, água livre reduz e esqueleto aumenta na mesma medida. Resistência e rigidez (macroscopicamente) aumentam proporcionalmente ao montante de produtos de hidratação, mas no nível micro da matéria, estas propriedades não se alteram. O concreto é um sistema composto pela superposição 
de um esqueleto sólido e de uma solução intersticial contínua dentro de um sistema poroso associado.

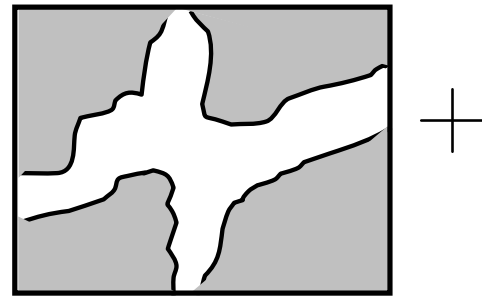

esqueleto

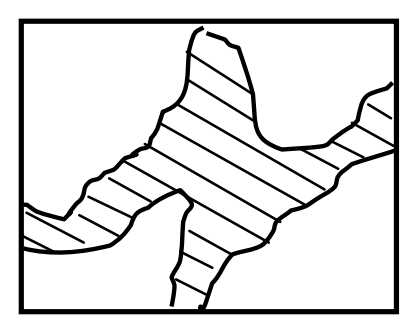

poros com água

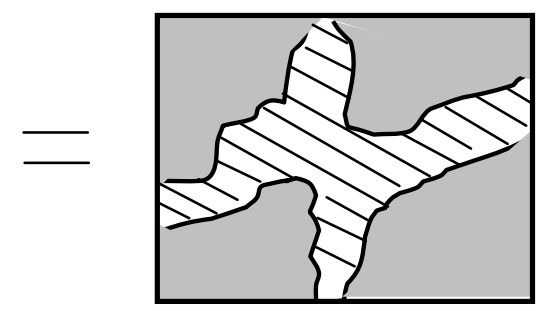

meio poroso

Figura 2.3 - Modelagem do concreto, segundo Ulm e Coussy (1995).

Para a modelagem constitutiva, a teoria termodinâmica dos meios porosos reativos (Coussy, 1995) é aplicada ao estudo de concreto nas primeiras idades (Ulm e Coussy, 1995 e 1997), que consideram o concreto como um meio poroso quimicamente reativo e apresentam linhas conceituais da teoria dos acoplamentos termo-químico-mecânicos para a descrição da reação e hidratação de sua interação com a evolução da temperatura (acoplamento termo-químico), deformação (acoplamento químico-mecânico) e endurecimento (acoplamento plasto-químico).

Para isso utiliza-se a segunda Lei da Termodinâmica:

$$
\frac{\mathrm{dS}}{\mathrm{dt}} \geq \frac{\mathrm{Q}}{\mathrm{T}}
$$

onde:

- $\mathrm{t}$ : tempo

- T: temperatura absoluta do sistema

- Q: calor trocado com o exterior

- S: entropia (forma de energia que não pode ser transformada em trabalho, ou seja, o sistema não pode transformar a entropia em energia utilizável, pode somente "produzir" entropia dissipando energia livre - utilizável). 
A desigualdade (3.1) decorre deste fenômeno interno dissipativo:

$$
\mathrm{T} \frac{\mathrm{dS}}{\mathrm{dt}}=\mathrm{Q}+\varphi
$$

sendo $\varphi \geq 0$, que representa a dissipação atribuída a deformações plásticas e a evolução da reação de hidratação.

A forma padrão da dissipação para sistemas fechados (desigualdade de Clausius-Duhem) é:

$$
\varphi=\sigma: \dot{\varepsilon}-S \dot{T}-\dot{\Psi} \geq 0
$$

onde:

- $\sigma$ - tensor das tensões macroscópicas, relacionado com o equilíbrio das forças externas

- $\varepsilon$ - tensor de deformações totais (observável)

- : - produto escalar entre tensores

- $\psi$ - energia livre (Helmholtz) unitária associada ao sistema que define os estados energéticos, em termos das variáveis de estado externas e internas.

O método, para a dedução das equações constitutivas acopladas do material, postula que o estado termodinâmico de um determinado meio material em um dado ponto e instante é definido pelo conhecimento de um certo número de variáveis naquele instante, dependentes da posição onde são consideradas. A descrição precisa de fenômenos físicos depende da escolha do número e da natureza das variáveis de estado ou das variáveis termodinâmicas. E o processo é admissível se, a cada instante da evolução do material, a desigualdade de Claussius-Duhem for satisfeita. A tabela 2.1 mostra a dependência das variáveis de estado externas e a tabela 2.2 a dependência das variáveis de estado internas. 
Tabela 2.1 - Variáveis de Estado Externas, observáveis macroscopicamente

\begin{tabular}{c|c}
\hline Para estudo de: & Dependem de: \\
\hline elasticidade & \\
viscoelasticidade & \\
plasticidade & T (temperatura) \\
viscoplasticidade & $\varepsilon$ (deformação total) \\
dano & \\
fratura & \\
fenômenos reversíveis & \\
\hline \hline
\end{tabular}

Tabela 2.2 - Variáveis de Estado Internas, observáveis macroscopicamente

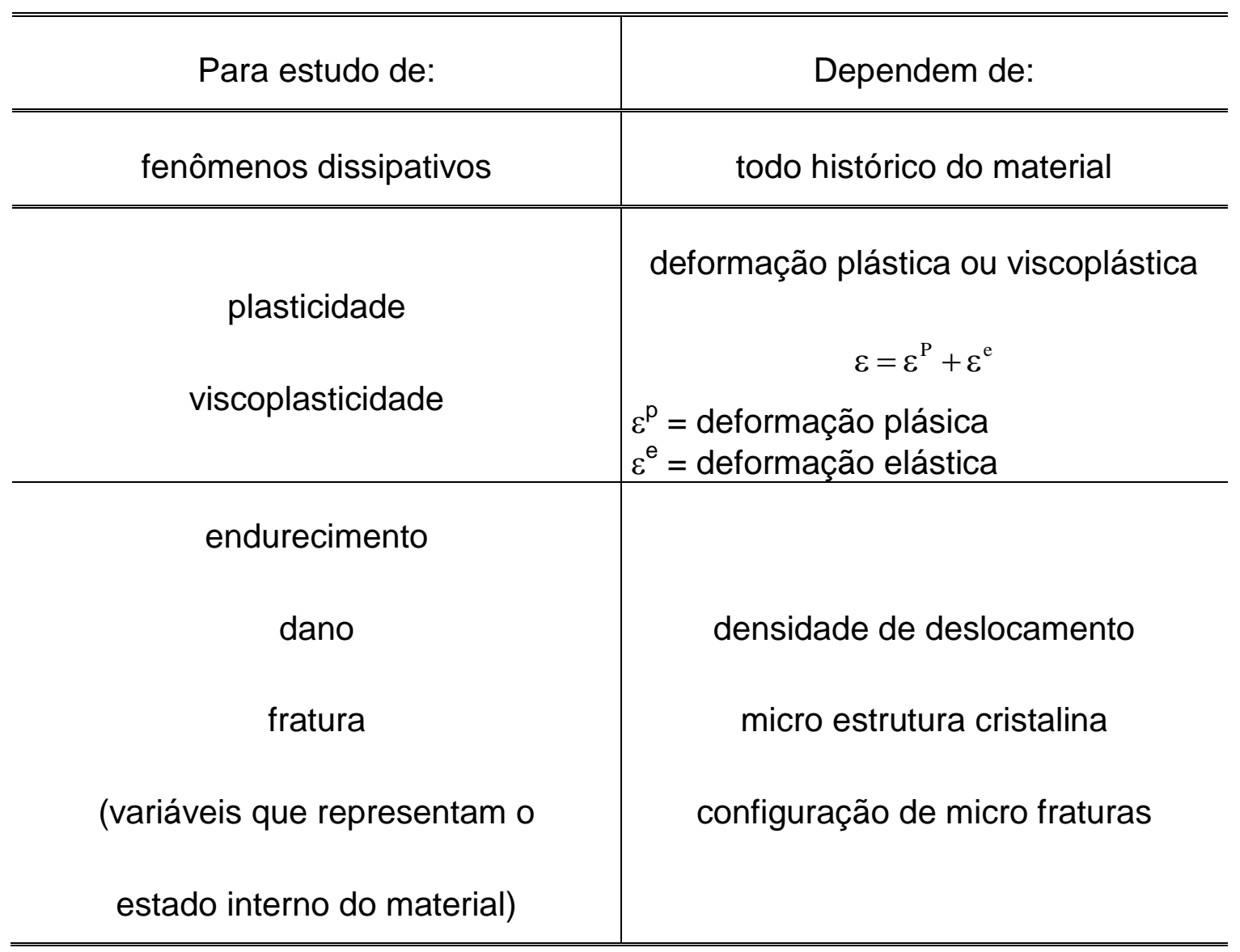




\subsubsection{Potencial termodinâmico}

Postulado a partir das variáveis de estado, a partir da qual são deduzidas as Leis de Estado. Sendo $\Psi$, a energia específica livre que depende de variáveis de estado internas e externas para formular as equações constitutivas para a análise termo-químico-mecânica do concreto.

$$
\Psi=\Psi\left(\mathrm{T}, \varepsilon, \varepsilon^{\mathrm{e}}, \varepsilon^{\mathrm{p}}, \mathrm{m}, \chi\right)
$$

onde:

- m: massa de esqueleto de hidratos já formado por unidade de volume (medida do avanço da reação hidratação)

- $\chi$ : conjunto de variáveis plásticas internas associadas a mudanças na microestrutura dos hidratos

$$
\Psi=W\left(T, \varepsilon-\varepsilon^{p}, m\right)+U(m, \chi)
$$

onde:

- W: parte da energia livre que considera os acoplamentos com a deformação $\varepsilon$

- U: energia bloqueada, que considera os acoplamentos com variáveis internas e deformações irreversíveis

Derivando a equação 2.4 em relação ao tempo:

$$
\dot{\Psi}=\frac{\partial \Psi}{\partial \varepsilon}: \dot{\varepsilon}+\frac{\partial \Psi}{\partial \varepsilon^{p}}: \dot{\varepsilon}^{p}+\frac{\partial \Psi}{\partial T} \dot{T}+\frac{\partial \Psi}{\partial \mathrm{m}} \dot{m}+\frac{\partial \Psi}{\partial \chi} \dot{\chi}
$$

$E$, substituindo-se a equação 2.6 na equação 2.3 :

$$
\varphi=\left(\mathrm{S}-\frac{\partial \mathrm{W}}{\partial \varepsilon}\right): \dot{\varepsilon}-\frac{\partial \mathrm{W}}{\partial \varepsilon^{\mathrm{p}}}: \dot{\varepsilon}^{\mathrm{p}}-\left(\mathrm{S}-\frac{\partial \mathrm{W}}{\partial \mathrm{T}}\right) \dot{\mathrm{T}}-\frac{\partial(\mathrm{W}+\mathrm{U})}{\partial \mathrm{m}} \dot{\mathrm{m}}-\frac{\partial \mathrm{U}}{\partial \chi} \dot{\chi}
$$


Considerando as seguintes hipóteses: deformação elástica, temperatura constante $\frac{\mathrm{dT}}{\mathrm{dt}}=0$, deformações plástica inalteradas $\frac{\mathrm{d} \varepsilon^{\mathrm{p}}}{\mathrm{dt}}=0$, variáveis internas inalteradas (material quimicamente inerte) $\frac{\mathrm{dm}}{\mathrm{dt}}=0$, regime elástico $\frac{\mathrm{d} \chi}{\mathrm{dt}}=0$ e dissipação nula $\varphi=0$, a equação 2.7 fica:

$$
\begin{gathered}
S=\frac{\partial W}{\partial \varepsilon^{\mathrm{e}}} \\
\sigma=\frac{\partial \Psi}{\partial \varepsilon^{\mathrm{e}}}=\frac{\partial \Psi}{\partial \varepsilon}=-\frac{\partial \Psi}{\partial \varepsilon^{\mathrm{p}}}
\end{gathered}
$$

Numa outra hipótese: deformação térmica, deformações plástica inalteradas $\frac{\mathrm{d} \varepsilon^{\mathrm{p}}}{\mathrm{dt}}=0$, variáveis internas inalteradas (material quimicamente inerte) $\frac{\mathrm{dm}}{\mathrm{dt}}=0$, regime elástico $\frac{\mathrm{d} \chi}{\mathrm{dt}}=0$ e dissipação nula $\varphi=0$, a equação 2.7 fica:

$$
S=-\frac{\partial W}{\partial T}
$$

Operando da mesma forma podem-se encontrar os termos associados à dissipação em função das variáveis internas, chamadas forças termodinâmicas.

$\rightarrow \quad$ em relação a $\mathrm{m}$ :

$$
A=-\frac{\partial \Psi}{\partial m}=-\frac{\partial(W+U)}{\partial m}
$$

$\rightarrow \quad$ em relação a $\chi$ :

$$
\zeta=-\frac{\partial \Psi}{\partial \chi}=-\frac{\partial(\mathrm{W}+\mathrm{U})}{\partial \chi}
$$


Pode-se, então, reescrever as Leis de Estado:

$$
\begin{gathered}
\sigma=\frac{\partial \Psi}{\partial \varepsilon}=-\frac{\partial \Psi}{\partial \varepsilon^{p}} \quad S=-\frac{\partial \Psi}{\partial T} \quad A=-\frac{\partial \Psi}{\partial m} \quad \zeta=-\frac{\partial \Psi}{\partial \chi} \\
\sigma=\frac{\partial W}{\partial \varepsilon}=-\frac{\partial W}{\partial \varepsilon^{p}} \quad S=-\frac{\partial W}{\partial T} \quad A=-\frac{\partial(W+U)}{\partial m} \quad \zeta=\frac{\partial U}{\partial \chi}
\end{gathered}
$$

A tabela 2.3 aponta as variáveis de estado externas e suas respectivas forças associadas.

Tabela 2.3 - Variáveis de Estado Externas e forças associadas

\begin{tabular}{lc|c|c}
\hline \hline Variáveis de estado & \multicolumn{2}{c}{ Forças associadas } \\
\hline Externas & $\varepsilon$ & $\sigma$ & $\begin{array}{c}\text { forças termodinâmicas, } \\
\text { atuam provocando mudanças } \\
\text { no sistema através de } \\
\text { fenômenos de dissipação, } \\
\text { isto é, transformação de } \\
\text { energia em calor. }\end{array}$ \\
\hline & $\varepsilon^{\mathrm{p}}$ & $-\sigma$ & $\mathrm{S}$ \\
\hline
\end{tabular}

A afinidade química da reação de hidratação é representada por A (força termodinâmica associada à taxa $(\mathrm{dm} / \mathrm{dt})$ de formação de novos hidratos pela combinação de água e cimento). Macroscopicamente pode-se interpretar A como a expressão do desequilíbrio entre água livre e água combinada, que atuará forçando a microdifusão da água através das camadas de hidratos já formados. $O$ termo $\zeta$ representa a força de endurecimento que está associada com a evolução da resistência do material, e relacionada com as variáveis internas $\chi$.

Substituindo as leis de estado 2.13 na equação 2.7 :

$$
\varphi=-\left(\frac{\partial \Psi}{\partial \varepsilon^{p}}: \dot{\varepsilon}^{p}+\frac{\partial \Psi}{\partial \chi} \dot{\chi}\right)-\frac{\partial \Psi}{\partial m} \dot{m}=\varphi^{p}+\varphi^{c}
$$


onde:

- dissipação plástica: $\varphi^{p}=\sigma: \dot{\varepsilon}^{p}+\zeta \dot{\chi}$

- dissipação química: $\varphi^{c}=A \dot{m}$

A dissipação está relacionada a fenômenos plásticos (relaciona com fenômenos situados no esqueleto do meio poroso, ocasionando por deformações plásticas que levam a mudanças na microestrutura dos hidratos) e químicos (que está relacionado com a microdifusão da água através das camadas de hidratos já formados).

Para explicar os efeitos dos acoplamentos entre os diferentes fenômenos representados pelas equações de estado, são utilizadas as simetrias de Maxwell, onde as derivadas parciais de segunda ordem em relação às variáveis de estado são simétricas.

$\frac{\partial^{2} \Psi}{\partial \alpha \partial \beta}=\frac{\partial^{2} \Psi}{\partial \beta \partial \alpha}$ onde $\alpha$ e $\beta$ são variáveis internas arbitrárias.

O objetivo é escrever cada equação de estado em sua forma diferencial para obter relações constitutivas que governam o problema em questão:

$$
d S=d\left(\frac{\partial W}{\partial \varepsilon}\right)=\frac{\partial\left(\frac{\partial W}{\partial \varepsilon}\right)}{\partial \varepsilon} d \varepsilon+\frac{\partial\left(\frac{\partial W}{\partial \varepsilon}\right)}{\partial \varepsilon^{p}} d \varepsilon^{p}+\frac{\partial\left(\frac{\partial W}{\partial \varepsilon}\right)}{\partial T} d T+\frac{\partial\left(\frac{\partial W}{\partial \varepsilon}\right)}{\partial m} d m
$$

E, utilizando as simetrias de Maxwell:

$$
d S=\frac{\partial^{2} W}{\partial \varepsilon^{2}}:\left(d \varepsilon^{e}-d \varepsilon^{p}\right)+\frac{\partial^{2} W}{\partial \varepsilon \partial T} d T+\frac{\partial^{2} W}{\partial \varepsilon \partial m} d m
$$

Analogamente para a entropia (S), força de endurecimento $(\zeta)$ e afinidade química $(A)$ :

$$
d S=-\frac{\partial^{2} W}{\partial T^{2}} d T-\frac{\partial^{2} W}{\partial T \partial \varepsilon}:\left(d \varepsilon-d \varepsilon^{p}\right)-\frac{\partial^{2} W}{\partial T \partial m} d m
$$




$$
\begin{gathered}
d \zeta=-\frac{\partial^{2} U}{\partial \chi^{2}} d \chi-\frac{\partial^{2} U}{\partial \chi \partial m} d m \\
d A=-\frac{\partial^{2} W}{\partial m \partial \varepsilon}:\left(d \varepsilon-d \varepsilon^{p}\right)-\frac{\partial^{2} W}{\partial m \partial T} d T-\frac{\partial^{2}(W+U)}{\partial m \partial \chi} d \chi-\frac{\partial^{2}(W+U)}{\partial m^{2}} d m
\end{gathered}
$$

A partir da equação 2.16, obtém-se a equação constitutiva acoplada:

$$
\mathrm{d} \varepsilon=\mathrm{C}^{-1}: \mathrm{dS}+\mathrm{d} \varepsilon^{\mathrm{p}}+\mathrm{a} \cdot \mathrm{dT}+\mathrm{b} \cdot \mathrm{dm}
$$

onde:

- $\mathrm{C}=\frac{\partial^{2} \mathrm{~W}}{\partial \varepsilon^{2}}$, que é o tensor de rigidez elástica (tangente), função de $\varepsilon, \varepsilon^{\mathrm{p}}, \mathrm{T}, \mathrm{m}, \mathrm{e} \chi$. Segundo Bazant (1995) depende apenas da massa de hidratos formada (m), desta forma C representa o acoplamento elasto-químico, ou seja, evolução da rigidez elástica do concreto com a evolução da reação de hidratação.

- $\quad a=-C^{-1}:\left(\frac{\partial^{2} W}{\partial \varepsilon \partial T}\right)$, que é o tensor dos coeficientes de dilatação térmica (tangente) e representa o acoplamento termo-mecânico, que descreve a variação de temperatura (dT) com a deformação macroscópica de origem térmica $\left(\mathrm{d} \varepsilon^{\top}={ }^{\mathrm{a}} \mathrm{d} T\right)$. O tensor de segunda ordem $\mathrm{A}=\frac{\partial^{2} \mathrm{~W}}{\partial \varepsilon \partial \mathrm{T}}$ mostra a tensão por unidade de variação de temperatura induzida pela restrição da expansão térmica ou fissuração.

- $b=-C^{-1}:\left(\frac{\partial^{2} W}{\partial \varepsilon \partial m}\right)$, que é o tensor dos coeficientes de dilatação química (tangente) e representa o acoplamento químico-mecânico, descrevendo a reação autógena como resultado da evolução da reação de hidratação: o consumo de água provoca um desequilíbrio de pressão entre o esqueleto e o fluído dos poros, o que leva a uma retração do esqueleto.

A equação 2.20 corresponde à relação usual entre deformações elásticas e inelásticas, onde foi incluído o termo b.dm. O parâmetro (tensor) b é similar ao 
parâmetro a, que correspondem, respectivamente, aos coeficientes de dilatação térmica.

\subsubsection{Isotropia}

Partindo-se das seguintes considerações:

$>\mathrm{a}=\alpha \mathrm{l}$; onde $\alpha$ é o coeficiente de dilatação térmica, determina-se então, parcela de formação decorrente da variação de temperatura.

$>b=\beta \mathrm{l}$; onde $\beta$ é coeficiente de retração química correspondendo às deformações por retração autógena.

A relação entre $\beta$ e a evolução da hidratação não é bem conhecida, mas é natural que $\beta$ seja função da maturidade do concreto, ou seja, da massa de hidratos formada $\beta=\beta(m)$.

Acoplamento termo-químico: substituindo-se a equação 2.20 na equação 2.2 , obtêm-se:

$$
\text { Ce.ं }- \text { T.D : }\left(\varepsilon-\varepsilon^{p}\right)-L m \cdot \dot{m}=Q+\varphi
$$

onde:

- $\mathrm{Ce}=-\mathrm{T} \frac{\partial^{2} \Psi}{\partial \mathrm{T}^{2}}$, que é o calor específico do material, considerando constante com o avanço da reação.

- $\quad \mathrm{D}=\frac{\partial^{2} \Psi}{\partial \mathrm{T} \partial \varepsilon}$, que é o tensor do calor latente para deformações elásticas.

- $\quad \mathrm{Lm}=\mathrm{T} \frac{\partial^{2} \Psi}{\partial \mathrm{T} \partial \mathrm{m}}$, que é o calor latente de hidratação, sempre positivo (devido à natureza exotérmica da reação de hidratação). 
Condução de calor para concreto nas primeiras idades: o calor latente para deformação elástica e o calor gerado pela dissipação interna são desprezados quando comparados com outros termos (por exemplo:Lm.m), obtendo-se assim a forma padrão da equação do calor:

$$
\text { Ce. } \dot{T}=Q+\varphi+L m \cdot \dot{m}
$$

sendo Lm o acoplamento da equação do calor com a evolução da reação química por $\dot{\mathrm{m}}$.

\subsubsection{Leis de evolução}

Para a modelagem da fissuração nas primeiras idades, dois fenômenos devem ser levados em consideração: a evolução da resistência mecânica do esqueleto de concreto (levando em conta dentro da aproximação da elastoplasticidade através de variáveis plásticas, do tensor de deformação plástica ou permanente $-\varepsilon^{p}$, das variáveis internas de endurecimento/amolecimento, $\chi$ ) e a evolução da fissuração na superfície com o avanço da hidratação.

As tensões plásticas admissíveis podem ser lidas da seguinte forma, não ultrapassando o domínio elástico do material $\mathrm{C}_{\mathrm{E}}$ para o estado de tensões:

$$
\sigma \in \mathrm{C}_{\mathrm{E}} \Leftrightarrow \mathrm{f}(\sigma, \zeta) \leq 0
$$

onde $f(\sigma, \zeta)$ é a função de carregamento.

As leis de evolução são utilizadas para descrever macroscopicamente os fenômenos de dissipação ocorridos microscopicamente no material, correlacionando as variáveis de estado internas com as respectivas forças termodinâmicas.

Sendo $U$, parte da energia livre relacionada com o fenômeno de endurecimento/amolecimento, tem-se: 
Análise Plasto-Química

$$
\mathrm{d} \zeta=-\frac{\partial^{2} U}{\partial \chi^{2}} \mathrm{~d} \chi-\frac{\partial^{2} U}{\partial \chi \partial \mathrm{m}} \mathrm{dm}
$$

que mostra a dependência de $\zeta$ (que está associado à resistência do material) com as variáveis internas $\mathrm{m}$ e $\chi$

$\zeta=\zeta(\mathrm{m}, \chi)$, onde a evolução da resistência do material está relacionada com a evolução da massa de hidratos $(m)$ e do estado plástico interno de microfissuração $(\chi)$.

$$
\mathrm{d} \zeta=-\frac{\partial^{2} U(\chi, m)}{\partial \chi \partial m} d m-\frac{\partial^{2} U(\chi, m)}{\partial \chi^{2}} d \chi
$$

E, admitindo um acoplamento plasto-químico linear:

$$
\mathrm{d} \zeta=-\zeta_{\infty} \cdot d m-m \frac{\partial^{2} \mathrm{U}(\chi)}{\partial \chi^{2}} \mathrm{~d} \chi
$$

onde:

- $-\zeta_{\infty} \cdot d m$, é o termo que representa o aumento da resistência devido ao endurecimento, e,

- $\quad-m \frac{\partial^{2} \mathrm{U}(\chi)}{\partial \chi^{2}} \mathrm{~d} \chi$, é o termo associado ao endurecimento ou amolecimento plástico.

Desta forma, o acoplamento dado pela equação 2.26 considera o efeito da evolução da hidratação, e o conseqüente aumento da resistência mecânica no surgimento de deformações irreversíveis (plásticas) no esqueleto do concreto.

Dentro do quadro de plasticidade associada, pode-se escrever:

Lei de Fluxo:

$$
\mathrm{d} \varepsilon^{p}=\mathrm{d} \lambda \frac{\partial \mathrm{g}(\sigma, \zeta)}{\partial \sigma}
$$


Lei de Endurecimento:

$$
\mathrm{d} \chi=\mathrm{d} \lambda \frac{\partial \mathrm{h}(\sigma, \zeta)}{\partial \zeta}
$$

onde:

- $\mathrm{d} \lambda$ : multiplicador plástico

- $g(\sigma, \zeta)$ : potencial plástico

- $\mathrm{h}(\sigma, \zeta)$ : potencial de endurecimento

A condição de consistência pode ser escrita da seguinte forma:

$$
\mathrm{df}=0 \Leftrightarrow \frac{\partial \mathrm{f}}{\partial \zeta} \frac{\partial \zeta(\chi, \mathrm{m})}{\partial \chi} \mathrm{d} \chi=-\mathrm{d}_{\chi} \mathrm{f}=-\mathrm{d} \lambda \mathrm{H}
$$

onde:

- $\mathrm{d}_{\chi} f$ : diferencial da função de carregamento f sob valores constantes da variável de endurecimento $(\chi)$

- H: módulo de endurecimento

Utilizando a Lei de endurecimento [equação (2.28)] e a expressão (2.26), na equação acima (3.29), obtêm-se as seguintes expressões para o multiplicados plástico e para o módulo de endurecimento:

$$
\begin{gathered}
\mathrm{d} \lambda=\frac{\mathrm{d}_{\chi} \mathrm{f}}{\mathrm{H}}=\frac{1}{\mathrm{H}}\left[\frac{\partial \mathrm{f}}{\partial \sigma}: \mathrm{d} \sigma+\frac{\partial \mathrm{f}}{\partial \zeta}\left(\zeta_{\infty}-\frac{\partial \mathrm{U}_{\infty}}{\partial \chi}\right) \mathrm{dm}\right] \\
\mathrm{H}=-\frac{\partial \mathrm{f}}{\partial \zeta} \cdot \frac{\partial \zeta}{\partial \chi} \cdot \frac{\mathrm{d} \chi}{\mathrm{d} \lambda}=\mathrm{mH}_{\infty}, \quad \mathrm{H}_{\infty}=\frac{\partial \mathrm{f}}{\partial \zeta}\left[\frac{\partial^{2} U_{\infty}(\chi)}{\partial \chi^{2}}\right] \frac{\partial \mathrm{h}}{\partial \chi}
\end{gathered}
$$

onde:

- $\mathrm{H}_{\infty}$ é o módulo de endurecimento no final da hidratação. 
A equação 2.31 é coerente com a definição do sinal do módulo de endurecimento, que é positiva no caso de endurecimento (com $d_{x} f>0$ ) e negativa no caso de amolecimento (com $d_{x} f<0$ ), e assegura o sinal, sempre positivo, do multiplicador plástico $(\mathrm{d} \lambda \geq 0)$.

O modelo de acoplamento quimo-plástico, descrito acima pode ser utilizado sem nenhuma restrição no que diz respeito à superfície de carga $f(\sigma, \zeta)$, ao potencial plástico $\mathrm{g}(\sigma, \zeta)$, e ao potencial de endurecimento $h(\sigma, \zeta)$, além daquelas impostas pelo modelo plástico.

Mesmo quando não há evolução plástica $(\mathrm{d} \lambda=0)$, ou que a variável interna $\mathrm{c}$ permaneça constante, o domínio elástico ainda envolve a dependência da força de endurecimento $z$ com a massa de hidratação $m$, e a sua evolução $\mathrm{dm}=\dot{\mathrm{m}}$.dt, no intervalo de tempo dt. Esta evolução deve ser determinada por uma lei de evolução, a cinética de hidratação

\subsubsection{Cinética da hidratação}

O concreto, tanto no nível micro quanto no macro estrutural, pode ser explicado através de grãos (células) de cimento anidro circundadas por camadas de hidratos. Estas células são conectadas entre si formando o esqueleto e o espaço entre elas é preenchido com água. A água deve penetrar nas camadas de hidrato para combinar-se à matéria no centro da celular formando novos hidratos. A formação dos hidratos, quando a água entra em contato com o cimento anidro, é considerada instantânea em relação à escala de tempo do processo de microdifusão. Isso quer dizer que a difusão da água através das camadas de hidratos pode ser considerada como sendo o mecanismo dominante na cinética da hidratação.

Como mencionado anteriormente, a difusão da água através das camadas de hidratos pode ser considerada o mecanismo dominante da cinética de hidratação. 
A conservação de massa num sistema fechado pode ser equacionada como:

$$
\frac{d m_{1}}{d t}=\frac{d m_{s}}{d t}
$$

onde:

- $\mathrm{m}_{\mathrm{l}}$ é a água livre

- $\mathrm{m}_{\mathrm{s}}$ é a massa do esqueleto de concreto formada

A massa de água do esqueleto sendo substituída pela massa de água combinada no esqueleto permite a equação química:

massa de água livre $\left(m_{l}\right) \Rightarrow$ massa combinada nos esqueleto $\left(m_{s}\right)$

A taxa de massa m pode ser vista como a medida da taxa de difusão. Isto é controlado pelo balanço termodinâmico (afinidade A) entre a água livre e a água combinada na fase sólida, e amplificada pela ativação térmica quando a água livre se combina com o cimento para formar novos hidratos. Uma lei de evolução tipo Arrhenius pode ser adotada:

$$
A=\eta \frac{d m}{d t} \exp \left(\frac{E a}{R T}\right)
$$

onde:

- Ea é a energia de ativação

- $\mathrm{R}$, constante universal dos gases

- T é a temperatura absoluta

Retomando a equação 2.19, tem-se:

$$
\mathrm{dA}=-\frac{\partial^{2} \mathrm{~W}}{\partial \mathrm{m} \partial \varepsilon}:\left(\mathrm{d} \varepsilon-\mathrm{d} \varepsilon^{\mathrm{p}}\right)-\frac{\partial^{2} \mathrm{~W}}{\partial \mathrm{m} \partial \mathrm{T}} \mathrm{dT}-\frac{\partial^{2}(\mathrm{~W}+\mathrm{U})}{\partial \mathrm{m} \partial \chi} \mathrm{d} \chi-\frac{\partial^{2}(\mathrm{~W}+\mathrm{U})}{\partial \mathrm{m}^{2}} \mathrm{dm}
$$

que descreve a forma diferencial para a afinidade química, e considera os diversos acoplamentos: químico - mecânicos, plasto-químicos e termo-químicos. No entanto, 
de acordo com Ulm e Coussy (1995), exceto para condições especiais, pode-se considerar a afinidade química como dependente apenas da massa de hidratos $\mathrm{m}$.

O grau de hidratação $(\xi)$ constitui um parâmetro objetivo para a medida do avanço da reação de hidratação, e é definido como uma relação entre a massa total de hidratos no término (teórico) da reação de hidratação, que pode ser entendido como uma normalização da variável m e definido por:

$$
\xi=\frac{m(t)}{m_{\infty}}
$$

onde:

- $\mathrm{m}_{\infty}$ é o valor alcançado por m quando hidratação está completa

Fazendo a mudança de $\mathrm{m}$ para $\xi$ na equação (2.33), a relação cinética pode ser reescrita de forma a obter a expressão da afinidade normalizada:

$$
\tilde{A}(\xi)=\frac{d \xi}{d t} \exp \left(\frac{E a}{R T}\right)
$$

onde

- $\tilde{A}(\xi)=A \frac{m(\xi)}{m_{\infty} \cdot \eta(\xi)}$, valores que podem ser obtido experimentalmente, através de ensaios adiabáticos, ou de compressão uniaxial realizados em diversas idades.

\subsubsection{Modelo proposto por Cervera}

O modelo de hidratação, proposto por Cervera et al (2002), é baseado no modelo estudado por Ulm e Coussy (1995, 1996), e adota uma descrição macroscópica para este fenômeno, considerando a hidratação como uma reação exotérmica e termoativada, que necessita de um modelo termoquímico para sua modelagem. O processo de hidratação se apresenta, desde o nível macroscópico, 
como uma reação química em que a água livre, na fase reativa, se combina com o cimento, para formar, como produto, água combinada nos hidratos, ou seja, pode considerar-se a (micro) difusão da água através das camadas de hidratos como o mecanismo dominante da cinética da reação.

São definidos conceitos de variáveis externas e internas, energia livre e leis de evolução exatamente iguais a Ulm e Coussy $(1995,1996)$. A diferença entre os modelos pode ser encontrada no cálculo do grau de hidratação $(\xi)$. Cervera et al (2002) consideram que é conveniente definir o grau de hidratação como:

$$
\xi=\frac{\chi}{\chi_{\infty}}
$$

onde:

- $\chi$ é considerado o número de moles de água combinada por unidade de volume (variável interna)

- $\chi_{\infty}$ é o valor final de $\chi$ em condições ideais, ou seja, com uma relação água/cimento $(\mathrm{w} / \mathrm{c})$ tal que assegure a hidratação completa do cimento

Mas, por razões práticas, e considerando que o valor final do grau de hidratação é função da relação água/cimento da mistura, o mesmo pode ser calculado da seguinte forma:

$$
\xi_{\infty}=\frac{1,031 w / c}{0,194+w / c}
$$

\subsubsection{Modelo utilizado por Mang}

O modelo proposto por Mang et al (2003) é integralmente baseado no conceito utilizado para o comportamento do concreto nas primeiras idades, publicado por Ulm e Coussy $(1995,1996)$. Modelo este, já aplicado com sucesso 
em publicações conjuntas entre Franz-Josef Ulm e Herbert Mang (1999). Desta forma, não há necessidade de descrevê-lo novamente.

$\mathrm{Na}$ realidade, a grande diferença entre os autores estudados consiste nas simulações experimentais, utilizadas para a adoção de valores adequados para as constantes envolvidas no processo de hidratação e no de endurecimento (no caso de Cervera et al - 2002).

\subsection{Endurecimento}

A diferença entre alguns termos utilizados em tecnologia de concreto, segundo Mehta e Monteiro (2005), merece uma explicação mais cuidadosa, como, por exemplo, enrijecimento, pega e endurecimento. Num primeiro instante, cabe salientar que a água livre na pasta de cimento é responsável pela plasticidade da mistura. Daí surge o conceito de enrijecimento, que é a perda da consistência da pasta plástica de cimento, ou seja, é a perda gradual de água livre do sistema devido às reações iniciais de hidratação. Estas reações (já mencionadas no item 2.2), aliadas à evaporação, causam o enrijecimento da pasta, a pega e o endurecimento. O termo pega implica na solidificação da pasta plástica de cimento. O começo da solidificação, chamado "início de pega", marca o ponto no tempo em que a pasta se torna não trabalhável, e, transcorrido o tempo necessário para que a pasta torne-se totalmente rígida, marca-se o tempo de fim de pega.

O termo "endurecimento" do concreto está relacionado com a evolução de suas propriedades mecânicas à medida que a reação de hidratação avança, ou seja, é o fenômeno de ganho de resistência com o tempo. O aumento da massa de hidratos e a diminuição dos espaços porosos capilares aumentam as superfícies de contato entre os hidratos e a conseqüente rigidez do material. Assim se dá o lento processo de endurecimento do concreto acompanhado de variação em sua relação tensão-deformação, e do desenvolvimento de resistências mecânicas consideráveis.

Os primeiros estudos realizados sobre as características mecânicas do concreto relacionavam a resistência última da pasta de cimento unicamente com a 
sua relação água/cimento. Estudos recentes mostram que a resistência da pasta é função da microestrutura que se desenvolve durante o processo de hidratação, ou seja, que a resistência de um concreto, com uma determinada relação água/cimento, depende das características químicas e físicas do cimento, da temperatura com que este é hidratado e da quantidade de ar dentro do concreto. Por estas razões considera-se necessário relacionar a evolução da microestrutura da pasta de cimento com suas propriedades mecânicas.

A alteração das tensões e das propriedades físicas dos constituintes básicos do cimento devido à reação química de hidratação faz com que, durante a reação, variem as propriedades mecânicas macroscópicas do concreto e provoca modificações nas propriedades térmicas do material. Desta forma, pode-se considerar, segundo Prato (1999) que o endurecimento se manifesta macroscopicamente pela variação das propriedades mecânicas e térmicas do concreto. No nível microscópico, o endurecimento se reflete através da troca das propriedades físicas e dos produtos da reação de hidratação do cimento.

\subsection{Propriedades mecânicas do concreto}

As curvas de evolução das propriedades do concreto apresentadas pelo Código Modelo CEB-FIP 1990 (1993), são baseadas no conceito de idade equivalente.

\subsubsection{Resistência à tração}

De acordo com o método da idade equivalente indicado no Código Modelo CEB-FIP 1990 (1993), o valor de $f_{c t}$, bem como a sua evolução ao longo do tempo, estão relacionados com a resistência à compressão, sendo traduzidos por: 


$$
f_{c t m}=f_{c t k 0, m}\left(\frac{f_{c k}}{f_{c k 0}}\right)^{\frac{2}{3}}
$$

onde:

- $\mathrm{f}_{\mathrm{ctk} 0, \mathrm{~m}}=1,40 \mathrm{MPa}$

- $\mathrm{f}_{\mathrm{ck} 0}=10 \mathrm{MPa}$

- $\mathrm{f}_{\mathrm{ck}}$ : valor característico da resistência à compressão [MPa]

- $\mathrm{f}_{\mathrm{ctm}}$ : valor médio da resistência à tração [MPa]

\subsubsection{Resistência à compressão}

$\mathrm{Na}$ consideração da evolução da resistência à compressão com a idade equivalente, tem-se, segundo Código Modelo CEB-FIP 1990 (1993):

$$
\begin{aligned}
& f_{c m}(t)=\beta_{c c}(t) \cdot f_{c m} \\
& \beta_{c c}(t)=e^{s\left(1-\left(\frac{28}{t / t_{1}}\right)^{\frac{1}{2}}\right)}
\end{aligned}
$$

onde:

- $\quad$ t: idade do concreto (deverá ser utilizada a idade equivalente, em dias)

- $t_{1}: 1$ dia

- $f_{c m}$ : resistência média à compressão do concreto aos 28 dias (cura a $20^{\circ} \mathrm{C}$ )

- $\mathrm{f}_{\mathrm{cm}}(\mathrm{t})$ : resistência média à compressão do concreto à idade $\mathrm{t}$

- $\beta_{c c}(t)$ - coeficiente que depende da idade do concreto

- s: coeficiente que depende do tipo de cimento utilizado: 


$$
\begin{aligned}
& s=0,20 \text { - cimentos de alta resistência de pega rápida } \\
& s=0,25 \text { - cimentos normais e de pega rápida } \\
& s=0,38 \text { - cimentos de pega lenta }
\end{aligned}
$$

Em termos experimentais, na consideração da análise do concreto endurecido a determinação do valor da resistência à compressão nas primeiras idades é feita através dos ensaios de ruptura por compressão de corpos de prova em forma de cubos ou cilindros.

\subsubsection{Módulo de elasticidade}

Seguindo o conceito de idade equivalente do Código Modelo CEB-FIP 1990 (1993), o módulo de elasticidade pode ser determinado da seguinte forma:

$$
\begin{gathered}
E_{c i}=\alpha_{E} \cdot E_{c 0} \cdot\left(\frac{f_{c m}}{f_{c m 0}}\right)^{\frac{1}{3}} \\
E_{c i}(t)=\beta_{E}(t) \cdot E_{c i} \\
\beta_{E}(t)=\left[\beta_{c c}(t)\right]^{\frac{1}{2}}
\end{gathered}
$$

onde:

- $E_{c t}$ : módulo de elasticidade tangente para tensão nula e idade de 28 dias

- $\mathrm{E}_{\mathrm{c} 0}=21500 \mathrm{MPa}$

- $\mathrm{f}_{\mathrm{cm}}$ : resistência média à compressão [MPa]

- $\mathrm{f}_{\mathrm{cm} 0}=10 \mathrm{MPa}$ 
- $\alpha_{\mathrm{E}}$ : coeficiente que depende do tipo de agregados:

$$
\begin{aligned}
& \text { basalto, calcário denso }=1,2 \\
& \text { agregados quartzíticos }=1,0 \\
& \text { calcário }=0,9 \\
& \text { areias }=0,7
\end{aligned}
$$

- $E_{\mathrm{ci}}(\mathrm{t}):$ módulo de elasticidade tangente [MPa] à idade $\mathrm{t}$

- $\beta_{E}(t):$ coeficiente que descreve a evolução de $E_{c i}$ com o tempo

- $\beta_{c c}(t):$ coeficiente definido na equação 2.44

\subsection{Fluência}

As deformações por fluência do concreto são um fator determinante na distribuições de tensões no concreto nas primeiras idades. A sua consideração é fundamental em um modelo numérico para a previsão da fissuração nesta situação.

\subsubsection{Coeficiente e função de fluência}

A formulação para a inclusão da fluência no modelo computacional deste trabalho é dada pelo Código Modelo CEB-FIP 1990 (1993). O coeficiente de fluência envolve a separação da deformação total numa componente instantânea e em outra de fluência: 


$$
\varepsilon_{\text {tot }}\left(\mathrm{t}, \mathrm{t}^{\prime}\right)=\left(1+\varphi\left(\mathrm{t}, \mathrm{t}^{\prime}\right)\right) \frac{\sigma\left(\mathrm{t}^{\prime}\right)}{\mathrm{E}\left(\mathrm{t}^{\prime}\right)},
$$

onde:

- $\sigma\left(\mathrm{t}^{\prime}\right)$ : tensão aplicada no instante $\mathrm{t}^{\prime}$

- $E\left(t^{\prime}\right)$ : módulo de elasticidade no instante $t^{\prime}$

- $\varphi\left(t, t^{\prime}\right):$ coeficiente de fluência para $o$ instante $t$, correspondente a um carregamento na idade t'

A função de fluência $\mathrm{J}\left(\mathrm{t}, \mathrm{t}^{\prime}\right)$ permite relacionar a tensão com a extensão para cada instante:

$$
\varepsilon_{\text {tot }}\left(\mathrm{t}, \mathrm{t}^{\prime}\right)=\mathrm{J}\left(\mathrm{t}, \mathrm{t}^{\prime}\right) \sigma\left(\mathrm{t}^{\prime}\right)
$$

\subsubsection{Fluência com história de tensões variável}

No domínio das tensões de utilização, as deformações por fluência, devidas a tensões aplicadas em dois instantes diferentes, são consideradas como aditivas (hipótese da superposição de efeitos). Desta hipótese, tem-se que a deformação por fluência, sob tensão constante, está ligada linearmente à tensão.

Em condições normais o histórico de tensões em qualquer ponto de uma estrutura sofre variações ao longo do tempo. A formulação apresentada pelo Código Modelo CEB-FIP 1990 (1993) apresenta o método da superposição linear, que consiste em formular a equação 2.51 na seguinte forma integral:

$$
\varepsilon_{\text {tot }}\left(t, t^{\prime}\right)=\int_{t}^{t} J\left(t, t^{\prime}\right) d \sigma\left(t^{\prime}\right)+\varepsilon_{0}(t)
$$

onde $\varepsilon_{0}(\mathrm{t})$ é a extensão independente de tensões, de origem térmica ou retração. 
De acordo com o código modelo de 1990 do CEB, a superposição linear é normalmente aceita para níveis de tensões menores que $40 \%$ da resistência à compressão média do concreto, se não houver secagem significativa da peça durante a fluência, garantindo a inexistência de fluência de secagem e se não houver acréscimos de tensões de magnitude bastante superiores ao inicial, pois caso contrário poderá ocorrer fluência de baixas tensões (fluxo plástico).

\subsection{Retração}

O fenômeno da retração é caracterizado pelas deformações ao longo do tempo que ocorrem quando a estrutura não está sob a ação de nenhum carregamento. A explicação físico-química que se dá a este fenômeno é a diminuição da massa de água livre dentro dos poros do concreto (aqui considerado como um material poroso).

A retração em materiais cimentícios ocorre de três modos principais: plástica, por secagem e autógena, segundo Repette e Mailvaganam (1999).

A retração plástica, também chamada Le Chatelier, ocorre antes do fim de pega, através da evaporação rápida inicial da água de amassamento, pela superfície exposta do concreto, resultando em fissuração superficial, facilmente observável. Esta retração está relacionada com o fato do volume de hidratos ser menor que o volume de cimento e de água livre, sendo verificada no período da ante-pega, onde o material ainda não possui resistência mecânica.

A retração por secagem acontece depois do fim da pega do cimento e ocorre devido à redução de volume causada pela diminuição da massa de água livre dentro dos poros do concreto para o meio ambiente.

E, por último, a retração autógena é definida como a mudança de volume sob temperatura constante e sem perda de umidade do concreto para o meio ambiente. Esta retração é causada pelo consumo de água na reação de hidratação, tornando-a 
ligada aos hidratos, ou seja, decorre da redução da umidade relativa no interior dos poros em função da evolução da hidratação do cimento.

A figura 2.4 apresenta a comparação entre os resultados de um estudo realizado por Cusson e Repette (2000). As curvas de deformação por retração autógena, calculadas pelos modelos de vários autores, foram comparadas com as curvas fornecidas pelos CEB-FIP Model Code e ACI Model Code.

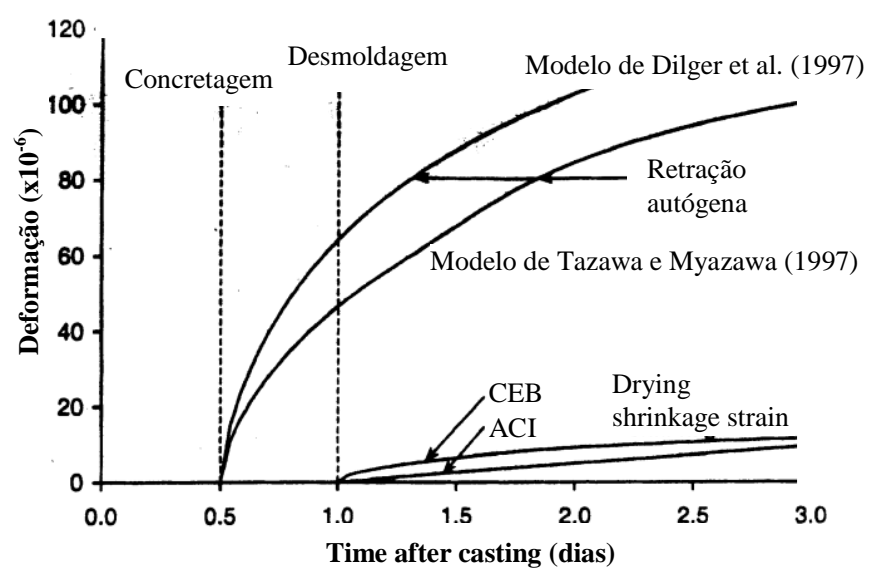

Figura 2.11 - Deformação por retração autógena (estimada) pelos modelos de Tazawa e Miyazawa (1997) e por Dilger, Niitani e Wang (1997) segundo os resultados da análise desenvolvida por Cusson e Repette (2000). 


\section{CAPÍTULO 3}

\section{ANÁLISE DO PROBLEMA QUÍMICO}

\subsection{Considerações gerais}

A adição de água ao cimento dá início à reação de hidratação que é a responsável pela formação da microestrutura da pasta hidratada e pelo desenvolvimento de propriedades mecânicas do concreto. As reações químicas associadas à hidratação do cimento são altamente exotérmicas, isto é, com grande libertação de calor. O material apresenta inicialmente uma expansão volumétrica seguida de uma contração, que na presença de restrições externas ou internas, pode provocar a fissuração do concreto.

A simulação processo de hidratação pode ser feita por modelos microestruturais, permitindo a obtenção da curva de evolução de temperatura do concreto em condições adiabáticas, que é essencial para a análise de estruturas de concreto nas primeiras idades. 


\subsection{Modelos microestruturais}

A necessidade de estudar os fenômenos associados à hidratação do cimento, como a geração de calor e as variações volumétricas, cuja previsão não pode ser feita através de modelos macroscópicos simples, justificou o aparecimento de diversas tentativas de modelagem microestrutural dos processos de hidratação.

Um estudo realizado por Azenha (2004) mostrou que entre os modelos micorestruturais mais conhecidos podem ser mencionados o HYMOSTRUC da Universidade de Delft, o da DuCOM da Universidade de Tóquio, e o CHEMY3D do National Institute of Standards and Technology dos Estados Unidos da América.

\subsubsection{Modelo de van Breugel - HYMOSTRUC}

O modelo HYMOSTRUC (Hydration Morphology and STRUCtural development) foi desenvolvido na Universidade de Delft pelo Prof. Klaas van Breugel, (Breugel 1991). O modelo considera a hidratação e o desenvolvimento da microestrutura da pasta de cimento como fenômenos inter-relacionados, tendo em conta vários aspectos, de entre os quais se podem destacar as composições química e mineralógica, a distribuição espacial e dimensional das partículas de cimento, a relação água-cimento e a temperatura.

\subsubsection{Modelo de Maekawa et al. - DuCOM}

A inovação do modelo DuCOM desenvolvido pelo Professor Maekawa e colaboradores da Universidade de Tóquio, Japão, é a análise multicomponente, segundo a qual o calor de hidratação de cada componente do cimento é modelado separadamente. A função que expressa a libertação de calor global por parte do 
cimento é posteriormente obtida a partir da soma proporcionada da contribuição das diversas componentes (Kishi e Maekawa 1995; Maekawa et al. 1999).

\subsubsection{Modelo de Bentz - CHEMY3D}

O modelo microestrutural de hidratação do cimento desenvolvido por Bentz é denominado de CHEMY3D, e considera os fenômenos de formação da microestrutura do cimento hidratado (Bentz, 1997). Inicia-se o processo com a obtenção de imagens do cimento que se pretende estudar através de microscópio eletrônico. Para identificar os componentes do cimento hidratado nas imagens obtidas (que abrangem partículas de C3S, C2S, C3A, C4AF, gesso, dentre outros) são aplicados algoritmos de extrapolação gráfica, que permitem a geração de uma estrutura tridimensional do cimento. Posteriormente aplica-se um conjunto de critérios de evolução a cada ponto da estrutura tridimensional idealizada. Estes critérios são aplicados seqüencialmente, permitindo a observação das diversas etapas de hidratação. $O$ modelo permite a simulação da retração química e a previsão do calor de hidratação gerado.

\subsection{Implementação computacional}

A grande dificuldade, nesta análise, foi a consideração de um modelo de hidratação que simulasse os cimentos brasileiros, uma vez que todos os modelos, que consideram os diferentes componentes químicos e reações, existentes na literatura são europeus, japoneses ou americanos, conforme foi discutido neste capítulo.

Como os parâmetros necessários para a calibragem dos modelos apresentados não são, em geral, fornecidos nos artigos disponíveis na literatura, se fez necessária a implementação de uma alternativa, a mesma utilizada por Witasse (2003) e Jeon (2008): a equação de elevação adiabática de temperatura do JSCE, 
que pode ser observada na figura 3.1. Assim, com os resultados experimentais da elevação da temperatura no interior do corpo de concreto, o programa calcula o calor gerado e passa à execução da análise térmica.

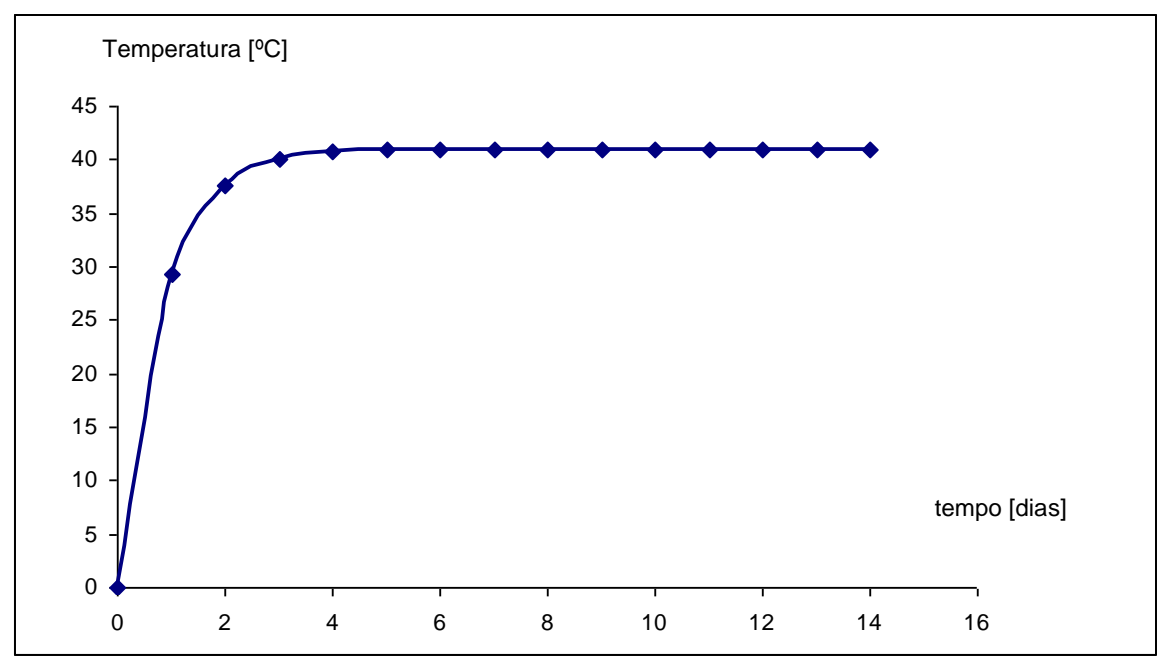

Figura 3.1 - Exemplo de elevação adiabática de temperatura, conforme Witasse (2003)

\subsubsection{Curva de elevação adiabática de temperatura- JSCE}

De acordo com o Japan Society of Civil Engineers (JSCE, 1999), pode-se estimar o valor das temperaturas adiabáticas durante o desenvolvimento das reações de hidratação, conforme pode ser visto na equação 3.1 .

$$
\mathrm{T}_{\text {adiab }}=\mathrm{T}_{\max }\left(1-\mathrm{e}^{1,25 . \mathrm{t}}\right)
$$

onde:

- $T_{\max }$ : temperatura máxima obtida pelo cimento no ensaio de calorimetria

- $\mathrm{t}$ t tempo (entre 0 e 70 dias) 


\subsubsection{Estimativa da elevação adiabática da temperatura}

Alternativa para o traçado da elevação adiabática da temperatura do concreto, a estimativa da mesma pode ser obtida através da expressão 3.2, sugerida por Kuperman (2004), que considera o calor de hidratação do cimento obtido no ensaio de calorimetria, o consumo de cimento estabelecido pelo traço de projeto e as médias do calor e massa específicos dos materiais empregados.

$$
\mathrm{T}_{\text {adiab }}=\frac{\mathrm{CH} . \text { consumode cimento }}{\mathrm{C}_{\mathrm{c}} \cdot \rho}
$$

onde:

- $\mathrm{CH}$ : calor de hidratação do cimento obtido no ensaio de calorimetria

- $\mathrm{c}_{\mathrm{c}}$ : calor específico do concreto

- $\rho:$ massa específica

O calor específico do concreto oscila, usualmente, entre 0,8 e $1,17 \mathrm{~kJ} / \mathrm{kg} .{ }^{\circ} \mathrm{C}$, segundo estudos de Breugel (1980) e Silveira (1996).

Para a determinação analítica do calor específico do concreto, Breugel (1980) apresenta um método a partir da ponderação dos calores específicos dos constituintes da mistura, expressa pela equação 3.3.

$$
\mathrm{c}_{\mathrm{c}}=\frac{\mathrm{W}_{\mathrm{cem}} \cdot \mathrm{c}_{\mathrm{cem}}+\left(\mathrm{W}_{\text {sand }}+\mathrm{W}_{\text {grav }}\right) \cdot \mathrm{c}_{\mathrm{agg}}+\mathrm{W}_{\mathrm{w}} \cdot \mathrm{c}_{\mathrm{w}}-\mathrm{c}_{\text {bindw }} \cdot \mathrm{W}_{\mathrm{cem}} \cdot \alpha \cdot \mathrm{c}_{\mathrm{w}}}{\rho_{\mathrm{c}}}
$$

onde:

- $\mathrm{C}_{\mathrm{cem}}$ : calor específico do cimento

- $\mathrm{c}_{\mathrm{c}}$ : calor específico do concreto

- $\mathrm{c}_{\mathrm{w}}$ : calor específico do água

- $C_{\text {agg }}$ : calor específico do agregados 
- $\quad C_{\text {bindW }}=0,2$

- $\alpha$ : grau de hidratação do cimento

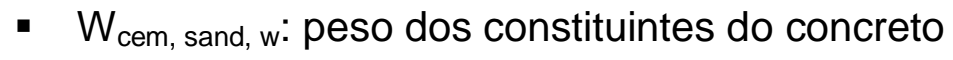

A parcela de subtração no numerador da expressão 3.3 considera o fato do calor especifica da água presentes nas ligações químicas do cimento hidratado ter um calor específico 50\% menor do que teria na situação de água livre.

A tabela 3.1 apresenta valores aproximados de calor específico para os componentes do concreto, considerando diferentes temperaturas.

Tabela 3.1 - Valores do calor específico, Breugel (1980)

\begin{tabular}{ccccc}
\hline \hline \multirow{2}{*}{ Material } & \multicolumn{4}{c}{ Calor específico $\left[\mathrm{kJ} / \mathrm{kg} .{ }^{\circ} \mathrm{C}\right]$} \\
& $21,1^{\circ} \mathrm{C}$ & $32,2^{\circ} \mathrm{C}$ & $43,3^{\circ} \mathrm{C}$ & $54,4^{\circ} \mathrm{C}$ \\
\hline \hline Água & 4,187 & 4,187 & 4,187 & 4,187 \\
Cimento & 0,456 & 0,536 & 0,662 & 0,825 \\
Quartzo & 0,699 & 0,745 & 0,795 & 0,867 \\
Basalto & 0,766 & 0,758 & 0,783 & 0,837 \\
Granito & 0,716 & 0,708 & 0,733 & 0,775 \\
Calcário & 0,749 & 0,758 & 0,783 & 0,921 \\
Riolito & 0,766 & 0,775 & 0,800 & 0,808 \\
\hline \hline
\end{tabular}


CAPÍTULO 4

\section{ANÁLISE DE ELEMENTOS FINITOS APLICADA}

\section{À TRANSFERÊNCIA DE CALOR}

\subsection{Introdução}

A modelagem computacional do comportamento do concreto nas primeiras idades, incluindo o fenômeno da hidratação, implica na consideração dao comportamento exotérmico das reações químicas. Deste modo, é necessária a utilização de um modelo numérico que seja capaz de prever os valores das temperaturas no concreto durante o processo de hidratação.

\subsection{Fundamentação básica}

Segundo Incropera e de Witt (2001) a transferência de calor consiste no trânsito de energia térmica provocado por uma diferença de temperatura. Desta forma, toda vez que houver uma diferença de temperatura num meio, ou entre vários 
meios a tranferência de calor ocorre obrigatoriamente. Existem três diferentes tipos de de processos de transferência de calor:

$\checkmark$ Denominamos condução à transferência de calor que ocorre num meio quando existe um gradiente de temperatura neste referrido meio estacionário, que pode ser um sólido ou um fluido.

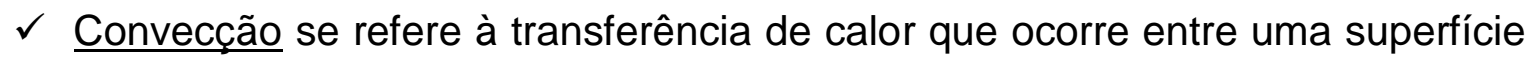
e um fluido em movimento, quando houver diferença de temperatura entre eles.

$\checkmark$ O terceiro modo de transferência de calor é a radiação térmica, que ocorre quando todas as superfícies numa temperatura finita emitem energia na forma de ondas eletromagnéticas. Por isso, na ausência de um meio interveniente, há transferência líquidade calor por radiação entre duas superfícies em temperaturas diferentes.

A distribuição das temperaturas em um corpo qualquer é controlada por apenas dois processos, condução e convecção, e não é possível isolar completamente um processo da influência do outro. No entanto, é usual a separação dos mesmos sem implicar erros significativos, simplificando, portanto, a análise térmica.

Desta forma, na consideração do concreto nas primeiras idades a transferência de calor será estudada por dois modos: condução e convecção, como pode ser observado na figura 4.1.

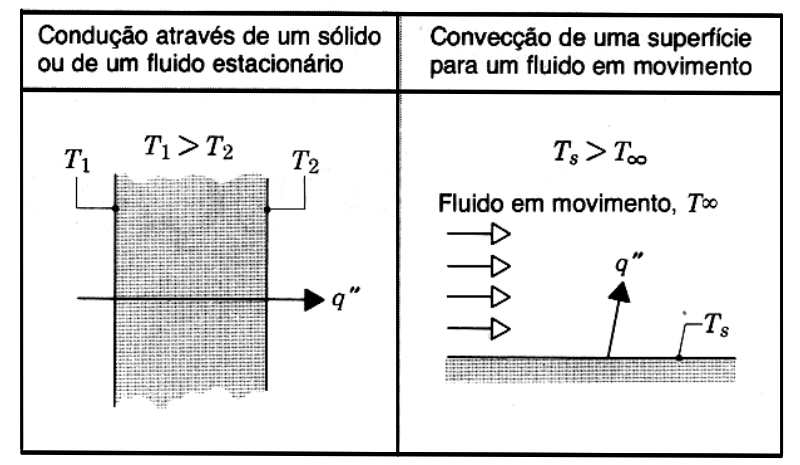

Figura 4.1 - Transferência de calor por condução e convecção. 


\subsubsection{Condução}

A condução é o processo típico de transmissão de calor dentro de um sólido. Neste processo de transferência de calor a troca de energia térmica é efetuada pelo movimento aleatório das moléculas, sendo necessário, portanto evocar os conceitos de atividade atômica e atividade molecular, pois são os processos nesse níveis que produzem a transferência de calor por condução. A condução pode ser considerada como a transferência de energia das partículas mais energéticas de um meio para as partículas menos energéticas, graças às interações entre as partículas.

Considerando um meio qualquer, a temperatura, em qualquer ponto, está associada à energia das moléculas na vizinhança daquele ponto. A energia relaciona-se ao movimento de translação aleatório das moléculas e também aos movimentos de rotação e vibração das mesmas. Além disso, as temperaturas mais elevadas estão associadas às energias moleculares mais altas, e, quando moléculas vizinhas colidem ocorre a tranferência de energia da molécula mais enérgica para a molécula menos enérgica. Na presença de um gradiente de temperatura, a transferência de energia pela condução deve ocorrer na direção da diminuição da temperatura, como evidenciado pela figura 4.2.
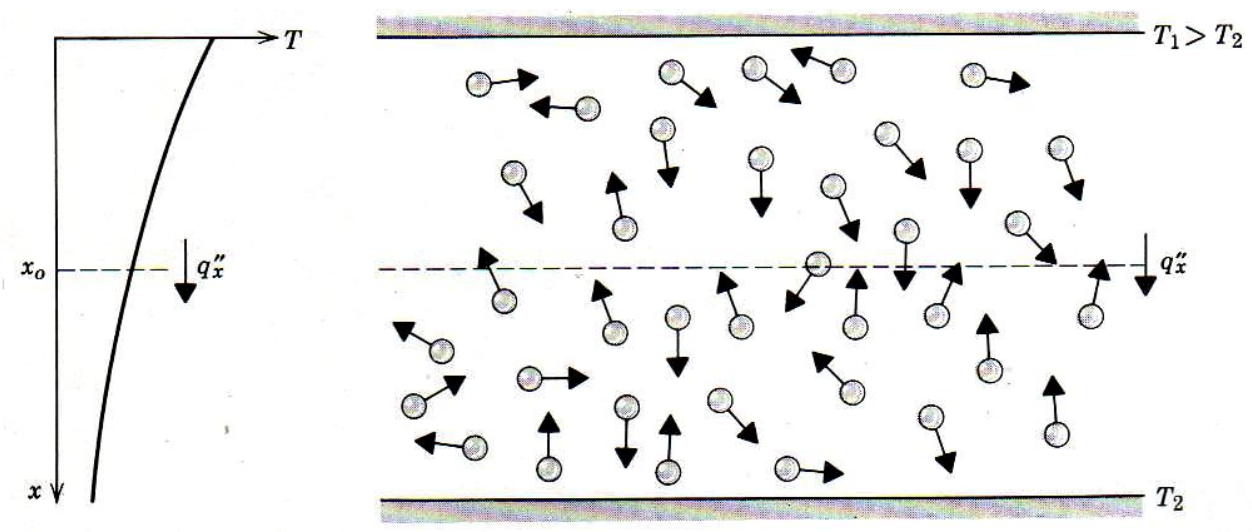

Figura 4.2 - Associação da transferência de calor por condução à difusão da energia provocada pela atividade molecular. 
Um exemplo de transferência de calor por condução é o caso da concretagem de uma barragem em camadas, onde a camada colocada sobre a outra, previamente existente. $O$ calor gerado pelas reações de hidratação da peça recém concretada será transmitido por condução à peça existente através sua superfície de contato.

A transferência de calor por condução num sólido pode ocorrer em dois tipos de regimes, o estacionário e 0 transiente. $O$ regime é considerado estacionário quando o fluxo de calor e a temperatura, em qualquer ponto, não variam ao longo do tempo. Já na transferência de calor em regime transiente, a temperatura muda não só com a posição no interior do corpo, ela também muda com o tempo em uma mesma posição; tanto a taxa de transferência de calor através do corpo, como a energia interna do corpo mudam com o tempo.

\subsubsection{Convecção}

A convecção é a transferência de calor entre a superfície de um corpo e de um fluido em movimento, por exemplo, o ar, quando existe uma diferença de temperatura entre os dois.

O modo de transferência de calor pela convecção compreende dois mecanismos. Além da transferência de energia provocada pelo movimento molecular aleatório (difusão), a energia também se transfere pelo movimento de massa, ou movimento macroscópico, do fluido. Esse movimento do fluido está associado ao fato de, em qualquer instante, um grande número de moléculas estar se movendo coletivamente ou em agregados. Esse movimento, na presença de um gradiente de temperatura, provoca a transferência de calor.

Em virtude das moléculas dos agregados continuarem a ter os respectivos movimentos aleatórios, a transferência total de calor se deve à superposição do transporte de energia pelo movimento aleatório das moléculas e ao transporte de energia provocado pelo movimento de massa do fluido. 
Considera-se o termo convecção para indicar o transporte acumulado pelo movimento aleatório das moléculas e o termo advecção para identificar o transporte devido ao movimento de massa do fluido.

O ponto de interesse do presente trabalho na consideração da convecção, é quando a mesma ocorre entre um fluido em movimento e uma superfície limitante, estando estes dois em temperaturas diferentes, como pode ser observado na figura 4.3.

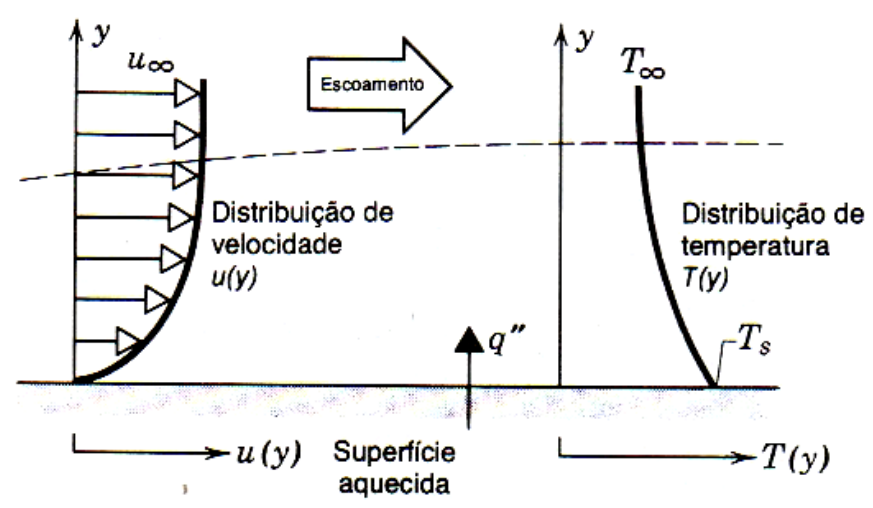

Figura 4.3 - Transferência convectiva de calor entre uma superfície limitante e um fluido em movimento

Uma conseqüência da interação do fluido com a superfície é o desenvolvimento de uma região no fluido na qual a velocidade varia desde zero, na superfície, até um valor finito, associado ao escoamento. Essa região do fluido é conhecida como a camada hidrodinâmica, a camada de velocidade ou a camada limite. Além disso, se a superfície e o fluido escoante tiverem temperaturas diferentes, haverá uma região no fluido através da qual a temperatura varia desde a temperatura da própria superfície até a temperatura externa. Essa região, denominada de camada limite térmica, pode ser menor ou maior que a camada através da qual a velocidade varia, ou ter o mesmo tamanho que esta. Em qualquer um dos casos, se a temperatura da superfície for maior que a temperatura externa, a transferência convectiva de calor ocorrerá da superfície para o escoamento externo. 
O modo de transferência convectiva de calor é sustentado pelo movimento molecular aleatório e pelo movimento macroscópico do fluido no interior da camada limite.

A contribuição devida ao movimento molecular aleatório, ou difusão, domina nas vizinhanças da superfície, onde a velocidade do fluido é baixa. Na realidade, na

interface entre a superfície e o fluido, a velocidade do fluido é nula e o calor é transferido exclusivamente pelo movimento molecular.

A contribuição devida ao movimento macroscópico do fluido se deve ao fato de a camada limite crescer a medida que o escoamento avança na horizontal. Desta forma, o calor conduzido para essa camada é arrastado pela corrente do fluido e se transfere para o fluido externo à camada limite.

\subsection{Resolução numérica do problema térmico}

Para a determinação dos fluxos de calor gerados pelas reações químicas de hidratação do cimento, e, consequentemente, os valores das temperaturas ao longo da estrutura, adotou-se o Método dos Elementos Finitos.

O Método dos Elementos Finitos é bastante difundido para a análise de sistemas estruturais, mas é também largamente utilizado na solução de problemas não estruturais, como, por exemplo, em problemas de transferência de calor e de mecânica dos fluidos. Neste capítulo o Método dos Elementos Finitos é aplicado na solução do problema de transferência de calor para o concreto nas primeiras idades. 


\subsection{Equações clássicas de transferência de calor}

De acordo com Bathe (1996), para uma análise de transferência de calor em um corpo bidimensional, admitindo-se que o material siga a Lei de Fourier de condução de calor, pode-se escrever que:

$$
\mathrm{q}_{\mathrm{x}}=-\mathrm{k}_{\mathrm{k}} \frac{\partial \theta}{\partial \mathrm{x}} \quad \mathrm{q}_{\mathrm{y}}=-\mathrm{k}_{\mathrm{y}} \frac{\partial \theta}{\partial \mathrm{y}}
$$

onde:

- $q_{x}, q_{y}$ : fluxos de calor por unidade de área

- $\theta$ : temperatura do corpo

- $\mathrm{k}_{\mathrm{x}}, \mathrm{k}_{\mathrm{y}}$ : condutividades térmicas correspondentes aos eixos principais $\mathrm{x}, \mathrm{y}$.

Considerando o equilíbrio do fluxo de calor no interior do corpo, tem-se que:

$$
\frac{\partial}{\partial x}\left(k_{k} \frac{\partial \theta}{\partial x}\right)+\frac{\partial}{\partial y}\left(k_{y} \frac{\partial \theta}{\partial y}\right)=-q^{B}
$$

onde $\mathrm{q}^{\mathrm{B}}$ é a taxa de calor gerado por unidade de volume.

Na superfície do corpo, as seguintes condições devem ser satisfeitas:

$$
\begin{gathered}
\left.\theta\right|_{\mathrm{S}_{\theta}}=\theta^{\mathrm{s}} \\
\left.\mathrm{k}_{\mathrm{n}} \frac{\partial \theta}{\partial \mathrm{n}}\right|_{\mathrm{S}_{\mathrm{q}}}=\mathrm{q}^{\mathrm{s}}
\end{gathered}
$$


onde:

- $\theta^{S}$ : temperatura conhecida na superfície S

- $\mathrm{k}_{\mathrm{n}}$ : condutividade térmica do corpo

- $n$ : vetor unitário normal à superfície do corpo

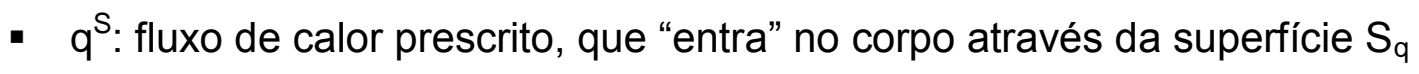

Para a utilização das expressões 4.2, 4.3 e 4.4 algumas hipóteses devem ser admitidas. A fundamental delas é que as partículas constituintes do corpo em estudo estão em repouso. Portanto, consideram-se as expressões acima descritas somente para condução de calor em sólidos e estruturas. Se a transferência de calor a ser analisada é em um fluido em movimento, deve ser acrescentado, na expressão 4.2, um termo que permita a transferência de calor por convecção através do meio.

Outra hipótese é que a análise aplicada à transferência de calor pode ser desacoplada da análise de tensões. Essa hipótese é valida para grande parte das análises estruturais, mas pode não ser apropriada, por exemplo, para a análise dos processos de fabricação de metais, onde as deformações podem gerar calor e mudanças no campo de temperaturas.

A terceira hipótese a ser considerada é que não existe mudança de fase no material em análise, nem efeitos de calor latente. Mas, será admitido na formulação apresentada a seguir, que os parâmetros dos materiais são dependentes da temperatura.

Três condições de contorno podem se consideradas na análise de transferência de calor:

$\checkmark$ Condições de temperatura: as temperaturas podem ser prescritas ou fixas, em determinados pontos ou superfícies do corpo, indicados por $S_{\square}$ na equação 4.3;

$\checkmark$ Condições de fluxo de calor: fluxos de calor podem ser prescritos em determinados pontos ou superfícies do corpo. Essas condições de contorno de fluxo de calor são indicadas por $S_{q}$ na equação 4.4 , 
$\checkmark$ Condições de contorno de convecção: pode-se incluir a convecção como condição de contorno, acrescentando na equação 4.4 o seguinte termo:

$$
q^{S}=h\left(\theta_{e}-\theta^{S}\right)
$$

onde h é o coeficiente de convecção. Aqui a temperatura ambiente $\square_{e}$ é conhecida, mas a temperatura na $\square$ s na superfície é desconhecida.

Além das condições de contorno acima mencionadas, a temperatura inicial da análise também deve ser especificada na análise transiente.

Para a solução por elementos finitos do problema de transferência de calor, utiliza-se o princípio das temperaturas virtuais, dado por:

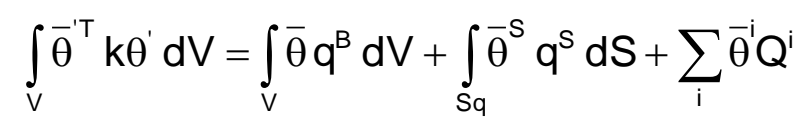

onde:

$$
\begin{gathered}
\theta^{\prime T}=\left[\begin{array}{ll}
\frac{\delta \theta}{\delta x} & \frac{\delta \theta}{\delta y}
\end{array}\right] \\
k=\left[\begin{array}{cc}
\mathrm{k}_{\mathrm{x}} & 0 \\
0 & \mathrm{k}_{\mathrm{y}}
\end{array}\right]
\end{gathered}
$$

e, $Q$ ' são os fluxos de calor concentrados. Cada $Q$ 'é equivalente ao fluxo de calor na superfície, sobre uma área muito pequena. $A$ barra sobre a temperatura $\theta$ indique que uma distribuição de temperatura virtual está sendo considerada.

O princípio das temperaturas virtuais é uma equação de equilíbrio de fluxo de calor: para $\theta$ ser a solução da temperatura do corpo estudado, a expressão 4.6 deve assegurar que a distribuição de temperatura virtual (contínua), que pode ser arbitrada, seja zero na $S_{\theta}$.

Ressalta-se que o princípio das temperaturas virtuais é semelhante ao princípio dos deslocamentos virtuais utilizado na análise de tensões. Utiliza-se o princípio das temperaturas virtuais do mesmo modo que o princípio dos deslocamentos virtuais, exceto que agora se tem somente o valor escalar da 
temperatura como incógnita, e anteriormente a análise era efetuada para calcular o vetor de deslocamentos.

É válido também, salientar que o princípio das temperaturas estacionárias corresponde à condição estacionária do seguinte funcional:

$$
\Pi=\int_{V} \frac{1}{2}\left\{k_{x}\left(\frac{\partial \theta}{\partial x}\right)^{2}+k_{y}\left(\frac{\partial \theta}{\partial y}\right)^{2}\right\} d V-\int_{V} \theta q^{B} d V-\int_{S q} \theta^{S} q^{S} d S-\sum_{i} \theta^{i} Q^{i}
$$

onde obtém-se:

$$
\int_{V} \delta \theta^{\prime T} k \theta^{\prime} d V=\int_{V} \delta \theta q^{B} d V+\int_{S q} \delta \theta^{S} q^{S} d S+\sum_{i} \delta \theta^{i} Q^{i}
$$

onde $\delta \theta$ pode ser arbitrada, mas deve ser zero na $\mathrm{S}_{\theta}$.

Aplicando uma integração por partes na expressão 4.10 pode-se obter a equação diferencial de equilíbrio (expressão 4.2) e as condições de contorno do fluxo de calor (equação 4.4). Por outro lado, comparando as expressões 4.10 e 4.6, observa-se que a 4.10 é o principio das temperaturas virtuais com $\delta \theta \equiv \bar{\theta}$.

No problema de transferência de calor admitem-se condições estacionárias. Entretanto, quando um fluxo de calor é atribuído apenas por um curto período de tempo (devido a mudanças de alguma condição de contorno ou do calor gerado no corpo) é importante incluir um termo que leve em conta a taxa com que o calor é armazenado pelo material. Esta taxa de absorção pode ser considerada por:

$$
q^{c}=\rho c \dot{\theta}
$$

onde c é a capacidade térmica do material. A variável $\mathrm{q}^{\mathrm{C}}$ pode ser entendida como uma parte do calor gerado - que deve ser subtraída do outro calor gerado, $\mathrm{q}^{\mathrm{B}}$, da expressão 4.6, pois $q^{c}$ é o calor armazenado - e este efeito leva a uma solução transiente. 


\subsection{Equações incrementais}

O princípio das temperaturas virtuais expressa o equilíbrio do fluxo de calor a qualquer momento. Para um esquema geral de solução para problemas estacionários ou transientes, devem-se desenvolver equações de equilíbrio incrementais. Como em uma análise de elementos finitos aplicada à análise de tensões, admite-se que a solução do problema para o tempo t já foi calculada e que as temperaturas serão determinadas para o tempo $t+\Delta t$, onde $\Delta t$ é o incremento de tempo.

\subsubsection{Solução para problema estacionário}

Considerando-se inicialmente o estado estacionário, onde o passo de tempo é usado apenas para descrever o carregamento do fluxo de calor, o princípio das temperaturas virtuais, aplicado no instante $\mathrm{t}+\square \mathrm{t}$, resulta:

$$
\int_{V} \bar{\theta}^{\prime T t+\Delta t} k^{t+\Delta t} \theta^{\prime} d V={ }^{t+\Delta t} Q+\int_{S c} \bar{\theta}^{S t+\Delta t} h\left({ }^{t+\Delta t} \theta_{e}-{ }^{t+\Delta t} \theta^{S}\right) d S
$$

onde:

- $t+\Delta t$ : indica "no tempo $t+\Delta t$ "

- $\mathrm{S}_{\mathrm{c}}$ : área da superfície com convecção

- ${ }^{t+\Delta t} Q$ : fluxo de calor externo dado ao sistema, no tempo $t+\Delta t$

Observa-se que, na expressão 4.12, a temperatura ${ }^{t+{ }^{t}} \theta_{e}$ é conhecida, enquanto ${ }^{t+\Delta t} \theta^{S}$, que é a temperatura na superfície Sc, é a incógnita. $O$ valor de ${ }^{t+\Delta t} Q$ inclui os feitos da geração interna de calor do corpo, ${ }^{t+\Delta t} q^{B}$, o fluxo de calor na 
superfície, ${ }^{t+\Delta t} q^{S}$, que não é incluído nas condições de contorno da convecção, e o fluxo de calor concentrado, ${ }^{\mathrm{t}+\Delta t} \mathrm{Q}$, como observa-se na expressão 4.13 .

$$
{ }^{t+\Delta t} Q=\int_{V} \bar{\theta}^{t+\Delta t} q^{B} d V+\int_{S_{2}} \bar{\theta}^{S t+\Delta t} q^{S} d S+\sum_{i} \bar{\theta}_{i}^{t+\Delta t} Q^{i}
$$

Considerando a equação geral de equilíbrio de fluxo de calor, dada pela equação 4.12 , deve-se notar que, no caso de análise linear, o termo ${ }^{t+\Delta t} h$ é constante, podendo-se reescrever a equação da seguinte forma:

$$
\int_{V} \bar{\theta}^{\prime T} k^{t+\Delta t} \theta^{\prime} d V+\int_{S c} \bar{\theta}^{S} h^{t+\Delta t} \theta^{S} d S={ }^{t+\Delta t} Q+\int_{S c} \bar{\theta}^{S} h^{t+\Delta t} \theta_{e} d S
$$

e, é possível resolve-la diretamente para a incógnita ${ }^{t+\Delta t} \theta$.

$\mathrm{Na}$ analise não linear de transferência de calor, a relação 4.12 é uma equação não linear, onde a incógnita é a temperatura no tempo $t+\Delta t$. Uma solução aproximada para essa temperatura pode ser obtida decompondo incrementalmente a equação 4.12. Como na análise de tensões, esta decomposição pode ser entendida com o primeiro passo da iteração de Newton-Raphson para o equilíbrio do fluxo de calor, onde:

$$
{ }^{\mathrm{t}+\Delta t} \theta^{(i)}={ }^{\mathrm{t}+\Delta \mathrm{t}} \theta^{(\mathrm{i}-1)}+\Delta \theta^{(i)}
$$

onde:

- ${ }^{\mathrm{t}+\Delta t} \theta^{(i-1)}$ : distribuição da temperatura no final de iteração i-1

- $\Delta \theta^{(i)}$ : incremento de temperatura na iteração i

- ${ }^{t+\Delta t} \theta^{(0)}={ }^{t} \theta$ 
Em uma iteração completa de Newton-Raphson a solução da expressão 4.12 pode ser obtida utilizando a equação 4.15 , recalculando todas as variáveis em cada iteração. Portanto, resolvendo para $i=1,2, \ldots$ tem-se:

$$
\begin{aligned}
& \int_{V} \bar{\theta}^{\prime T}{ }^{t+\Delta t} k^{(i-1)} \Delta \theta^{(i)} d V+\int_{S c} \bar{\theta}^{S t+\Delta t} h^{(i-1)} \Delta \theta^{S(i)} d S= \\
& { }^{\mathrm{t}+\Delta t} Q+\int_{S c} \bar{\theta}^{S}{ }^{t+\Delta t} h^{(i-1)}\left({ }^{t+\Delta t} \theta_{e}-{ }^{t+\Delta t} \theta^{S(i-1)}\right) d S-\int_{V} \bar{\theta}^{\prime T}{ }^{t+\Delta t} k^{(i-1)}{ }^{t+\Delta t} \theta^{\prime(i-1)} d V
\end{aligned}
$$

onde:

- ${ }^{t+\Delta t} h^{(i-1)}:$ coeficiente de convecção

- ${ }^{t}+\Delta t h^{(i-1)}$ : matriz constitutiva de condutividade que corresponde à temperatura ${ }^{t+\Delta t} \theta^{(i-1)}$

Frequentemente, na prática, o método de iteração Newton-Raphson modificado é utilizado. Neste caso, a parte esquerda da equação 4.16 é calculada apenas no começo de cada passo e não é recalculada até o próximo incremento de tempo.

A expressão 4.16 representa a solução iterativa geral onde, em particular, podem ser aplicadas quando as relações dos materiais são dadas como função da temperatura. Se a convergência de cada iteração é obtida, a solução correta do princípio das temperaturas virtuais foi calculada, desde que a equação 4.6 seja satisfeita com o lado direito da equação 4.16 igual a zero. E, frequentemente na prática, apenas poucas iterações são necessárias para valores razoáveis de incremento de tempo.

\subsubsection{Solução para problema transiente}

$\mathrm{Na}$ análise transiente, o efeito da capacidade térmica é incluído do mesmo modo com que são introduzidas as forças de inércia na análise de tensões. $O$ princípio das temperaturas virtuais nesta solução é dado por: 


$$
\begin{aligned}
& \int_{V} \bar{\theta}^{\prime T}{ }^{t+\Delta t}(\rho c)^{(i-1)}{ }^{t+\Delta t} \dot{\theta} d V+\int_{V} \bar{\theta}^{\prime T}{ }^{t+\Delta t} k^{t+\Delta t} \theta^{\prime} d V= \\
& { }^{t+\Delta t} Q+\int_{S c} \bar{\theta}^{S}{ }^{t+\Delta t} h\left({ }^{t+\Delta t} \theta_{e}-{ }^{t+\Delta t} \theta^{S}\right) d S
\end{aligned}
$$

onde:

- ${ }^{t+\Delta t} Q$ : fluxo de calor externo dado ao sistema, no tempo $t+\Delta t$ (eq. 4.13)

- ${ }^{t+\Delta t} q^{B}$ : taxa de calor gerado excluindo o efeito da capacidade térmica

\subsection{Discretização das equações de transferência de calor}

A solução de elementos finitos para as equações que governam a transferência de calor é obtida utilizando procedimentos análogos aos empregados na análise de tensões. Admite-se que o corpo em estudo está inteiramente dividido em elementos finito, e, tem-se para o elemento $m$ no tempo $t+\Delta t$ :

$$
\begin{aligned}
{ }^{t+\Delta t} \theta^{(m)} & =H^{(m)}{ }^{t+\Delta t} \theta \\
{ }^{t+\Delta t} \theta^{S(m)} & =H^{S(m)}{ }^{t+\Delta t} \theta \\
{ }^{t+\Delta t} & \theta^{\prime(m)}=B^{(m)}{ }^{t+\Delta t} \theta
\end{aligned}
$$

onde

- (m): indica o elemento

- ${ }^{\mathrm{t}+\Delta t} \theta$ : é o vetor das temperaturas nodais, no tempo $t+\Delta t$, dado por:

$$
{ }^{\mathrm{t}+\Delta \mathrm{t}} \theta^{\top}=\left[{ }^{\mathrm{t}+\Delta \mathrm{t}} \theta_{1}{ }^{\mathrm{t}+\Delta \mathrm{t}} \theta_{2} \ldots . .{ }^{\mathrm{t}+\Delta \mathrm{t}} \theta_{\mathrm{n}}\right]
$$

- $\mathrm{H}^{(\mathrm{m})}$ : matriz de temperaturas no elemento 
- $\mathrm{B}^{(\mathrm{m})}$ : matriz de interpolação dos gradientes de temperatura no elemento

- $H^{(S)}$ : matriz de interpolação das temperaturas na superfície

Calculam-se, nas expressões 4.18 , as temperaturas nos elementos e os gradientes de temperatura no tempo $t+\Delta$ t. Mas as mesmas matrizes de interpolação são utilizadas para o cálculo da temperatura no elemento em qualquer incremento de tempo, inclusive para incrementos de temperatura e incremento dos gradientes de temperatura.

\subsubsection{Condição estacionária: linear}

Utilizando as equações 4.18 e substituindo em 4.14 , obtêm-se as equações que governam a análise linear de transferência de calor:

$$
\left(K^{k}+K^{c}\right)^{t+\Delta t} \theta={ }^{t+\Delta t} Q+{ }^{t+\Delta t} Q^{e}
$$

onde:

- $\mathrm{K}^{\mathrm{k}}$ : a matriz de condutividade, dada por:

$$
K^{k}=\sum_{m} \int_{V^{(m)}} B^{(m) \top} k^{(m)} B^{(m)} d V^{(m)}
$$

- $\mathrm{K}^{\mathrm{c}}$ : a matriz de convecção, dada por:

$$
K^{c}=\sum_{m} \int_{S_{c}^{(m)}} h^{(m)} H^{S(m) T} H^{S(m)} d V^{(m)}
$$

- ${ }^{\mathrm{t}+\Delta t} \mathrm{Q}$ : vetor de entrada do fluxo de calor nodal

$$
{ }^{t+\Delta t} Q={ }^{t+\Delta t} Q_{B}+{ }^{t+\Delta t} Q_{S}+{ }^{t+\Delta t} Q_{c}
$$


sendo:

$$
\begin{aligned}
& { }^{t+\Delta t} Q_{B}=\sum_{m} \int_{V^{(m)}} H^{(m) T} \quad{ }^{t+\Delta t} b^{B} d V^{(m)} \\
& { }^{t+\Delta t} Q_{S}=\sum_{m} \int_{S_{q}^{(m)}} H^{S(m) T} \quad{ }^{t+\Delta t} b^{S} d S^{(m)}
\end{aligned}
$$

ainda:

- ${ }^{t+\Delta t} Q_{c}$ : vetor nodal de fluxo de calor concentrado

- ${ }^{t+\Delta t} Q^{e}$ : contribuição do fluxo de calor nodal devido à convecção no contorno do elemento, dado por:

$$
{ }^{\mathrm{t}+\Delta t} Q^{e}=\sum_{m} \int_{S_{c}(m)} h^{(m)} H^{S(m) T} H^{S(m)}{ }^{t+\Delta t} \theta_{e} d S^{(m)}
$$

\subsubsection{Condição estacionária: não linear}

Para análise não linear a temperatura o a interpolação dos gradientes de temperatura da expressão 4.18 são substituídos por uma relação de equilíbrio de fluxo de calor, dada pela expressão 4.16, para obter-se:

$$
\left({ }^{t+\Delta t} K^{k(i-1)}+{ }^{t+\Delta t} K^{c(i-1)}\right) \Delta \theta^{(i)}={ }^{t+\Delta t} Q+{ }^{t+\Delta t} Q^{c(i-1)}-{ }^{t+\Delta t} Q^{k(i-1)}
$$

onde as temperaturas nodais no final de cada iteração são dadas por:

$$
{ }^{\mathrm{t}+\Delta t} \theta^{(\mathrm{i})}={ }^{\mathrm{t}+\Delta \mathrm{t}} \theta^{(\mathrm{i}-1)}+\Delta \theta^{(\mathrm{i})}
$$

As matrizes e vetores usados na expressão 4.27 são diretamente obtidos dos termos individuais utilizados na expressão 4.16, e o vetor de fluxo de calor nodal, ${ }^{\mathrm{t}+\Delta t} \mathrm{Q}$, já foi definido em 4.23 . 
$\mathrm{Na}$ questão das condições de contorno, além da convecção temperaturas nodais também podem ser especificadas. Essas condições de contorno podem ser incorporadas do mesmo modo que os deslocamentos nodais conhecidos são prescritos na análise de tensões.

O procedimento comum é substituir as temperaturas nodais conhecidas nas equações de equilíbrio de fluxo de calor (4.20 e 4.27) e apagar as correspondentes equações do sistema. Outro modo efetivo de impor temperaturas nodais pode ser 0 procedimento empregado para impor as condições de contorno no casa de convecção. Isto é, atribuindo um grande valor para o coeficiente de convecção $h$, sendo $\mathrm{h}$ muito maior que a condutividade do material, a temperatura nodal na superfície será igual à temperatura do ambiente, temperatura nodal prescrita.

\subsubsection{Condição transiente}

Como mencionado anteriormente, na análise transiente de transferência de calor, os efeitos da capacidade térmica são incluídos na análise como parte da taxa de geração interna de calor. As equações a serem utilizadas na solução do problema dependem se o método de integração utilizado é implícito ou explícito, como na análise estrutural.

Se o método implícito de Euler for empregado, as equações de equilíbrio do fluxo de calor que são utilizadas são obtidas diretamente pelas equações que governam a condição estacionária (4.17).

Utilizando para o elemento $\mathrm{m}$ :

$$
\dot{\theta}^{(m)}(x, y, t)=H^{(m)}(x, y) \cdot \dot{\theta}(t)
$$


e, utilizando a expressão 4.11, tem-se, em 4.27:

$$
{ }^{t+\Delta t} Q=\sum_{m} \int_{V^{(m)}} H^{(m)^{\top}}\left({ }^{t+\Delta t} q^{B(m)}-^{t+\Delta t}(\rho c)^{(m)} H^{(m) t+\Delta t} \dot{\theta}\right) d V^{(m)}
$$

onde ${ }^{t+\Delta t} q^{B(m)}$ não mais inclui a taxa em que o calor é armazenado no material.

As equações de equilíbrio para o fluxo de calor, considerando a solução transiente, em uma análise linear, são:

$$
C^{t+\Delta t} \dot{\theta}+\left(K^{k}+K^{c}\right)^{t+\Delta t} \theta={ }^{t+\Delta t} Q+{ }^{t+\Delta t} Q^{e}
$$

e, em uma análise não linear, utilizando Newton-Raphson:

$$
\left.C^{(1)}{ }^{t+\Delta t} \dot{\theta}^{(1)}+\left({ }^{t+\Delta t} K^{k(i-1)}+{ }^{t+\Delta t} K^{c(i-1)}\right)\right)^{t+\Delta t} \theta^{(1)}={ }^{t+\Delta t} Q+{ }^{t+\Delta t} Q^{c(i-1)}-{ }^{t+\Delta t} Q^{k(i-1)}
$$

onde

$$
\begin{gathered}
C=\sum_{m} \int_{V^{(m)}} H^{(m)^{\top}}(\rho c)^{(m)} H^{(m)} d V^{(m)} \\
{ }^{t+\Delta t} Q=\sum_{m} \int_{V^{(m)}} H^{(m)^{\top}}{ }^{t+\Delta t}(\rho c)^{(m)} H^{(m)^{(i)}} d V^{(m)}
\end{gathered}
$$

As matrizes definidas na expressão 4.33 são matrizes que consideram a capacidade térmica, pois as mesmas interpolações no elemento são utilizadas tanto para as temperaturas quanto para as derivadas da temperatura em relação ao tempo.

Se, por outro lado, a formulação explícita de Euler for utilizada, a solução para as temperaturas desconhecidas no tempo $t+\Delta t$ são obtidas considerando 0 equilíbrio do fluxo de calor no tempo $t$.

Aplicando a relação da expressão 4.6 no tempo t, e substituindo as interpolações de elementos finitos para temperaturas, gradientes de temperatura e 
derivadas da temperatura em relação ao tempo, obtêm-se as seguintes equações para análise linear e não linear, respectivamente:

$$
\begin{aligned}
& \mathrm{C}^{\mathrm{t}} \dot{\theta}={ }^{\mathrm{t}} \mathrm{Q}+{ }^{\mathrm{t}} \mathrm{Q}^{\mathrm{c}}-{ }^{\mathrm{t}} \mathrm{Q}^{\mathrm{k}} \\
& { }^{\mathrm{t}} \mathrm{C}^{\mathrm{t}} \dot{\theta}={ }^{\mathrm{t}} \mathrm{Q}+{ }^{\mathrm{t}} Q^{\mathrm{c}}-{ }^{\mathrm{t}} \mathrm{Q}^{\mathrm{k}}
\end{aligned}
$$




\section{ANÁLISE DE ELEMENTOS FINITOS APLICADA}

\section{À DIFUSÃO DE UMIDADE}

\subsection{Considerações gerais}

Estudos sempre mostraram, desde o precursor trabalho de Bazant (1972), que a correta predição da distribuição da umidade nas estruturas de concreto é de extrema importância. Estudos atuais (Kwon e Shah, 2008; Baluch et al, 2008) atestam que a solução deste problema é imprescindível para a determinação da retração, fluência, dilatação térmica e o efeito dos mesmos sobre tensões, deformações e formação de fissuras. Além disso, a umidade presente nos poros afeta diretamente a resistência, condutividade térmica e a grau de velocidade da hidratação, possuindo um papel importantíssimo nas questões de durabilidade e resistência a incêndios. 


\subsection{Primeira Lei da Difusão de Fick}

No caso mais geral de difusão, segundo o Código Modelo CEB-FIP 1990 (1993), gases, líquidos e soluções dissolvidas são transportados através de um meio poroso de acordo com a Primeira Lei da Difusão de Fick:

$$
\mathrm{Q}=\mathrm{D} \cdot \frac{\mathrm{C}_{1}-\mathrm{C}_{2}}{1} \cdot \mathrm{A} \cdot \mathrm{t}
$$

onde:

- Q: quantidade de substância transportada (g)

- $c_{1}-c_{2}$ : diferença em concentração $\left(\mathrm{g} / \mathrm{m}^{3}\right)$

- 1: espessura da seção transposta $(m)$

- A: área da seção transposta $\left(\mathrm{m}^{2}\right)$

- T: tempo (s)

- D: coeficiente de difusão $\left(\mathrm{m}^{2} / \mathrm{s}\right)$

No caso específico da difusão de água num meio poroso, o transporte da mesma pode ser descrito através da Primeira Lei da Difusão de Fick, com a introdução de um gradiente da umidade relativa do meio poroso. O coeficiente de difusão $D$ é uma função não linear em função da umidade relativa do meio poroso, $\mathrm{H}$.

\subsection{Lei de Fick aplicada a concreto}

$\mathrm{Na}$ consideração de um fenômeno transiente, como a secagem do concreto, a equação de equilíbrio é dada por: 


$$
\frac{\partial \mathrm{H}}{\partial \mathrm{t}}=\frac{\partial}{\partial \mathrm{x}}\left(\mathrm{D}(\mathrm{H}) \frac{\partial \mathrm{H}}{\partial \mathrm{x}}\right)
$$

O volume do fluxo de água dentro do meio poroso, por sua vez, é dado por:

$$
V=D(H) \cdot \frac{d H}{d x} \cdot A \cdot t
$$

onde:

- V: volume de água fluindo $\left(\mathrm{m}^{3}\right)$

- $D(H)$ : coeficiente de difusão $\left(\mathrm{m}^{2} / \mathrm{s}\right)$ da umidade relativa do poro $H$

- $\frac{\mathrm{dH}}{\mathrm{dx}}:$ gradiente da umidade relativa do poro $\left(\mathrm{m}^{-1}\right)$

- A: área da seção transposta $\left(\mathrm{m}^{2}\right)$

- $\mathrm{t}$ : tempo (s)

Para condições isotérmicas, o coeficiente de difusão pode ser expresso como função da umidade relativa do poro, sendo $0<\mathrm{H}<1$, como mostra a expressão abaixo:

$$
D(H)=D_{1}\left(\alpha+\frac{1-\alpha}{1+\left(\frac{1-H}{1+H_{c}}\right)^{n}}\right)
$$

onde:

- $D_{1}$ : máximo $D(H)$ para $H=1\left(\mathrm{~m}^{2} / \mathrm{s}\right)$

- $\mathrm{D}_{0}$ : mínimo $\mathrm{D}(\mathrm{H})$ para $\mathrm{H}=0\left(\mathrm{~m}^{2} / \mathrm{s}\right)$

$$
\alpha=\frac{D_{0}}{D_{1}}
$$

- H: umidade relativa do poro 
- $H_{c}$ : umidade relativa do poro com $D(H)=0,5 . D_{1}$

- $\mathrm{n}$ : expoente

Podem ser usadas as seguintes aproximações para a expressão acima:

- $\mathrm{H}_{\mathrm{c}}=0,80$

- $\mathrm{n}=15$

- $\mathrm{D}_{1}=0,7 \cdot 10^{-10}-6,0 \cdot 10^{-10}\left(\mathrm{~m}^{2} / \mathrm{s}\right)$

- $\alpha=0,05$

Como os valores de $D_{1}$ podem variar bastante, o mesmo pode ser estimado de acordo com a seguinte expressão:

$$
D_{1}=\alpha_{D} \frac{120.10^{-10}}{\left(\frac{f_{c k}}{f_{c k 0}}\right)}
$$

onde:

- $\alpha_{D}=0,1 \mathrm{~m} / \mathrm{s}^{2}$

- $\mathrm{f}_{\mathrm{ck} 0}=10 \mathrm{MPa}$

\subsection{Resolução numérica do problema de difusão de umidade}

Adotou-se o Método dos Elementos Finitos para a determinação da umidade no interior de um corpo de concreto, da secagem devido às condições ambientes que cercam o elemento em estudo e da quantidade de água livre ao longo do corpo de concreto.

Como mencionado anteriormente, o Método dos Elementos Finitos é largamente utilizado na solução de problemas não estruturais, como, por exemplo, 
em problemas de transferência de calor, como já foi descrito neste trabalho. Neste capítulo o Método dos Elementos Finitos é aplicado na solução do problema de difusão da umidade no interior de um corpo de concreto nas primeiras idades.

\subsubsection{Analogia entre transferência de calor e difusão de umidade}

Baluch (2008) realizou um estudo que estabeleceu uma analogia entre a análise de transferência de calor e a análise de difusão de umidade no interior de um corpo de concreto.

Reescrevendo a equação diferencial que governa o fenômeno da transferência de calor, na solução transiente, tem-se:

$$
\frac{\partial \theta}{\partial t}=\frac{k}{\rho c}\left(\frac{\partial^{2} \theta}{\partial x^{2}}+\frac{\partial^{2} \theta}{\partial y^{2}}\right)
$$

onde:

- $\theta=\theta(x, y, t): a$ temperatura é função da posição $x$ e y considerada e da variável tempo $\mathrm{t}$

- $\mathrm{k}$ : condutividade térmica

- c: calor específico

- $\rho$ : densidade

Analogamente, reescrevendo a equação diferencial que governa o fenômeno da difusão de umidade, tem-se:

$$
\frac{\partial \mathrm{H}}{\partial \mathrm{t}}=\mathrm{D}(\mathrm{H})\left(\frac{\partial^{2} \mathrm{H}}{\partial \mathrm{x}^{2}}+\frac{\partial^{2} \mathrm{H}}{\partial \mathrm{y}^{2}}\right)
$$

onde: 
- $H=H(x, y, t): a$ umidade relativa do poro é função da posição $x$ e $y$ considerada e da variável tempo $t$

- $D(H)$ : coeficiente de difusão do material (geralmente em função de $H$ )

Considerando as condições de contorno da análise de transferência de calor, tem-se a expressão 5.9 .

$$
\frac{\partial \theta}{\partial \mathrm{n}}=\mathrm{h}\left(\theta_{\mathrm{e}}-\theta^{\mathrm{s}}\right)
$$

onde:

- $\frac{\partial \theta}{\partial \mathrm{n}}$ : gradiente térmico na superfície

- h: coeficiente de convecção

- $\theta_{\mathrm{e}}$ : temperatura na superfície do sólido

- $\theta^{S}$ : temperatura ambiente

Por outro lado, na consideração das condições de contorno da análise de difusão de umidade, pode-se observar a expressão 5.10.

$$
D(H) \frac{\partial H}{\partial n}=\alpha_{m}\left(H_{e}-H^{s}\right)
$$

onde:

- $\frac{\partial \mathrm{H}}{\partial \mathrm{n}}$ : gradiente de umidade na superfície

- $\alpha_{m}$ : fator de transferência de massa

- $H_{\mathrm{e}}$ : umidade relativa nos poros junto à superfície do sólido

- $H^{S}$ : umidade relativa do ambiente 
Comparando as equações que descrevem os problemas de transferência de calor e de difusão de umidade, torna-se claro que existe analogia entre ambas as análises. A correspondência entre os referidos termos dos dois problemas pode ser observada na tabela 5.1 .

Tabela 5.1 - Correspondentes termos nas equações diferenciais das análises de transferência de calor e difusão de umidade (Baluch, 2008)

\begin{tabular}{|c|c|c|}
\hline Transferência de calor & & Difusão de umidade \\
\hline$\theta(x, y, t)$ & $\leftrightarrow$ & $H(x, y, t)$ \\
\hline$\frac{\mathrm{k}}{\rho \mathrm{c}}$ & $\leftrightarrow$ & $\mathrm{D}(\mathrm{H})$ \\
\hline $\mathrm{h}$ & $\leftrightarrow$ & $a m$ \\
\hline$\theta_{\mathrm{e}}$ & $\leftrightarrow$ & $\mathrm{H}_{\mathrm{e}}$ \\
\hline$\theta^{S}$ & $\leftrightarrow$ & $\mathrm{H}^{\mathrm{S}}$ \\
\hline
\end{tabular}


CAPÍTULO 6

\section{ANÁLISE DA ETAPA DE SOLUÇÃO \\ DO PROBLEMA MECÂNICO}

\subsection{Modelo para um material elasto-viscoplástico}

Owen e Hinton (1980) apresentam um programa para análise de um material elasto-viscoplástico. Neste programa, o modelo reológico adotado é apresentado na figura 6.1 .

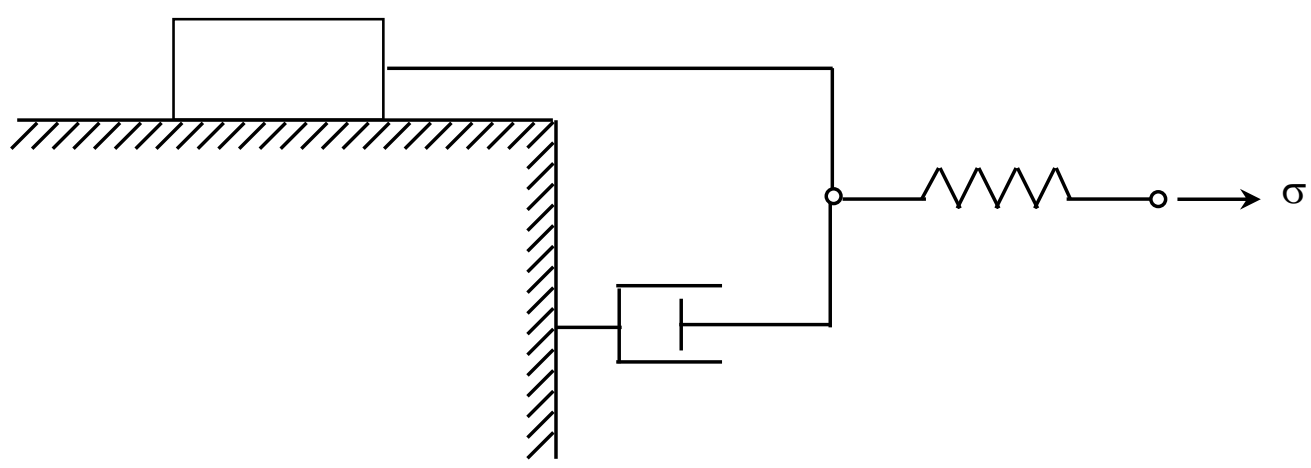

Figura 6.1 - Modelo elasto-viscoplástico

A resposta elástica instantânea é proporcionada pela mola linear. Tendo em vista que o amortecedor não sofre deformação instantânea, o elemento de atrito também apresentará deformação nula, pois ambos estão conectados em paralelo. 0 
elemento de atrito torna-se ativo somente se a tensão corrente $\sigma$ for maior que a tensão de plastificação $\sigma_{0}$. Este excesso de tensão $\left(\sigma-\sigma_{0}\right)$ é absorvido gradativamente pelo amortecedor, caracterizando desta maneira, o comportamento elasto-viscoplástico do material.

Nesta tese, na parte mecânica da formulação implementada para o comportamento do concreto nas primeiras idades é necessário representar o comportamento de um material viscoelástico. Para tal, utilizou-se o programa computacional desenvolvido por Owen e Hinton (1980) adaptado para essa situação.

Calcula-se o estado de deformação da estrutura, decorrido um período de tempo da aplicação da carga. Há um processo de incremento no tempo, onde ocorrem os efeitos ao longo do tempo na estrutura (fluência e retração do concreto). Considera-se que a tensão de plastificação é nula. Esta resposta representa um comportamento viscoelástico dos materiais.

\subsubsection{Formulação do comportamento elasto-viscoplástico conforme Owen e Hinton (1980)}

Neste item, são apresentados os fundamentos para a formulação matemática de elementos finitos, considerando análise tridimensional não-linear e admitindo o material como sendo isótropico, homogêneo, de comportamento elasto-viscoplástico, conforme o modelo reológico da figura 6.6. O programa básico para solução deste problema encontra-se apresentado em Owen e Hinton (1980).

De um modo geral, na formulação usual para problemas contínuos nãolineares, admite-se que as componentes de deformação total, em um dado ponto, são compostas por uma parcela elástica $\left\{\varepsilon_{\mathrm{e}}\right\}$, e outra viscoplástica $\left\{\varepsilon_{\mathrm{vp}}\right\}$

$$
\{\varepsilon\}=\left\{\varepsilon_{\mathrm{e}}\right\}+\left\{\varepsilon_{\mathrm{vp}}\right\}
$$

ou diferenciando em relação ao tempo t, 


$$
\{\dot{\varepsilon}\}=\left\{\dot{\varepsilon}_{\mathrm{e}}\right\}+\left\{\dot{\varepsilon}_{\mathrm{vp}}\right\}
$$

As tensões são produzidas unicamente pelas deformações elásticas,

$$
\{\sigma\}=[D]\left\{\varepsilon_{\mathrm{e}}\right\}
$$

onde [ D ] é a matriz constitutiva do material, cujas expressões, dependendo do problema a ser estudado, podem ser observadas na tabela 6.1.

\begin{tabular}{|c|c|c|c|c|c|}
\hline Estado Plano de Tensão & & $\frac{E}{\left.-v^{2}\right)}$ & {$\left[\begin{array}{lll}1 & v & \\
v & 1 & \\
0 & 0 & (1\end{array}\right.$} & $\left.\begin{array}{c}0 \\
0 \\
-v) \\
2\end{array}\right]$ & \\
\hline $\begin{array}{c}\text { Estado Plano de } \\
\text { Deformação }\end{array}$ & $\frac{E}{(1-v) \cdot(1-z}$ & $\frac{(}{2 v)}$ & $\begin{array}{c}(1-v) \\
v \\
0\end{array}$ & $\begin{array}{l}v \\
-v) \\
0 \quad 1\end{array}$ & $\left.\begin{array}{l}0 \\
0 \\
-2 v) \\
2\end{array}\right]$ \\
\hline Axissimétrica & $\frac{E}{(1-v) \cdot(1-2 v)}$ & {$\left[\begin{array}{c}(1-v \\
v \\
0 \\
0\end{array}\right.$} & $\begin{array}{c}v \\
(1-v) \\
v \\
0\end{array}$ & $\begin{array}{c}0 \\
v \\
(1-v) \\
0\end{array}$ & $\begin{array}{c}0 \\
0 \\
0 \\
(1-2 v) \\
\frac{2}{2}\end{array}$ \\
\hline
\end{tabular}

Tabela 6.1 - Expressões para a matriz constitutiva $D$

No espaço das tensões, tem-se uma superfície de plastificação expressa genericamente por:

$$
F\langle\{\sigma\}\rangle-F_{0}\langle\kappa\rangle=0
$$

onde $\mathrm{F}_{0}$ é um valor que define a posição da superfície de plastificação, sendo uma função do parâmetro de endurecimento k. Se $F<F_{0}$, tem-se um comportamento elástico, se $\mathrm{F}=\mathrm{F}_{0}$, plástico, e se $\mathrm{F}>\mathrm{F}_{0}$, viscoplástico. 
É imperativo estabelecer uma lei específica para determinar as deformações viscoplásticas a partir do estado de tensões. Uma forma explícita para esta lei, conforme Hinton (1977), é

$$
\begin{gathered}
\left\{\dot{\varepsilon}_{\mathrm{vp}}\right\}=\gamma\langle\Phi(\mathrm{F})\rangle \frac{\partial \mathrm{Q}}{\partial\{\sigma\}}, \text { para } \mathrm{F}>\mathrm{F}_{0} \\
\left\{\dot{\varepsilon}_{\mathrm{vp}}\right\}=0, \text { para } \mathrm{F} \leq \mathrm{F}_{0}
\end{gathered}
$$

na qual:

- $\gamma=1 / \eta$ é o coeficiente de fluidez;

- $\mathrm{Q}=\mathrm{Q}\left(\{\sigma\},\left\{\varepsilon_{\mathrm{vp}}\right\}, \kappa\right)$ é a função de potencial plástico.

A expressão $<\Phi(F)>$ é igual a $\Phi(F)$ para valores positivos de $F$, e é nula para os demais.

Limitando-se ao caso de plasticidade associada, na qual $F \equiv Q$, a equação 6.5 fica

$$
\left\{\varepsilon_{\mathrm{vp}}\right\}=\gamma\langle\Phi(\mathrm{F})\rangle \frac{\partial \mathrm{F}}{\partial\{\sigma\}}=\gamma\langle\Phi(\mathrm{F})\rangle\{\mathrm{a}\}
$$

onde $\{a\}$ é o vetor de fluxo plástico que define a direção do escoamento viscoplástico, cujas expressões, dependendo do problema a ser estudado, podem ser observadas na tabela 6.2 .

Tabela 6.2 - Expressões para o vetor de fluxo plástico

\begin{tabular}{c|c}
\hline $\begin{array}{c}\text { Estado Plano de Tensão e } \\
\text { Deformação }\end{array}$ & $\left\{\frac{\partial \mathrm{F}}{\partial \sigma_{\mathrm{x}}}, \frac{\partial \mathrm{F}}{\partial \sigma_{\mathrm{y}}}, \frac{\partial \mathrm{F}}{\partial \tau_{\mathrm{xy}}}, \frac{\partial \mathrm{F}}{\partial \sigma_{\mathrm{z}}}\right\}$ \\
\hline Axissimétrica & $\left\{\frac{\partial \mathrm{F}}{\partial \sigma_{\mathrm{r}}}, \frac{\partial \mathrm{F}}{\partial \sigma_{\mathrm{z}}}, \frac{\partial \mathrm{F}}{\partial \tau_{\mathrm{rz}}}, \frac{\partial \mathrm{F}}{\partial \sigma_{\theta}}\right\}$ \\
\hline
\end{tabular}




\subsubsection{Incremento de deformação viscoplástica}

A regra de escoamento viscoplástico, expressa em 6.6, é válida para todos os tempos t. Em um procedimento numérico passo por passo, esta relação será satisfeita somente para tempos discretos separados de $\Delta$ t. A deformação viscoplástica é dada por

$$
\left\{\left(\varepsilon_{\mathrm{vp}}\right)_{\mathrm{n}+1}\right\}=\left\{\left(\varepsilon_{\mathrm{vp}}\right)_{\mathrm{n}}\right\}+\left[(1-\beta)\left\{\left(\dot{\varepsilon}_{\mathrm{vp}}\right)_{\mathrm{n}}\right\}+\beta\left\{\left(\dot{\varepsilon}_{\mathrm{vp}}\right)_{\mathrm{n}+1}\right\}\left\langle\Delta \mathrm{t}_{\mathrm{n}}\right.\right.
$$

onde o intervalo de tempo é $\Delta t_{n}=t_{n+1}-t_{n}$.

Deste modo, o incremento de deformação viscoplástica, dentro de um intervalo, é definido em termos da regra de escoamento viscoplástico nas extremidades do intervalo. Para $\beta=0$, obtém-se o esquema de integração explícito de Euler, onde apenas a regra de escoamento viscoplástico, no início do intervalo, é relevante

$$
\left\{\left(\Delta \varepsilon_{\mathrm{vp}}\right)_{\mathrm{n}}\right\}=\left\{\left(\dot{\varepsilon}_{\mathrm{vp}}\right)_{\mathrm{n}}\right\} \Delta \mathrm{t}_{\mathrm{n}}
$$

Neste trabalho, utilizou-se este esquema de integração.

\subsubsection{Incrementos de tensão}

Usando a forma incremental das equações 6.1 e 6.3 , obtém-se

$$
\left\{\Delta \sigma_{\mathrm{n}}\right\}=[\mathrm{D}]\left\{\left(\Delta \varepsilon_{\mathrm{e}}\right)_{\mathrm{n}}\right\}=[\mathrm{D}]\left(\left\{\Delta \varepsilon_{\mathrm{n}}\right\}-\left\{\left(\Delta \varepsilon_{\mathrm{vp}}\right)_{\mathrm{n}}\right\}\right)
$$

Expressando o incremento de deformação total em termos de incrementos de deslocamentos, têm-se

$$
\left\{\Delta \varepsilon_{n}\right\}=[B]\left\{\Delta u_{n}\right\}
$$


onde $[B]$ é a matriz de relações deformações-deslocamentos e $\left\{\Delta u_{n}\right\}$ é o vetor de incrementos de deslocamentos nas direções ortogonais $x$ e $y$. Usando as equações 6.8 e 6.10 , a expressão 6.9 resulta em

$$
\left\{\Delta \sigma_{n}\right\}=\left[D_{n}\right]\left([B]\left[\Delta u_{n}\right\}-\left\{\left(\dot{\varepsilon}_{v p}\right)_{n}\right\} \Delta t_{n}\right)
$$

As expressões para a matriz de relações deformações-deslocamentos podem ser observadas na tabela 6.3.

Tabela 6.3 - Expressões para a matriz de relações deformações-deslocamentos B

\begin{tabular}{c|cc}
\hline $\begin{array}{c}\text { Estado Plano de Tensão e } \\
\text { Deformação }\end{array}$ & {$\left[\begin{array}{cc}\left(\frac{\partial N_{i}}{\partial x}\right)^{(e)} & 0 \\
0 & \left(\frac{\partial N_{i}}{\partial y}\right)^{(e)} \\
\left(\frac{\partial N_{i}}{\partial y}\right)^{(e)} & \left(\frac{\partial N_{i}}{\partial x}\right)^{(e)}\end{array}\right]$} \\
\hline Axissimétrica & {$\left[\begin{array}{ll}\left(\frac{\partial N_{i}}{\partial r}\right)^{(e)} & 0 \\
\left(\frac{\partial N_{i}}{\partial r}\right)^{(e)} & 0 \\
0 & \left(\frac{\partial N_{i}}{\partial z}\right)^{(e)} \\
\left(\frac{\partial N_{i}}{\partial r}\right)^{(e)} & \left(\frac{\partial N_{i}}{\partial z}\right)^{(e)}\end{array}\right]$} \\
\hline \hline
\end{tabular}

\subsubsection{Equações de equilíbrio}

As equações de equilíbrio a serem satisfeitas, a cada instante de tempo $t_{n}$, são:

$$
\int_{V}[B]^{\top}\left\{\sigma_{n}\right\} d V-\left\{P_{n}\right\}=0
$$


onde $\left\{\mathrm{P}_{\mathrm{n}}\right\}$ é o vetor de cargas nodais e nodais equivalentes devido as forças de superfície e de volume. Durante um incremento de tempo, as equações de equilíbrio que devem ser satisfeitas, são dadas pela forma incremental de 6.12, como segue

$$
\int_{V}[B]^{\top}\left\{\Delta \sigma_{n}\right\} d V-\left\{\Delta P_{n}\right\}=0
$$

na qual $\left\{\Delta P_{n}\right\}$ representa a variação nas cargas durante o intervalo de tempo $\Delta t_{n} . N a$ maioria dos casos, os incrementos de cargas são aplicados como passos discretos, e então, $\left\{\Delta \mathrm{P}_{n}\right\}=0$ para todos os passos de tempo, exceto para o primeiro dentro de um incremento de carga.

O incremento de deslocamento, ocorrido durante cada passo de tempo $\Delta t_{n}$, pode ser calculado como:

$$
\left\{\Delta \mathrm{u}_{\mathrm{n}}\right\}=\left[\mathrm{K}_{\mathrm{n}}\right]^{-1}\left\{\Delta \mathrm{P}_{\mathrm{n}}\right\}
$$

onde $\left[K_{n}\right.$ ] é a matriz de rigidez tangente global, dada por

$$
\left[K_{n}\right]=\int_{V}[B]^{\top}[D]_{n}[B] d V
$$

$\left\{\Delta u_{n}\right\}$ é o vetor que contém os incrementos dos deslocamentos nodais;

$\left\{\Delta \mathrm{P}_{\mathrm{n}}\right\}$ é o vetor de incrementos de cargas nodais equivalentes de toda a estrutura no passo $n$.

Aplicando-se as condições de contorno, determinam-se os incrementos de deslocamentos $\left\{\Delta u_{n}\right\}$, que substituídos em 6.11, dão os incrementos de tensões $\left\{\Delta \sigma_{n}\right\}$. Assim,

$$
\begin{aligned}
& \left\{\sigma_{n+1}\right\}=\left\{\sigma_{n}\right\}+\left\{\Delta \sigma_{n}\right\} \\
& \left\{u_{n+1}\right\}=\left\{u_{n}\right\}+\left\{\Delta u_{n}\right\}
\end{aligned}
$$


Usando 6.9 e 6.10 resulta:

$$
\left\{\left(\Delta \varepsilon_{\mathrm{vp}}\right)_{\mathrm{n}}\right\}=[\mathrm{B}]^{\top}\left\{\Delta \mathrm{u}_{\mathrm{n}}\right\}-[\mathrm{D}]^{-1}\left\{\Delta \sigma_{\mathrm{n}}\right\}
$$

e então

$$
\left\{\left(\varepsilon_{\mathrm{vp}}\right)_{n+1}\right\}=\left\{\left(\varepsilon_{\mathrm{vp}}\right)_{\mathrm{n}}\right\}+\left\{\left(\Delta \varepsilon_{\mathrm{vp}}\right)_{\mathrm{n}}\right\}
$$

As condições de estado estacionário podem ser controladas pelo exame da variação dos deslocamentos nodais. A convergência é atingida quando esta quantidade torna-se adequadamente pequena.

O cálculo do incremento de deslocamento está baseado numa forma linearizada das equações incrementais de equilíbrio 6.14. Portanto, torna-se necessário efetuar correções iterativas sobre $\Delta u$, a fim de alcançar o equilíbrio no tempo $\mathrm{t}+\Delta \mathrm{t}$. Há vários procedimentos de solução disponíveis para realizar as correções necessárias. Neste trabalho, utiliza-se um procedimento iterativo, que consiste em calcular as forças não equilibradas em cada iteração, e em seguida reaplicá-las na iteração subseqüente.

\subsection{Modelo para um material viscoelastico}

A simplificação do modelo elasto-viscoplástico de Owen e Hinton (1980) considerando a tensão de plastificação nula, resulta no modelo de Maxwell. Este modelo reológico, formado por uma mola em série com um amortecedor, é demasiadamente simples para representar o comportamento real do concreto. Desta forma, para a implementação no programa, usou-se uma cadeia de Maxwell com cinco elementos.

Para a implementação deste modelo reológico foi utilizada a técnica de camadas superpostas. 


\subsection{Modelo de Camadas}

O modelo reológico, correspondente ao comportamento elasto-viscoplástico, descrito no item 6.1, é constituído por uma mola em série com um elemento formado por um amortecedor viscoso em paralelo com um elemento de atrito (slider). A história de deformação com o tempo (curvas de fluência) de muitos materiais reais, como o concreto, não pode ser precisamente representada por um modelo elastoviscoplástico tão simples.

Uma resposta de um material mais elaborado pode ser obtida pelo método das camadas superpostas (overlay models), conforme Pande e Owen (1977), no qual o sólido analisado é suposto como sendo composto de várias camadas de materiais simples, cada uma das quais apresentando a mesma deformação. $O$ campo de tensões totais é obtido pela soma das contribuições de cada camada.

Mediante a introdução de um número conveniente de camadas superpostas, com a atribuição de diferentes características materiais a cada uma, pode-se reproduzir fielmente o comportamento experimental de materiais complexos como o concreto.

No caso mais geral, o modelo reológico é formado por um conjunto de elementos tipo Maxwell em paralelo. Têm-se como parâmetros as espessuras das camadas $e_{i}$, os módulos de elasticidade das molas $E_{i}$, as constantes dos amortecedores $\gamma_{i}$ e as tensões de escoamento $F_{0 i}$, nas quais começam a atuar os elementos de atrito. A maior dificuldade reside na determinação dos parâmetros para ajustar o modelo ao comportamento experimental do material.

Neste trabalho, aplicar-se-á o modelo de camadas superpostas para representar o comportamento viscoelástico com envelhecimento do concreto. $\mathrm{Na}$ figura 6.2 ilustra-se, esquematicamente, a situação de um modelo de camadas superpostas em duas dimensões.

Cada camada do modelo pode ter uma espessura e um comportamento material diferentes. Como os nós em todas as camadas coincidem, em cada uma 
delas tem-se a mesma deformação. Isto resulta em um campo de tensões $\left\{\sigma_{i}\right\}$ diferente em cada camada.

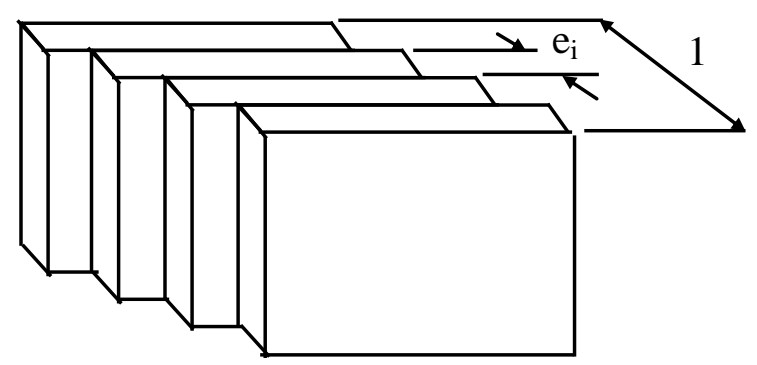

Figura 6.2 - Analogia da técnica de camadas em duas dimensões

A contribuição de cada camada, para o campo de tensões totais $\sigma$, é dada por

$$
\{\sigma\}=\sum_{i=1}^{k}\left\{\sigma_{i}\right\} e_{i}
$$

onde k é o número de camadas do modelo e,

$$
\sum_{i=1}^{k} e_{i}=1
$$

sendo $e_{i}$ a espessura relativa de cada camada, isto é, sua espessura dividida pela espessura total.

A matriz de rigidez de cada elemento simples de concreto será obtida pela soma das contribuições de cada camada individualmente, ou seja:

$$
\left[K_{S S}\right]=\sum_{i=1}^{K} \int_{v}[B]^{\top}[D]_{i l}[B] d v
$$

onde $[D]_{i}$ é a matriz constitutiva de cada camada. Esta matriz será distinta para cada uma das camadas, dependendo de suas propriedades materiais. O processo de solução é idêntico ao descrito nas seções anteriores, com os termos de deformação e tensão sendo calculados para cada camada separadamente. É importante 
salientar que, embora as deformações viscoplásticas, em cada camada, possam ser diferentes, devido aos diferentes valores dos do coeficiente de fluidez e do módulo de elasticidade, a deformação total deve ser a mesma.

\subsection{Propriedades dos materiais dependentes do tempo}

\subsubsection{Fluência}

O concreto, quando submetido a solicitações de longa duração, sofre uma deformação imediata, seguida de uma deformação lenta, devida ao efeito de fluência (creep), que se desenvolve ao longo do tempo. Deste modo, mesmo sob tensões constantes, as deformações ocorridas no concreto aumentam no decorrer do tempo, conforme ilustrado na figura 6.3.

Este fenômeno manifesta-se, mais acentuadamente, nas primeiras idades, posteriores ao aparecimento das tensões. Está relacionado com efeitos decorrentes devidos, principalmente, à circulação de água na massa de concreto e sua dissipação para o exterior. Em sua magnitude e desenvolvimento, influem diversos fatores, podendo-se destacar a umidade e a temperatura ambientes, a idade do carregamento e o período transcorrido após a sua aplicação, as dimensões da peça, as condições de cura, a composição do concreto e a velocidade de endurecimento do cimento.

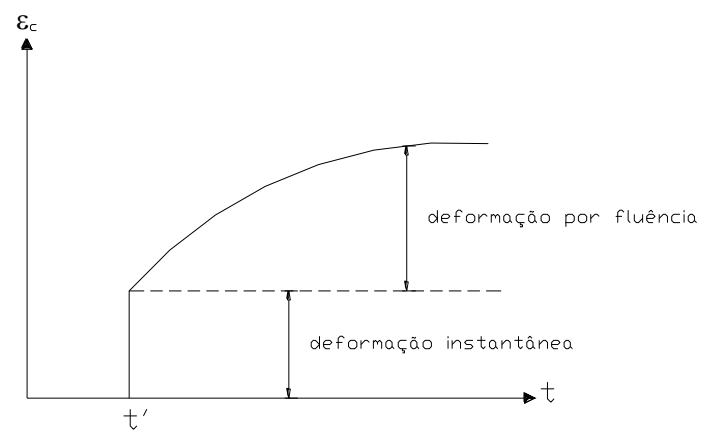

Figura 6.3 - Evolução da deformação por fluência para uma tensão constante aplicada em t' 


\subsubsection{Retração}

Após a concretagem e cura do concreto, pode-se ainda encontrar água no seu interior, alojada em pequenos vasos capilares. Tal quantidade de água é o resíduo da reação de hidratação do cimento, a qual sempre vai existir, uma vez que o fator água/cimento, utilizado na reação, é menor que o mínimo necessário para se trabalhar com o concreto. Com o tempo, o resíduo de água tende a evaporar, levando os vasos capilares, sem a pressão interna do mesmo, ao esmagamento. Este efeito provoca uma perda de volume, conhecido como retração (shrinkage).

Esta deformação, ao longo do tempo, é independente da tensão atuante e está relacionada a fatores semelhantes aos da fluência, também devidos à água que, em parte hidrata os componentes do cimento, em parte fica retida dentro da massa de concreto.

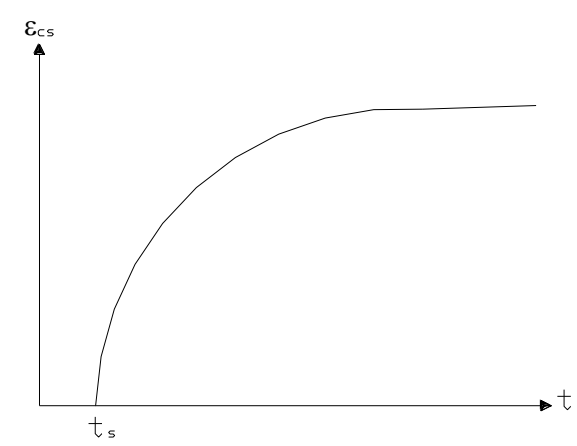

Figura 6.4 - Curva de deformação por retração

A seguir, descreve-se, detalhadamente, a inclusão dos efeitos de fluência e retração no modelo computacional. 


\subsection{Relações constitutivas para o concreto}

\subsubsection{Hipótese básica}

No domínio das tensões de utilização as deformações por fluência, devidas a tensões em dois instantes diferentes, podem ser consideradas como aditivas, obedecendo a lei da superposição de efeitos.

De acordo com o Código Modelo CEB-FIP 1990 (1993), a superposição linear de deformações é normalmente aceita, quando se trabalham com níveis de tensões menores que $40 \%$ do valor da resistência média à compressão do concreto. Este é o caso do modelo apresentado neste trabalho.

\subsubsection{Lei do tipo integral para fluência}

Para uma história prescrita de tensões, o somatório das respostas lineares de deformação, devidas a todos os pequenos incrementos de tensões uniaxiais aplicados, antes do tempo t, de acordo com a hipótese básica, induz a uma lei do tipo integral para a fluência:

$$
\varepsilon_{\text {tot }}(t)-\varepsilon_{n}(t)=\int_{0}^{t} J(t, \tau) d \sigma(\tau),
$$

onde:

- $\quad$ é a idade do concreto;

- $\sigma$ é a tensão uniaxial;

- $\varepsilon_{\text {tot }}(\mathrm{t})$ é a deformação axial total (inclui as parcelas dependentes e independentes do tempo); 
- $\varepsilon_{\mathrm{n}}(\mathrm{t})$ é a deformação axial inelástica (parcela decorrente da fluência, retração, dilatação térmica, etc);

- $J(t, \tau)$ representa a função de fluência, deformação no tempo, $t$, causada por uma tensão unitária constante, agindo no intervalo entre $\tau$ e t.

A função de fluência, analogamente ao módulo de elasticidade longitudinal dos materiais elásticos, relaciona a tensão aplicada com a deformação ocorrida. Esta, porém, não é apenas um número, mas sim, uma função dependente do tempo e da idade do material, no instante da colocação da carga.

Seja $\sigma(\mathrm{t})$, caracterizado por um valor inicial, $\sigma\left(\mathrm{t}^{\prime}\right)$ para $\tau=\mathrm{t}^{\prime}$, isto é:

$$
\begin{gathered}
\sigma(\mathrm{t})=0, \text { para } \mathrm{t}<\mathrm{t}^{\prime} ; \\
\Delta \sigma\left(\mathrm{t}^{\prime}\right)=\sigma\left(\mathrm{t}^{\prime}\right),
\end{gathered}
$$

pode-se, então, reescrever a equação (6.22), como:

$$
\varepsilon_{\text {tot }}(t)-\varepsilon_{n}(t)=\sigma\left(t^{\prime}\right) J\left(t, t^{\prime}\right)+\int_{t^{+}}^{t} J(t, \tau) d \sigma(\tau)
$$

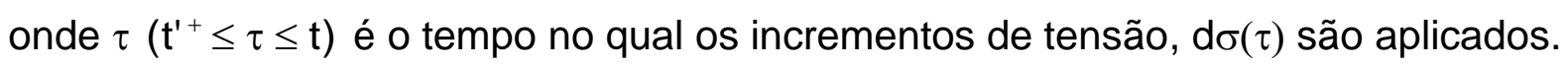

Se $\sigma(\mathrm{t})$ varia em passos discretos, $\Delta \sigma\left(\mathrm{t}_{\mathrm{i}}\right)$, tem-se, então:

$$
\varepsilon_{\text {tot }}(t)-\varepsilon_{n}(t)=\sigma\left(t^{\prime}\right) J\left(t, t^{\prime}\right)+\sum_{i=1}^{n} J\left(t, t_{i}\right) \Delta \sigma\left(t_{i}\right)
$$

\subsubsection{Lei do tipo integral para relaxação}

Para uma história prescrita de deformações, o somatório das respostas lineares de tensão, devidas a todos os pequenos incrementos de deformações 
uniaxiais aplicados, antes do tempo t, de acordo com a hipótese básica, induz uma lei do tipo integral para a relaxação:

$$
\sigma(t)=\int_{0}^{t} R(t, \tau) d\left[\varepsilon_{\text {tot }}(\tau)-\varepsilon_{n}(\tau)\right]
$$

onde $\mathrm{R}(\mathrm{t}, \tau)$ representa a função de relaxação, tensão no tempo, $t$, causada por uma deformação unitária constante, agindo no intervalo entre $\tau$ e t.

Seja a deformação dependente da tensão, $\varepsilon_{\text {tot }}(\mathrm{t})-\varepsilon_{\mathrm{n}}(\mathrm{t})$, caracterizada por um valor inicial, $\varepsilon_{\text {tot }}\left(\mathrm{t}^{\prime}\right)-\varepsilon_{\mathrm{n}}\left(\mathrm{t}^{\prime}\right)$, para $\tau=\mathrm{t}^{\prime}$, isto é:

$$
\begin{gathered}
\varepsilon_{\text {tot }}(\mathrm{t})-\varepsilon_{\mathrm{n}}(\mathrm{t})=0 \text {, para } \mathrm{t}<\mathrm{t}^{\prime} ; \\
\Delta\left[\varepsilon_{\mathrm{tot}}\left(\mathrm{t}^{\prime}\right)-\varepsilon_{\mathrm{n}}\left(\mathrm{t}^{\prime}\right)\right]=\varepsilon_{\text {tot }}\left(\mathrm{t}^{\prime}\right)-\varepsilon_{\mathrm{n}}\left(\mathrm{t}^{\prime}\right),
\end{gathered}
$$

pode-se, então, reescrever a equação (6.26) como:

$$
\sigma\left(t, t^{\prime}\right)=\left[\varepsilon_{\text {tot }}\left(t^{\prime}\right)-\varepsilon_{n}\left(t^{\prime}\right)\right] R\left(t, t^{\prime}\right)+\int_{t^{\prime+}}^{t} R(t, \tau) d\left[\varepsilon_{\text {tot }}(\tau)-\varepsilon_{n}(\tau)\right]
$$

onde $\tau\left(\mathrm{t}^{+} \leq \tau \leq \mathrm{t}\right)$ é o tempo no qual os incrementos de deformação dependente do tempo, $d\left[\varepsilon_{\text {tot }}(\tau)-\varepsilon_{\mathrm{n}}(\tau)\right]$, são aplicados.

Se $\left[\varepsilon_{\text {tot }}(\mathrm{t})-\varepsilon_{\mathrm{n}}(\mathrm{t})\right]$ varia em passos discretos, $\Delta\left[\varepsilon_{\text {tot }}\left(\mathrm{t}_{\mathrm{i}}\right)-\varepsilon_{\mathrm{n}}\left(\mathrm{t}_{\mathrm{i}}\right)\right]$, tem-se, então:

$$
\sigma\left(t, t^{\prime}\right)=\left[\varepsilon_{\text {tot }}\left(t^{\prime}\right)-\varepsilon_{n}\left(t^{\prime}\right)\right] R\left(t, t^{\prime}\right)+\sum_{i=1}^{n} R(t, \tau) d\left[\varepsilon_{\text {tot }}\left(t_{i}\right)-\varepsilon_{n}\left(t_{i}\right)\right]
$$

\subsubsection{Discussão das leis do tipo integral para fluência e relaxação}

Os seguintes aspectos merecem particular atenção:

As equações 6.22 e 6.26, ou 6.24 e 6.27, mostram a importância da determinação das funções de fluência e relaxação. Esta é a razão pela qual os 
resultados de testes com tensão ou deformação "constantes" são, especialmente, interessantes.

Se, ao contrário, a história de deformações, $\varepsilon_{\text {tot }}(\mathrm{t})$, for prescrita na equação 6.22 e a história de tensões, $\sigma(t)$, for prescrita na equação 6.26, estas duas equações representam as equações integrais de Volterra, não-homogêneas, respectivamente, para a história incógnita de tensões e deformações.

Pode-se dizer, então, que as equações 6.22 e 6.26 representam a solução uma da outra, conforme está sintetizado na tabela 6.4:

Tabela 6.4 - Representação das soluções das equações 6.23 e 6.27

\begin{tabular}{|c|c|c}
\hline Problemas, onde: & $\begin{array}{c}\text { Fluência } \\
\mathrm{J}(\mathrm{t}, \tau)\end{array}$ & $\begin{array}{c}\text { Relaxação dada: } \\
(\mathrm{t}, \tau)\end{array}$ \\
\hline \hline $\begin{array}{c}\text { a história de tensões } \\
\text { é prescrita }\end{array}$ & $\begin{array}{c}\varepsilon(\mathrm{t})=\text { ? - integração simples } \\
\text { da equação 6.22, ou 6.24 }\end{array}$ & $\begin{array}{c}\varepsilon(\mathrm{t})=\text { ? - solução da } \\
\text { equação de Volterra, } \\
\text { equação 6.26, ou 6.28 }\end{array}$ \\
\hline $\begin{array}{c}\text { a história de } \\
\text { deformações } \\
\text { é prescrita }\end{array}$ & $\begin{array}{c}\sigma(\mathrm{t})=? \text { - solução da } \\
\text { equação de Volterra, } \\
\text { equação 6.22, ou 6.24 }\end{array}$ & $\begin{array}{c}\sigma(\mathrm{t})=? \text { - integração } \\
\text { simples da equação 6.26, } \\
\text { ou 6.28 }\end{array}$ \\
\hline
\end{tabular}

O caso mais freqüente, onde a solução da equação integral de Volterra é necessária, encontra-se em destaque.

A relação entre as funções de fluência e de relaxação pode ser obtida, considerando-se a história de deformações, como sendo uma função do tipo salto unitário, ou seja:

$$
\begin{aligned}
& \varepsilon_{\text {tot }}(\mathrm{t})-\varepsilon_{\mathrm{n}}(\mathrm{t})=0 \text {, para } \mathrm{t}<\mathrm{t}^{\prime} \\
& \varepsilon_{\text {tot }}\left(\mathrm{t}, \mathrm{t}^{\prime}\right)-\varepsilon_{\mathrm{n}}(\mathrm{t})=1 \text {, para } \mathrm{t} \geq \mathrm{t}^{\prime}
\end{aligned}
$$

em cujo caso, a resposta de tensão é, por definição, $\sigma\left(t, t^{\prime}\right)=R\left(t, t^{\prime}\right)$.

Substituindo-se a resposta de tensão na equação 6.24 e considerando-se que $\mathrm{R}\left(\mathrm{t}^{\prime}, \mathrm{t}^{\prime}\right)=\mathrm{E}_{\mathrm{c}}\left(\mathrm{t}^{\prime}\right)$, tem-se, então: 


$$
1=E_{c}\left(t^{\prime}\right) J\left(t, t^{\prime}\right)+\int_{t^{\prime+}}^{t} J(t, \tau) d R(\tau)
$$

A equação 6.31 representa uma equação integral, não-homogênea, de Volterra, para a determinação da função de relaxação, a partir da função de fluência.

\subsubsection{Inclusão da fluência no modelo}

O modelo reológico, adotado para representar o comportamento viscoelástico do concreto, foi uma cadeia de elementos tipo Maxwell, conforme a figura 6.5. Esta cadeia é formada por uma associação, em paralelo, de elementos compostos por uma mola elástica, em série com um amortecedor viscoso.

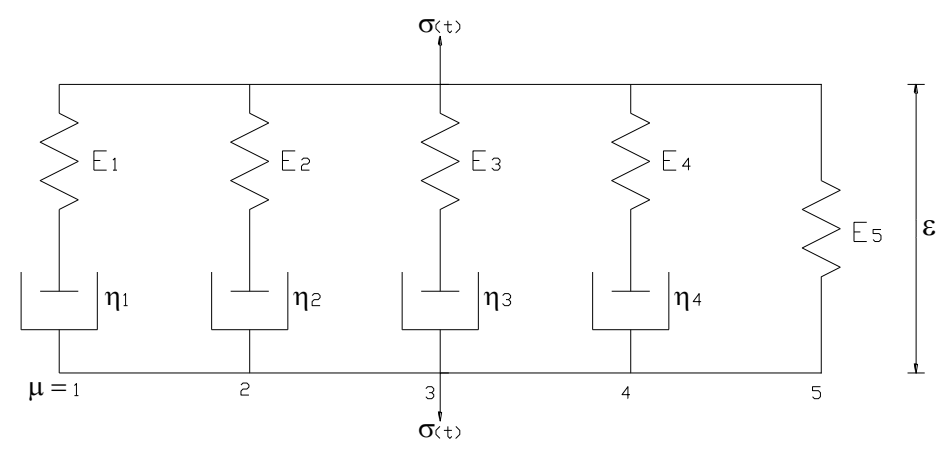

Figura 6.5 - Modelo reológico do concreto

Este modelo é um caso particular do modelo elasto-viscoplástico básico, admitindo-se que todos os elementos de atrito (componentes plásticas do modelo) possuam tensão de plastificação nula.

As molas da unidade, $\mu$, da cadeia têm módulo de elasticidade, $E_{\mu}(t)$, dependente da idade, $t$, do concreto. Já os coeficientes de viscosidade, $\eta_{\mu}(t)$, são caracterizados por:

$$
\eta_{\mu}=\mathrm{E}_{\mu} \tau_{\mu}
$$

onde $\tau_{\mu}$ é o tempo de relaxação da unidade, $\mu$, considerado constante no tempo. 
Bazant \& Wu (1974) desenvolveram um modelo deste tipo, com a finalidade de representar o comportamento viscoelástico, com envelhecimento, do concreto, sob baixos níveis de tensão, de acordo com a hipótese básica apresentada anteriormente. Bazant (1982) propôs, também, um algoritmo, o qual determina, automaticamente, todos os parâmetros, $E_{\mu}(t)$ e $\eta_{\mu}(t)$, para cada idade, $t$, do concreto, a partir de resultados de ensaios ou informações, obtidas em normas, para estruturas de concreto.

\subsubsection{Formulação matemática do modelo de Maxwell}

Neste trabalho, utiliza-se o modelo idealizado por Bazant e Wu (1974). Fairbairn, Longo e Zheng (1987) utilizaram o mesmo modelo e sugeriram o uso de cinco unidades, suficientes para representar o comportamento viscoelástico do concreto. Este modelo é computacionalmente adequado, quando se utiliza uma formulação, baseada em elementos finitos, com integração por intervalos discretos de tempo. Além disso, não necessita que se conheça toda a história de tensões.

Os tempos de relaxação de cada unidade da cadeia, de acordo com o período de tempo que se deseja cobrir, após a aplicação da carga, são obtidos por:

$$
\tau_{\mu}=10^{\mu-1} \tau_{1}, \mu=1, \ldots, 4
$$

Considera-se, na unidade, $\mu=5$, cuja mola não está acoplada a nenhum amortecedor, que $\tau_{5}=10^{30}, \eta_{5} \rightarrow \infty, \tau_{5} \rightarrow \infty$, a fim de tornar a deformação, assintoticamente, convergente, para uma certa data, conforme o comportamento real do concreto.

A tensão, $\sigma(\mathrm{t})$, aplicada na cadeia, pode ser expressa como:

$$
\sigma(t)=\sum_{\mu=1}^{5} \sigma_{\mu}(t)
$$


na qual, $\sigma_{\mu}(t)$ representa a tensão, no tempo, $t$, em um elemento da cadeia de Maxwell.

Estando a mola e o amortecedor em série, pode-se escrever:

$$
\dot{\varepsilon}=\frac{\dot{\sigma}_{\mu}}{E_{\mu}}+\frac{\sigma_{\mu}}{\eta_{\mu}} .
$$

A equação diferencial 6.34 representa a tensão resultante para o elemento de Maxwell, cuja solução é dada por:

$$
\sigma\left(t, t^{\prime}\right)=\sigma_{\mu}\left(t^{\prime}\right) e^{\frac{-\left(t-t^{\prime}\right)}{\tau_{\mu}}}
$$

A função de relaxação do modelo, $\mathrm{R}\left(\mathrm{t}, \mathrm{t}^{\prime}\right)$ representa a tensão resultante para uma deformação unitária, imposta em $\mathrm{t}=\mathrm{t}^{\prime}$ 'e mantida constante para $\mathrm{t}>\mathrm{t}$, dos elementos de Maxwell e pode ser calculada por:

$$
R\left(t, t^{\prime}\right)=\sum_{\mu=1}^{5} E_{\mu}\left(t^{\prime}\right) e^{\frac{-\left(t-t^{\prime}\right)}{\tau_{\mu}}} .
$$

Esta equação traduz o desenvolvimento da função de relaxação, em séries de exponenciais reais, séries de Dirichlet ou séries de Prony. A determinação dos termos $E_{\mu}\left(t^{\prime}\right)$, desta função, pode ser feita a partir de uma função de relaxação, $\tilde{R}\left(t_{i}, t^{\prime}\right)$, cujos valores discretos, nos tempos $t_{i}$, são conhecidos.

\subsubsection{Determinação da função de relaxação, a partir da função de fluência}

Os pontos discretos, $\tilde{\mathrm{R}}\left(\mathrm{t}_{\mathrm{i}}, \mathrm{t}^{\prime}\right)$, são obtidos, geralmente, a partir de funções de fluência, $\mathrm{J}\left(\mathrm{t}, \mathrm{t}^{\prime}\right)$, resolvendo-se, numericamente, a equação 6.29, para uma história conhecida de deformações. As funções de fluência podem ser obtidas em laboratório, ou por expressões analíticas, encontradas em normas, como é o caso 
deste trabalho. Os pontos discretos da função de relaxação também poderiam ser obtidos da mesma maneira.

Para a determinação de $\tilde{R}\left(t_{i}, t^{\prime}\right)$, necessita-se conhecer $J\left(t, t^{\prime}\right)$ para qualquer idade, $t^{\prime}$, de aplicação da carga e a sua duração, $t-t^{\prime}$, dentro da faixa de tempo considerada. Para tanto, são necessárias apenas algumas curvas de fluência. Neste trabalho, adotaram-se oito curvas.

Existem duas aproximações recomendáveis da equação 6.29:

$\checkmark$ a primeira baseia-se em uma regra retangular:

$$
\varepsilon_{\text {tot }}\left(t_{k}\right)-\varepsilon_{n}\left(t_{k}\right)=\sum_{i=1}^{K} J\left(t_{k}, t_{i}\right) \Delta \sigma\left(t_{i}\right)
$$

$\checkmark$ a segunda, em uma regra trapezoidal:

$$
\varepsilon_{\text {tot }}\left(\mathrm{t}_{\mathrm{k}}\right)-\varepsilon_{\mathrm{n}}\left(\mathrm{t}_{\mathrm{k}}\right)=\sum_{\mathrm{i}=1}^{\mathrm{K}} \frac{1}{2}\left[\mathrm{~J}\left(\mathrm{t}_{\mathrm{k}}, \mathrm{t}_{\mathrm{i}}\right)+\mathrm{J}\left(\mathrm{t}_{\mathrm{k}}, \mathrm{t}_{\mathrm{i}-1}\right)\right] \Delta \sigma\left(\mathrm{t}_{\mathrm{i}}\right) .
$$

Neste trabalho, aplicou-se a regra trapezoidal, por induzir uma precisão mais adequada para histórias usuais de deformações.

As equações 6.38 e 6.39 são válidas, inclusive, para incrementos instantâneos de $\varepsilon$ e $\sigma$. Se um incremento instantâneo ocorre num certo tempo, $t_{m}$, basta fixar-se $\Delta t_{m+1}=0$, ou $t_{m+1}=t_{m}$.

As duas aproximações também englobam o caso particular de um incremento instantâneo de tensão, ocorrido em um tempo inicial qualquer, $t_{0}$. Observa-se que $\mathrm{t}_{1}=\mathrm{t}_{0}, \Delta \mathrm{t}_{1}=0, \Delta \sigma\left(\mathrm{t}_{1}\right)=\sigma_{1}$ e deste modo:

$$
\varepsilon_{\text {tot }}\left(\mathrm{t}_{1}\right)-\varepsilon_{\mathrm{n}}\left(\mathrm{t}_{1}\right)=\Delta \varepsilon_{\text {tot }}\left(\mathrm{t}_{1}\right)=\varepsilon_{1}=\mathrm{J}\left(\mathrm{t}_{1}, \mathrm{t}_{1}\right) \sigma_{1} \text {, com } \Delta \varepsilon_{\mathrm{n}}\left(\mathrm{t}_{1}\right)=0 .
$$

Usando-se a regra trapezoidal para aproximar a equação 6.9 , sua solução fica: 


$$
\Delta \tilde{R}_{i}=-\left(J_{i, i}+J_{i, j-1}\right)^{-1} \sum_{j=1}^{i-1} \Delta \tilde{R}_{j}\left(J_{i, j}+J_{i, j-1}-J_{i-1, i}-J_{i-1, j-1}\right),
$$

com:

- $\mathrm{J}_{\mathrm{i}, \mathrm{j}}=\mathrm{J}\left(\mathrm{t}_{\mathrm{i}}, \mathrm{t}_{\mathrm{j}}\right)$;

- $\Delta \tilde{\mathrm{R}}_{1}=\mathrm{E}\left(\mathrm{t}^{\prime}\right)=$ valor inicial

$$
\tilde{R}\left(t_{i}, t^{\prime}\right)=\tilde{R}\left(t_{i-1}, t^{\prime}\right)+\Delta \tilde{R}_{i}
$$

Desta forma, conhecendo-se os valores de $\mathrm{J}\left(\mathrm{t}_{\mathrm{i}}, \mathrm{t}^{\prime}\right)$ para quaisquer valores de t'e $\mathrm{t}-\mathrm{t}$ ', dentro da faixa de tempo considerada, obtêm-se os respectivos valores de $\tilde{\mathrm{R}}\left(\mathrm{t}_{\mathrm{i}}, \mathrm{t}^{\prime}\right)$ nos $\mathrm{N}$ tempos discretos. Entre os valores de $\mathrm{t}^{\prime} \mathrm{e} \mathrm{t}-\mathrm{t}^{\prime}$, considera-se uma variação linear com $\log \left(\mathrm{t}^{\prime}\right) \mathrm{e} \log \left(\mathrm{t}-\mathrm{t}^{\prime}\right)$.

Os valores de $\mathrm{t}-\mathrm{t}$ ', de durações de carga, foram escolhidos por uma razão constante crescente, em escala logarítmica, do tipo:

$$
\left(t_{i}-t^{\prime}\right)=10^{\frac{1}{10}}\left(t_{i-1}-t^{\prime}\right)
$$

onde $\left(\mathrm{t}_{1}-\mathrm{t}^{\prime}\right)=3,52$ dias e $\left(\mathrm{t}_{30}-\mathrm{t}^{\prime}\right)=2224,12 \operatorname{dias}$.

Assim, têm-se três décadas em $\log \left(\mathrm{t}-\mathrm{t}^{\prime}\right)$, com dez passos por década. $\mathrm{E}$, para as idades, t', de carregamento, adotou-se uma faixa de tempo, considerada de boa precisão com respeito à dispersão dos dados de fluência, de forma que:

$$
\mathrm{t}_{\mathrm{i}}=10^{\frac{1}{2}} \mathrm{t}_{\mathrm{i}-1}
$$

para a qual $\mathrm{t}_{1}^{\prime}=2,8$ dias e $\mathrm{t}_{8}^{\prime}=8854,28$ dias, ou seja, quatro décadas em $\log \left(\mathrm{t}^{\prime}\right)$, com dois passos por década. 


\subsubsection{Determinação dos parâmetros $E_{\mu}(t)$ e $\eta_{\mu}(t)$}

A equação da curva de relaxação, para uma idade, $t^{\prime}$, pode ser determinada pelo método dos mínimos quadrados, a partir dos pontos conhecidos, $\widetilde{R}\left(t_{i}, t^{\prime}\right)$. A aplicação deste método é feita através da minimização da soma dos quadrados do desvio, $\phi$, ou seja:

$$
\phi=\sum_{\mathrm{i}=1}^{30}\left[\mathrm{R}\left(\mathrm{t}_{\mathrm{i}}, \mathrm{t}^{\prime}\right)-\tilde{\mathrm{R}}\left(\mathrm{t}_{\mathrm{i}}, \mathrm{t}^{\prime}\right)\right]^{2}+\pi,
$$

sendo $\pi$, o termo residual para melhorar o ajuste da função, definido por:

$$
\pi=\varpi_{1} \sum_{\mu=1}^{3}\left(E_{\mu+1}-E_{\mu}\right)^{2}+\varpi_{2} \sum_{\mu=1}^{2}\left(E_{\mu+2}-2 E_{\mu+1}+E_{\mu}\right)^{2},
$$

onde $\varpi_{1}=0,01$ e $\varpi_{2}=0,08$ representam os pesos adotados para o termo residual.

Substituindo-se a função de relaxação, equação 6.37 , na expressão 6.45 do desvio, sem o termo residual, tem-se:

$$
\phi=\sum_{\mathrm{i}=1}^{30}\left[\sum_{\mu=1}^{5} \mathrm{E}_{\mu}\left(\mathrm{t}^{\prime}\right) \mathrm{e}^{\frac{-\left(\mathrm{t}-\mathrm{t}^{\prime}\right)}{\tau_{\mu}}}-\tilde{\mathrm{R}}\left(\mathrm{t}_{\mathrm{i}}, \mathrm{t}^{\mathrm{t}}\right)\right]^{2} .
$$

As incógnitas $\mathrm{E}_{\mu}\left(\mathrm{t}^{\prime}\right)$ são obtidas através das condições de minimização:

$$
\frac{\partial \phi}{\partial \mathrm{E}_{\mu}}=0, \quad \mu=1, \ldots, 5 .
$$

As equações 6.48 formam um sistema de cinco equações com cinco incógnitas. A resolução deste sistema conduz a valores positivos de $\mathrm{E}_{\mu}\left(\mathrm{t}^{\prime}\right)$, pois a inclinação da curva de relaxação é sempre positiva. Desenvolvendo-se a equação j do sistema 6.48, obtém-se:

$$
\sum_{i=1}^{30}\left[\sum_{\mu=1}^{5} E_{\mu}\left(t^{\prime}\right) e^{\frac{-\left(t-t^{\prime}\right)}{\tau_{\mu}}}-\tilde{R}\left(t_{i}, t^{\prime}\right)\right] \sum_{i=1}^{30} e^{\frac{-\left(t-t^{\prime}\right)}{\tau_{j}}}=0 .
$$


Esta expressão pode ser reescrita da seguinte forma:

$$
\sum_{\mathrm{i}=1}^{30}\left[\sum_{\mu=1}^{5} \mathrm{E}_{\mu}\left(\mathrm{t}^{\prime}\right) \mathrm{e}^{-\left(\frac{\mathrm{t}-\mathrm{t}^{\mathrm{t}}}{\tau_{\mu}}+\frac{\mathrm{t}-\mathrm{t}^{\prime}}{\tau_{\mathrm{j}}}\right)}\right]=\sum_{\mathrm{i}=1}^{30} \tilde{\mathrm{R}}\left(\mathrm{t}_{\mathrm{i}}, \mathrm{t}^{\prime}\right) \mathrm{e}^{\frac{-\left(\mathrm{t}-\mathrm{t}^{\prime}\right)}{\tau_{\mathrm{j}}}}
$$

que, sob a forma matricial, fica:

$$
[A]\{E\}=\{B\},
$$

onde:

- $A_{j k}=\sum_{i=1}^{30} e^{-\left(\frac{t-t^{\prime}}{\tau_{\mu}}+\frac{t-t^{\prime}}{\tau_{j}}\right)}, \quad k=1, \ldots, 5$;

- $E_{j}=E_{j}(t)$;

- $B_{j}=\sum_{i=1}^{30} \tilde{R}\left(t_{i}, t^{\prime}\right) e^{\frac{-\left(t-t^{\prime}\right)}{\tau_{j}}}$

Introduzindo-se o termo residual, $\pi$, nas equações 6.48 , os elementos $A_{j k}$, da matriz $[A]$, devem ser corrigidos da seguinte forma:

$$
\begin{array}{ll}
\mathrm{A}_{1,1}=\mathrm{A}_{1,1}+\varpi_{1}+\varpi_{2} & \mathrm{~A}_{3,1}=\mathrm{A}_{3,1}+\varpi_{2} \\
\mathrm{~A}_{1,2}=\mathrm{A}_{1,2}-\varpi_{1}+2 \varpi_{2} & \mathrm{~A}_{3,2}=\mathrm{A}_{3,2}-\varpi_{1}+4 \varpi_{2} \\
\mathrm{~A}_{1,3}=\mathrm{A}_{1,3}+\varpi_{2} & \mathrm{~A}_{3,3}=\mathrm{A}_{3,3}+2 \varpi_{1}+5 \varpi_{2} \\
\mathrm{~A}_{2,1}=\mathrm{A}_{2,1}-\varpi_{1}-2 \varpi_{2} & \mathrm{~A}_{3,4}=\mathrm{A}_{3,4}-\varpi_{1}-2 \varpi_{2} \\
\mathrm{~A}_{2,2}=\mathrm{A}_{2,2}+2 \varpi_{1}+5 \varpi_{2} & \mathrm{~A}_{4,3}=\mathrm{A}_{4,3}-\varpi_{1}-2 \varpi_{2} \\
\mathrm{~A}_{2,3}=\mathrm{A}_{2,3}-\varpi_{1}-4 \varpi_{2} & \mathrm{~A}_{4,4}=\mathrm{A}_{4,4}+\varpi_{1}+\varpi_{2} . \\
\mathrm{A}_{2,4}=\mathrm{A}_{2,4}+\varpi_{2} &
\end{array}
$$


Resolvendo-se o sistema 6.53, determinam-se os valores dos módulos de elasticidade da cadeia de Maxwell, $E_{\mu}\left(t^{\prime}\right)$, para os valores de $t^{\prime}$, nos quais são dados os pontos discretos $\tilde{\mathrm{R}}\left(\mathrm{t}_{\mathrm{i}}, \mathrm{t}^{\prime}\right)$. Já, para qualquer idade, $\mathrm{t}$, os valores de $E_{\mu}(t)$ são interpolados pela expressão:

$$
E_{\mu}(t)=\left\{E_{\mu}\left(t_{i-1}\right)\left[\log \left(t_{i}\right)-\log (t)\right]+E_{\mu}\left(t_{i}\right)\left[\log (t)-\log \left(t_{i-1}^{\prime}\right)\right] /\left[\log \left(t_{i}\right)-\log \left(t_{i-1}^{\prime}\right)\right],\right.
$$

para $i=2, \ldots, 8$ e $\mu=1, \ldots, 5$.

Conhecidos os valores de $\mathrm{E}_{\mu}$ para as cinco camadas, obtêm-se os respectivos valores de $\eta_{\mu}$, através da expressão 6.54. Assim sendo, com este modelo, tais valores de $E_{\mu}$ e $\eta_{\mu}$ podem ser obtidos para qualquer idade, $t$, do concreto na fase viscoelástica.

\subsubsection{Determinação dos parâmetros da função de fluência}

\subsection{Equação básica}

Como foi visto, anteriormente, para a obtenção da função de relaxação, $\mathrm{R}\left(\mathrm{t}, \mathrm{t}^{\prime}\right)$, necessita-se saber alguns valores da função de fluência, $\mathrm{J}\left(\mathrm{t}, \mathrm{t}^{\prime}\right)$. Neste trabalho, adotou-se a formulação apresentada pelo Código Modelo CEB-FIP 1990 (1993), em que a função de fluência, para uma tensão menor que $0,4 f_{c m}$ e aplicada no tempo t', é dada por:

$$
J\left(t, t^{\prime}\right)=\frac{1}{E_{c}\left(t^{\prime}\right)}+\frac{\phi\left(t, t^{\prime}\right)}{E_{c}}
$$


onde:

- $J\left(t, t^{\prime}\right)$ é a função de fluência, que representa a deformação na idade $t$, causada por uma tensão unitária, atuando a partir do tempo t' ;

- $\mathrm{E}_{\mathrm{c}}\left(\mathrm{t}^{\prime}\right)$ é o módulo de elasticidade na idade $\mathrm{t}^{\prime}$ (em dias) do carregamento;

- $\phi\left(t, t^{\prime}\right)$ é o coeficiente de fluência;

- $\mathrm{E}_{\mathrm{c}}$ é o módulo de elasticidade do concreto aos 28 dias de idade, que pode ser determinado pela expressão:

$$
E_{c}=2,15 \times 10^{4}\left(\frac{f_{c m}}{10}\right)^{\frac{1}{3}},\left[f_{c m}\right] \text { em MPa; }
$$

sendo $\mathrm{f}_{\mathrm{cm}}$ a resistência média à compressão do concreto ao 28 dias de idade. $\mathrm{O}$ valor de $\mathrm{E}_{\mathrm{c}}$ deve ser acrescido de $20 \%$, se o concreto tiver agregados de basalto. Para uma idade, $t^{\prime}$, o módulo de elasticidade, $\mathrm{E}_{\mathrm{c}}\left(\mathrm{t}^{\prime}\right)$, será calculado da seguinte maneira:

$$
E_{c}\left(t^{\prime}\right)=\beta_{c c}\left(t^{\prime}\right)^{\frac{1}{2}} E_{c},
$$

com:

$$
\beta_{\mathrm{cc}}\left(\mathrm{t}^{\prime}\right)=\exp \left\{\mathrm{s}\left[1-\left(28 / \mathrm{t}_{\mathrm{T}}\right)^{0,5}\right]\right\},
$$

onde s é um parâmetro, dependente do tipo de cimento, que vale:

0,20 para cimento de endurecimento rápido e alta resistência inicial

0,25 para cimento de endurecimento rápido e normal

0,38 para cimento de endurecimento lento 


\subsection{Coeficiente de fluência}

O coeficiente de fluência é calculado por:

$$
\phi\left(t, t^{\prime}\right)=\phi_{0} \beta_{c}\left(t-t^{\prime}\right)
$$

onde:

- $\phi_{0}$ é o coeficiente de fluência nominal;

- $\quad \beta_{c}$ é o coeficiente que descreve o desenvolvimento da fluência com o tempo;

- t'é a idade de aplicação da carga;

- $\quad$ é a idade atual, em dias, do concreto.

O coeficiente de fluência nominal, $\phi_{0}$ vale:

$$
\phi_{0}=\phi_{\mathrm{RH}} \beta\left(\mathrm{f}_{\mathrm{cm}}\right) \beta\left(\mathrm{t}^{\prime}\right) \text {, }
$$

sendo:

$$
\phi_{\mathrm{RH}}=1+\frac{1-\mathrm{RH} / 100}{0,46(\mathrm{~h} / 10)^{1 / 3}} \text { e } \quad \mathrm{h}=\frac{2 \mathrm{~A}_{\mathrm{c}}}{\mu},
$$

onde:

- $\mathrm{RH}$ é a umidade relativa do ar em [\%];

- h é a espessura fictícia em [cm];

- $A_{c}$ é a área da seção transversal e $\mu$ é o perímetro de contato com a atmosfera.

$$
\begin{gathered}
\beta\left(f_{\mathrm{cm}}\right)=\frac{5,3}{\left(\mathrm{f}_{\mathrm{cm}} / 10\right)^{0,5}} ; \\
\beta\left(\mathrm{t}^{\prime}\right)=\frac{1}{0,1+\left(\mathrm{t}^{\prime}\right)^{0,2}} .
\end{gathered}
$$


O coeficiente, $\beta_{c}$, que descreve o desenvolvimento da fluência com o tempo, é expresso por:

$$
\beta_{c}\left(t-t^{\prime}\right)=\left[\frac{\left(t-t^{\prime}\right)}{\beta_{H}+\left(t-t^{\prime}\right)}\right]^{0,3},
$$

com:

$$
\beta_{H}=150\left\{1+(1,2 \mathrm{RH} / 100)^{18}\right\} \mathrm{h} / 10+250 \leq 1500 .
$$

\subsection{Efeito do tipo de cimento e variação da temperatura}

No modelo apresentado acima, os efeitos do tipo de cimento e da variação da temperatura ao longo do tempo, sobre as deformações por fluência, são considerados através de correções dos coeficientes e funções descritos acima. Os efeitos de altas ou baixas temperaturas, a maturidade do concreto, devem ser considerados, ajustando-se o valor do tempo, $\mathrm{t}^{\prime}$, conforme:

$$
\mathrm{t}^{\mathrm{t}}=\mathrm{t}_{\mathrm{T}}\left[\frac{9}{2+\left(\mathrm{t}_{\mathrm{T}}\right)^{1,2}}+1\right]^{\alpha} \geq 0,5 \text { dias }
$$

onde o valor de $\alpha$, dependendo do tipo do cimento, vale:

1 para cimento de endurecimento rápido e alta resistência inicial

0 para cimento de endurecimento rápido e normal

-1 para cimento de endurecimento lento

$$
\mathrm{t}_{\mathrm{T}}=\sum_{\mathrm{i}=1}^{\mathrm{n}} \Delta \mathrm{t}_{\mathrm{i}} \exp -\left[\frac{4000}{273+\mathrm{T}\left(\Delta \mathrm{t}_{\mathrm{i}}\right)}-13,65\right]
$$

onde $t_{T}$ é o tempo ajustado, devido a efeitos ocorridos para temperaturas diferentes de $20^{\circ} \mathrm{C}$, compreendidas entre $0^{\circ} \mathrm{C}$ e $80^{\circ} \mathrm{C}$; e $\mathrm{T}\left(\Delta \mathrm{t}_{\mathrm{i}}\right)$ é a temperatura média atuante por um período de $\Delta \mathrm{t}_{\mathrm{i}}$ dias. 
Os coeficientes $\beta_{\mathrm{H}}$ e $\phi_{\mathrm{RH}}$ são corrigidos, respectivamente, por:

$$
\begin{gathered}
\beta_{\mathrm{H}, \mathrm{T}}=\beta_{\mathrm{H}} \beta_{\mathrm{T}} ; \\
\phi_{\mathrm{RH}}=\phi_{\mathrm{T}}+\left(\phi_{\mathrm{RH}}-1\right) \phi_{\mathrm{T}}{ }^{0,5},
\end{gathered}
$$

onde:

$$
\begin{gathered}
\beta_{T}=\exp -\left[\frac{1500}{273+T\left(\Delta t_{i}\right)}-5,12\right] ; \\
\phi_{T}=\exp \left\{0,015\left[T\left(\Delta t_{i}\right)-20\right]\right\} .
\end{gathered}
$$

\subsubsection{Inclusão da retração no modelo}

As deformações por retração do concreto são tratadas como deformações impostas à estrutura. Para isto, determina-se um vetor de forças nodais equivalentes, através da expressão:

$$
\Delta \mathrm{P}_{\mathrm{CS}}=\int_{\mathrm{V}}[\mathrm{B}]^{\top}[\mathrm{D}]\left\{\Delta \varepsilon_{\mathrm{cs}}\right\} \mathrm{dV} .
$$

onde:

$$
\left\{\Delta \varepsilon_{\mathrm{cS}}\right\}=\left\{\begin{array}{c}
\Delta \varepsilon_{\mathrm{cs}} \\
\Delta \varepsilon_{\mathrm{cs}} \\
0
\end{array}\right\} .
$$

A exemplo da fluência, a deformação originada por retração não produz, diretamente, tensões no concreto. Por isso, para a avaliação da tensão no concreto, desconta-se o seu valor da deformação total, que pode ser obtida a partir do vetor de deslocamentos. 


\subsubsection{Determinação dos parâmetros de retração}

As deformações, oriundas do efeito de retração do concreto, podem ser calculadas, conforme o Código Modelo CEB-FIP 1990 (1993), como:

$$
\varepsilon_{c s}\left(t, t_{s}\right)=\varepsilon_{c s 0} \beta_{s}\left(t-t_{s}\right),
$$

onde:

- $\varepsilon_{\mathrm{cs} 0}$ é o coeficiente de retração nominal;

- $\beta_{\mathrm{s}}$ é o coeficiente que descreve o desenvolvimento da retração com o tempo;

- t é a idade do concreto, em dias;

- $\mathrm{t}_{\mathrm{s}}$ é a idade de começo da retração no concreto, em dias.

O coeficiente de retração nominal é obtido por:

$$
\varepsilon_{\mathrm{cs} 0}=\varepsilon_{\mathrm{s}}\left(\mathrm{f}_{\mathrm{cm}}\right) \beta_{\mathrm{RH}},
$$

com:

$$
\varepsilon_{\mathrm{s}}\left(\mathrm{f}_{\mathrm{cm}}\right)=\left[160+10 \beta_{\mathrm{sc}}\left(9-\mathrm{f}_{\mathrm{cm}} / 10\right)\right] \times 10^{-6},
$$

onde $\beta_{\mathrm{sc}}$, dependendo do tipo do cimento, vale:

8 para cimento de endurecimento rápido e alta resistência inicial

5 para cimento de endurecimento rápido e normal

4 para cimento de endurecimento lento 
e,

$$
\beta_{\mathrm{RH}}\left(\mathrm{f}_{\mathrm{cm}}\right)=\left\{\begin{array}{cl}
-1,55(1-\mathrm{RH} / 100)^{3} & \text { para } 0 \% \leq \mathrm{RH} \leq 99 \% \\
0,25 & \text { para } \mathrm{RH}>99 \%
\end{array}\right.
$$

O valor do coeficiente de desenvolvimento da retração no tempo, $\beta_{\mathrm{s}}$, pode ser calculado através da expressão:

$$
\beta_{s}\left(t-t_{s}\right)=\left[\frac{\left(t-t_{s}\right)}{\alpha_{s t}+\left(t-t_{s t}\right)}\right]^{0,5}
$$

com:

$$
\alpha_{s t}=350\left(\frac{h^{2}}{10}\right)
$$

Os efeitos da variação da temperatura são, também, levados em consideração no cálculo da deformação por retração, através de correções nos coeficientes $\alpha_{\mathrm{st}}$ e $\beta_{\mathrm{RH}}$, tais como:

$$
\alpha_{s t}=350\left(\frac{h^{2}}{10}\right) \exp \left\{-0,06\left[T\left(\Delta t_{i}\right)-20^{\circ} \mathrm{C}\right]\right\}
$$

e

$$
\beta_{\mathrm{RH}, \mathrm{T}}=\beta_{\mathrm{RH}} \beta_{\mathrm{st}}
$$

com:

$$
\beta_{\mathrm{st}}=1+\left(\frac{8}{103-\mathrm{RH}}\right)\left[\frac{\mathrm{T}\left(\Delta \mathrm{t}_{\mathrm{i}}\right)-20^{\circ} \mathrm{C}}{40}\right]
$$




\subsection{Critério de Fissuração}

\subsubsection{Critério de ruptura}

Neste trabalho, utiliza-se o critério de ruptura proposto por Ottosen (1977) para identificar a situação de fissuração do concreto. Este critério de ruptura foi adotado pelo Código Modelo CEB-FIP 1990 (1993) e é expresso por:

$$
\alpha \frac{J_{2}}{f_{c m}^{2}}+\lambda \frac{\sqrt{J_{2}}}{f_{c m}}+\beta \frac{l_{1}}{f_{c m}}-1=0,
$$

onde $\mathrm{f}_{\mathrm{cm}}$ é a resistência média à compressão do concreto e:

$$
\begin{gathered}
\lambda=c_{1} \cos \left[1 / 3 \arccos \left(-c_{2} \operatorname{sen} 3 \theta\right)\right], \text { para sen } 3 \theta \leq 0 \\
\lambda=c_{1} \cos \left[\pi / 3-1 / 3 \arccos \left(c_{2} \operatorname{sen} 3 \theta\right)\right], \text { para sen } 3 \theta>0,
\end{gathered}
$$

com

$$
\operatorname{sen} 3 \theta=-\frac{3 \sqrt{3}}{2} \frac{J_{3}}{J_{2}^{3 / 2}}
$$

e,

$$
\begin{gathered}
\mathrm{I}_{1}=\sigma_{1}+\sigma_{2}+\sigma_{3} \\
\mathrm{~J}_{2}=\frac{1}{6}\left[\left(\sigma_{1}-\sigma_{2}\right)^{2}+\left(\sigma_{2}-\sigma_{3}\right)^{2}+\left(\sigma_{3}-\sigma_{1}\right)^{2}\right] \\
\mathrm{J}_{3}=\left(\sigma_{1}-\sigma_{\mathrm{m}}\right)\left(\sigma_{2}-\sigma_{\mathrm{m}}\right)\left(\sigma_{3}-\sigma_{\mathrm{m}}\right) \\
\sigma_{\mathrm{m}}=\mathrm{I}_{1} / 3
\end{gathered}
$$


Os quatro parâmetros do modelo são determinados a partir da resistência média à compressão uniaxial do concreto $f_{\mathrm{cm}}$ e da resistência média à tração uniaxial do concreto $\mathrm{f}_{\mathrm{tm}}$, dada por

$$
\begin{gathered}
f_{t m}=a\left(\frac{f_{c m}-8}{10}\right)^{2 / 3}, \text { em MPa } \\
0,95 \leq a \leq 1,85
\end{gathered}
$$

Conforme o CEB (1993), a resistência à tração do concreto é mais variável que a sua resistência à compressão e pode ser reduzida substancialmente por efeitos ambientais. Desta forma o valor médio proposto é por demais cauteloso e, para comparações com valores experimentais, preferiu-se adotar $\mathrm{a}=1,85$, conforme Dantas (2000). Além disto, a diferença de $8 \mathrm{MPa}$ entre $\mathrm{f}_{\mathrm{cm}}$ e $\mathrm{f}_{\mathrm{ck}}$, proposta pelo CEB, é exagerada para concretos de baixa resistência. Achou-se mais conveniente adotar para este valor, uma fração de $f_{c m}(20 \%)$.

Sendo assim, a resistência média à tração adotada no modelo foi:

$$
f_{t m}=1,85\left(\frac{0,8 f_{c m}}{10}\right)^{2 / 3}
$$

Os parâmetros do critério de Ottosen são então calculados por

$$
\begin{gathered}
\alpha=\frac{1}{9 k^{1,4}} \\
\beta=\frac{1}{3,7 k^{1,1}} \\
c_{1}=\frac{1}{0,7 k^{0,9}} \\
c_{2}=1-6,8(k-0,07)^{2}
\end{gathered}
$$


onde

$$
\mathrm{k}=\frac{\mathrm{f}_{\mathrm{tm}}}{\mathrm{f}_{\mathrm{cm}}}
$$

O critério de ruptura de Ottosen, se forem adotados $\beta=\mathrm{c}_{2}=0$, ou, então, $\alpha=$ $\mathrm{c}_{2}=0$, reduz-se aos critérios de Von Mises ou Drucker-Prager, respectivamente.

As figuras 6.6 a e b representam a forma geral da superfície de ruptura do concreto, podendo ser vista por seus meridianos, e suas seções transversais. Para um material isotrópico e com mesmas resistências à tração e compressão, a superfície de ruptura apresenta tríplice simetria com origem em 0 , tornando-se necessário o estudo de apenas meio setor com $0^{\circ} \leq \theta \leq 30^{\circ}$. Como o concreto possui resistência à tração muito menor do que à compressão, mas considerando que este é um material isotrópico, continua havendo tal simetria, porém a origem passa a não ser mais em 0 e o setor a ser estudado agora é de $-30^{\circ} \leq \theta \leq 30^{\circ}$.

Desta forma, a superfície de ruptura do concreto:

$\checkmark$ é dependente dos três invariantes de tensão $\left(\mathrm{I}_{1}, \mathrm{~J}_{2}, \mathrm{~J}_{3}\right)$;

$\checkmark$ tem uma forma é suave e convexa, com exceção do seu vértice;

$\checkmark$ tem meridianos que são parabólicos e que abrem no sentido negativo do eixo hidrostático;

possui seções transversais que mudam, de uma forma triangular para circular, com o aumento da pressão hidrostática. 


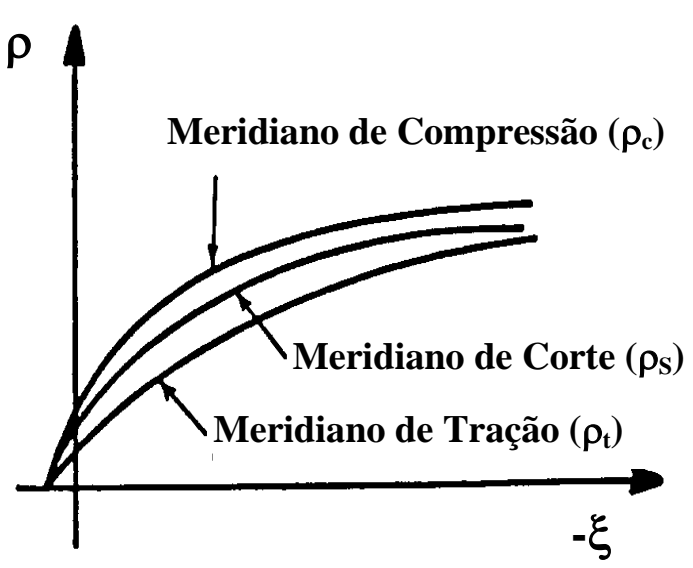

Figura 6.6 a - Meridianos da superfície de ruptura

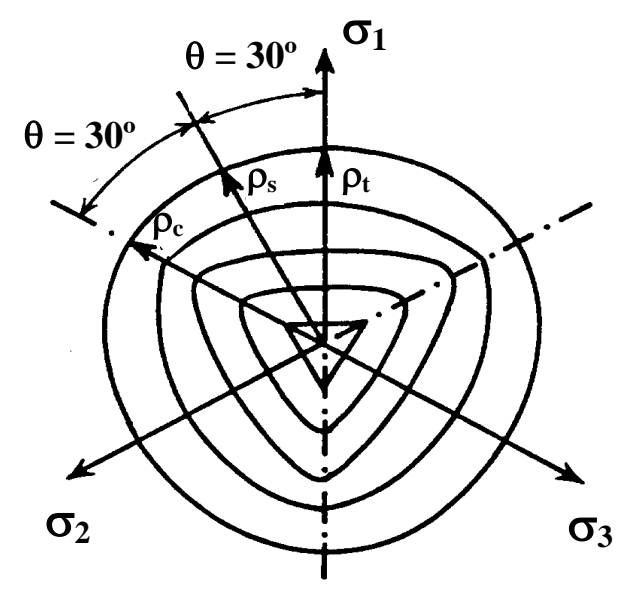

Figura 6.6 b - Seções tranversais da superfície de ruptura

\subsubsection{Comportamento pós-fissuração}

A relação tensão-deformação do concreto, quando submetido a tensões de tração, deve ser expressa por duas relações: uma relação tensão-deformação, que traduza o comportamento do concreto não fissurado, e uma relação tensão-abertura das fissuras, que descreva as deformações que ocorrem no concreto fissurado.

O Código Modelo CEB-FIP 1990 (1993) apresenta uma relação tensãoabertura das fissuras, $\sigma-\mathrm{w}$, para o concreto fissurado, como pode ser observado na figura 6.7. Representar de forma adequada esta relação é de fundamental importância para a análise de uma peça tracionada de concreto.

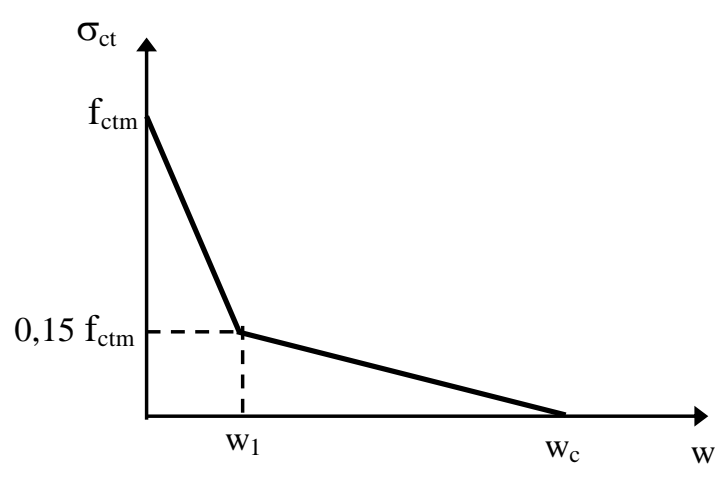

Figura 6.7 - Relação bilinear da tensão-abertura de fissuras 
A relação bilinear, sugerida pelo Código Modelo, reproduz bem o comportamento experimental observado em laboratório e tem seus parâmetros determinados através das seguintes expressões para o concreto não fissurado:

$$
\begin{aligned}
& \checkmark \text { para } \sigma \leq 0,9 \mathrm{f}_{\mathrm{ctm}} \text { : } \\
& \qquad \sigma_{\mathrm{ct}}=\mathrm{E}_{\mathrm{c}} \cdot \varepsilon_{\mathrm{ct}} \\
& \checkmark \text { para } 0,9 \mathrm{f}_{\mathrm{ctm}} \leq \sigma_{\mathrm{ct}} \leq \mathrm{f}_{\mathrm{ctm}}: \\
& \sigma_{\mathrm{ct}}=\mathrm{f}_{\mathrm{ctm}}-\frac{0,1 \mathrm{f}_{\mathrm{ctm}}}{0,00015-\frac{0,9 \mathrm{f}_{\mathrm{ctm}}}{\mathrm{E}_{\mathrm{c}}}}\left(0,00015-\varepsilon_{\mathrm{ct}}\right)
\end{aligned}
$$

onde:

- $\mathrm{E}_{\mathrm{c}}$ : Módulo de elasticidade tangente (MPa)

- $f_{c t m}$ : resistência à tração

- $\sigma_{\mathrm{ct}}$ : tensão de tração $(\mathrm{MPa})$

- $\varepsilon_{\mathrm{ct}}$ : deformação de tração

E as seguintes expressões para o concreto fissurado:

$$
\begin{array}{r}
\checkmark \text { para } 0,15 \mathrm{f}_{\mathrm{ctm}} \leq \sigma_{\mathrm{ct}} \leq \mathrm{f}_{\mathrm{ctm}}: \\
\sigma_{\mathrm{ct}}=\mathrm{f}_{\mathrm{ctn}}\left(1-0,85 \frac{\mathrm{w}}{\mathrm{w}_{1}}\right) \\
\checkmark \text { para } 0 \leq \sigma_{\mathrm{ct}} \leq 0,15 \mathrm{f}_{\mathrm{ctm}}: \\
\sigma_{\mathrm{ct}}=\frac{0,15 \mathrm{f}_{\mathrm{ctn}}}{\mathrm{w}_{\mathrm{c}}-\mathrm{w}_{1}}\left(\mathrm{w}_{\mathrm{c}}-\mathrm{w}\right)
\end{array}
$$


sendo:

$$
\begin{gathered}
w_{1}=2 \frac{G_{F}}{f_{c t m}}-0,15 w_{c} \\
w_{c}=\beta_{F} \frac{G_{F}}{f_{c t m}}
\end{gathered}
$$

onde:

- $\mathrm{w}_{1}$ : abertura da fissura $(\mathrm{mm})$

- $\mathbf{w}_{\mathrm{c}}$ : abertura da fissura para $\sigma_{\mathrm{ct}}=0$

- $\mathrm{G}_{\mathrm{F}}$ : energia de fratura $\left(\mathrm{Nm} / \mathrm{m}^{2}\right)$

- $\beta_{\mathrm{F}}$ : coeficiente que depende do tamanho máximo do agregado, cujos valores podem ser observados na tabela 6.5

A energia de fratura, $G_{F}$, por sua vez, pode ser calculada a partir de seguinte expressão:

$$
G_{F}=\alpha_{F}\left(\frac{f_{c t m}}{10}\right)^{0,7}
$$

onde $\alpha_{F}$ é um coeficiente que depende do tamanho máximo do agregado, também fornecido na tabela 6.5 .

Tabela 6.5 - Valores dos coeficientes $\alpha_{F}$ e $\beta_{F}$

\begin{tabular}{c|c|c}
\hline \hline$d_{\text {máx }}(\mathrm{mm})$ & $\alpha_{F}$ & $\beta_{F}$ \\
\hline 8 & 0,02 & 8 \\
\hline 16 & 0,03 & 7 \\
\hline 32 & 0,05 & 5 \\
\hline \hline
\end{tabular}




\section{ALGORITMO PROPOSTO PARA ANÁLISE DO CONCRETO}

\section{NAS PRIMEIRAS IDADES}

\subsection{Considerações gerais}

Neste capítulo é detalhado o desenvolvimento do modelo computacional, baseado no método dos elementos finitos, para análise do comportamento de estruturas de concreto nas primeiras idades. Através deste modelo busca-se acompanhar a evolução da fissuração, avaliando a elevação da temperatura, devido ao calor de hidratação e a secagem da mesma, através da difusão da umidade no interior de estrutura, as tensões desenvolvidas, devidas à questão térmica e de difusão, e a problemas mecânicos.

Uma breve explicação sobre o funcionamento geral do programa, as diferentes análises disponibilizadas pelo mesmo, entrada e saída de dados, bem como os modelos finitos utilizados para o concreto e a incorporação das análises em seqüência são apresentados nos itens a seguir. 


\subsection{Elementos finitos}

Conforme o programa implementado, os materiais podem ser modelado por três elementos finitos isoparamétricos quadrangulares: um linear e dois quadráticos, um da família Serendipity e outro da família de Lagrange, Owen e Hinton (1980). Estes possuem quatro, oito e nove nós, respectivamente, com dois graus de liberdade em cada nó, correspondentes às translações na direção dos eixos xy do sistema global de coordenadas, como pode ser observado na figura 7.1.

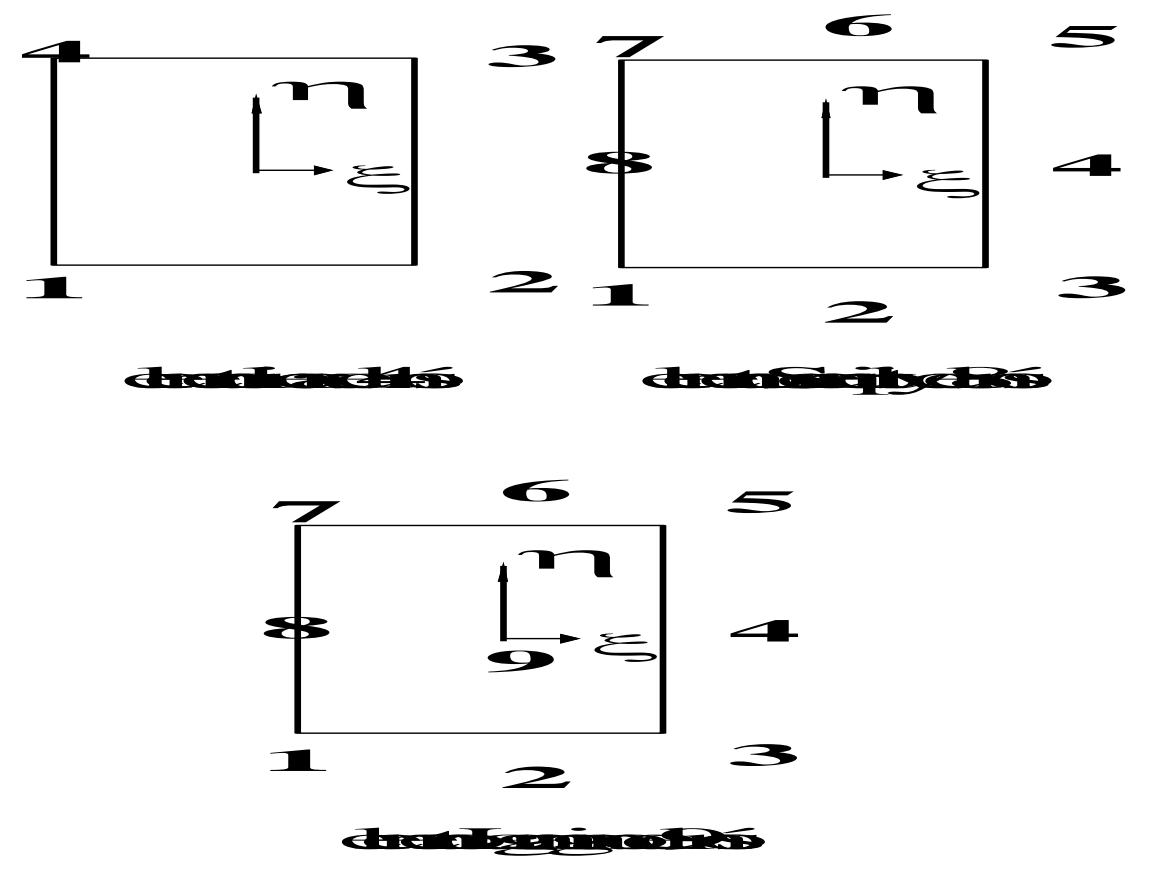

Figura 7.1 - Elementos isoparamétricos quadrangulares

Para o elemento linear, o campo de deslocamentos possui variação linear e o de deformações é constante ao longo dos lados do elemento. Para os outros elementos (8 e 9 nós), o campo de deslocamento possui variação quadrática e o de deformações, variações lineares

As funções de interpolação (ou de forma), que têm como variáveis independentes as coordenadas normalizadas $(\xi, \eta)$ e a numeração dos nós, conforme indicado na figura 7.1, são: 
a) Elemento linear

$$
N_{i}=1 / 4\left(1+\xi_{0}\right)\left(1+\eta_{0}\right), \quad i=1,2,3,4
$$

onde $\xi_{0}=\xi \xi_{\mathrm{i}}, \eta_{0}=\eta \eta_{\mathrm{i}}$ e $\left(\xi_{\mathrm{i}}, \eta_{\mathrm{i}}\right)$ são as coordenadas naturais do nó em consideração.

b) Elemento quadrático da família Serendipity

- para os nós de canto:

$$
N_{i}=1 / 4\left(1+\xi_{0}\right)\left(1+\eta_{0}\right)\left(\xi_{0}+\eta_{0}-1\right), \quad i=1,3,5,7
$$

- para os nós de meio de lado

$$
N_{i}=\xi_{i}^{2} / 2\left(1+\xi_{0}\right)\left(1-\eta^{2}\right)+\eta_{i}^{2} / 2\left(1+\eta_{0}\right)\left(1-\xi^{2}\right), \quad i=2,4,6,8
$$

c) Elemento quadrático de Lagrange

- para os nós de canto:

$$
N_{i}=1 / 4\left(\xi^{2}+\xi_{0}\right)\left(\eta^{2}+\eta_{0}\right), \quad i=1,3,5,7
$$

- para os nós de meio de lado:

$$
N_{i}=1 / 2 \eta_{i}^{2}\left(\eta^{2}-\eta_{0}\right)\left(1-\xi^{2}\right)+1 / 2 \xi_{i}^{2}\left(\xi^{2}-\xi_{0}\right)\left(1-\eta^{2}\right), \quad i=2,4,6,8
$$

- para o nó central:

$$
N_{i}=\left(1-\xi^{2}\right)\left(1-\eta^{2}\right), \quad i=9
$$

Trabalhando com elementos isoparamétricos, pode-se representar as coordenadas cartesianas $(\mathrm{x}, \mathrm{y})$, de um ponto no interior deste elemento, como

$$
\left\{\begin{array}{l}
x \\
y
\end{array}\right\}=\sum_{i=1}^{n}\left[\begin{array}{cc}
N_{i} & 0 \\
0 & N_{i}
\end{array}\right] \cdot\left\{\begin{array}{l}
x_{i} \\
y_{i}
\end{array}\right\}
$$

na qual $N_{i}$ é a função de forma correspondente ao nó i do elemento de coordenadas cartesianas $\left(x_{i}, y_{i}\right)$ e $n$ é o número de nós do elemento. 
A matriz de rigidez para o concreto é dada por

$$
\left[\mathrm{K}_{\mathrm{c}}\right]=\int_{\mathrm{V}}[\mathrm{B}]^{\mathrm{T}}[\mathrm{D}][\mathrm{B}] \mathrm{d} V
$$

e, pode ser calculada numericamente através da expressão

$$
\left[K_{c}\right]=\sum_{i=1}^{n g} \sum_{j=1}^{n g}\left[B_{i j}\right]^{\top}[D]\left[B_{i j}\right] w_{i} w_{j} e_{i j} \operatorname{det} J
$$

onde:

- $\quad$ ng é o número de pontos de integração em cada direção do elemento;

- $\left[\mathrm{B}_{\mathrm{i}}\right]$ é a matriz de relações deformações-deslocamentos calculadas no ponto de integração com coordenadas naturais $\left(\xi_{\mathrm{i}, \mathrm{j}}, \eta_{\mathrm{i}, \mathrm{j}}\right)$;

- [D] é a matriz constitutiva elástica para estado plano de tensão;

$$
[D]=\frac{E}{1-v^{2}}\left[\begin{array}{ccc}
1 & v & 0 \\
v & 1 & 0 \\
0 & 0 & (1-v) / 2
\end{array}\right]
$$

onde

- E: módulo de elasticidade longitudinal

- $\quad$ : coeficiente de Poisson;

- $\mathrm{w}_{\mathrm{i}}, \mathrm{w}_{\mathrm{j}}$ : fatores de peso;

- $e_{\mathrm{i} j}$ : espessura no ponto de integração;

- det J: determinante da matriz Jacobiana do elemento, calculada por

$$
[J]=\left[\begin{array}{ll}
\frac{\partial x}{\partial \xi} & \frac{\partial y}{\partial \xi} \\
\frac{\partial x}{\partial \eta} & \frac{\partial y}{\partial \eta}
\end{array}\right]=\left[\begin{array}{ll}
\sum_{i=1}^{n} \frac{\partial N_{i}}{\partial \xi} x_{i} & \sum_{i=1}^{n} \frac{\partial N_{i}}{\partial \xi} y_{i} \\
\sum_{i=1}^{n} \frac{\partial N_{i}}{\partial \eta} x_{i} & \sum_{i=1}^{n} \frac{\partial N_{i}}{\partial \eta} y_{i}
\end{array}\right]
$$


As coordenadas naturais e fatores de peso dos pontos de integração encontram-se em Owen e Hinton (1977).

\subsection{EACB - Programa Early Age Concrete's Behavior}

De modo bastante conciso, pode-se resumir o funcionamento do programa EACB - Programa Early Age Concrete's Behavior, implementado neste trabalho, através do fluxograma mostrado na figura 7.2.

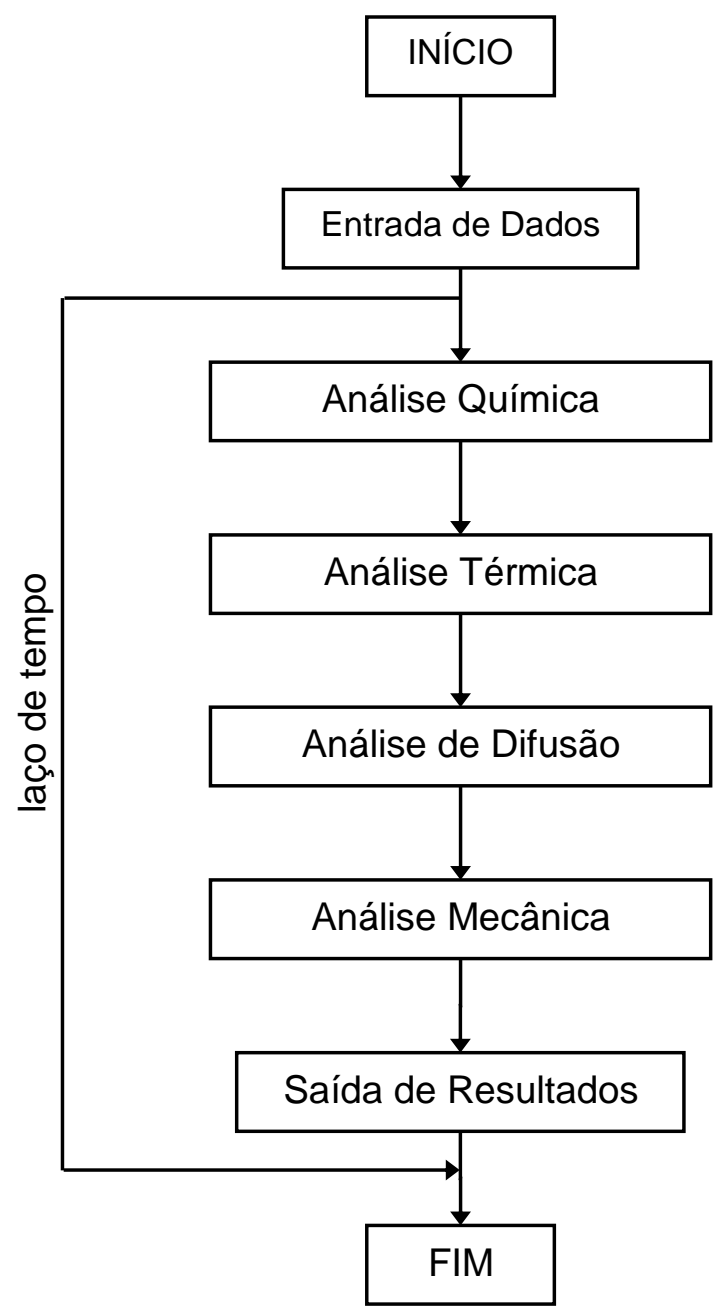

Figura 7.2 - Fluxograma básico do algoritmo de solução do EACB. 
O programa desenvolvido para o presente trabalho possibilita três diferentes tipos de análise: axissimétrica, estado plano de tensão e estado plano de deformação. Pode-se escolher entre os três tipos de elementos finitos já apresentados na figura 7.1 e os materiais utilizados na análise.

O programa gera sua própria malha de elementos finitos, bem como suas conetividades, e a saída dos resultados é apresentada através de um outro programa de visualização.

\subsubsection{Entrada de dados}

$\mathrm{Na}$ questão da entrada de dados, o programa exige somente as dimensões da estrutura a ser analisada e as propriedades dos materiais que constituem a mesma.

Para a montagem da malha de elementos finitos deve ser especificado 0 número de elementos na horizontal e na vertical, e a espessura/largura de cada elemento, como pode ser observado na figura 7.3.

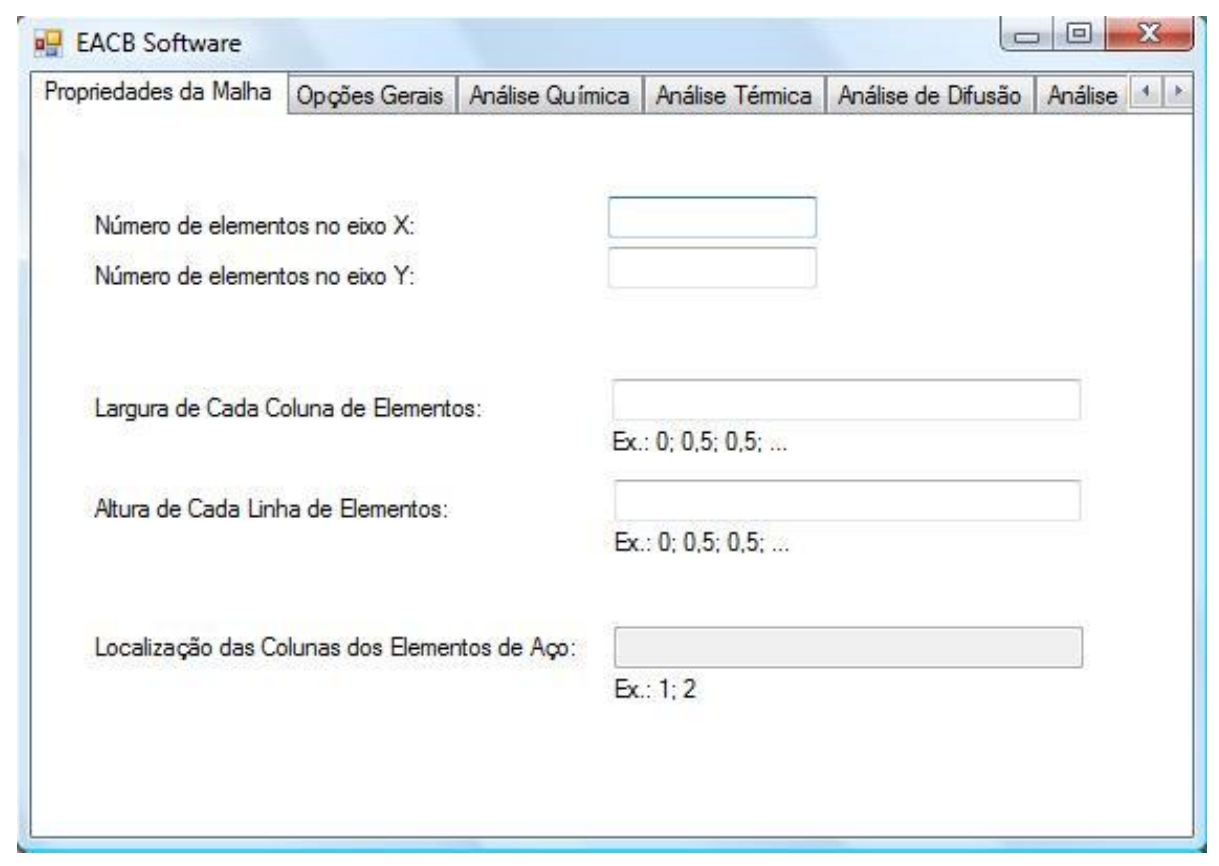

Figura 7.3 - Propriedades da malha de elementos finitos 
A figura 7.4 apresenta as opções gerais do programa, como o tipo de análise a ser efetuada, o tempo a ser considerado na simulação, bem como alguns nós específicos para impressão de temperatura e umidade pontuais, com a finalidade de posterior comparação.

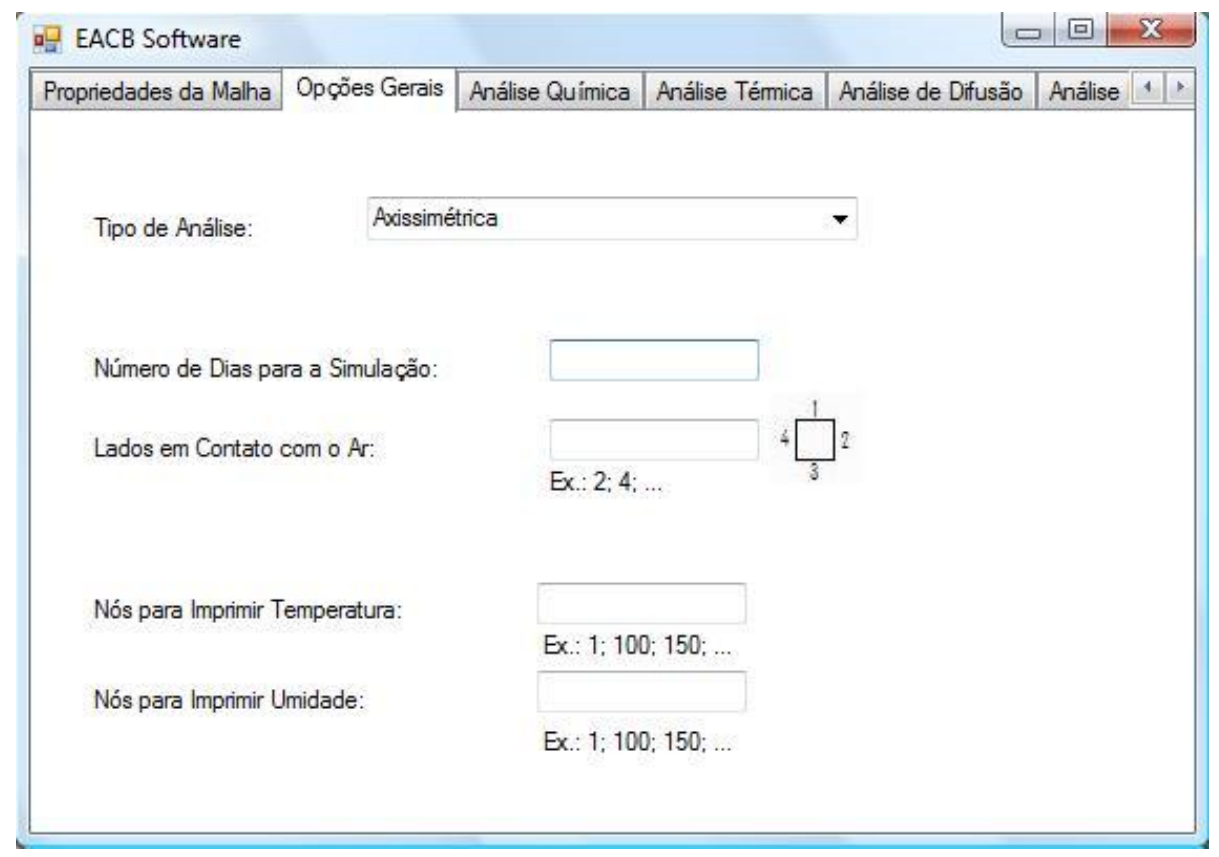

Figura 7.4 - Opções gerais do programa

Cada uma das quatro análises exige diferentes propriedades dos materiais constituintes, tornando-se necessária, portanto, a particularizar a entrada de dados para cada análise. A tabela 7.1 mostra as propriedades dos materiais necessárias para cada análise.

Tabela 7.1 - Propriedades dos materiais requeridas para cada análise

\begin{tabular}{c|c}
\hline ANÁLISE & PROPRIEDADES \\
\hline Química & $\checkmark$ Elevação adiabática da temperatura \\
\hline \multirow{2}{*}{ Térmica } & $\checkmark$ Coeficiente de condutividade térmica \\
& $\checkmark$ Coeficiente de convecção \\
& $\checkmark$ Capacidade térmica \\
\hline
\end{tabular}


Tabela 7.1 - Propriedades dos materiais requeridas para cada análise (cont.)

\begin{tabular}{c||c}
\hline \hline \multicolumn{1}{c|}{ ANÁLISE } & PROPRIEDADES \\
\hline \hline Difusão de Umidade & $\checkmark$ Coeficiente de difusão \\
& $\checkmark$ Fator de transferência de massa \\
\hline \hline Mecânica & $\checkmark$ Módulo de elasticidade \\
& $\checkmark$ Coeficiente de Poisson \\
\hline \hline
\end{tabular}

\subsubsection{Análise química}

O calor gerado pelas reações exotérmicas de hidratação do cimento é determinado por uma curva de elevação adiabática da temperatura do concreto. Nos termos do presente trabalho, pode-se escolher entre a curva proposta pelo JSCE ou uma curva específica fornecida pelo usuário, determinada a partir de dados experimentais.

Esta análise gera uma carga volumétrica, numa analogia perfeita com peso próprio, mas no lugar de uma força, gera calor. Este calor gerado pelo aumento de temperatura no interior do corpo é dado de entrada para a próxima etapa, a análise térmica. 


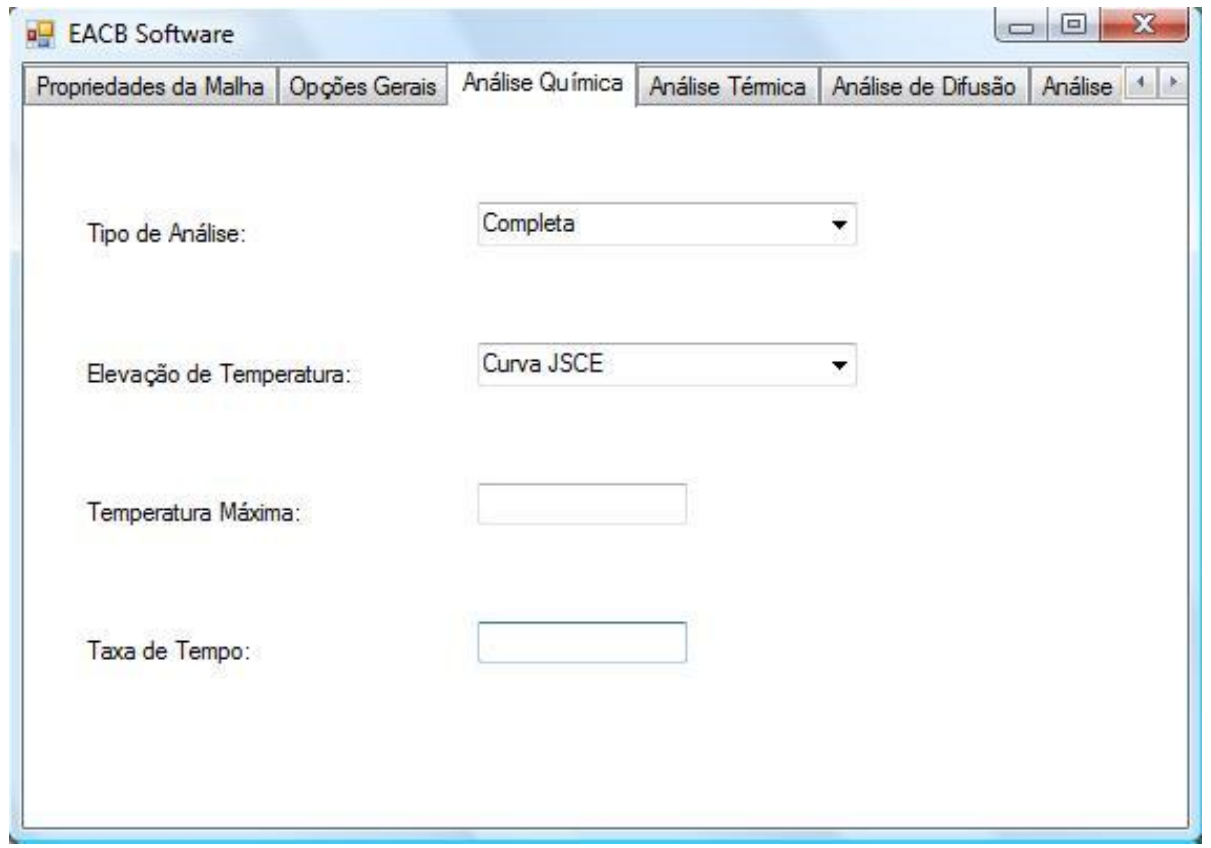

Figura 7.5 - Análise química

\subsubsection{Análise térmica}

A figura 7.6 apresenta as propriedades necessárias para a análise térmica.

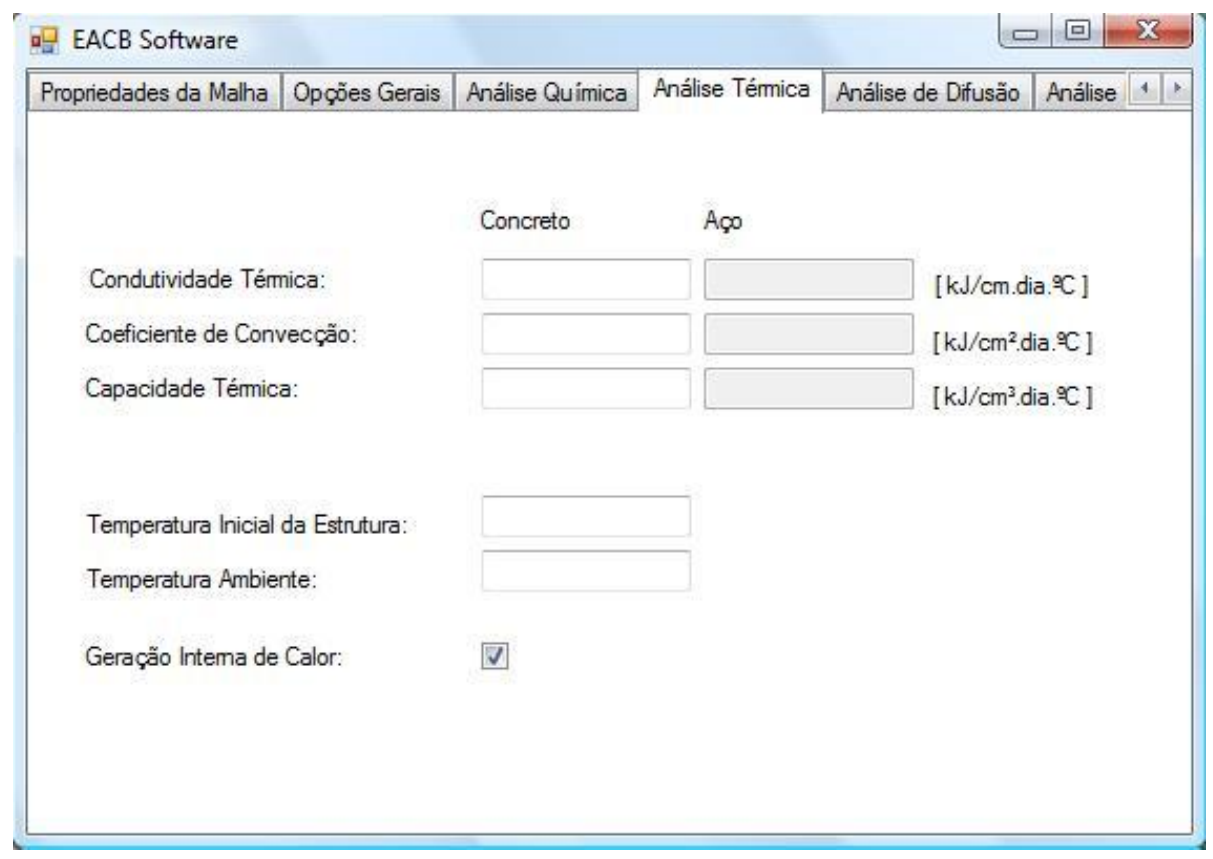

Figura 7.6 - Análise térmica 
$\mathrm{Na}$ análise química foi determinado o calor por unidade de volume em decorrência do processo químico de hidratação do concreto. Na análise térmica este calor é transformado em valores nodais equivalentes. Considerando que a temperatura do corpo e do ambiente são distintas, o programa considera o fluxo de calor devido a esta diferença, também calculando o valor nodal equivalente.

A partir dos coeficientes de condutividade térmica dos materiais e da geometria do corpo em estudo é determinada a matriz que relaciona calor nodal e temperatura. De posse dos valores nodais equivalentes de calor e desta matriz, calculam-se as temperaturas nodais.

Estes valores de temperatura nodais são dados de entrada para a última etapa de solução, a análise mecânica.

\subsubsection{Análise da difusão de umidade}

A consideração da distribuição de água num meio poroso, e da difusão da mesma no interior do corpo de concreto é considerada importantíssima para a correta determinação da retração, fluência e o efeito dos mesmos sobre tensões, deformações e formação de fissuras. Desta forma, a aplicação das leis da difusão de Fick na etapa anterior à execução da análise mecânica é fundamental.

As propriedades requeridas para a análise de difusão de umidade podem ser observadas na figura 7.7 .

Analogamente à analise térmica, é determinada a matriz que relaciona as propriedades de difusibilidade dos materiais e a geometria do elemento em estudo. De posse dos valores equivalentes nodais de umidade relativa e desta matriz, calcula-se o valor nodal da umidade relativa.

Estes valores, por sua vez, também são dados de entrada para a análise mecânica. 


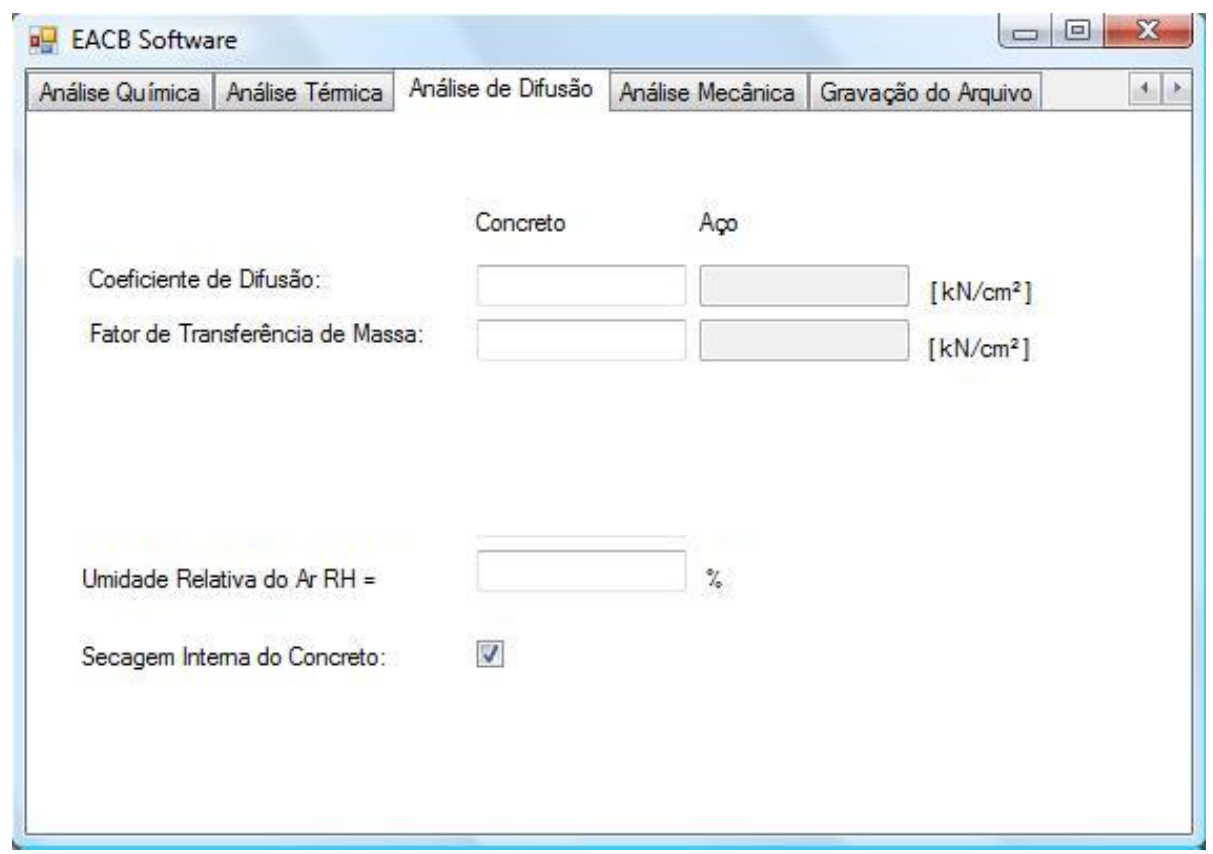

Figura 7.7 - Análise de difusão de umidade

\subsubsection{Análise mecânica}

Por último executa-se a análise mecânica. No modelo de análise de tensões são consideradas as temperaturas e umidades relativas determinadas nas etapas anteriores, e calculadas as deformações de origem térmica, por retração e por fluência do concreto.

Foi, também, implementado no programa um critério de fissuração e um modelo constitutivo para o concreto fissurado.

A figura 7.8 apresenta as propriedades requeridas para esta análise. 


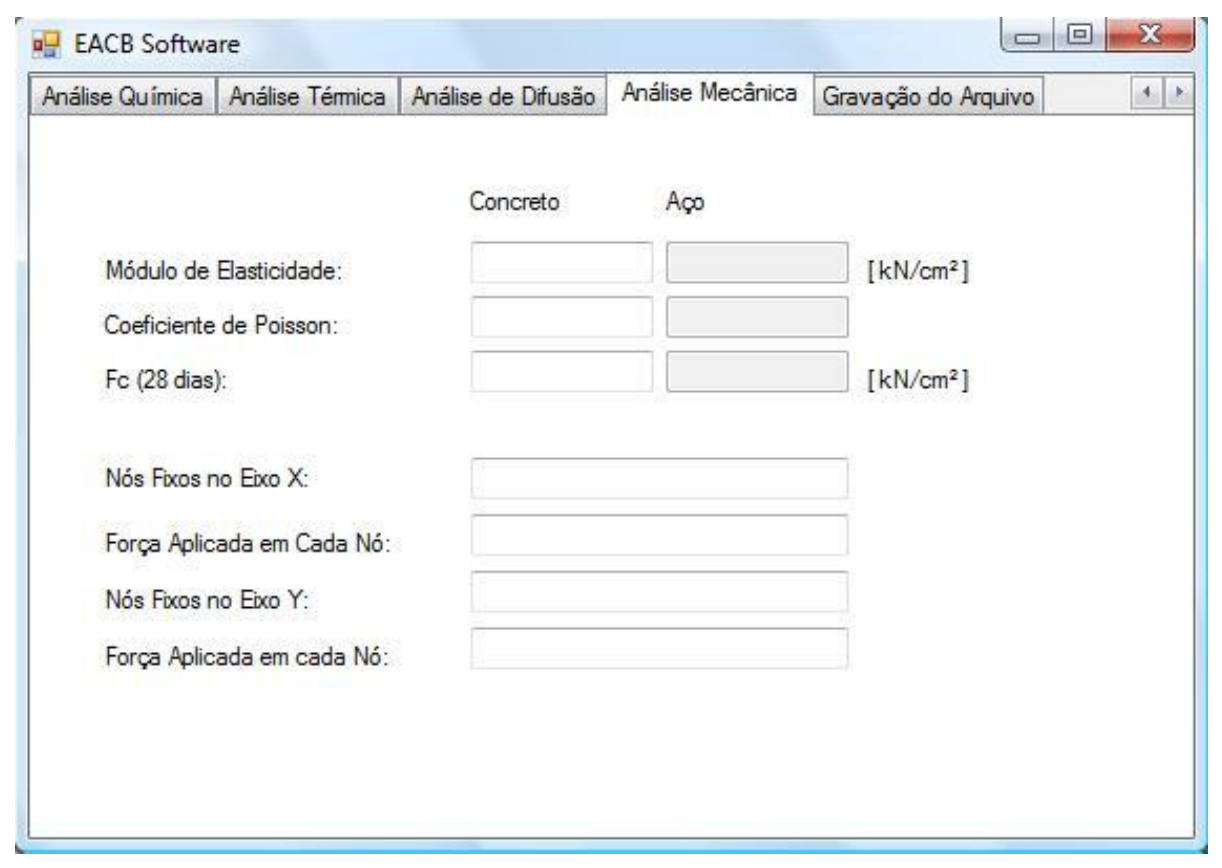

Figura 7.8 - Análise mecânica

\subsubsection{Saída de resultados}

Após a entrada de todos os dados, o programa gera o arquivo e procede à execução das análises. A figura 7.8 mostra a tela de gravação do arquivo de dados.

Os resultados podem ser apresentados pelo programa de duas formas: tabelas ou mapas de resultados. A impressão dos resultados sob forma de tabela é utilizada para posteriores comparações, utilizando, por exemplo, valores de temperatura, umidade, deslocamentos, tensões ou aberturas de fissuras, em nós pré-estabelecidos.

Para a apresentação dos resultados sob forma de mapas e facilitar a interpretação dos valores apresentados sob forma de tabelas utiliza-se o programa GiD - pre and post processor. Este programa foi desenvolvido na Universidade da Cataluña para visualização de resultados de análises por elementos finitos. 


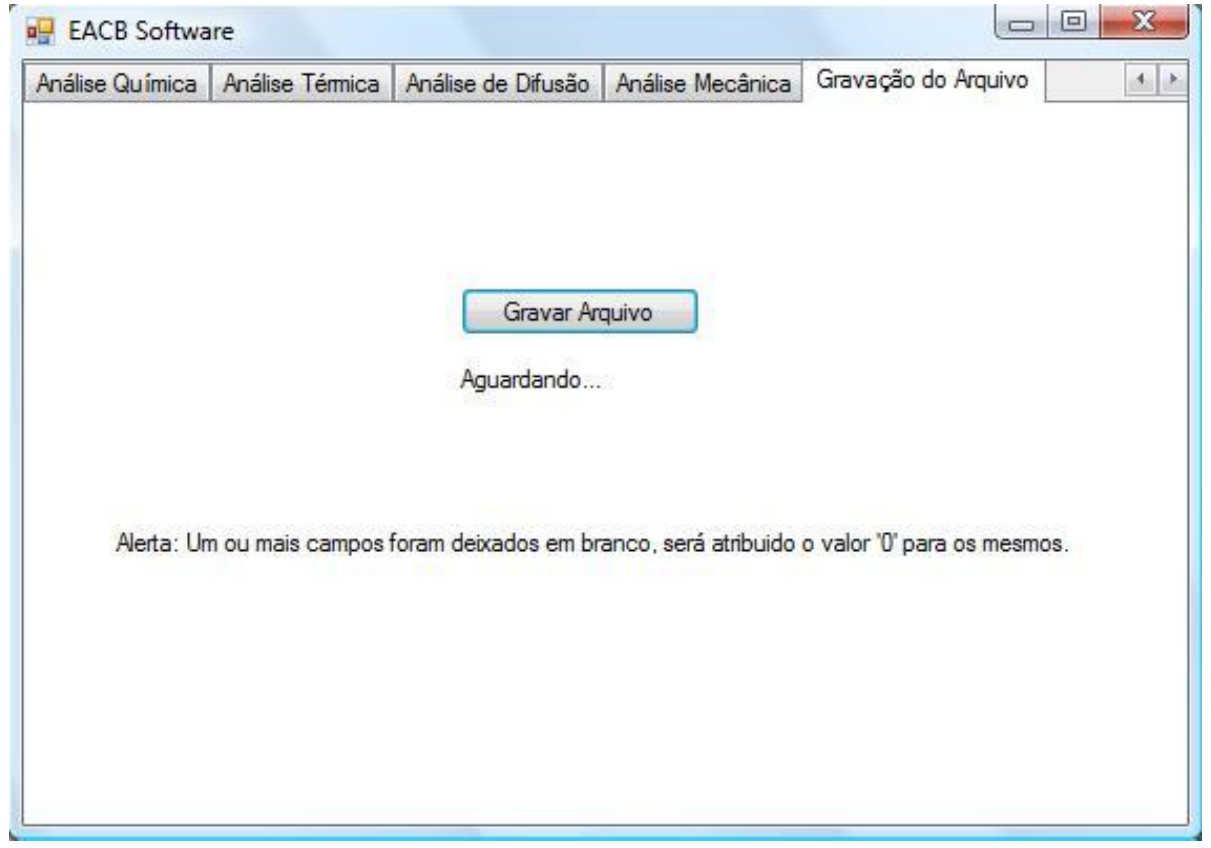

Figura 7.9 - Tela de gravação do arquivo de dados 


\section{CAPÍTULO 8}

\section{APLICAÇÕES NUMÉRICAS}

\subsection{Introdução}

Apresentam-se, neste capítulo, aplicações numéricas das metodologias descritas ao longo deste trabalho. É efetuado, através do algoritmo computacional desenvolvido, o acoplamento das análises térmica, de difusão de umidade e mecânica, simulando o comportamento de peças de concreto que apresentam problemas de fissuração já nas primeiras idades. As aplicações abrangerão a análise dos seguintes elementos:

$\checkmark$ anéis de concreto, comparando os resultados de ensaios realizados em laboratório com as previsões, obtidas através do modelo computacional, para a data de fissuração e abertura das fissuras;

$\checkmark$ prismas de concreto, estudando o efeito da variação da relação água/cimento, e conseqüente resistência à tração, comparando, novamente, resultados de ensaios com os obtidos pelo modelo computacional, para tensões atuantes e data de fissuração.

$\checkmark$ tetrápode de concreto, apresentando os resultados obtidos para os problemas de fissuração usualmente associados a este tipo de peça. 


\subsection{Anéis de concreto}

\subsubsection{Descrição geral}

Grzybowski e Shah (1990) desenvolveram um ensaio utilizando um corpo de prova tipo anel para simular a fissuração do concreto com retração restringida. 0 ensaio consiste em um anel de concreto limitado internamente por um anel de aço, onde são colocados strain-gages para a medição de deformações, e um microscópio externo para a determinação de medidas de abertura de fissura. Os ensaios propostos pelos autores foram realizados no laboratório ACBM (Center for Advanced Cement-Based Materials na Northwestern University, Evanston, Illinois), e tiveram por objetivo a comparação de diferentes aditivos redutores de fissuração por retração no concreto nas primeiras idades. As dimensões dos anéis ensaiados podem ser observadas na figura 8.1.

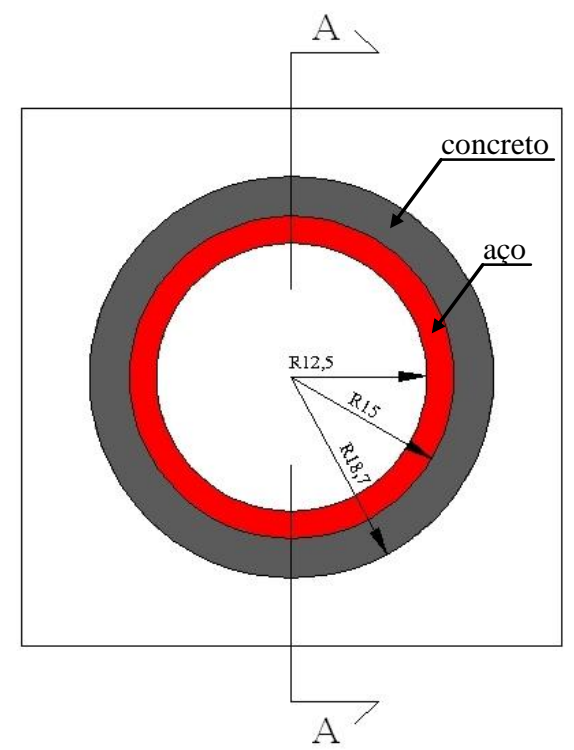

\section{Corte AA:}

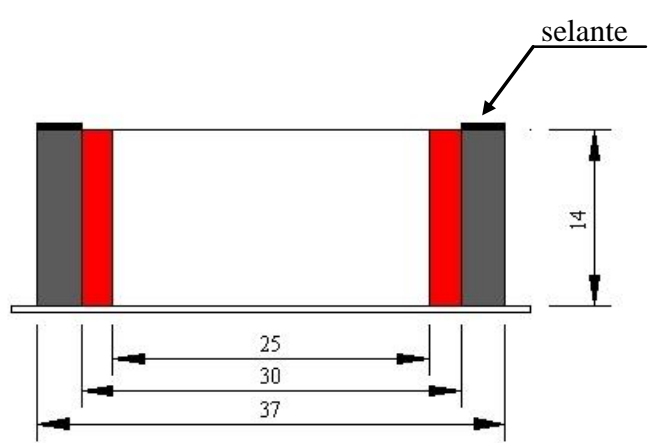

Figura 8.1 - Dimensões dos anéis ensaiados (cotas em cm)

$\mathrm{Na}$ câmara de ensaio, a temperatura ambiente de $20^{\circ} \mathrm{C}$ e a umidade relativa do ar de $40 \%$ foram mantidas constantes durante a realização dos experimentos. 
Para a determinação dos parâmetros relacionados aos materiais foram utilizados os corpos de prova mostrados nas figuras 8.2 , 8.3 e 8.4.

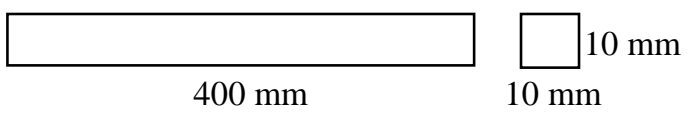

Figura 8.2 - Dimensões do corpo de prova usado para determinação da retração livre

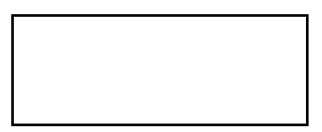

$225 \mathrm{~mm}$

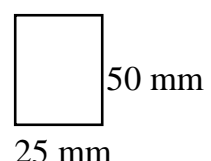

$25 \mathrm{~mm}$

Figura 8.3 - Dimensões do corpo de prova usado para determinação dos parâmetros de fratura

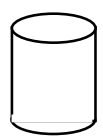

$150 \mathrm{~mm}$

$75 \mathrm{~mm}$

Figura 8.4 - Dimensões do corpo de prova usado para determinação da resistência à compressão

A figura 8.5 ilustra o ensaio, a posição dos strain-gages para medição das deformações e os anéis de aço e concreto finalizados para o ensaio.
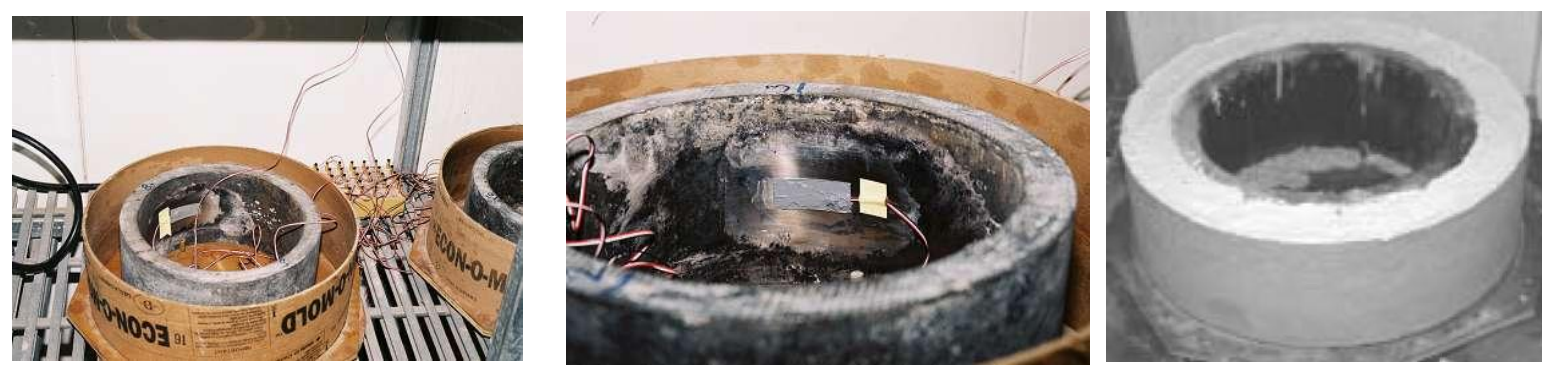

Figura 8.5 - Forma para o anel de concreto, posição dos strain-gages no anel de aço e o anel de concreto finalizado para ser ensaiado

Para a análise dos resultados obtidos pelo algoritmo, o presente trabalho estuda dois anéis ensaiados por Shah, Karaguler e Sarigaphuti (1993) e Shah et al (1994). Apresentam-se resultados para elevação da temperatura e da difusão da umidade no interior dos mesmos, bem como a evolução das tensões, e a comparação da data de formação da fissura e abertura da mesma. 


\subsubsection{Geometria e parâmetros utilizados na modelagem computacional}

Para a discretização do problema, foram utilizadas duas malhas de elementos finitos, uma com 42 elementos e outra, mais refinada, com 168 elementos, como pode ser observado na figura 8.6.

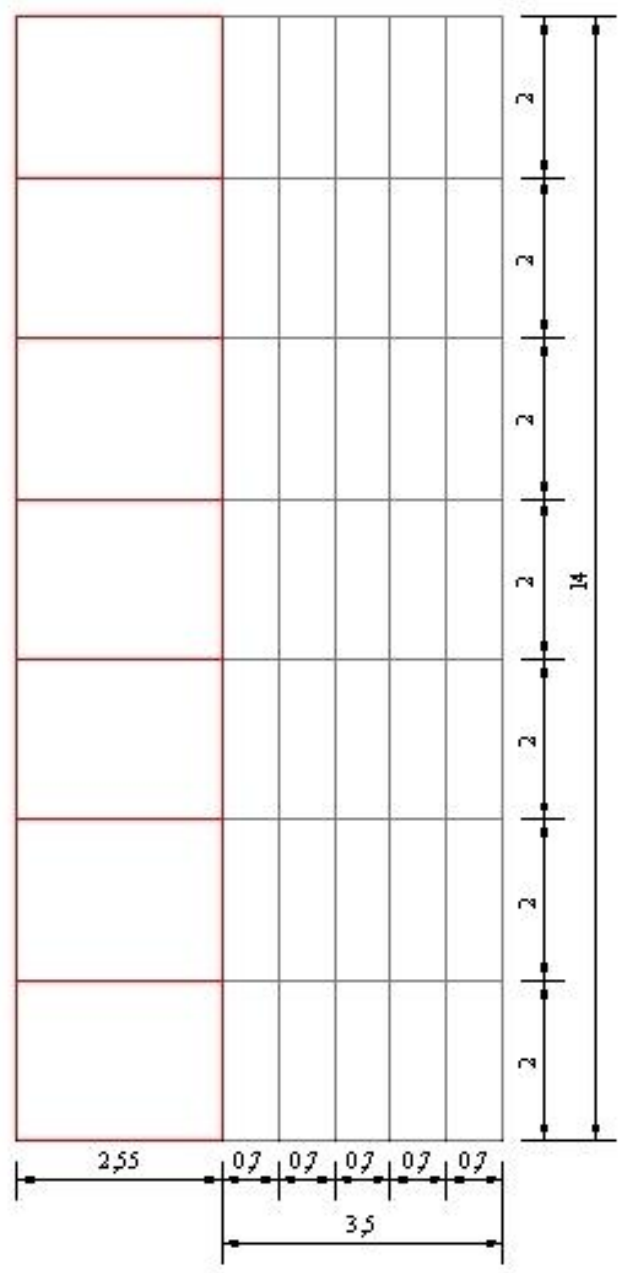

(a)

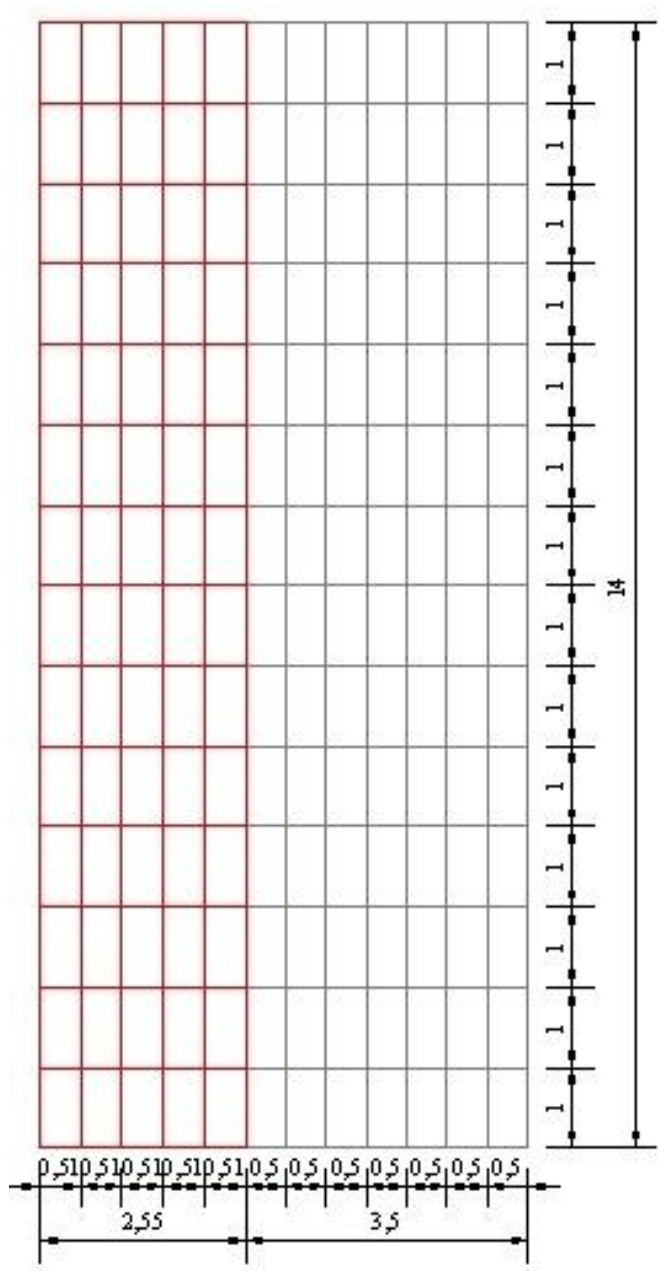

(b)

Figura 8.6 - Malhas de elementos finitos utilizadas: (a) 42 elementos

(b) 168 elementos

As condições de contorno utilizadas para a análise axissimétrica de cada uma das etapas de solução, térmica, de difusão de umidade e mecânica, são mostradas nas figuras 8.7, 8.8 e 8.9, respectivamente. 


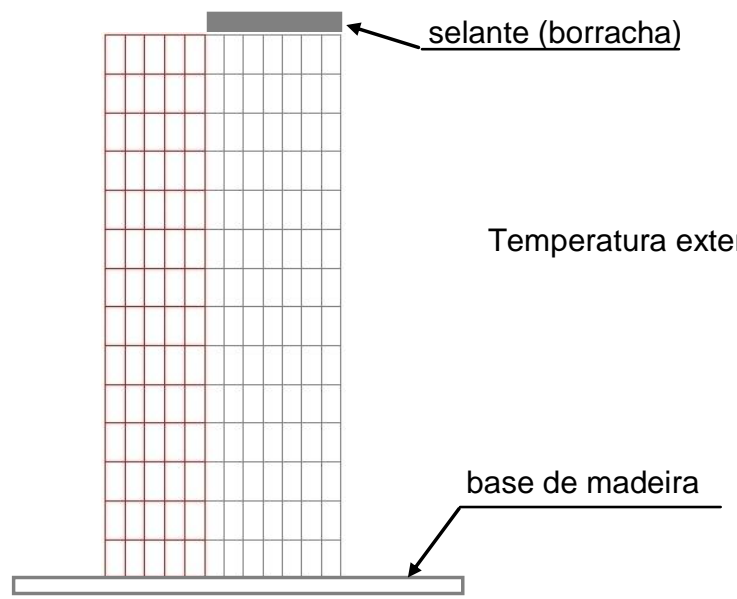

Figura 8.7 - Condições de contorno para a análise térmica

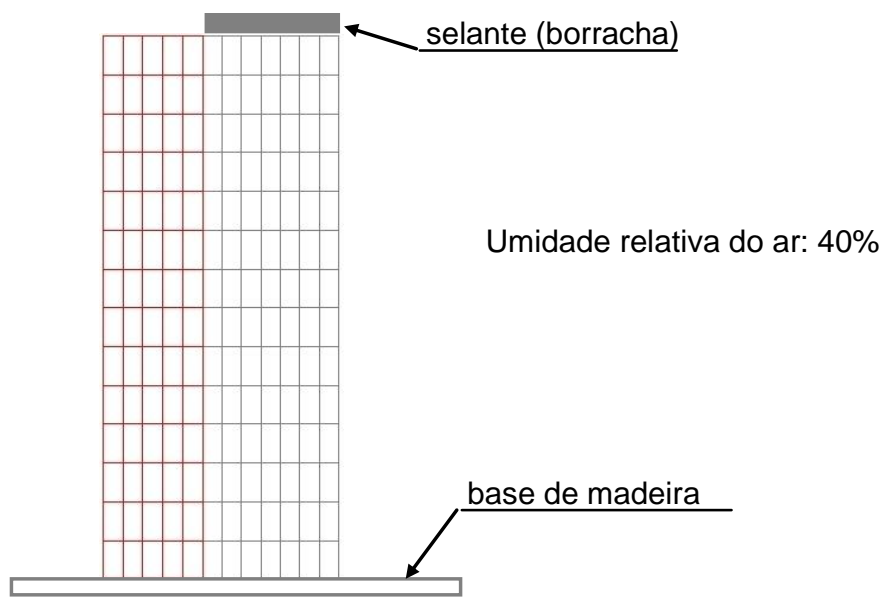

Figura 8.8 - Condições de contorno para a análise de difusão de umidade

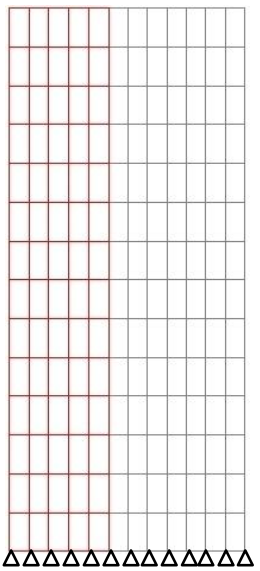

Figura 8.9 - Condições de contorno para a análise mecânica

Os parâmetros utilizados na análise térmica, de difusão de umidade e mecânica, para os dois ensaios de anéis estudados, são indicados, respectivamente, nas tabelas $8.1,8.2$ e 8.3 . 
Tabela 8.1 - Propriedades Térmicas dos Materiais

\begin{tabular}{ccc}
\hline \hline Propriedade & Concreto & Aço \\
\hline Condutividade Térmica & 2,33 & 45,55 \\
{$\left[\mathrm{~kJ} / \mathrm{cm}\right.$. dia. $\left.{ }^{\circ} \mathrm{C}\right]$} & & \\
Coeficiente de Convecção & 0,12 & \\
{$\left[\mathrm{~kJ} / \mathrm{cm}^{2}\right.$. dia. $\left.{ }^{\circ} \mathrm{C}\right]$} & & \\
Capacidade Térmica & & 0,419 \\
{$\left[\mathrm{~kJ} / \mathrm{cm}^{3}\right.$. dia $]$} & 1,16 & \\
\hline \hline
\end{tabular}

Tabela 8.2 - Propriedades de Difusão de Umidade dos Materiais

\begin{tabular}{c|c|c}
\hline \hline Propriedade & Concreto & Aço \\
\hline Coeficiente de Difusão \\
{$\left[\mathrm{m}^{2} / \mathrm{s}\right]$} & 0,06048 & $1.10^{-9}$ \\
\hline $\begin{array}{c}\text { Fator de Transferência de } \\
\text { Massa }\end{array}$ & 3,33 & - \\
\hline \hline
\end{tabular}

Tabela 8.3 - Propriedades Mecânicas dos Materiais

\begin{tabular}{ccc}
\hline Propriedade & Concreto & Aço \\
\hline $\begin{array}{cc}\text { Módulo de Elasticidade } \\
{\left[\mathrm{kN} / \mathrm{cm}^{2}\right]}\end{array}$ & $2500($ anel 1$)$ & 20000 \\
Coeficiente de Poisson & $3500($ anel 2$)$ & \\
Resistência à Compressão (28 dias) & 3,034 (anel 1) & \\
{$\left[\mathrm{kN} / \mathrm{cm}^{2}\right]$} & 3,556 (anel 2) & - \\
\hline
\end{tabular}




\subsubsection{Resultados do modelo térmico}

As figuras 8.10 e 8.11 mostram a evolução da temperatura para dois nós, P1, localizado no interior do anel de concreto, e P2, localizado na superfície externa do mesmo, para as duas malhas ensaiadas. Pode-se constatar que os resultados da análise térmica são idênticos para as duas malhas, concluindo-se assim, que a malha de 42 elementos já é suficientemente refinada para produzir resultados precisos.

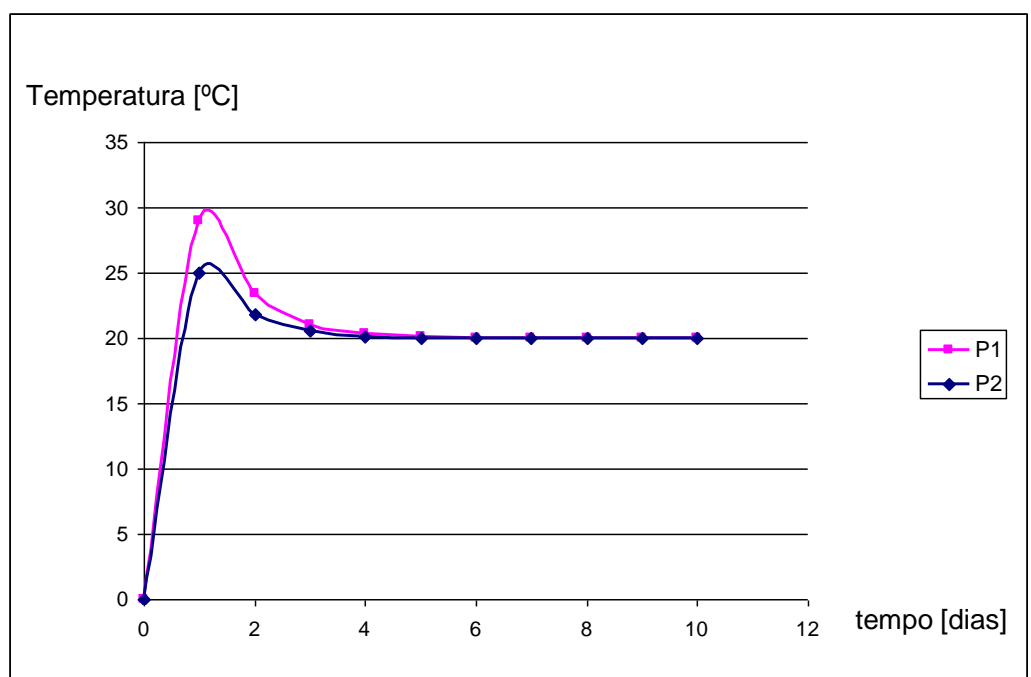

Figura 8.10 - Evolução da temperatura nos pontos P1 e P2, utilizando a malha 1 (42 elementos)

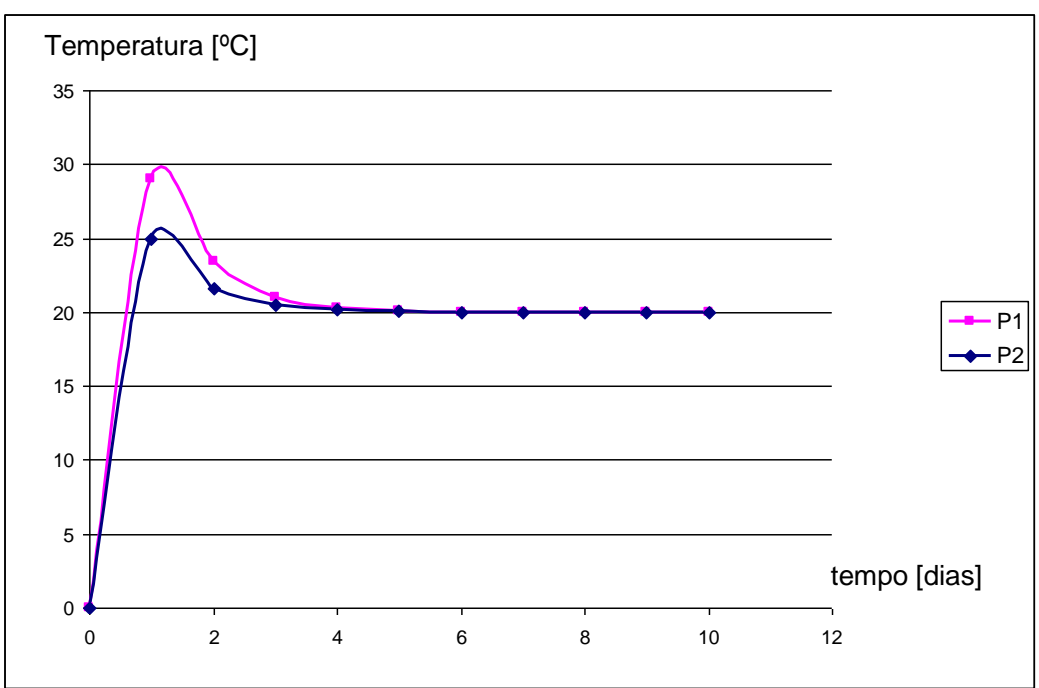

Figura 8.11 - Evolução da temperatura nos pontos P1 e P2, utilizando a malha 2 (168 elementos) 
Os mapas de evolução da temperatura, em instantes selecionados, são apresentados na figura 8.12. Observa-se que os picos de temperatura, decorrentes do calor gerado pelas reações de hidratação do cimento na análise química, ocorrem na região central do anel de concreto. Isto já havia sido constatado nas figuras 8.10 e 8.11, onde o nó P1, localizado no interior do anel de concreto, alcançou uma temperatura mais alta que o nó P2, localizado na superfície externa. Nota-se, também, que ao quinto dia a temperatura do anel de concreto já se uniformizou com a do ambiente.

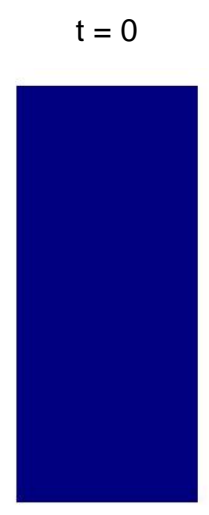

$\mathrm{t}=4$ dias

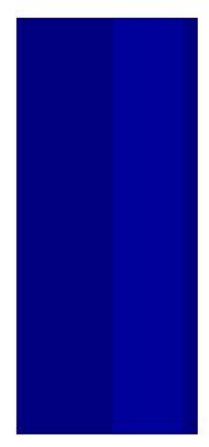

$t=1$ dia

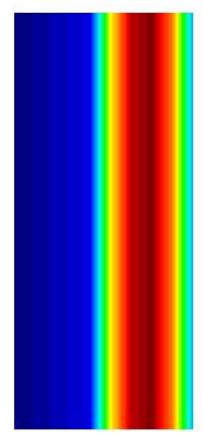

$\mathrm{t}=5$ dias

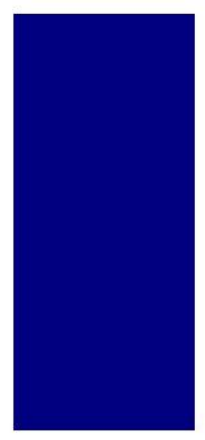

$\mathrm{t}=2$ dias

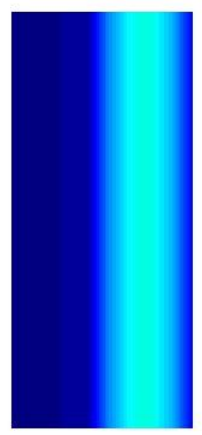

$\mathrm{t}=8$ dias

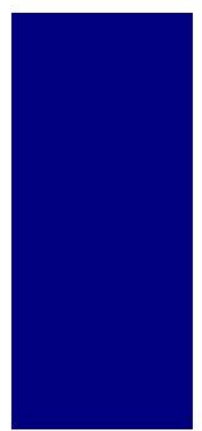

$\mathrm{t}=3$ dias
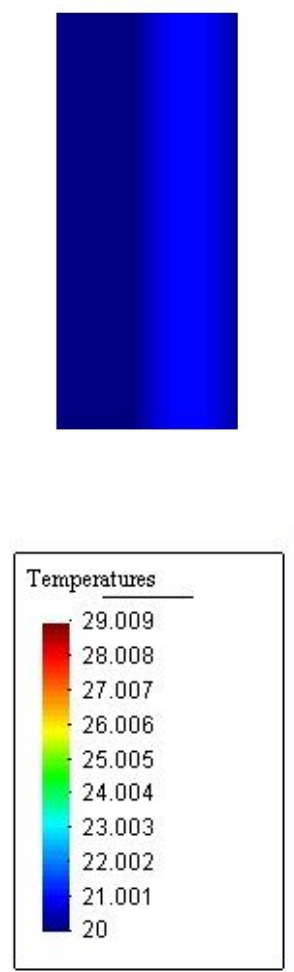

Figura 8.12 - Evolução das temperaturas [ $\left.{ }^{\circ} \mathrm{C}\right]$

\subsubsection{Resultados do modelo de difusão de umidade}

As figuras 8.13 e 8.14 mostram a evolução da difusão de umidade para dois nós, P1, localizado na superfície externado anel de concreto, e P2, localizado no 
interior do mesmo, para as duas malhas ensaiadas. A exemplo do que já havia sido observado na análise térmica, não houve diferença, na análise de difusão de umidade, dos resultados obtidos para as malhas de 42 e 168 elementos. Novamente não foi observada diferença dos resultados obtidos ao aumentar-se o refinamento da malha.

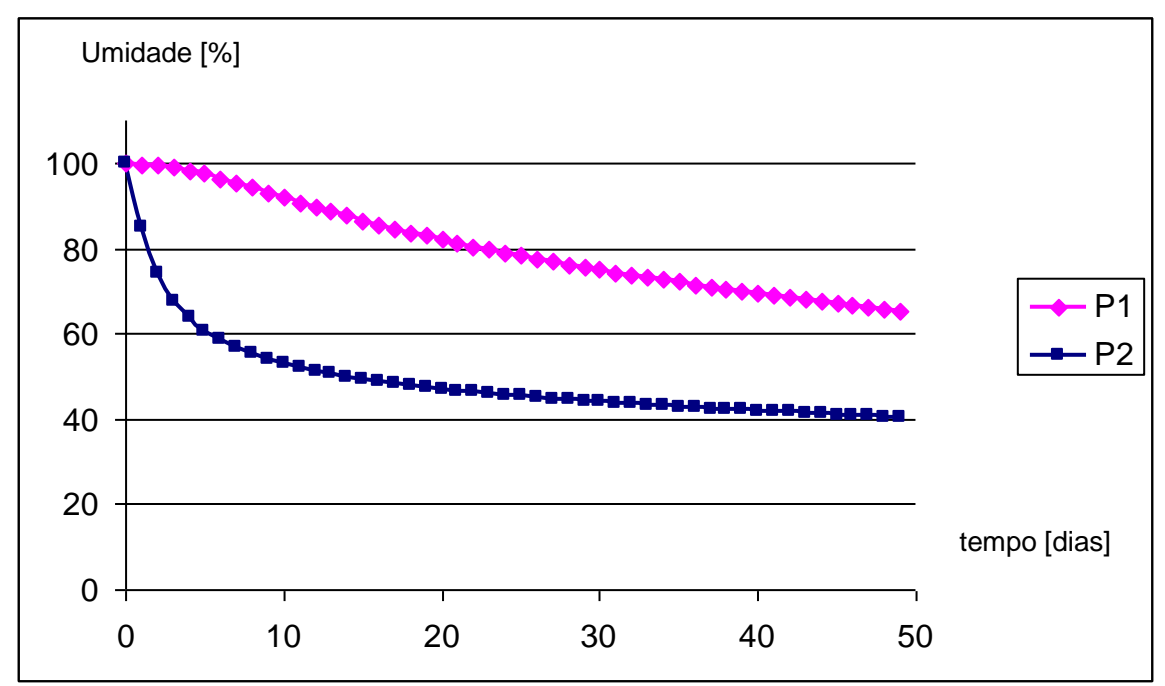

Figura 8.13 - Evolução da difusão de umidade nos pontos P1 e P2, utilizando amalha 1 (42 elementos)

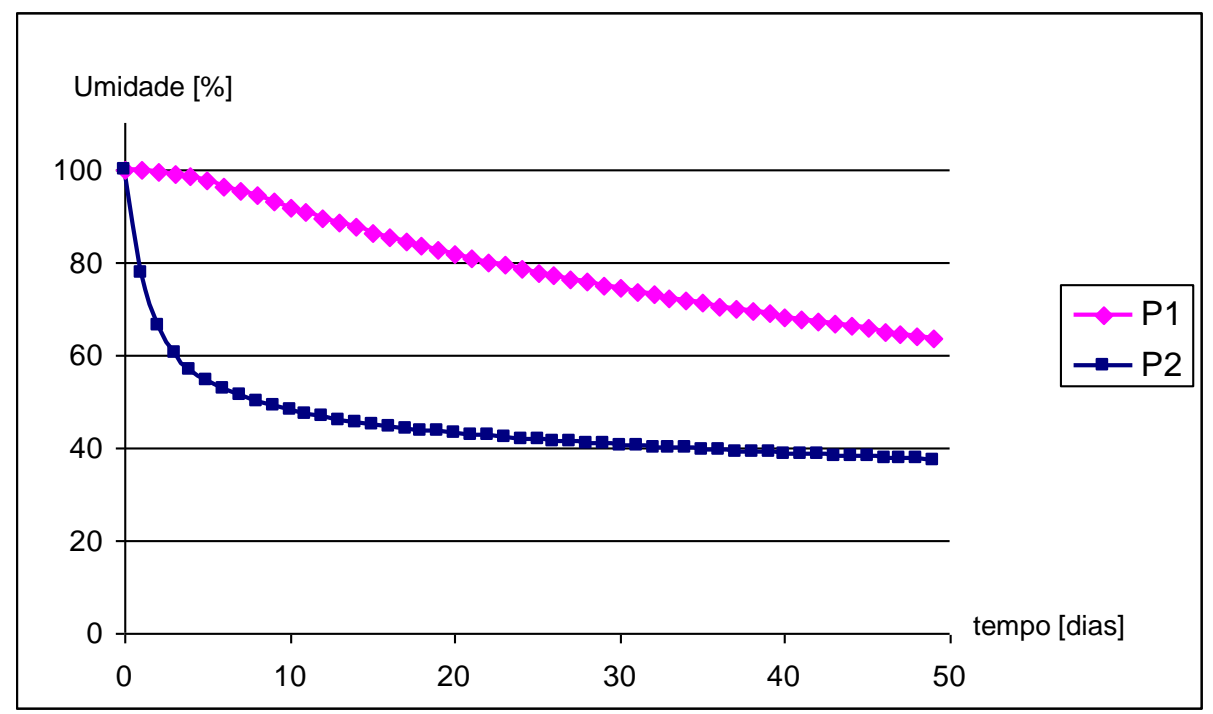

Figura 8.14 - Evolução da difusão de umidade nos pontos P1 e P2, utilizando a malha 2 (168 elementos) 
Os mapas de evolução da difusão de umidade, em instantes selecionados, são apresentados na figura 8.15. Observa-se que o processo de secagem, devido à umidade relativa do ambiente ser inferior à inicial do anel de concreto, ocorre no sentido da superfície externa para o interior. Isto já havia sido observado nas figuras 8.13 e 8.14 .

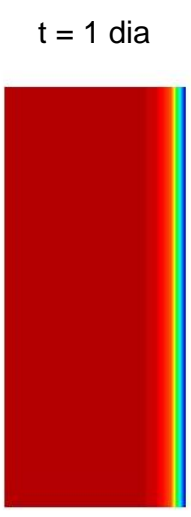

$\mathrm{t}=20$ dias

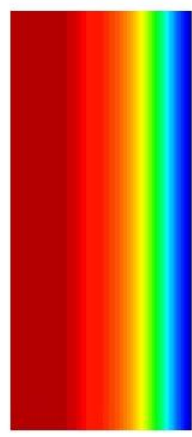

$t=5$ dias

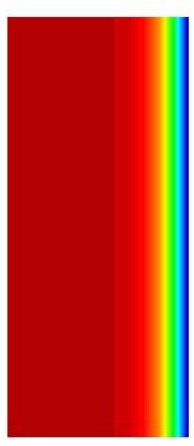

$\mathrm{t}=30$ dias

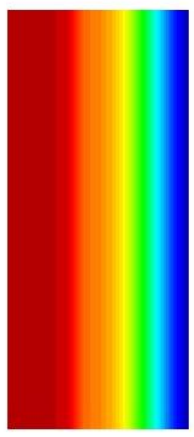

$t=10$ dias

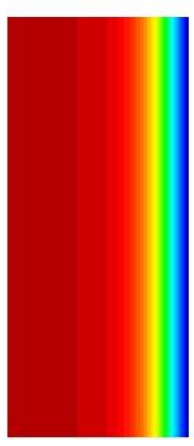

$\mathrm{t}=40$ dias

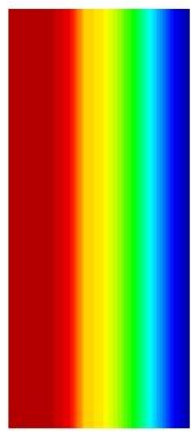

$t=15$ dias

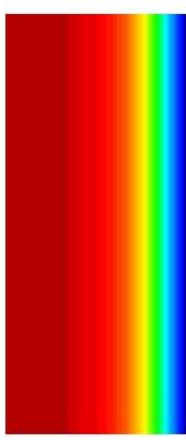

Free moisture content

103.26

96.232

89.204

82.175

75.146

68.118

61.089

54.06

47.031

40.003

Figura 8.15 - Evolução difusão de umidade [\%]

\subsubsection{Resultados do modelo mecânico}

Os resultados da análise mecânica são apresentados para os dois anéis estudados, cujas propriedades foram listadas na tabela 8.3. O anel 1 (Shah et al, 1994) foi confeccionado com um concreto de menor resistência à compressão e módulo de deformação do que o anel 2 (Shah, Karaguler e Sarigaphuti,1993) 
As figuras 8.16 e 8.17 apresentam a comparação de data de fissuração e a abertura da fissura entre os resultados para anel 1 (Shah et al, 1994) e o algoritmo proposto, considerando as duas malhas de elementos finitos estudadas, 42 e 168 elementos, respectivamente. As figuras 8.18 e 8.19 apresentam os mesmos resultados para o anel 2 (Shah, Karaguler e Sarigaphuti,1993).

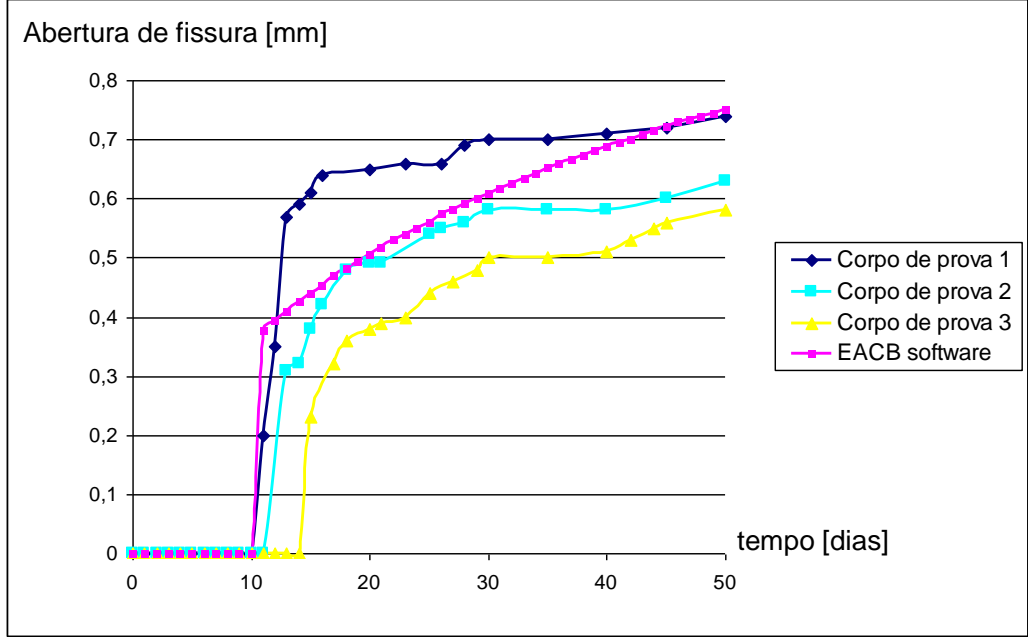

Figura 8.16 - Abertura de fissuras para anel 1 (Shah, 1993), resultados para a malha 1

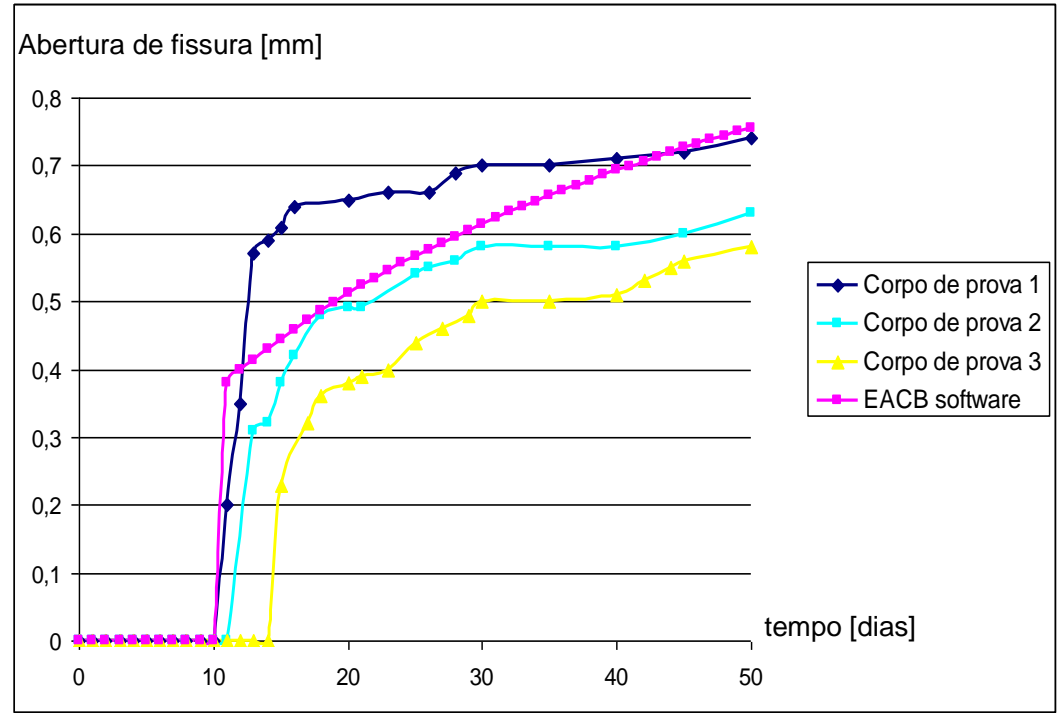

Figura 8.17 - Abertura de fissuras para anel 1 (Shah, 1993), resultados para a malha 2 
Abertura de fissura [mm]

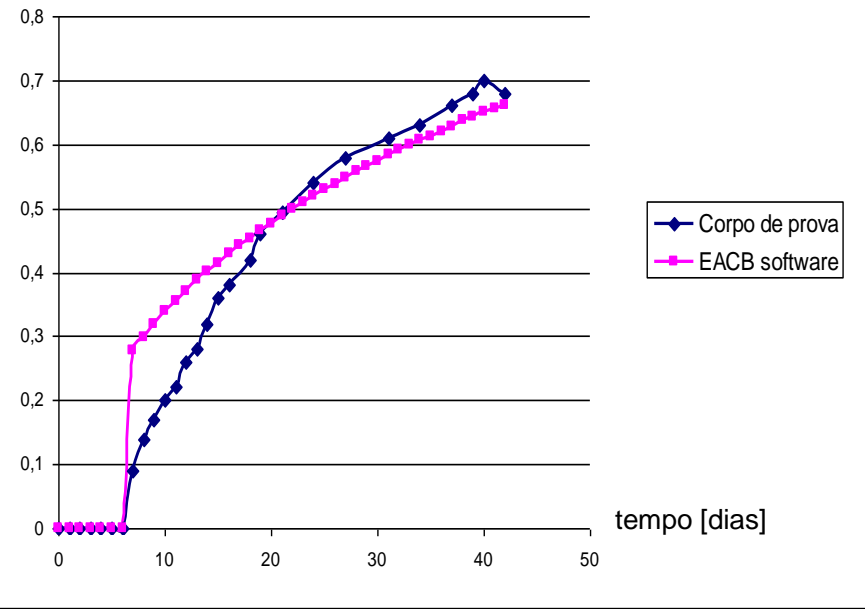

Figura 8.18 - Abertura de fissuras para anel 1 (Shah, 1993), resultados para a malha 1

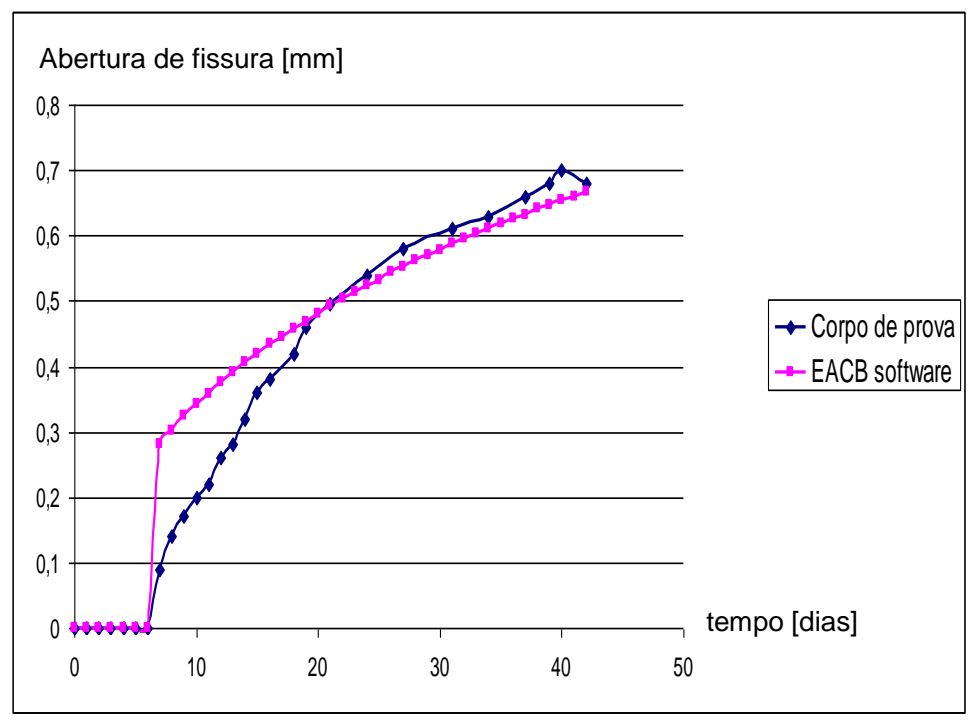

Figura 8.19 - Abertura de fissuras para anel 1 (Shah, 1993), resultados para a malha 2 
A concordância dos resultados das análises numéricas com os valores experimentais é excelente, tanto para a data da fissuração quanto para os valores de abertura da fissura. Conforme resultados numéricos e experimentais, 0 anel 1 fissura aos 10 dias, e o anel 2 aos 7 dias. A análise computacional evidencia 0 porquê do anel 2, de maior resistência, fissurar mais cedo. As deformações impostas por retração do concreto geram tensões proporcionais ao módulo de deformação e a evolução da resistência à tração nas primeiras idades não é suficiente para evitar a fissuração do anel de maior rigidez em primeiro lugar.

Os mapas de evolução das tensões no anel 1 (Shah et al, 1994) para as duas malhas estudadas são apresentados nas figuras 8.20 e 8.21. Nestas figuras pode-se acompanhar a evolução da abertura da fissura da face externa do anel para o seu interior, confirmando o que de fato foi observado experimentalmente, de acordo com a figura 8.22 .

Nos mapas de distribuição de tensões apresentados, por exemplo, na figura 8.20 , pode-se acompanhar bem a evolução da abertura das fissuras no sentido da superfície para o interior do anel. No décimo dia, aparece a cor vermelha, nível de tensão correspondente à resistência à tração do concreto, na superfície do anel. $\mathrm{A}$ fissura se forma, então, junto à superfície e o valor da tensão cai. No décimo quarto dia, observa-se novamente o nível de tensão vermelho sendo atingido em uma posição mais interna (na superfície do anel a tensão já está próxima de zero). Em seguida, com a propagação da abertura da fissura, o nível de tensão cai. No décimo nono dia, o pico de tensões é atingido em uma posição ainda mais interna, para logo em seguida cair. Isto se repete sucessivamente em posições cada vez mais próximas da superfície do anel de aço. É interessante observar que as tensões de compressão no anel de aço vão caindo à medida que a frente de fissuração vai se aproximando.

Também não é observada diferença significativa na evolução da abertura da fissura utilizando-se a malha mais refinada. 

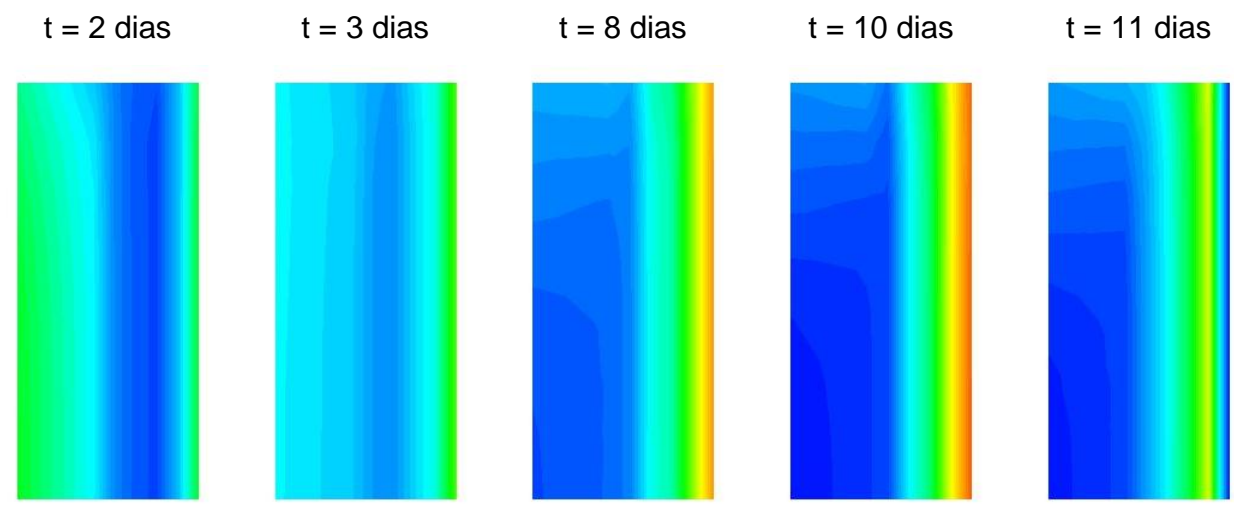

$t=14$ dias

$t=16$ dias

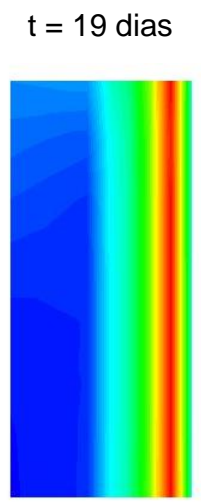

$t=23$ dias

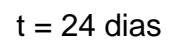

$\mathrm{t}=30$ dias
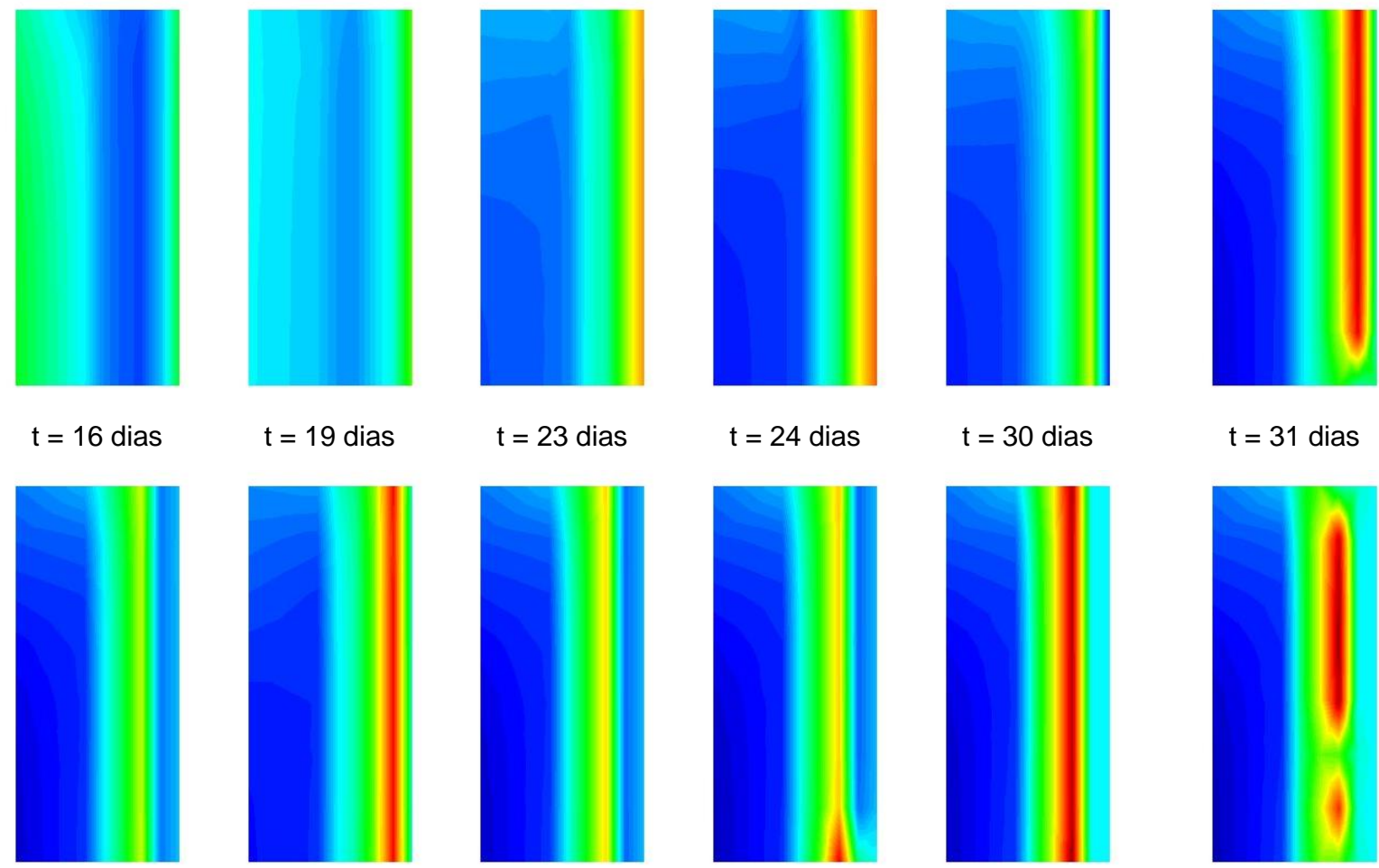

$\mathrm{t}=31$ dias

$\mathrm{t}=32$ dias

$t=36$ dias

$t=42$ dias

$t=48$ dias

$\mathrm{t}=49$ dias
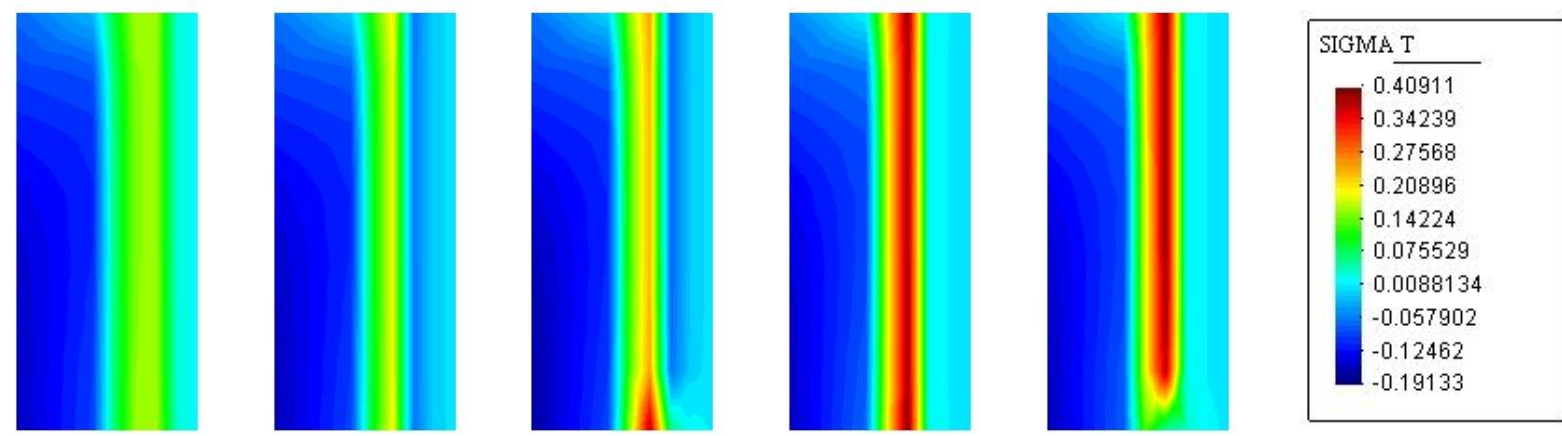

Figura 8.20 - Evolução das tensões circunferenciais $\left[\mathrm{kN} / \mathrm{cm}^{2}\right]$, resultados para a malha 1 

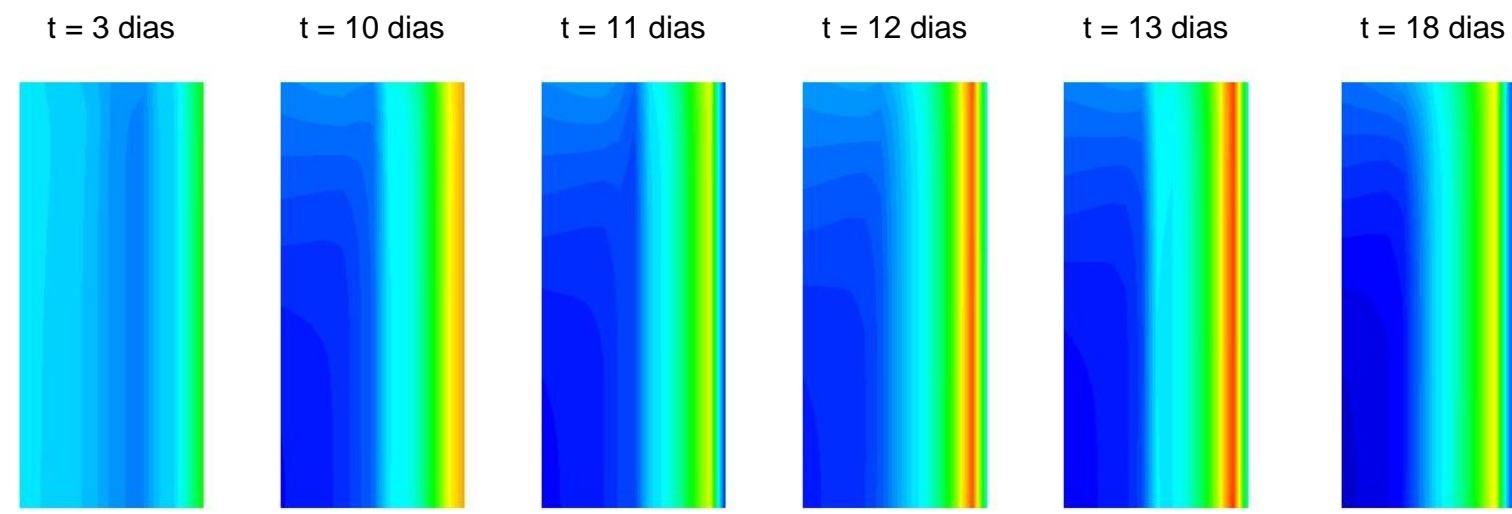

$t=20$ dias

$$
t=22 \text { dias }
$$

$\mathrm{t}=29$ dias

$$
t=30 \text { dias }
$$

$t=32$ dias
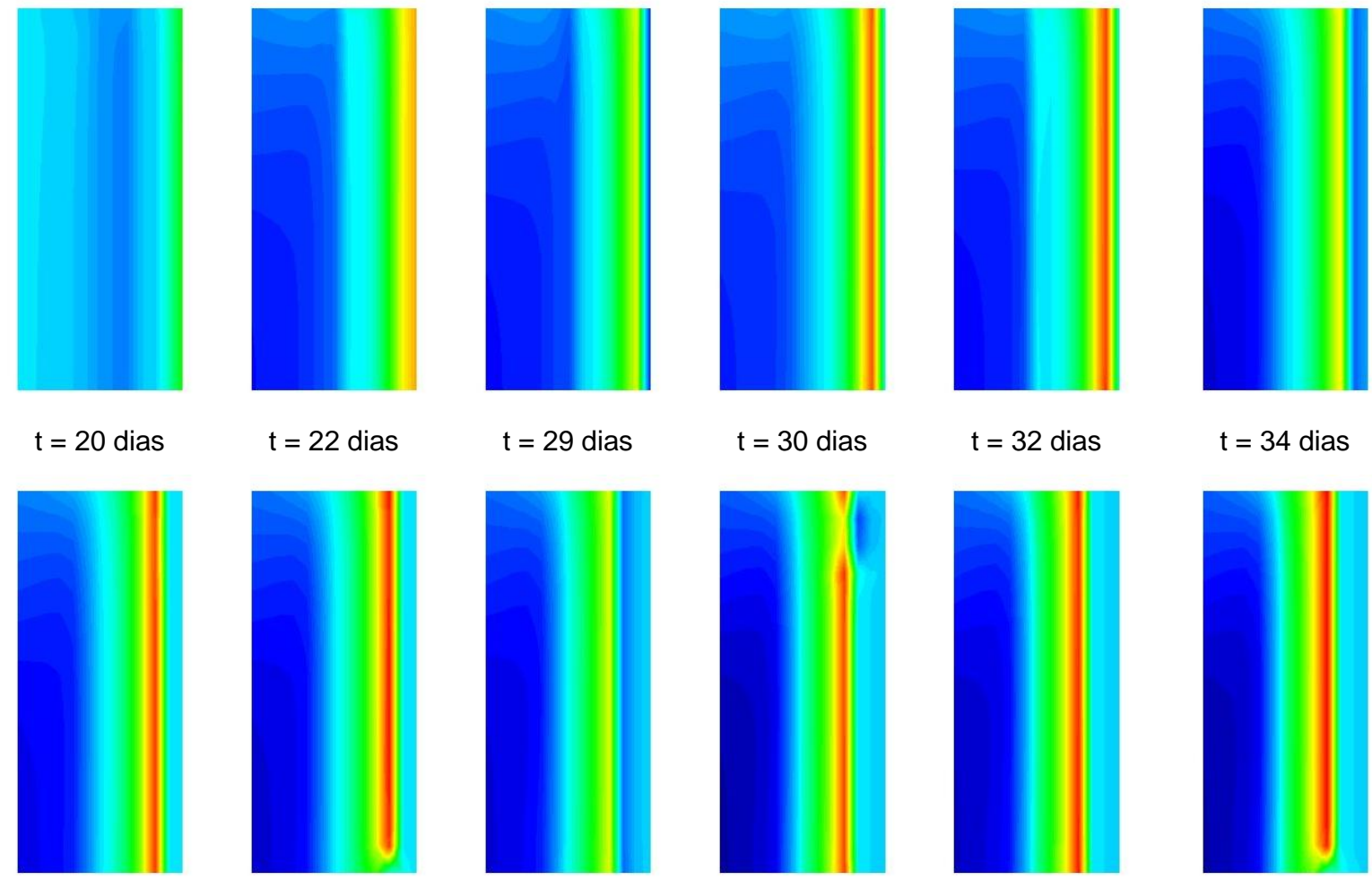

$\mathrm{t}=34$ dias

$t=40$ dias

$t=42$ dias

$\mathrm{t}=44$ dias

$t=46$ dias

$\mathrm{t}=48$ dias
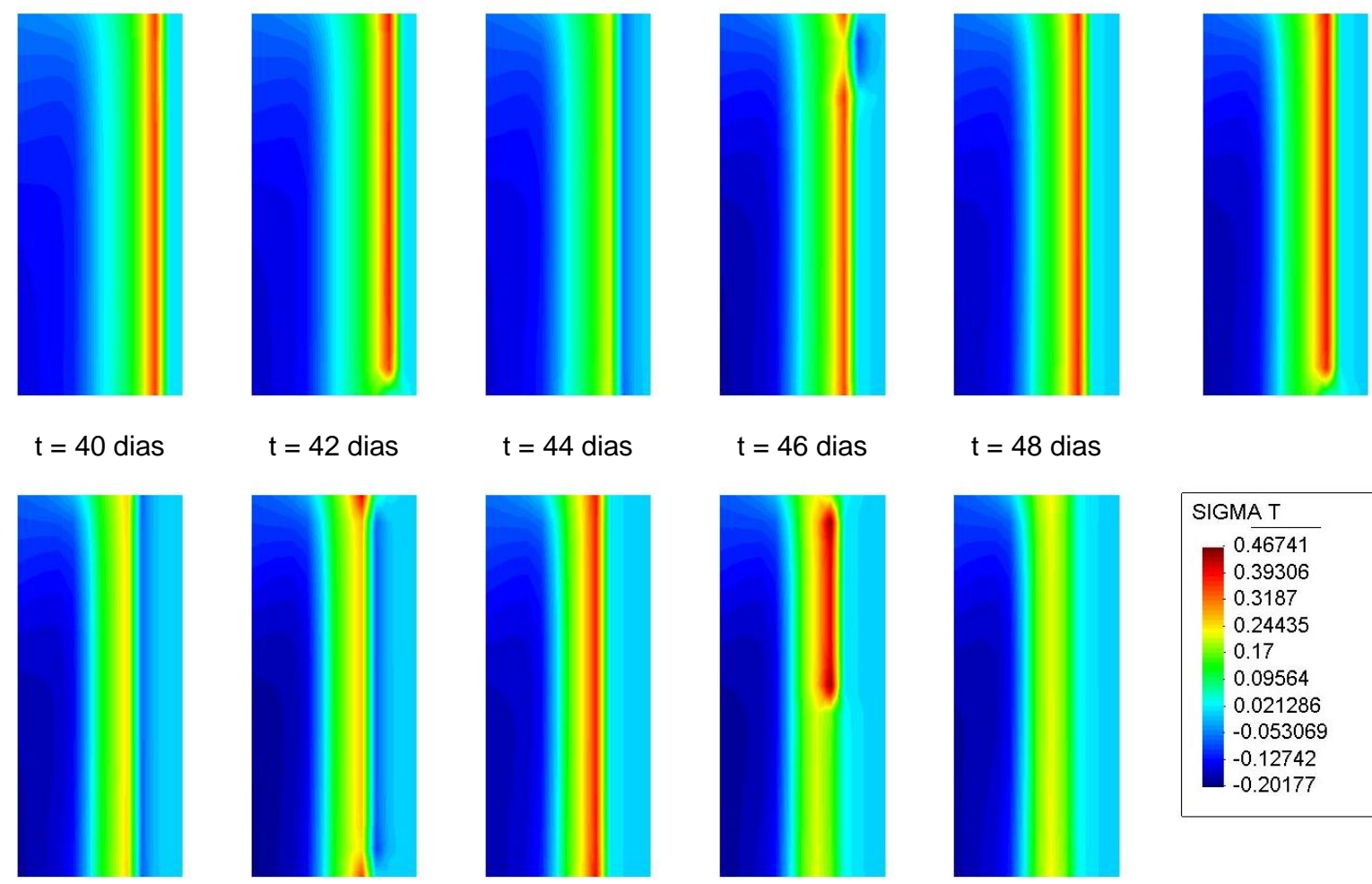

Figura 8.21 - Evolução das tensões circunferenciais $\left[\mathrm{kN} / \mathrm{cm}^{2}\right]$, resultados para a malha 2

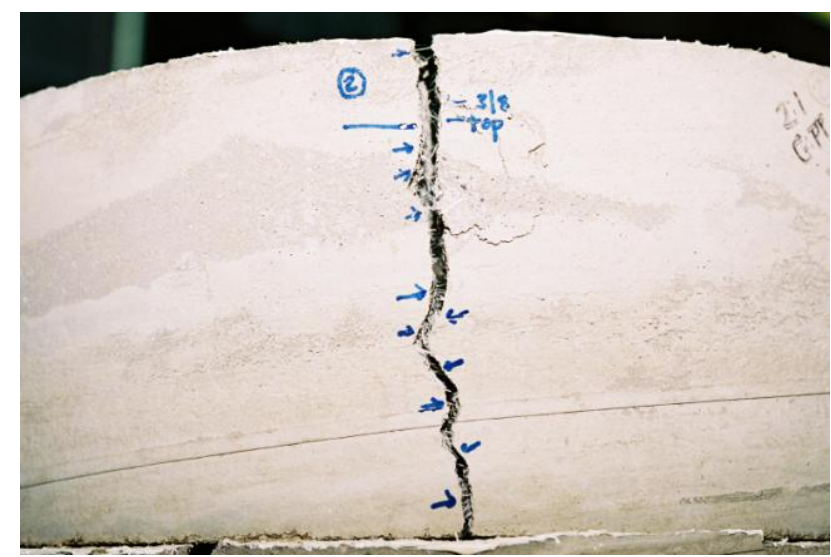

Figura 8.22 - Anel fissurado após a realização do ensaio 


\subsection{Prisma de concreto}

\subsubsection{Descrição geral}

Kvoler (1994) desenvolveu um ensaio uniaxial utilizando um corpo de prova tipo I (dog bone specimen) para simular a fissuração do concreto com retração restringida. A idéia básica do sistema é analisar o elemento exposto a condições de temperatura e umidade controlada, com o objetivo de medir as tensões até o instante da fissuração. As dimensões do prisma ensaiado podem ser observadas na figura 8.23 .

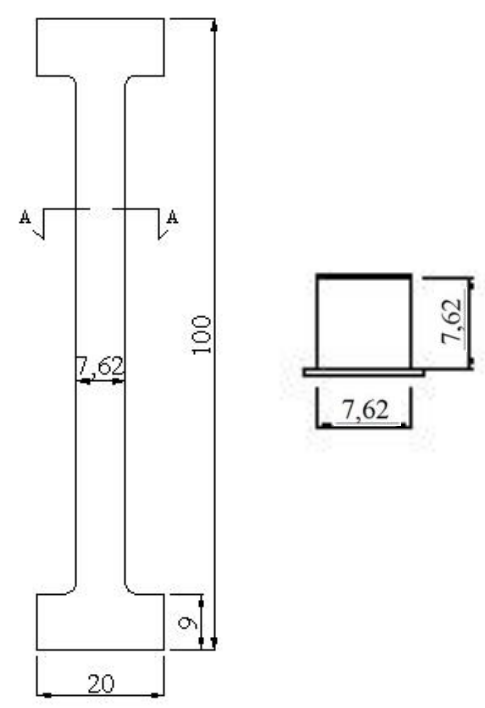

Figura 8.23 - Dimensões do prisma ensaiado (cotas em $\mathrm{cm}$ )

Como pode ser observado na figura 8.24 , no sistema montado para o ensaio, as medições foram realizadas somente no corpo do prisma, ao longo de um comprimento de $62,23 \mathrm{~cm}$. A seção transversal das extremidades foi gradualmente aumentada para que as mesmas coubessem no mecanismo de ensaio, sendo que, cabe salientar, esta nova configuração do prisma resulta em uma total restrição nas extremidades e minimiza a concentração de tensões nas áreas de contato do prisma com o mecanismo de ensaio. 


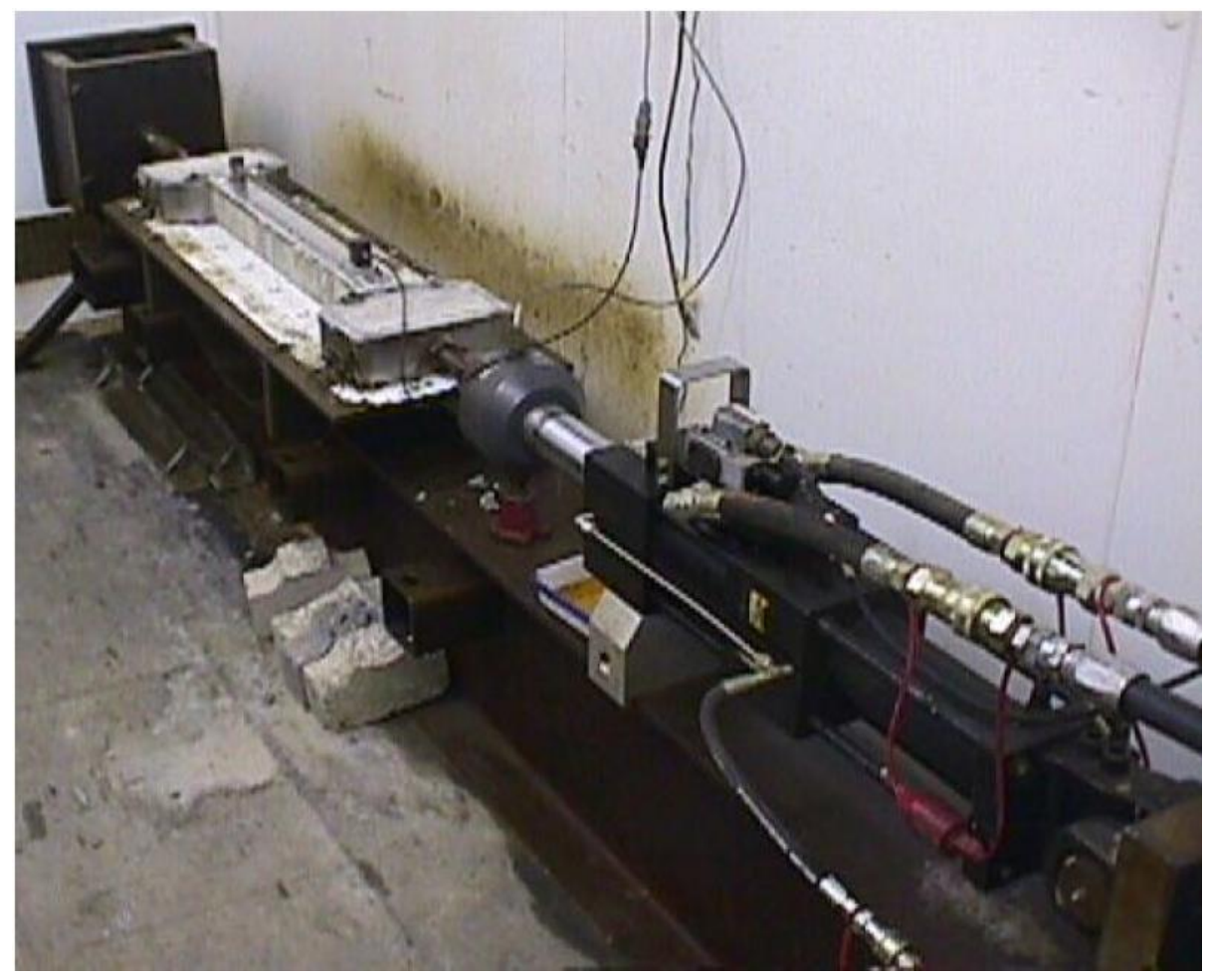

Figura 8.24 - Ensaio do prisma

Para a análise dos resultados obtidos pelo programa, o presente trabalho estuda dois prismas ensaiados por Altoubat e Lange (2001). Apresentam-se resultados para elevação da temperatura e da difusão da umidade no interior dos mesmos, bem como a comparação da evolução das tensões e da data de fissuração.

\subsubsection{Geometria e parâmetros utilizados na modelagem computacional}

Para a discretização do problema, foi utilizada uma malha de elementos finitos com 100 elementos, como pode ser observado na figura 8.25 . 


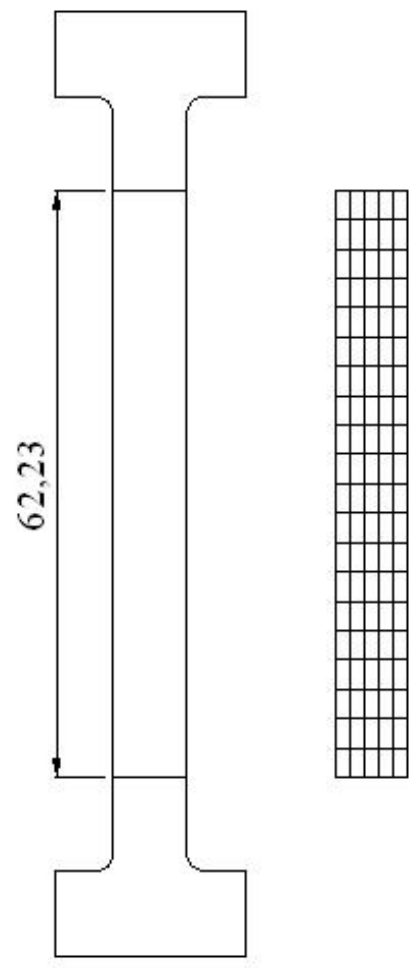

Figura 8.25 - Malha de elementos finitos utilizada

$\mathrm{E}$, as condições de contorno utilizadas para a análise no estado plano de cada uma das etapas de solução, térmica, de difusão de umidade e mecânica, são mostradas nas figuras $8.26,8.27$ e 8.28 , respectivamente

Temperatura externa: $20^{\circ} \mathrm{C}$

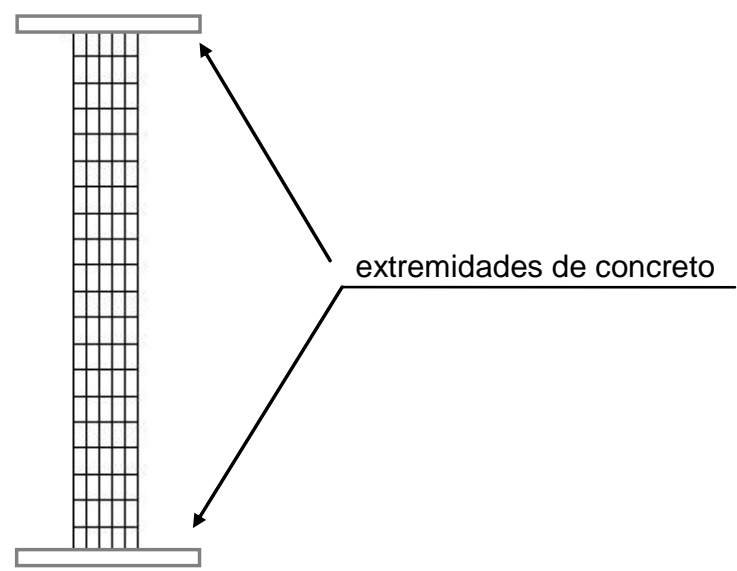

Figura 8.26 - Condições de contorno para a análise térmica 
Umidade do ar: $50 \%$

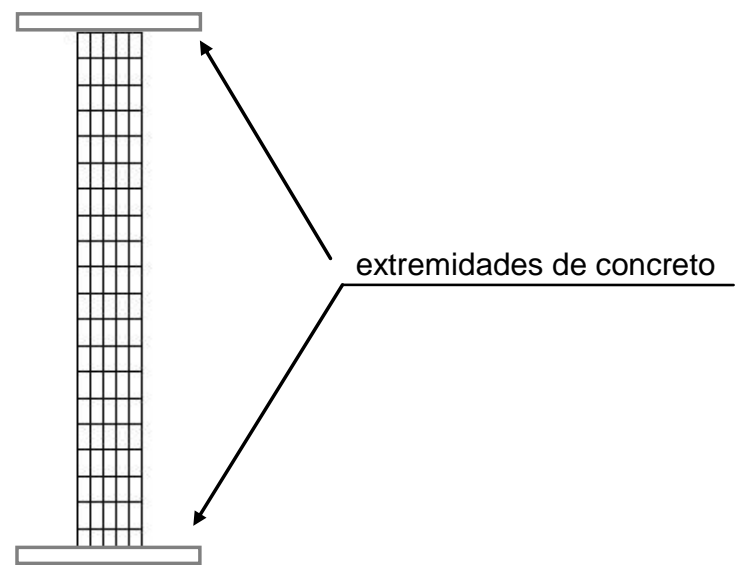

Figura 8.27 - Condições de contorno para a análise de difusão de umidade

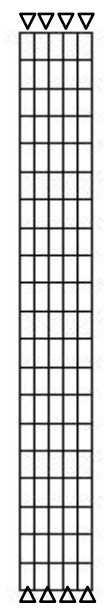

Figura 8.28 - Condições de contorno para a análise mecânica

Os parâmetros utilizados na análise térmica, de difusão de umidade e mecânica, para os dois prismas estudados, são indicados nas tabelas 8.4, 8.5 e 8.6, respectivamente.

Tabela 8.4 - Propriedades Térmicas do Concreto

\begin{tabular}{c|c}
\hline \hline Condutividade Térmica & 2,33 \\
{$\left[\mathrm{~kJ} / \mathrm{cm}\right.$. dia. $\left.{ }^{\circ} \mathrm{C}\right]$} & \\
\hline Coeficiente de Convecção & 0,12 \\
{$\left[\mathrm{~kJ} / \mathrm{cm}^{2} \cdot\right.$ dia.$\left.{ }^{\circ} \mathrm{C}\right]$} & \\
\hline Capacidade Térmica & 1,16 \\
{$\left[\mathrm{~kJ} / \mathrm{cm}^{3} \cdot\right.$ dia $]$} & \\
\hline \hline
\end{tabular}


Tabela 8.5 - Propriedades de Difusão de Umidade do Concreto

\begin{tabular}{c|c}
\hline Coeficiente de Difusão & \\
{$\left[\mathrm{m}^{2} / \mathrm{s}\right]$} & 0,06048 \\
\hline Fator de Transferência de & \\
Massa & 3,33 \\
\hline
\end{tabular}

Tabela 8.6 - Propriedades Mecânicas do Concreto

\begin{tabular}{c|c}
\hline \hline $\begin{array}{c}\text { Módulo de Elasticidade } \\
{\left[\mathrm{kN} / \mathrm{cm}^{2}\right]}\end{array}$ & 3500 (prisma 1) \\
2500 (prisma 2) \\
\hline Coeficiente de Poisson & 0,2 \\
\hline Resistência à Compressão (28 dias) & 2,80 (prisma 1) \\
{$\left[\mathrm{kN} / \mathrm{cm}^{2}\right]$} & 2,10 (prisma 2) \\
\hline \hline
\end{tabular}

\subsubsection{Resultados do modelo térmico}

Os mapas de evolução da temperatura, em instantes selecionados, são apresentados na figura 8.29. Pelas dimensões do corpo de prova não é observada uma variação significativa de temperatura na espessura do corpo de prova. Após 228 horas (9,5 dias) a temperatura do corpo já está praticamente equilibrada com a do ambiente. 


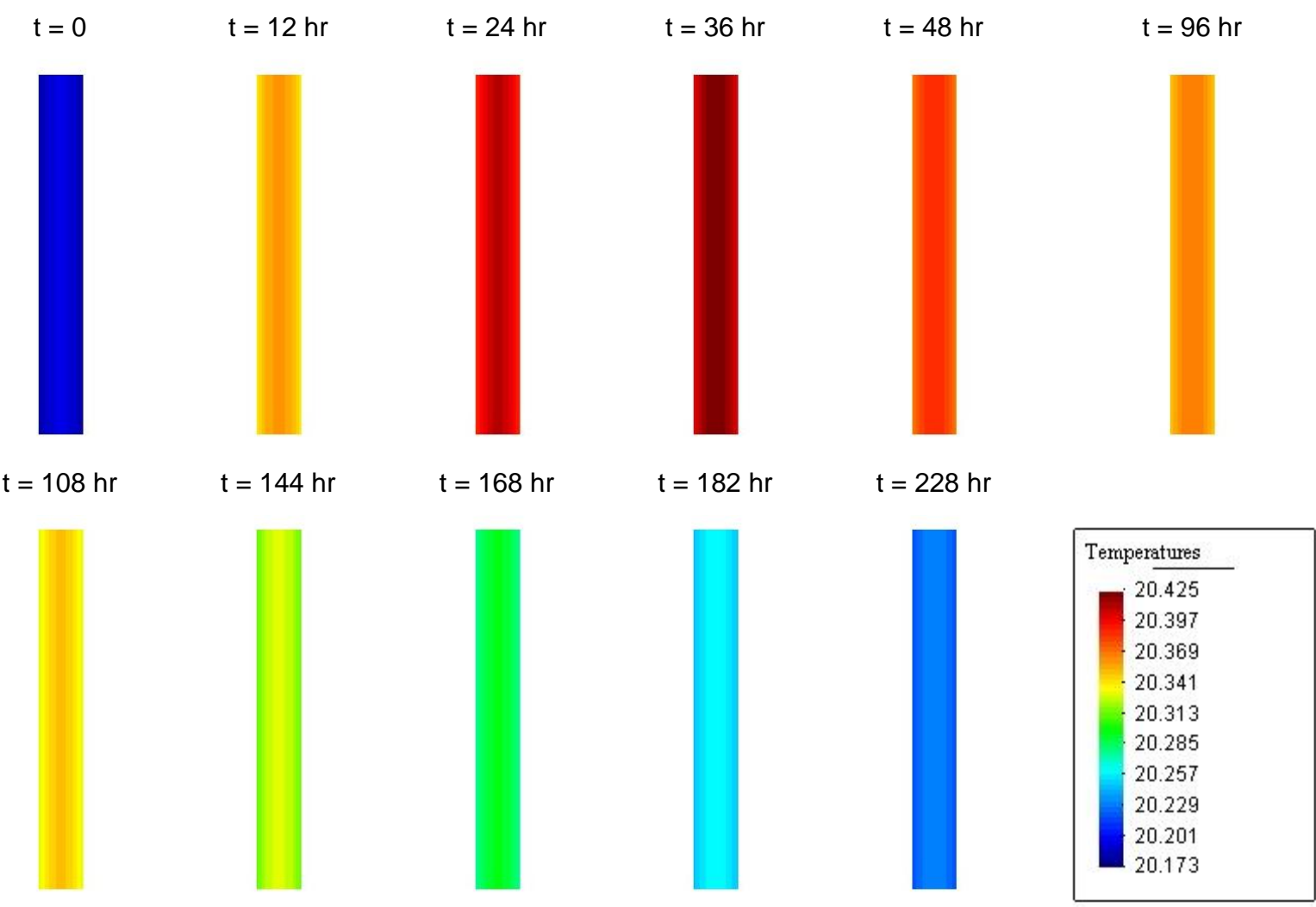

Figura 8.29 - Evolução das temperaturas $\left[{ }^{\circ} \mathrm{C}\right]$

\subsubsection{Resultados do modelo de difusão de umidade}

Os mapas de evolução da difusão de umidade, em instantes selecionados, são apresentados na figura 8.30. Pode-se observar que a secagem se dá do exterior do corpo de concreto para o interior. Transcorridos dez dias da concretagem ainda existe uma diferença significativa da umidade na superfície e no interior do corpo. 


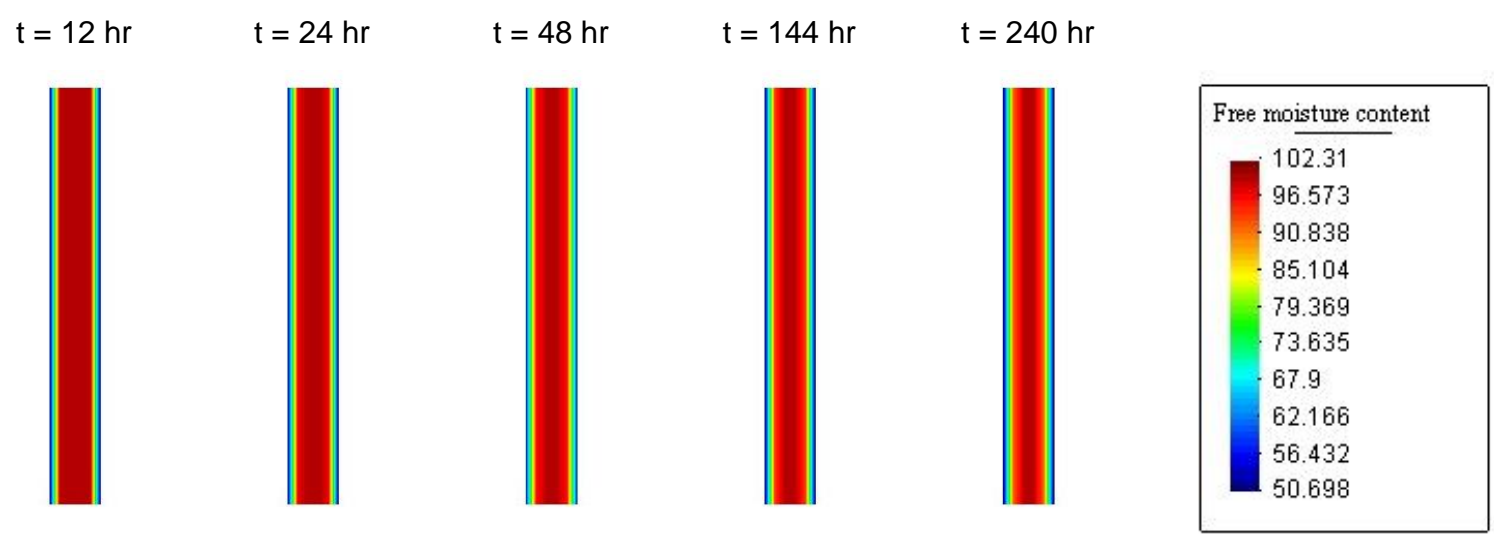

Figura 8.30 - Evolução difusão de umidade [\%]

\subsubsection{Resultados do modelo mecânico}

As figuras 8.31 e 8.32 apresentam a comparação dos valores para as tensões atuantes e data de fissuração, obtidos experimentalmente e através do algoritmo desenvolvido no presente trabalho, para os dois prismas ensaiados.

Novamente, a aproximação dos valores numéricos com os experimentais é excelente. O prisma 2 fissura poucas horas após o prisma 1 (6,5 e 6 dias, respectivamente). A tensão de tração por ocasião da fissuração no prima 1 é de 0,25 $\mathrm{kN} / \mathrm{cm}^{2}$ e no prisma 2, de $0,21 \mathrm{kN} / \mathrm{cm}^{2}$. Essa diferença se justifica por ser o módulo de deformação do concreto do prisma 1 superior ao do prisma 2. Como a resistência do concreto do prisma 1 é muito superior ao do prisma $2\left(2,80\right.$ e 2,10 kN/cm ${ }^{2}$, respectivamente) a fissuração acabou ocorrendo quase no mesmo momento. 


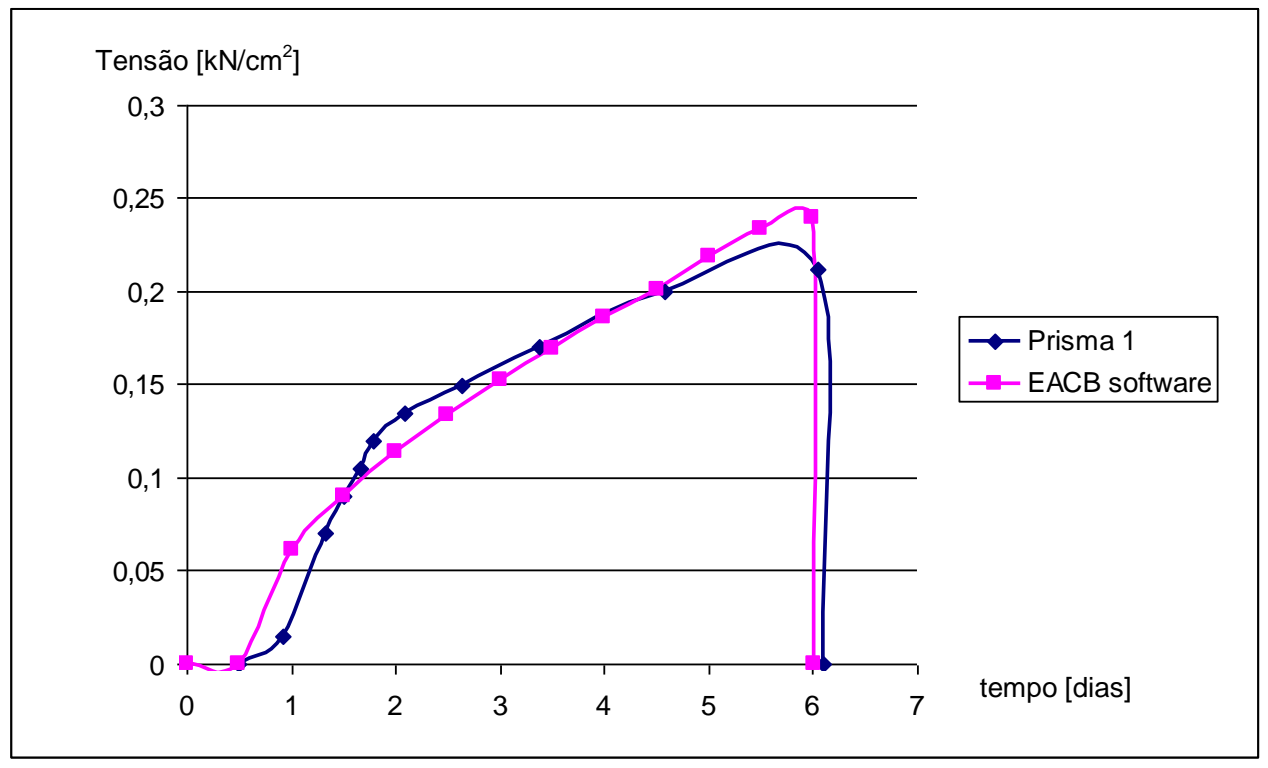

Figura 8.31 - Tensões atuantes para o prisma 1

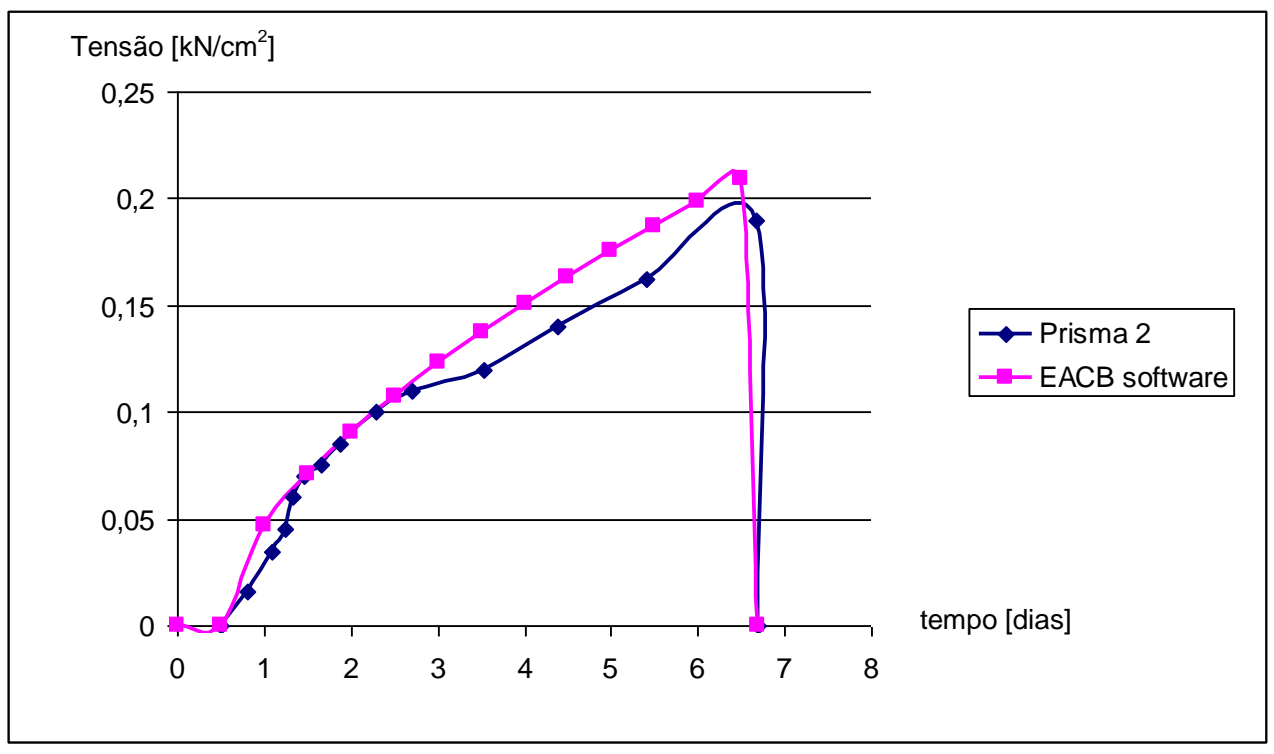

Figura 8.32 - Tensões atuantes para o prisma 2 
Os mapas de evolução das tensões, em instantes selecionados, são apresentados na figura 8.33. Deve-se observar que neste ensaio, ao contrário do que acontece no ensaio dos anéis, no momento da formação das fissuras, ocorre a ruptura do corpo de prova, por não haver possibilidade de redistribuição das tensões.

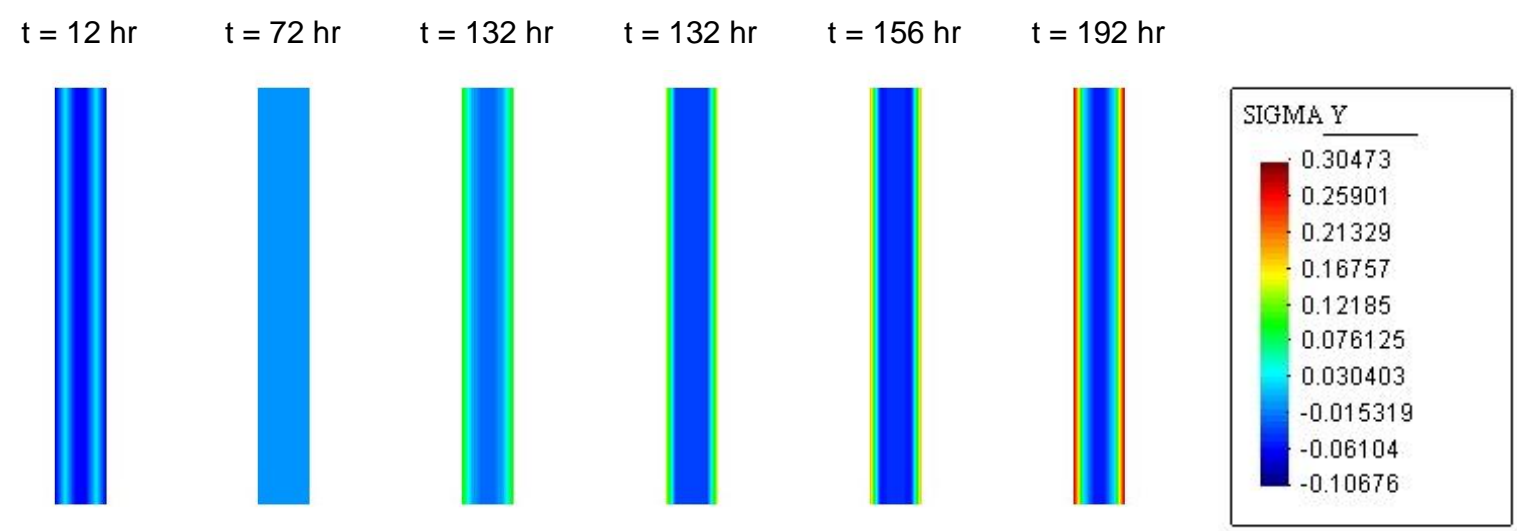

Figura 8.33 - Evolução das tensões $\left[\mathrm{kN} / \mathrm{cm}^{2}\right]$

\subsection{Tetrápode}

\subsubsection{Descrição geral}

O tetrápode é uma peça utilizada na proteção de quebra-mares, consistindo num bloco de concreto simples composto por quatro pernas tronco-cônicas saindo de um ponto central (Azenha, 2004), como pode ser observado nas figuras $8.34 \mathrm{e}$ 8.35. 

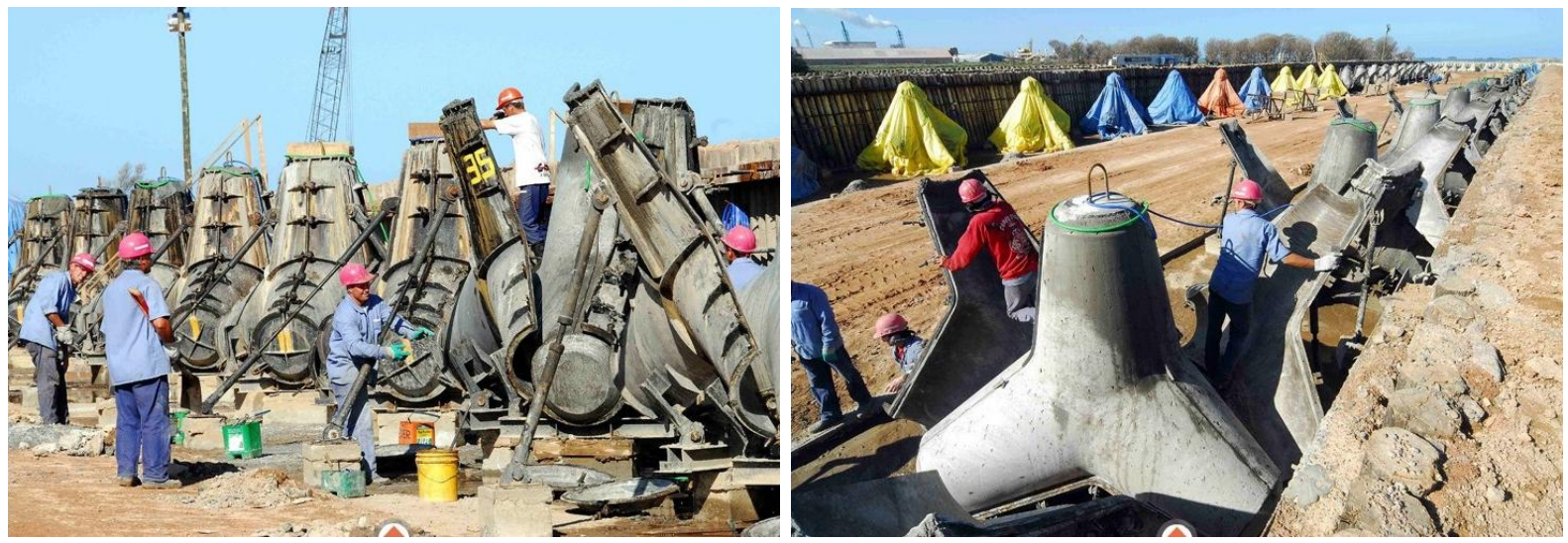

Figura 8.34 - Execução dos tetrápodes nos Molhes de Rio Grande - RS (fonte: Jornal Zero Hora)

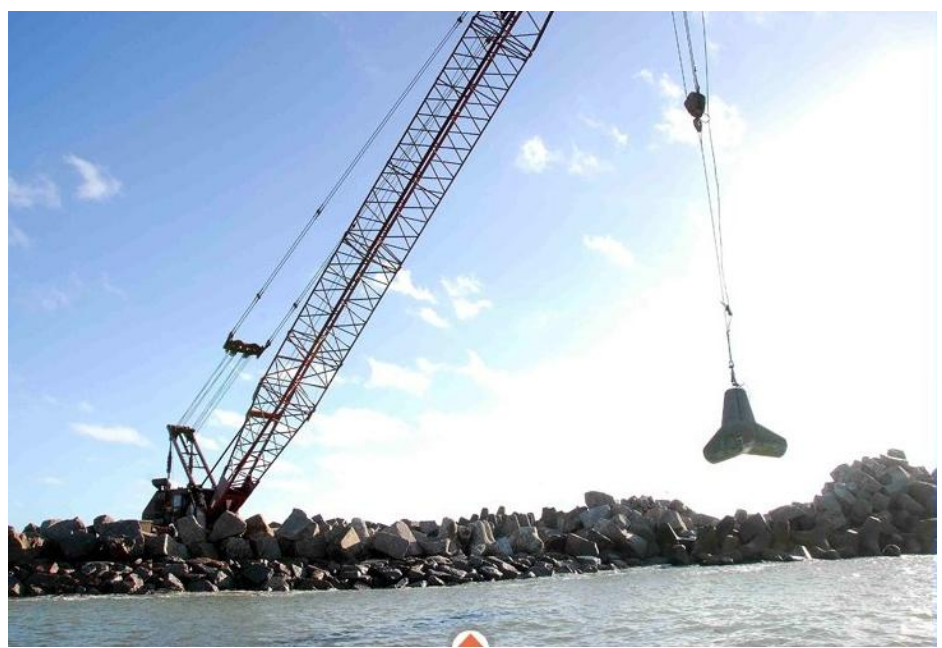

Figura 8.35 - Colocação dos tetrápodes nos Molhes de Rio Grande - RS (fonte: Jornal Zero Hora)

Onforme Azenha (2004), as proporções geométricas do tetrápode seguem, aproximadamente, o indicado na figura 8.36. Podem atingir alturas da ordem de 4 metros com diâmetro máximo das pernas de 2 metros.

Para a análise deste tipo de elemento, o presente trabalho estuda o tetrápode analisado por de Borst e van der Boogaard (1994). Apresentam-se resultados para a elevação da temperatura no interior do mesmo, bem como da difusão da umidade e evolução das tensões. 

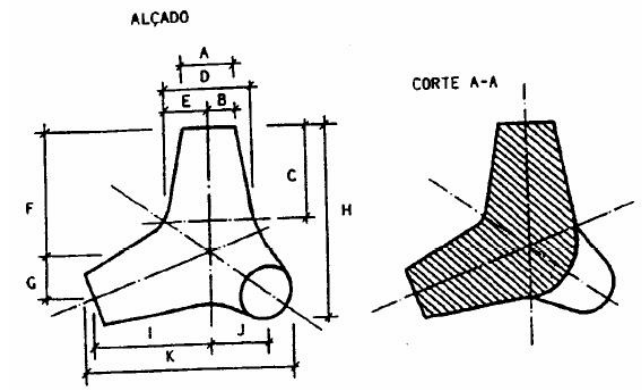

$\mathrm{V}=0,280 \mathrm{H}^{3}$

$A=0,302 \mathrm{H}$

$B=0,151 \mathrm{H}$

$\mathrm{C}=0,477 \mathrm{H}$

$\mathrm{D}=0,470 \mathrm{H}$

$E=0,235 \mathrm{H}$

$\mathrm{F}=0,644 \mathrm{H}$

$G=0,215 \mathrm{H}$
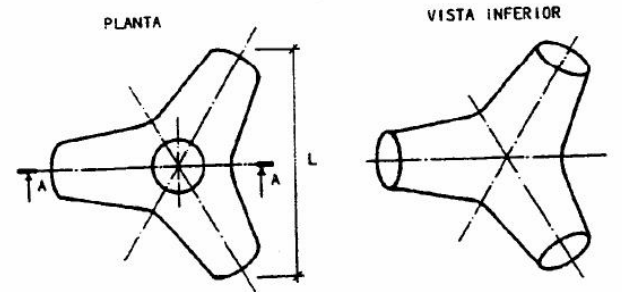

$\mathrm{I}=0,606 \mathrm{H}$

$\mathrm{J}=0,303 \mathrm{H}$

$\mathrm{K}=1,091 \mathrm{H}$

$L=1,201 \mathrm{H}$

Figura 8.36 - Características geométricas dos tetrápodes (Azenha, 2004)

\subsubsection{Geometria e parâmetros utilizados na modelagem computacional}

Para a discretização do problema, foi utilizada uma malha de elementos finitos com 165 elementos, como pode ser observado na figura 8.37 .
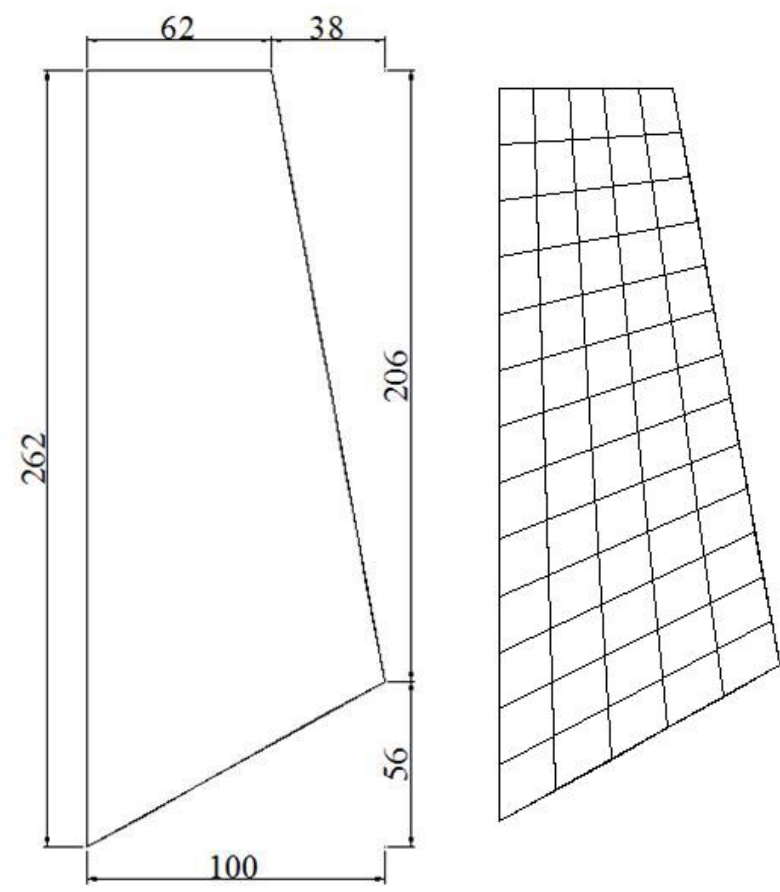

Figura 8.37 - Malha de elementos finitos utilizada 
As condições de contorno utilizadas para a análise axissimétrica de cada uma das etapas de solução, térmica, de difusão de umidade e mecânica, são mostradas nas figuras $8.38,8.39$ e 8.40 , respectivamente.

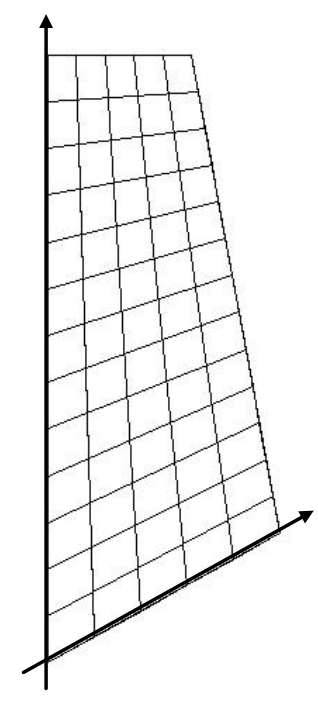

Temperatura externa: $15^{\circ} \mathrm{C}$

Figura 8.38 - Condições de contorno para a análise térmica

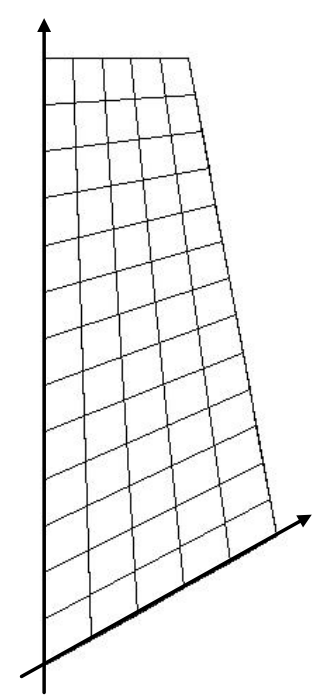

Umidade do ar: $50 \%$

Figura 8.39 - Condições de contorno para a análise de difusão de umidade 


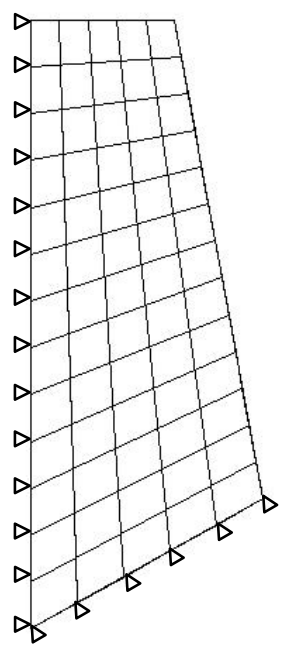

Figura 8.40 - Condições de contorno para a análise mecânica

Os parâmetros utilizados na análise térmica, de difusão de umidade e mecânica, para o tetrápode estudado, são indicados, respectivamente, nas tabelas 8.7, 8.8 e 8.9 .

Tabela 8.7 - Propriedades Térmicas do Concreto

\begin{tabular}{c|}
\hline \hline Condutividade Térmica \\
{$\left[\mathrm{kJ} / \mathrm{cm} \cdot\right.$ dia. $\left.^{\circ} \mathrm{C}\right]$}
\end{tabular}

Tabela 8.8 - Propriedades de Difusão de Umidade do Concreto

\begin{tabular}{c|c}
\hline Coeficiente de Difusão & \\
{$\left[\mathrm{m}^{2} / \mathrm{s}\right]$} & 0,06048 \\
\hline Fator de Transferência de & \\
Massa & 3,33 \\
\hline
\end{tabular}


Tabela 8.9 - Propriedades Mecânicas do Concreto

\begin{tabular}{c|c}
\hline $\begin{array}{c}\text { Módulo de Elasticidade } \\
{\left[\mathrm{kN} / \mathrm{cm}^{2}\right]}\end{array}$ & 2700 \\
\hline $\begin{array}{c}\text { Coeficiente de Poisson } \\
\text { Resistência à Compressão (28 dias) } \\
{\left[\mathrm{kN} / \mathrm{cm}^{2}\right]}\end{array}$ & 0,2 \\
\hline \hline
\end{tabular}

\subsubsection{Resultados do modelo térmico}

Os mapas de evolução da temperatura, em instantes selecionados, são apresentados na figura 8.41 .

Pelo calor gerado pela hidratação do cimento, nota-se claramente que a temperatura cresce na região mais interna do tetrápode. Com o passar das horas a temperatura decresce da superfície para o interior, alcançando o equilíbrio com o ambiente aos dez dias.

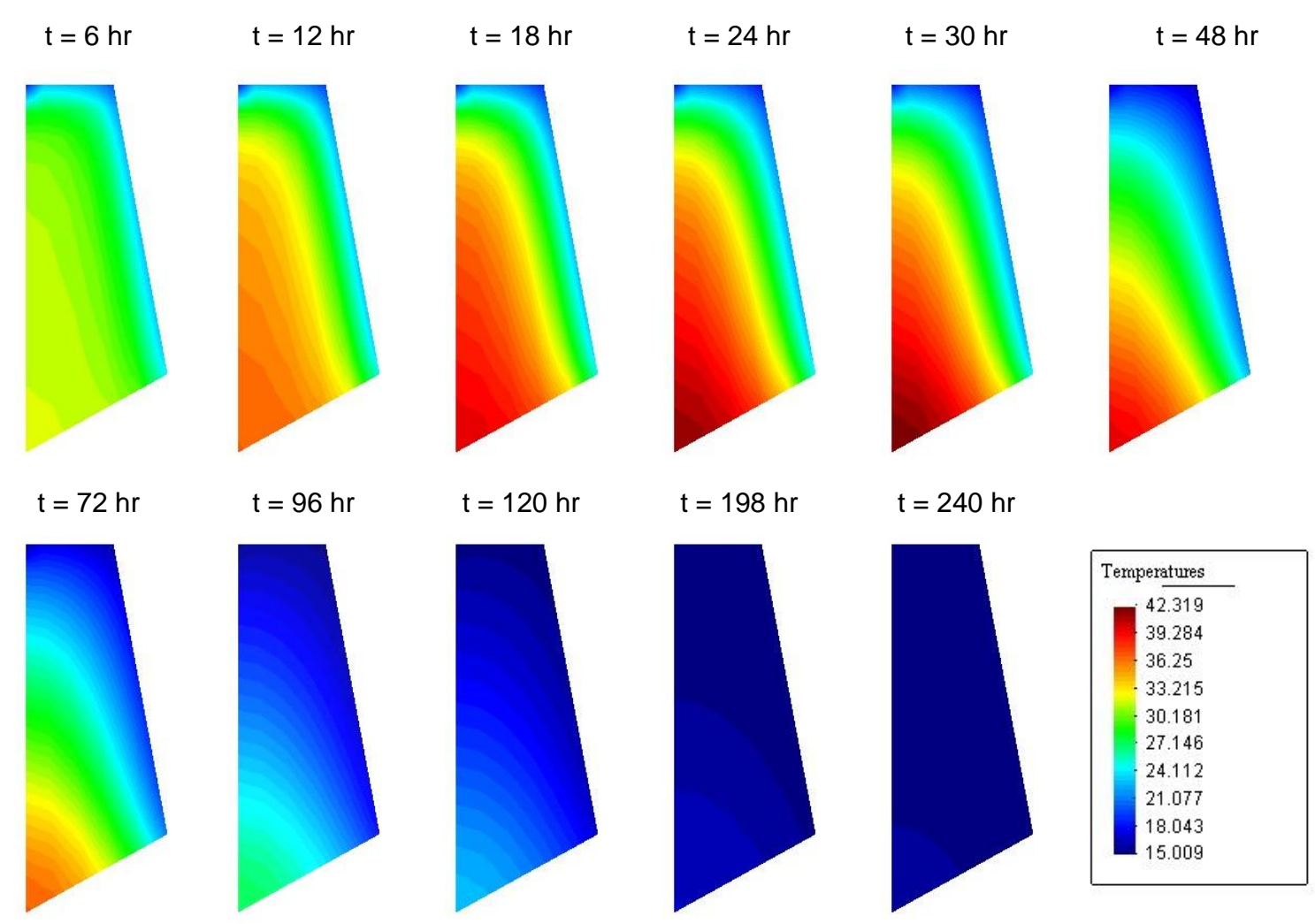

Figura 8.41 - Evolução das temperaturas $\left[^{\circ} \mathrm{C}\right]$ 


\subsubsection{Resultados do modelo de difusão de umidade}

A figura 8.42 apresenta os mapas de evolução da difusão de umidade, em instantes selecionados. Observar-se que a secagem se desenvolve do exterior do tetrápode para o interior. Passados dez dias da concretagem ainda existe uma diferença significativa da umidade na superfície e no interior do corpo.
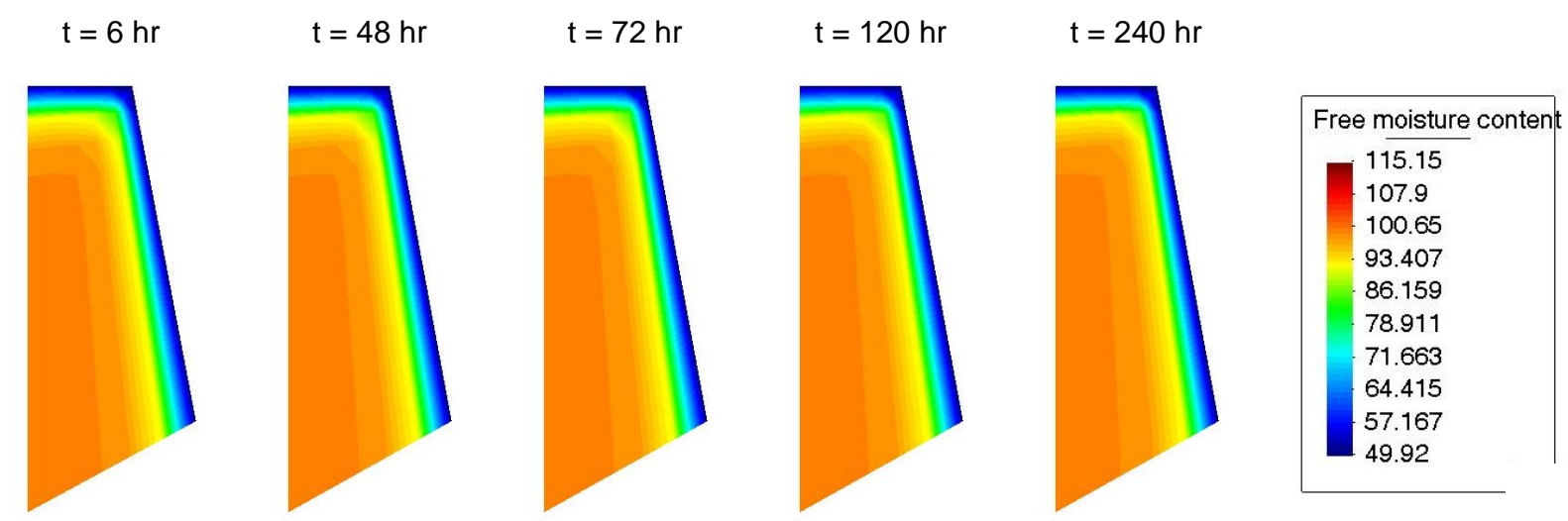

Figura 8.42 - Evolução difusão de umidade [\%]

\subsubsection{Resultados do modelo mecânico}

Os mapas de evolução das tensões, em instantes selecionados, são apresentados na figura 8.43 .

Ressalta-se que, de acordo com a análise de elementos finitos, o valor mais elevado das tensões surge na superfície do tetrápode, provocando fissuras nessas regiões, confirmando o que de fato foi observado, de acordo com a figura 8.44. 


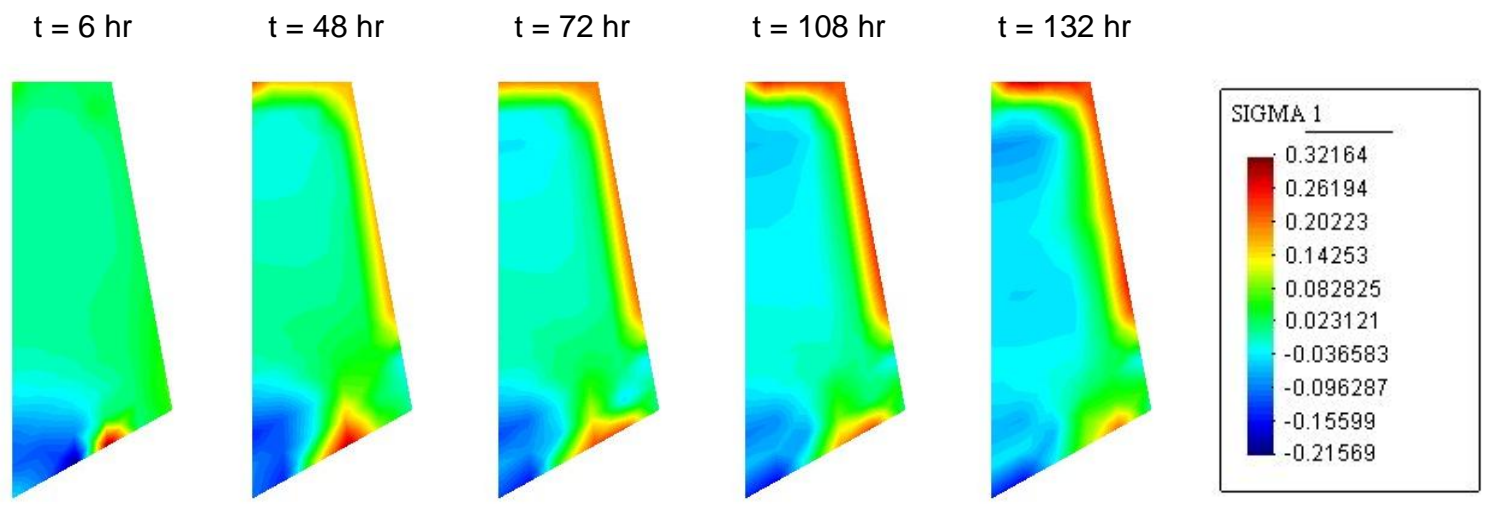

Figura 8.43 - Evolução das tensões principais $\left[\mathrm{kN} / \mathrm{cm}^{2}\right]$
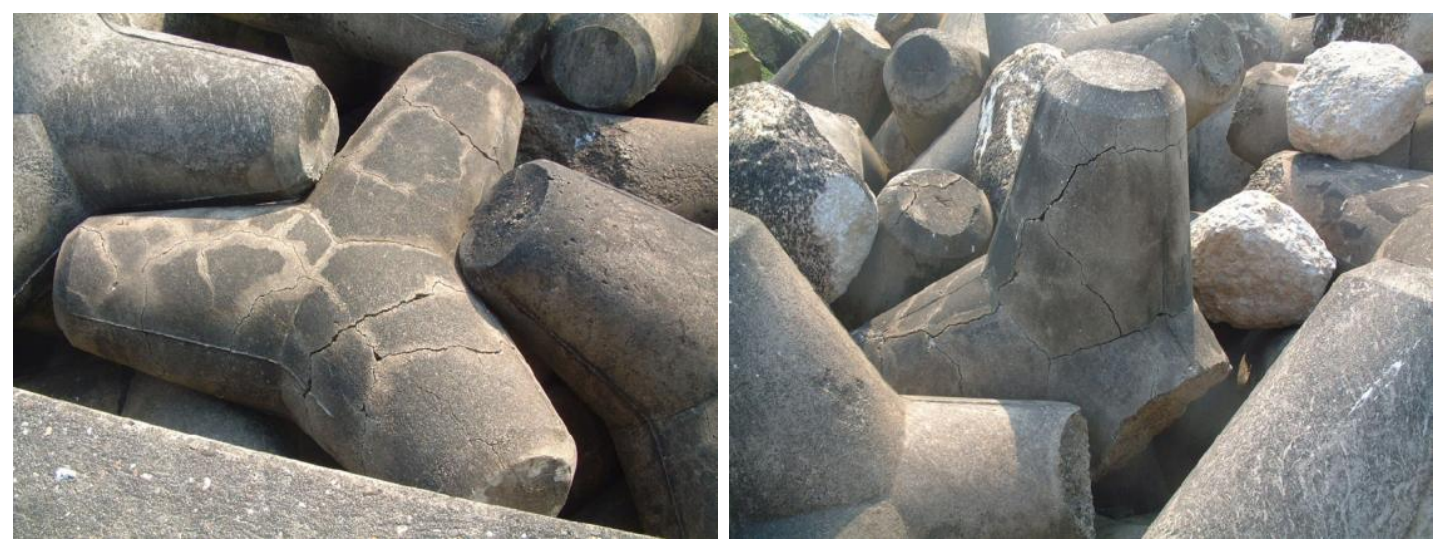

Figura 8.44 - Tetrápodes fissurados (Azenha, 2004) 


\section{CAPÍTULO 9}

\section{CONCLUSÕES}

\subsection{Disposições finais}

Neste trabalho foi implementado um modelo computacional, baseado no método dos elementos finitos, para a simulação do comportamento de peças de concreto nas primeiras idades e, em especial, com o propósito de avaliar o potencial risco de fissuração.

A análise por elementos finitos abrange a modelagem computacional dos fenômenos químicos, térmicos, de difusão de umidade e mecânicos que ocorrem nos primeiros dias após o lançamento do concreto.

$\mathrm{Na}$ análise química é determinado o calor gerado pelas reações exotérmicas de hidratação do cimento através de uma curva de elevação adiabática da temperatura do concreto. No presente trabalho, pode-se escolher entre a curva proposta pelo JSCE ou uma curva específica fornecida pelo usuário, determinada a partir de dados experimentais. Para o calor gerado por unidade de volume é calculado um valor equivalente nodal que será considerado na análise que se segue.

$\mathrm{Na}$ análise térmica, além do calor gerado pelas reações químicas do processo de hidratação do cimento, o programa considera o fluxo de calor devido à diferença 
de temperatura entre o corpo e o ambiente. Em função das propriedades térmicas e geométricas do corpo em estudo são determinadas as temperaturas nodais. Estes valores de temperatura serão dados de entrada para a última etapa do algoritmo de solução, a análise mecânica.

Na seqüência, realiza-se a análise de difusão de umidade. Aproveitando a semelhança entre as equações que regem os fenômenos de transferência de calor e difusão de umidade, empregam-se os mesmos procedimentos da etapa anterior para a determinação do valor nodal da umidade relativa dos poros. Estes valores também serão utilizados na análise mecânica.

$\mathrm{Na}$ análise mecânica, por sua vez, são calculados os estados de tensões decorrentes das variações de temperatura e umidade determinadas nas etapas anteriores e dos fenômenos de retração e fluência do concreto. Quando o estado de tensão de determinado ponto de integração atinge a superfície de ruptura, o ponto passa a ser considerado fissurado. O programa considera a fissuração através de um modelo de fissuras distribuídas com fisssura fixa.

Os resultados desta modelagem computacional foram comparados com valores experimentais encontrados na literatura, demonstrando excelente aproximação em todas as etapas de solução implementadas.

Inicialmente foram analisados os resultados de ensaios de anéis com retração restringida realizados por Shah et al. (1994) e Shah, Karaguler e Sarigaphuti (1993). Os ensaios, para avaliar a fissuração por retração no concreto nas primeiras idades, consistiram em um anel de concreto limitado internamente por um anel de aço, onde foram colocados strain-gages para a medição de deformações, e um microscópio externo para a determinação de medidas de abertura de fissura.

O problema foi discretizado através de duas malhas de elementos finitos, uma com 42 elementos e outra, mais refinada, com 168 elementos. Foram utilizados elementos planos para a representação de sólidos axissimétricos. Apresentaram-se resultados para variação da temperatura e da difusão da umidade no interior dos anéis, bem como a evolução das tensões, e a comparação da data de formação da fissura e abertura da mesma. 
Constatou-se que os resultados das análises foram idênticos para as duas malhas, concluindo-se assim, que a malha de 42 elementos já era suficientemente refinada para produzir resultados precisos.

$\mathrm{Na}$ análise térmica observou-se que os picos de temperatura, decorrentes do calor gerado pelas reações de hidratação do cimento na análise química, ocorrem na região central do anel de concreto. Notou-se, também, que ao quinto dia a temperatura do anel de concreto já havia se uniformizado com a do ambiente.

No estudo da difusão de umidade, verificou-se que o processo de secagem, devido à umidade relativa do ambiente ser inferior à inicial do anel de concreto, ocorre no sentido da superfície externa para o interior.

$\mathrm{Na}$ análise mecânica foram comparadas as estimativas do modelo com os valores experimentais para a data da fissuração e abertura das fissuras. A concordância dos resultados foi excelente. Através dos mapas de evolução das tensões pôde-se acompanhar a evolução da abertura da fissura da face externa do anel para o seu interior, confirmando o que de fato foi observado experimentalmente.

A segunda situação analisada foi o ensaio uniaxial utilizando um corpo de prova tipo I (dog bone specimen) para simular a fissuração do concreto com retração restringida, realizado por Altoubat e Lange (2001). O ensaio teve como propósito a análise de um elemento exposto a condições de temperatura e umidade controlada, com o objetivo de medir as tensões até o instante da fissuração.

Este estudo apresentou resultados para a variação da temperatura e da difusão da umidade no interior dos corpos de prova, bem como a comparação da evolução das tensões e da data de fissuração.

Pelas reduzidas dimensões do corpo de prova não foi observada uma variação significativa de temperatura ao longo da espessura do mesmo. A secagem ocorreu do exterior do corpo de concreto para o interior e, transcorridos dez dias da concretagem ainda existia uma diferença significativa da umidade na superfície e no interior do corpo. 
$\mathrm{Na}$ análise mecânica foram comparados os valores para as tensões atuantes e a data de fissuração, obtidos experimentalmente e através do algoritmo desenvolvido no presente trabalho. Novamente, a aproximação dos valores numéricos com os experimentais foi excelente. Observou-se ainda que, no momento da formação das fissuras, ao contrário do que acontece no ensaio dos anéis, ocorre a ruptura do corpo de prova, por não haver possibilidade de redistribuição das tensões.

Finalmente analisou-se o comportamento de um tetrápode nas primeiras idades. O tetrápode é uma peça utilizada na proteção de quebra-mares, consistindo num bloco de concreto simples composto por quatro pernas tronco-cônicas saindo de um ponto central. Para a análise deste tipo de elemento estudou-se o tetrápode analisado por Borst e van der Boogaard (1994). Apresentaram-se resultados para a elevação da temperatura no interior do mesmo, bem como da difusão da umidade e evolução das tensões.

Pelo calor gerado pela hidratação do cimento, notou-se que a temperatura cresce na região mais interna do tetrápode e, com o passar das horas, a temperatura decresce da superfície para o interior, alcançando o equilíbrio com o ambiente aos dez dias.

Observou-se ainda que a secagem se desenvolve do exterior do tetrápode para o interior. Passados dez dias da concretagem ainda existe uma diferença significativa da umidade na superfície e no interior do corpo.

Ressalta-se que, de acordo com a análise de elementos finitos, o valor mais elevado das tensões surgiu na superfície do tetrápode, provocando fissuras nessa região, confirmando o que de fato foi observado in loco.

Pelos resultados alcançados, mesmo considerando a variabilidade inerente ao comportamento de peças de concreto, evidencia-se que os modelos implementados conseguem reproduzir de forma fiel o real comportamento do concreto nas primeiras idades. $O$ modelo de elementos finitos implementado mostrou-se uma ferramenta precisa e adequada para avaliar a fissuração inicial do concreto, abrindo perspectiva para a realização de diversos estudos de variadas situações encontradas em estruturas de concreto. 


\subsection{Desenvolvimentos Futuros}

Os resultados alcançados incentivam aperfeiçoamentos futuros do modelo proposto, com o intuito de estender sua aplicabilidade.

Para ampliar o número de situações abrangidas pelo modelo computacional seria interessante expandir a análise atual, bidimensional, para análise tridimensional.

Neste mesmo sentido, a implementação de elementos finitos para a representação de barras de armadura, possibilitaria a realização de simulações de outros problemas relevantes de engenharia estrutural.

Outro aspecto que merece atenção é a inclusão de diferentes modelos para calibrar funções de fluência e retração, com intuito de comparar a variabilidade dos resultados e possibilitar a análise para outros tipos de concreto, como, por exemplo, concreto com adição de fibras. 


\section{REFERÊNCIAS BIBLIOGRÁFICAS}

ALTOUBAT, S. A., LANGE, D. A.. Creep, shrinkage and cracking of restrained concrete at early age. ACI Materials Journal, v.98, n. 4, pp. 323-331. 2001.

AURICH, M.. Modelo da ligação entre concreto e armadura na análise de estruturas de concreto pelo método dos elementos finitos. Dissertação de Mestrado. Universidade Federal do Rio Grande do Sul, CPGEC. 132p. 2001.

AZENHA, M.. Comportamento do betão nas primeiras idades. Fenomenologia e análise termo-mecânica. Dissertação de Mestrado. Faculdade de Engenharia da Universidade do Porto. 2004.

BALUCH, M. H., RAHMAN, M. K., MAHMOUD, I. A.. Calculating drying-shrinkage stresses. Concrete International Magazine, july, pp. 37-41. 2008.

BATHE, K. J.. Finite Element Procedures. Englewood Cliffs, New Jersey, Prentice Hall. (Edição revisada de Finite Element procedures in Engineering Analysis, 1982). 1996.

BAZANT, Z. P.; NAJJAR, L. J.. Nonlinear Water Diffusion in Nonsaturated Concrete. Materials and Structures, v. 5, pp. 3-20, 1972.

BAZANT, Z. P. \& WU, S.T. Rate-type creep law of aging concrete based on Maxwell chain. Materials and Structures, v. 7, n. 34, p. 45-60, 1974.

BAZANT, Z. P. Mathematical models for creep and shrinkage of concrete. In: INTERNATIONAL SYMPOSIUM ON FUNDAMENTAL RESEARCH AND SHRINKAGE OF CONCRETE, 1980, Lausanne Papers...Chichester: John Willey, 1982, cap. 7, p. 163-256.1980. 
BAZANT, Z. P.. Creep and Damage in Concrete. Material Science of concrete IV, J. Skalney and S. Mindess, eds., Am. Ceramic Soc., Westerville, Ohio, pp. 335-389, 1995.

BEEK, A.. Dielectric properties of young concrete. Tese de Doutorado. Delft. 2000.

BENTZ, D., COVENEY, P., GARBOCZI, E., KLEYN, M. E STUTZMAN, P.. Cellular automation simulations of cement hydration and microstructure development. Modelling Simul. Mater. Sci. Eng., 2. 1994.

BENTZ, D.. A three-dimensional cement hydration and microstructure program. I. Hydration rate, heat of hydration, and chemical shrinkage. NISTIR 5756. NIST. 1995.

BENTZ, D.. Three-dimensional computer simulation of Portland cement hydration and microstructure development. J. Am. Ceram. Soc., 80, 1. 1997.

BENTZ, D., WALLER, V. E LARRARD, F.. Prediction of adiabatic temperature rise in conventional and high performance concretes using a 3-D microstructural model. Cement and Concrete Research, 28, 2. 1997.

BRANCO, F., MENDES, P. e MIRAMBELL, E.. Heat of hidration effects in concrete structures. ACI Materials Journal, v. 89, n. 2, pp. 139-145.1992

BREUGEL, K.. Artificial cooling of hardening concrete. Concrete Structures in Delft University of Technology. Delft. 1980.

BREUGEL, K.. Simulation of hydration and formation of structure in hardening cement-based materials. Tese de Doutorado. Delft. 1991.

BREUGEL, K.. Numerical simulation of hydration and microstructural development in hardening cement-based materials. Cement and Concrete Research, 25, 2. 1995.

BREUGEL, K.. Prediction of temperature development in hardening concrete. Prevention of thermal cracking in concrete at early ages. Report $15, \mathrm{R}$. Springenschmid, E \& FN SPON. 1998. 
BREUGEL, K.. Hydration of Cement-Based Systems. Aspects of hydration of cement-based systems and possibilities to quantify the evolution of hydration processes. IPACS Document, Subtask 2.1. 2001a.

BREUGEL, K.. Stress predictions in hardening concrete. The role of microstructural development. IPACS Document, Subtask 3.4. 2001b.

CERVERA, M.; FARIA, R.; OLIVER, J.; PRATO, T.. Numerical Modelling of Concrete Curing, Regarding Hydration and Temperature Phenomena. Computers \& Structures, V. 80, pp. 1511-1521, 2002.

COMITÉ EURO-INTERNATIONAL DU BETON. CEB-FIP Model Code 1990. Lausanne, 1993. (Bulletin d'Information, 213/214)

COUSSY, O.. Mechanics of Porous Continua, 1 ed. Chichester, John Wiley \& Sons. 1995.

COUTINHO, J.. Materiais de construção 2. Parte 1 - Ligantes e Caldas. Textos de Materiais de Construção da Licenciatura em Engenharia Civil da FEUP. 2002.

CUSSON, D.; REPETTE, W. L.. Early-Age Cracking in Reconstructed Concrete Bridge Barrier Walls. ACI Materials Journal, v. 97, n. 4, pp. 438-446. 2000.

DANTAS, A. U.. Simulação numérica dos processos de recuperação e reforço de peças estruturais em concreto armado.Dissertação de Mestrado. Universidade Federal do Rio Grande do Sul, CPGEC. 133 p. 2000.

DE BORST, R., VAN DER BOOGAARD, A. H.. Finite element modeling of deformation and cracking in early age concrete. ASCE - Journal of Engineering Mechanics, v. 120, n. 12, pp. 2519-2534. 1994.

DILGER, W.H.; NIITANI, K.; WANG, C..Creep and shrinkage model for highperformance concrete. International Conference on Engineering Materials, Ottawa, pp. 615-630. 1997.

FAIRBAIRN, E. M. R.; LONGO, H. I. \& ZHENG, R. Formulação diferencial do problema da relaxação do concreto - estudo teórico experimental. In: 
JORNADAS SUL-AMERICANAS DE ENGENHARIA ESTRUTURAL, 24, 1987, Porto Alegre. Anais. Porto Alegre: CPGEC/UFRGS, 1987, v.2, p. 103-117.

GRZYBOWSKI, M.; SHAH, S.P.. Shrinkage Cracking of Fiber Reinforced Concrete. Journal of the American Concrete Institute, v. 87, n. 2, pp. 138-148. 1990.

INCROPERA, F. P., DEWITT, D. P.. Introduction to heat transfer. New York, John Wiley \& Sons, Inc. 2001.

JEON, S-J.. Advanced assessment of cracking due to heat of hydration and internal restraint. ACI Materials Journal, v.105, n. 4, pp. 325-333. 2008.

JONASSON, J.-E.. Modelling of Temperature, Moisture and Stresses in Young Concrete. Tese de Doutorado. Lulea University of Technology, Lulea. 1994.

KISHI, T. E MAEKAWA, K.. Multi-component model for hydration heating of portland cement. Translation from proceedings of JSCE., 29, 526. 1995.

KRAUB, M., HAIRIRI, K. E ROSTÁSY, F.. Non-destructive assessment of mechanical properties of concrete at very early ages by US techniques Method, results and modelling. IPACS Document, Task 2 (T2.1/T2.2). 2001a.

KRAUB, M., ROSTÁSY, F. E GUTSCH, A.. Modelling of degree of hydration on basis of adiabatic heat release. IPACS Document, Task 2 (T2.1/T2.3). 2001b.

KUPERMAN, S. C.. Disciplina de Concreto Massa - notas de aula. Departamento de Engenharia de Construção Civil da Escola Politécnica da Universidade de São Paulo. 2004

KVOLER, K.. Testing System for Determining the Mechanical Behavior of Early Age Concrete under Restrained and Free Uniaxial Shrinkage. Materials and Structures, v.27, n.34, pp. 324-330. 1994.

KWON, S. H., SHAH, S. P.. Prediction of Early Age Cracking of Fiber-Reinforced Concrete due to Restrained Shrinkage. ACI Materials Journal, v.105, n. 4, pp. 381-389. 2008. 
LURA, P.. Autogenous deformation and internal curing of concrete. Tese de Doutorado. Delft University of Technology. Delft. 2000.

LURA, P. E BREUGEL, K.. Thermal Properties of Concrete: Sensitivity studies. IPACS Document. Subtask 2.5. 2001.

MACHADO, M. A. S.. Aplicação do Método dos Elementos Finitos para a Análise Elasto-Viscoplástica de Peças de Concreto Armado e Protendido, submetidas a Estados Planos de Tensão. Dissertação de Mestrado. Universidade Federal do Rio Grande do Sul, CPGEC. 150p. 2002.

MAEKAWA, K., CHAUBE, R. E KISHI, T.. Modelling of concrete performance. E \& FN SPON. 1999.

MANG, H., ULM, F. J., HELLMICH, C.. Consistent linearisation in finite element analysis of coupled chemo-thermal problems with exo or endothermal reactions. Journal of Computational Mechanics, v. 24, n. 4, pp. 238-244. 1999.

MANG, H., ULM, F. J., HELLMICH, C.. Multisurface chemoplasticity I: Material model for shotcrete. Journal of Engineering Mechanics (ASCE), v. 125, n. 6, pp. 692-701, Jun. 1999.

MANG, H., HELLMICH, C., LACKNER, R.. Thermochemomechanical material model for shotcrete. Numerical Simulation in Tunnelling. Gernot Beer Editor, Graz, Austria, pp 61-81. 2003.

MEHTA, P. K., MONTEIRO, P. J. M.. Concreto: Estruturas, propriedades e Materiais. 1 ed. São Paulo. Editora PINI. 2005.

MORABITO, P.. Methods to determine the heat of hydration of concrete. Prevention of thermal cracking in concrete at early ages. Report 15, R. Springenschmid, E \& FN SPON. 1998.

MORABITO, P.. Thermal properties of concrete - Variations with the temperature and during the hydration phase. IPACS Document. Subtask 2.3. 2001. 
OTTOSEN, N. S.. A failure criterion for concrete. Journal of Engineering Mechanics Division, ASCE, v. 103, n. 4, p. 527-535, Aug. 1977.

OWEN, D. R. J. \& HINTON, E.. Finite elements in plasticity - Theory and Practice. Swansea: Pineridge Press, 1980. 594p.

OWEN, D. R. J., HINTON, E.. Finite element programming. London: Academic Press, 1977. $305 \mathrm{p}$.

PANDE, G. N.; OWEN. D. R. J. \& ZIENKIEWICZ, O. C.. Overlay models in timedependent non-linear material analysis. Computers and Structures, v.7, n.3, p. 435-443, 1977.

PINTO, T.. Trabalhos fluviais e marítimos - Dimensionamento hidráulico e estrutura de quebramares de taludes. FEUP - Faculdade de Engenharia da Universidade do Porto. Porto. 2001.

PRATO, T. G.. Comportamiento del Hormigón en Edades Tempranas Modelización y Aplicaciones. Tese de Doutorado. Universidad Politécnica de Catalunya. 1999.

REPeTte, W.L., MAILVAGANAM, N.P. Pre-hydrated High Alumina Cement Based Admixture for Compensating Autogenuos Shrinkage in HPC. Proceedings of the International Conference on High-Performance and Quality of Concrete Structures. CANMET/ACI International Conference. Gramado, Brasil. 1999.

SCHINDLER, A. E FOLLIARD, K.. Influence of supplementary cementing materials on the heat of hydration of concrete. Advances in Cement and Concrete IX, Colorado. 2003.

SHAH, S. P.; KARAGULER, M. E.; SARIGAPHUTI, M.. Effects of ShrinkageReducing Admixtures on Restrained Shrinkage Cracking f Concrete. ACl Materials Journal, v. 89, n. 3, pp. 138-148, 1993. 
SHAH, S. P.; OUYANG, C.; MARIKUNTE, S.; YANG, W.; ALDEA, C.. Control of Cracking with Shrinkage-Reducing Admixtures. Transportation Research Record, n. 1574, pp. 25-36, 1994.

SILVEIRA, A.. A influência das acções térmicas no comportamento de pontes de betão armado. Tese de Doutorado. LNEC - Laboratório Nacional de Engenharia Civil. Lisboa. 1996.

TAZAWA, E.; MIYAZAWA, S.. Influence of Curing Conditions on Autogenous Shrinkage of Concrete. In: International Conference on Engineering Materials. Ottawa. pp.373-384. 1997

UNDERWOOD, P. G.; PARK, K. C.. A Variable-step Central Difference Method for Structural Dynamic Analysis - Part 1: Theoretical Aspects. Computer Methods in Applied Mechanics Engineering. v. 22, pp. 241-258. 1980.

UNDERWOOD, P. G.; PARK, K. C.. A Variable-step Central Difference Method for Structural Dynamic Analysis - Part 2: Implementation and Performance Evaluation. Computer Methods in Applied Mechanics Engineering. v. 23, pp. 259279. 1980.

UNDERWOOD, P. G.. Computational Methods for Transient Analysis. Edited by T. Belytschko and T. J. R. Hughes. Elsevier Science Publishers. pp. 245-265. 1983.

ULM, F. J.; COUSSY, O.. Modelling of themochemomechanical couplings of concrete at early ages. Journal or Engineering Mechanics (ASCE), v. 121, n. 7, pp. 785-794, Jul. 1995.

ULM, F. J.; COUSSY, O.. Strength Growth as Chemo-Plastic Hardening in Early Age Concrete. Journal of Engineering Mechanics (ASCE), v. 122, n. 12, pp. 1123-1132, Dec. 1996.

WADSÖ, L.. An experimental comparison between isothermal calorimetry, semiadiabatic calorimetry and solution calorimetry for the study of cement hydration. Nordtest report TR 522. 2003. 
WITASSE, R. Early Age Behaviours of a Purification Wall. Presentation of DIANA features for Young Hardening Concrete Modelling. TNO DIANA BV, Delft, 7-9. 2003.

ZIENKIEWICZ, O. C.; TAYLOR, R.L.. The finite element method. Oxford: Butterworth-Heinemann, 3v. 2000. 

